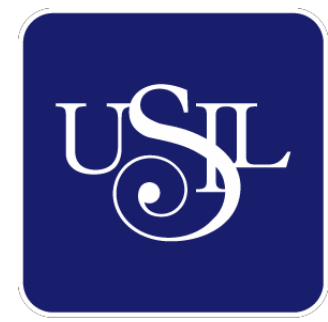

UNIVERSIDAD

SAN IGNACIO

DE LOYOLA

ESCUELA DE POSTGRADO

\title{
PLAN DE NEGOCIO PARA EMBOTELLAR $Y$ COMERCIALIZAR OXÍGENO INDUSTRIAL EN LA REGIÓN PUNO
}

Trabajo de Investigación para optar el grado de:

\section{ORLANDO JAVIER PAZ PAZ}

Maestro en Ciencias Empresariales con Mención en Gestión de Proyectos

\section{ROGER GUILLERMO PICARDO CASTILLO}

Maestro en Ciencias Empresariales con Mención en Marketing y Gestión Comercial

\author{
Asesor: \\ Edmundo Rafael Casavilca Maldonado \\ Lima - Perú
}

2019 


\section{DEDICATORIA.}

Dedicamos esta tesis a DIOS, a nuesta familia, y a la Virgen María, quienes inspiraron nuestro espíritu para la conclusión de esta tesis. A nuestros padres quienes nos dieron vida, educación, apoyo y consejos. A nuestros compañeros de estudio, maestros y amigos, quienes sin su ayuda nunca hubiera podido hacer esta tesis. A todos ellos se los agradecemos desde lo más profundo de nuestroscorazones. A las personas esperciales que estuvieron con nosotros y ya no lo están que nos dieron las fuerzas para continuar con su apoyo incesante y aliento.

Para todos ellos hago esta dedicatoria. 


\section{AGRADECIMIENTO}

Nuestro agradecimiento se dirige a quien ha forjado nuestro camino y nos ha dirigido por el sendero correcto, a Dios, el que en todo momento está conmigo ayudándome a aprender de nuestros errores y a no cometerlos otra vez. Eres quien guía el destino de nuestra vida. También agradecemos a una persona quien nos ayudo en este largo camino Percy Rivaños, gracias por tu apoyo Hno.

Te lo agradecemos, Padre. 


\section{RESUMEN EJECUTIVO}

La propuesta de Plan de Negocio "OXIGENO DEL SUR” (nombre tentativo), está enfocado en embotellar oxigeno con fines industriales y distribuirlo al cliente final. El valor de nuestra propuesta se basa en la seguridad, calidad y servicio que ofreceremos. Confiamos en que estas características nos permitirán generar confianza en los clientes. La venta de oxígeno industrial representa una oportunidad de negocio llamativa, justificada en cubrir una necesidad existente que actualmente se encuentra atendida de forma parcial en la región Puno.

La propuesta de negocio está orientado inicialmente al sector metalmecánico y minero, ambos sectores requieren del oxígeno industrial para el desarrollo de sus actividades, se encuentran en la ciudad de Juliaca y Puno, con el objetivo a largo plazo de atender a todo el departamento de Puno y posteriormente expandirnos a otros departamentos de la parte Sur del país (por ser objetivos a largo plazo, no se están considerando en el desarrollo del flujo de caja de la tesis).

En el estudio de mercado, se utilizó para la recolección de datos dos instrumentos, la encuesta, que nos ayudó a determinar las características de nuestro público objetivo, y la entrevista, que nos permitió identificar lo que esperan del servicio de Oxigeno industrial.

Considerando que la mayoría de empresas consumidoras de Oxigeno industrial tienen sus oficinas comerciales distribuidas entre la ciudad de Juliaca y Puno, se llegó a la conclusión de que el centro de operaciones del negocio de Oxigeno industrial 
debería estar localizado en el centro industrial de la ciudad de Juliaca, lo que nos permitirá atender oportunamente los requerimientos de nuestros clientes. En la ciudad de Juliaca se concentra una mayor cantidad de negocios metalmecánicos, lo que también nos llevó a decidirnos por dicha ciudad.

Luego de la elaboración de la matriz FODA se han establecido seis estrategias para el presente plan de negocios, centrándose principalmente en la calidad y seguridad del producto y servicio y en el plan de marketing.

Al inicio de nuestras operaciones estimamos atender ocho requerimientos diarios durante el primer año de servicio, esperando poder alcanzar con trabajo y dedicación los 11 servicios diarios.

La inversión inicial total del proyecto, asciende S/. 630,807.86, este monto abarca tanto la inversión tangible, como la inversión intangible y el capital de trabajo. En cuanto al financiamiento se determinó que un $60 \%$ este destinado a la deuda y un $40 \%$ sea el aporte de capital propio. 


\section{Índice}

dedicatoria ¡Error! Marcador no definido.

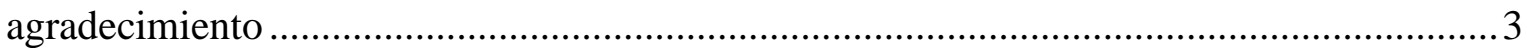

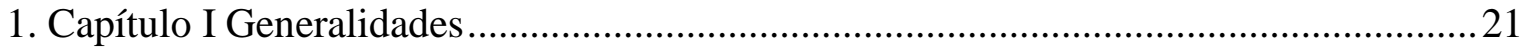

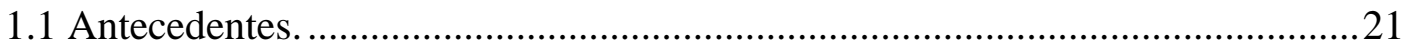

1.2 Determinación del Problema u Oportunidad. ..................................................2 24

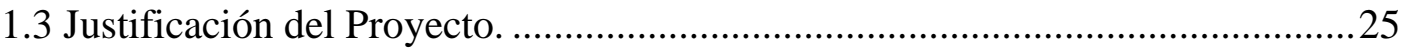

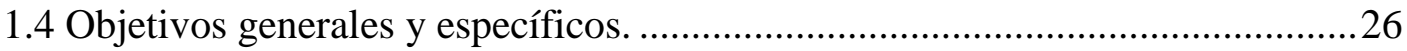

1.5 Alcances y limitaciones de la investigación. .................................................22

2. Capítulo II Estructura Económica del Sector..................................................................28

2.1 Descripción del estado actual de la industria.................................................28

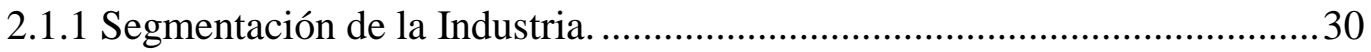

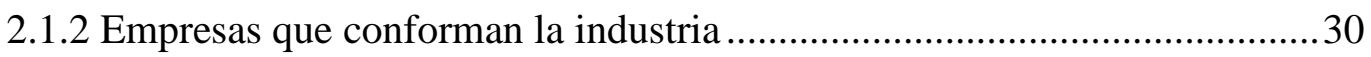

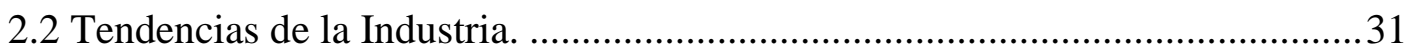

2.3 Análisis Estructural el Sector - Oxígeno Industrial...................................... 37

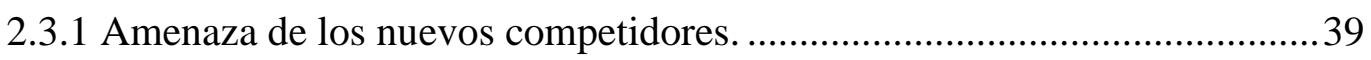

2.3.2 Amenaza Productos Sustitutos...............................................................4 42

2.3.3 Poder de Negociación de Proveedores..........................................................43

2.3.4 Poder de Negociación de los Compradores. ..............................................45

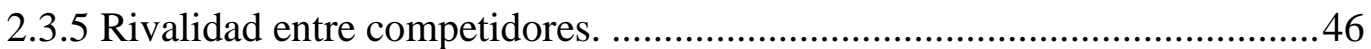

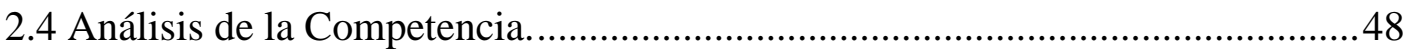

2.4.1 Características, Semejanzas y Diferencias entre el Plan de Negocios y los tipos de competencia. 
2.4.2 Matriz De Perfil Competitivo .56

2.5 Análisis del Contexto Actual y Esperado .........................................................61

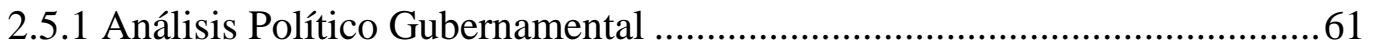

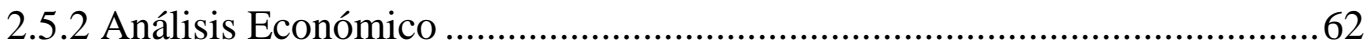

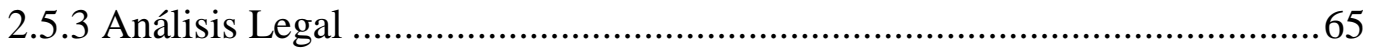

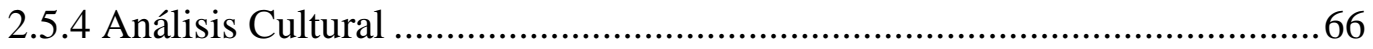

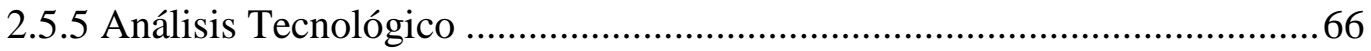

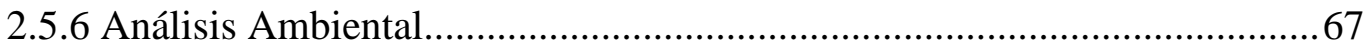

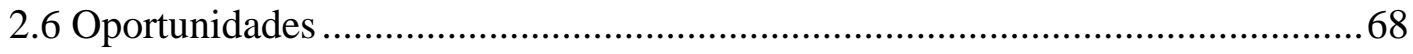

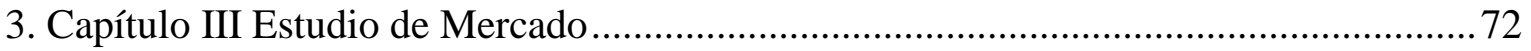

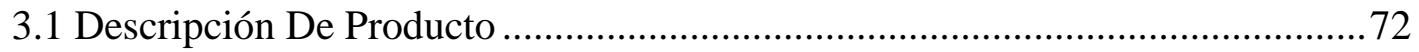

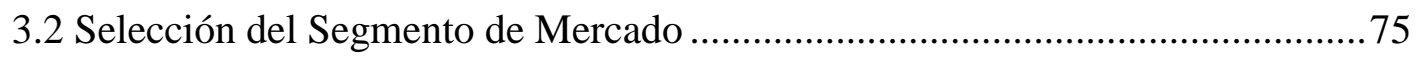

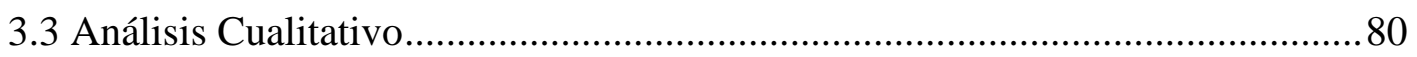

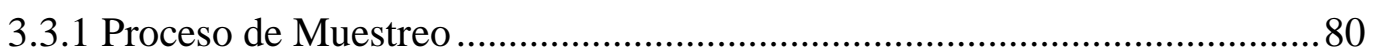

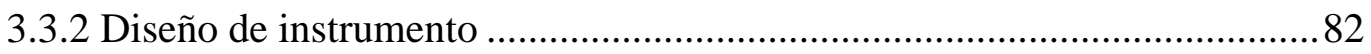

3.3.3 Análisis y Procesamiento de datos: La entrevista ............................. 83

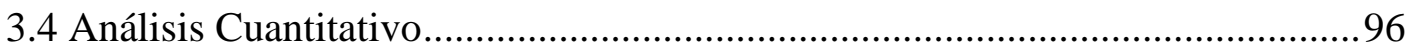

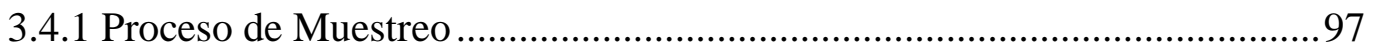

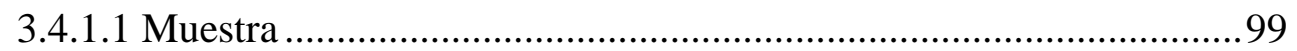

3.4.2 Diseño de instrumento ....................................................................... 102

3.4.3 Análisis y procesamiento de datos ............................................................ 103

3.5 Conclusiones Y Recomendaciones Del Estudio Cualitativo y Cuantitativo ... 123 
3.5.1 Análisis del estudio cualitativo 123

3.5.2 Conclusiones del estudio cualitativo. 124

3.5.3 Conclusiones del estudio cuantitativo 125

3.5.4 Convergencia del estudio cualitativo y cuantitativo 127

3.5.5 Recomendaciones del estudio cualitativo cuantitativo 128

3.6 Perfil Del Consumidor Tipo y Sus Variantes 129

4. Capítulo IV Proyección del Mercado Objetivo. 131

4.1 El ámbito de la proyección 131

4.2 Selección del método de proyección.

4.2.1 Mercado Potencial 132

4.2.2 Mercado Disponible 134

4.2.3 Mercado Efectivo 137

4.2.4 Mercado Objetivo 141

4.3 Pronóstico de Ventas. 146

4.4 Aspectos críticos que impactan el pronóstico de ventas 148

5. Capítulo V Ingeniería del Proyecto.

5.1 Estudio de ingeniería. 149

5.1.1 Modelamiento y selección de procesos productivos. 150

5.1.2 Selección Del Equipamiento. 158

5.1.3 Lay Out 159

5.1.4 Distribución de Equipos y maquinarias 160

5.2 Determinación del Tamaño 162 
5.2.1 Proyección de crecimiento 162

5.2.2 Recursos 162

5.2.3 Tecnología 168

5.2.4 Flexibilidad. 168

5.2.5 Selección del Tamaño Ideal. 168

5.3 Estudio de localización. 168

5.3.1 Definición de Factores locacionales. 168

5.3.2 Consideraciones legales 169

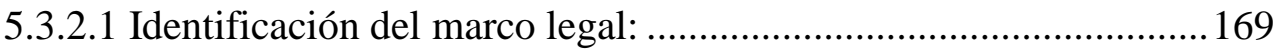

5.3.2.2 Ordenamiento Jurídico de la empresa: ........................................ 169

5.4 Determinación de la localización optima:...................................................... 171

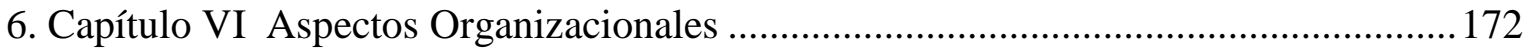

6.1 Caracterización de la cultura organizacional deseada. ..................................172

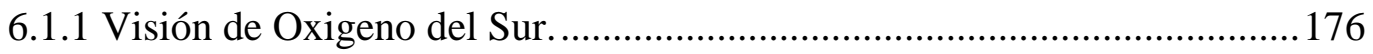

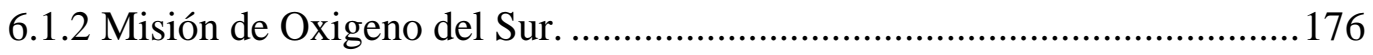

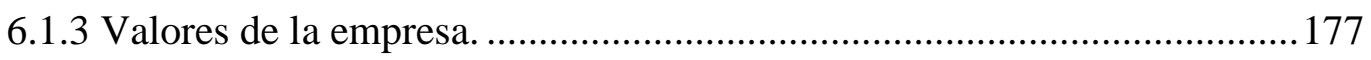

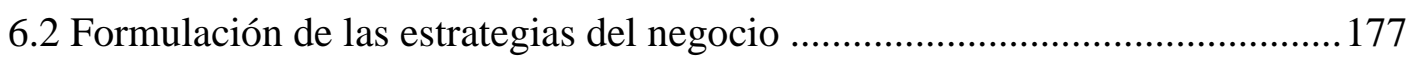

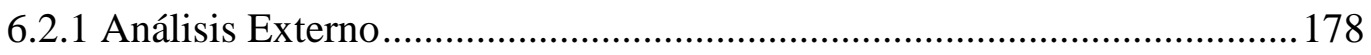

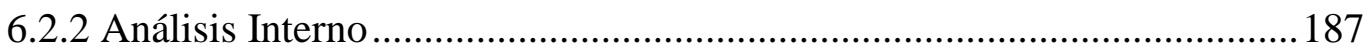

6.2.3 Matriz de Ventajas Competitivas Sostenibles........................................... 194

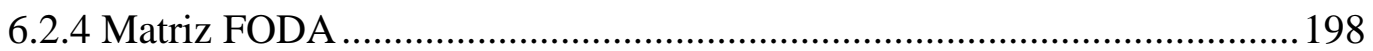

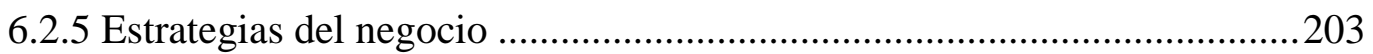


6.3 Determinación de las Ventajas Competitivas Críticas. 204

6.4 Diseño De La Estructura Organizacional Deseada 205

6.5 Diseño de Los Perfiles en Puestos Claves: 205

6.6 Remuneraciones e Incentivos 212

6.6.1 Objetivo General

6.6.2 Objetivos Específicos

6.7 Política de Recursos Humanos.

6.7.1 Política de Reclutamiento

6.7.2 Política de Ingreso

6.7.3 Estrategias de Selección.....

6.7.4 Política de Capacitación y Entrenamiento

Estrategias de Entrenamiento. 216

Capacitación en Protocolo de Seguridad y Servicio al Cliente 216

6.7.5 Política de Seguridad Y Bienestar de Personal 216

6.7.6 Política de Retención de Personal de "OXIGENO DEL SUR" 217

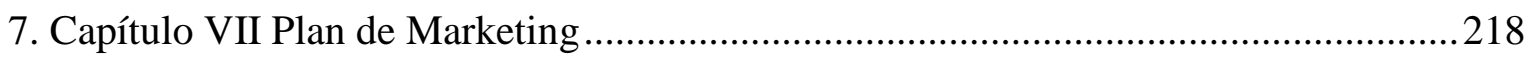

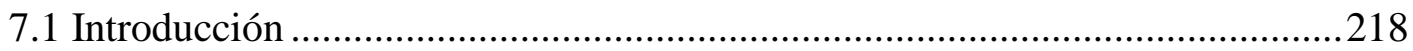

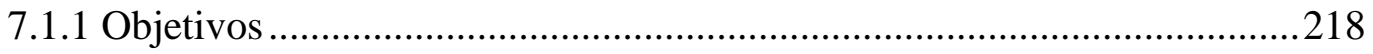

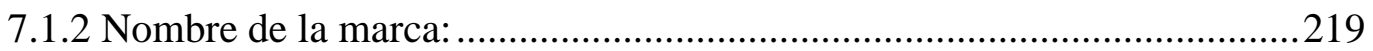

7.1.3 Servicios: 219

7.2 Estrategias de Marketing 220

7.2.1 Estrategias de Producto .220 
7.2.2 Estrategias de Precio .222

7.2.3 Estrategias de Precio .223

7.2.4 Estrategias de Promoción .224

7.3 Estrategia de ventas. 230

7.3.1 Política de servicios 231

Política para manejo de cuentas ... 231

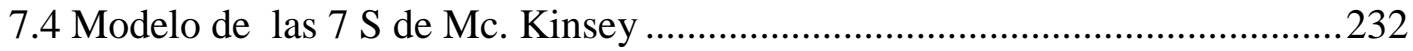

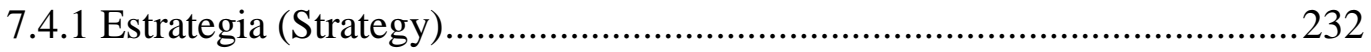

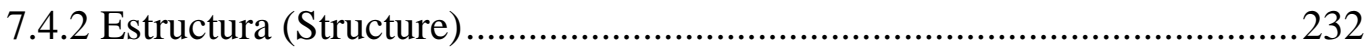

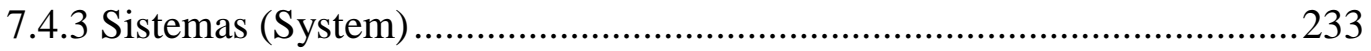

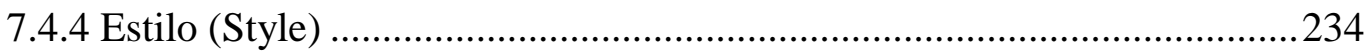

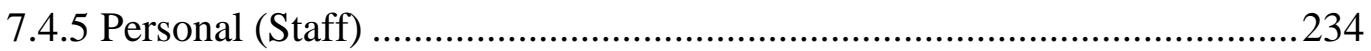

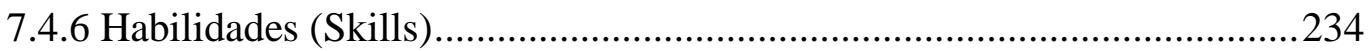

7.4.7 Valores Compartidos (Shared values) ................................................2235

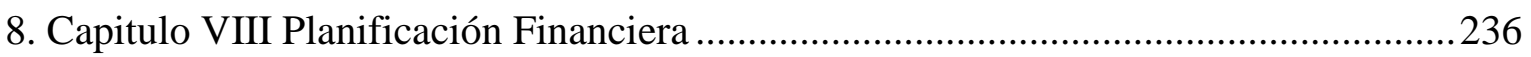

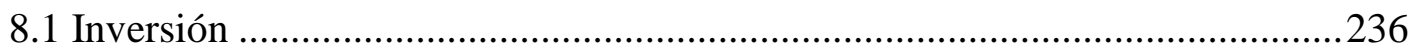

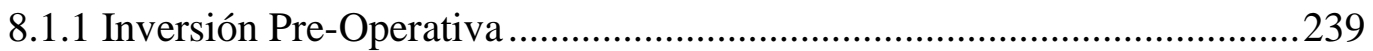

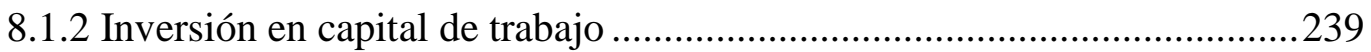

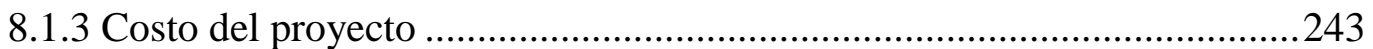

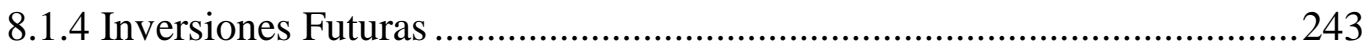

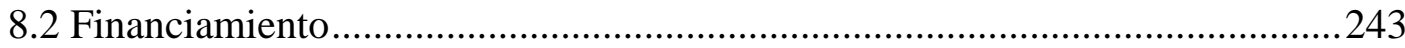

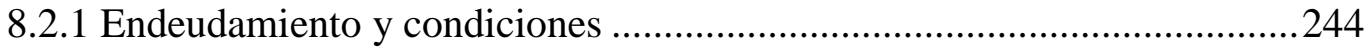


8.2.2 Capital y Costo de Oportunidad............................................................244

8.2.3 Costo de capital promedio Ponderado ...................................................24

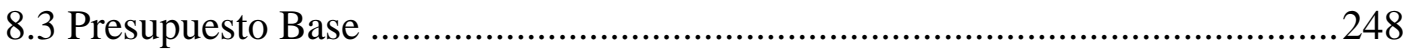

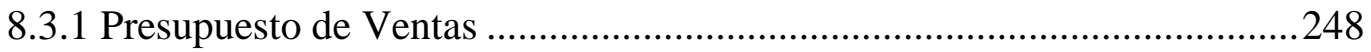

8.3.2 Presupuesto de Costo de Producción ........................................................249

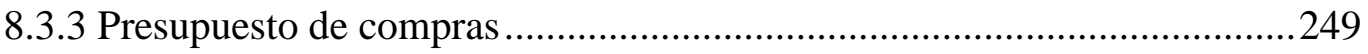

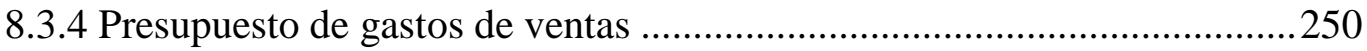

8.3.5 Presupuesto de gastos de administración ................................................250

8.3.6 Presupuesto de marketing y ventas ........................................................251

8.3.7 Presupuesto de Gastos Financieros ......................................................251

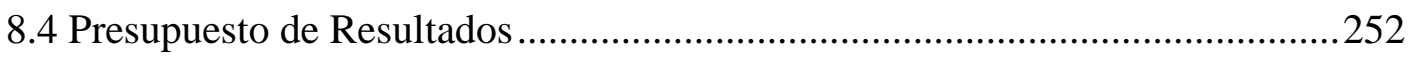

8.4.1 Estado de Resultados Integrales proyectado .........................................2252

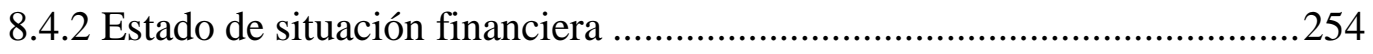

8.4.3 Flujo de caja Proyectado....................................................................25

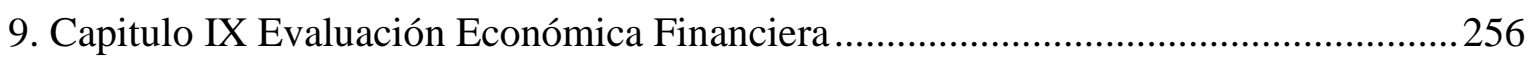

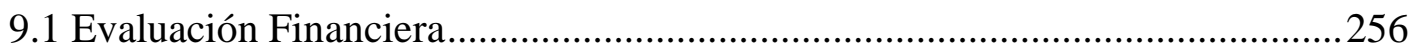

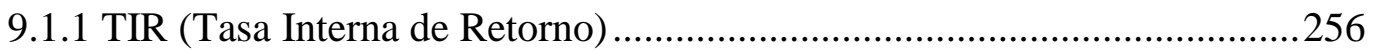

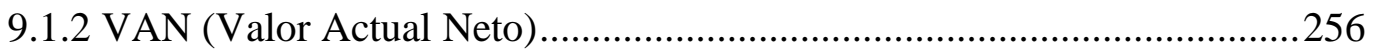

9.1.3 PRI (Periodo de Recuperación de la Inversión).......................................2257

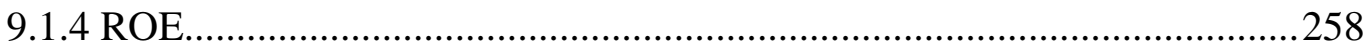

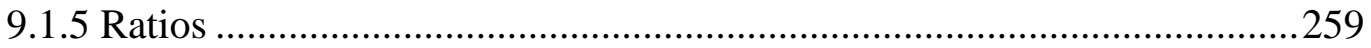

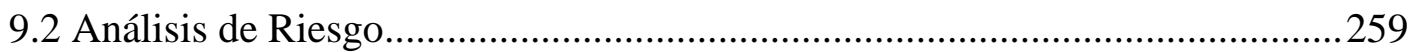


9.2.1 Análisis de Punto de Equilibrio 265

9.2.2 Análisis de sensibilidad. 267

9.2.3 Análisis de escenarios 269

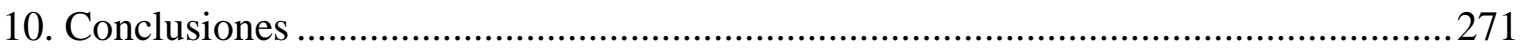

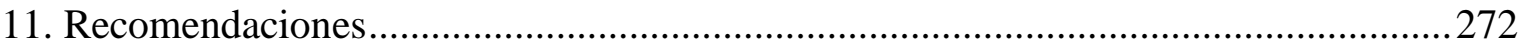

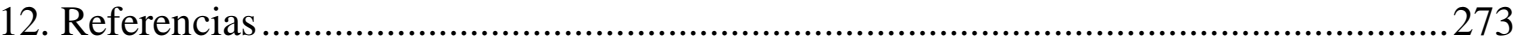

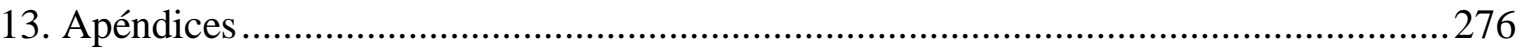

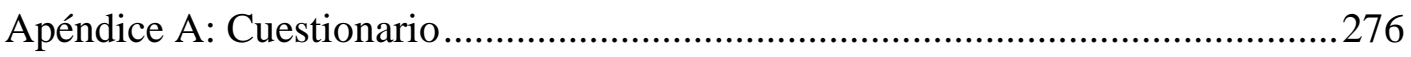

Apéndice B: Cuestionario (entrevista a tomadores de decisiones) ........................280

Apéndice C: Ficha técnica del oxígeno industrial ............................................281 


\section{Lista De Tablas}

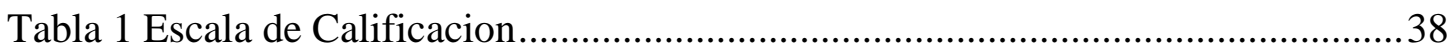

Tabla 2 Amenaza entrada de nuevos competidores .................................................. 40

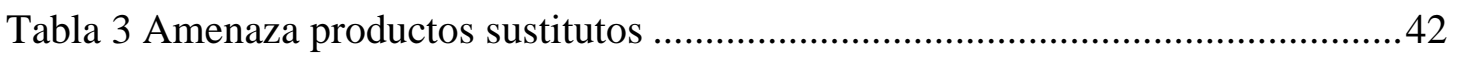

Tabla 4 Poder de negociación de proveedores .............................................................4 44

Tabla 5 Poder de negociación de los compradores ......................................................45

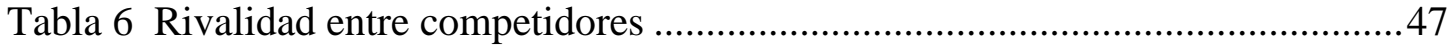

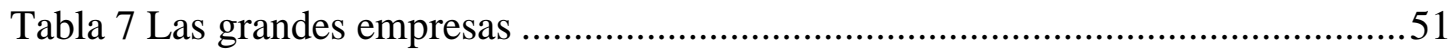

Tabla 8 Diferencias entre las grandes empresas y Oxigeno del sur...........................52

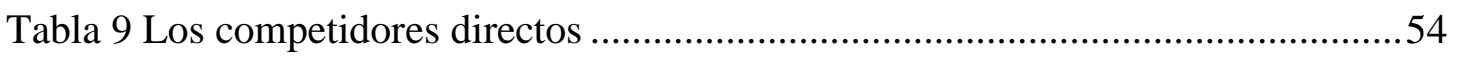

Tabla 10 Diferencias entre los competidores directos y Oxigeno del sur....................55

Tabla 11 Valores Matriz de Perfil Competitiva ..........................................................59

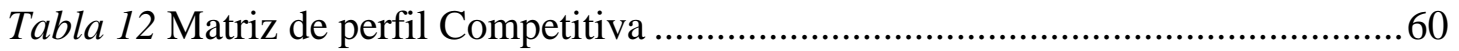

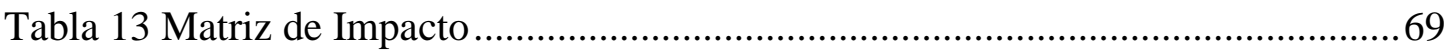

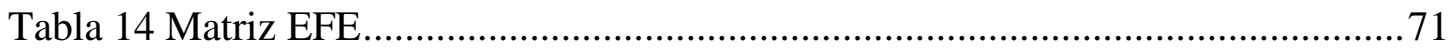

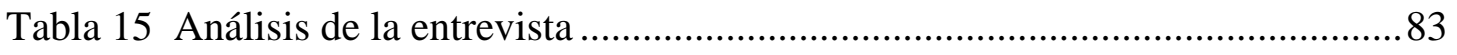

Tabla 16 Empresas según su actividad económica ....................................................98

Tabla 17 Cantidad de empresas a encuestar segun rubro ........................................ 100

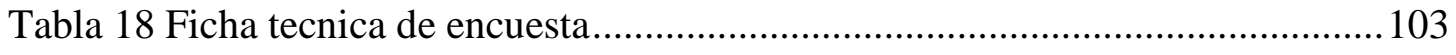

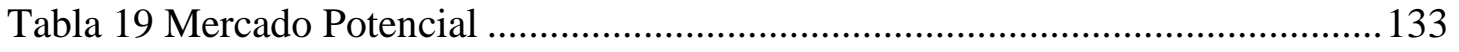

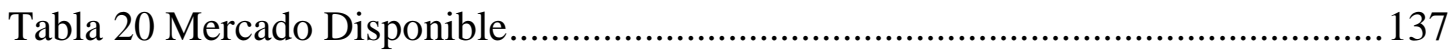

Tabla 21 Determinacion del Mercado Dsiponible ..................................................... 140

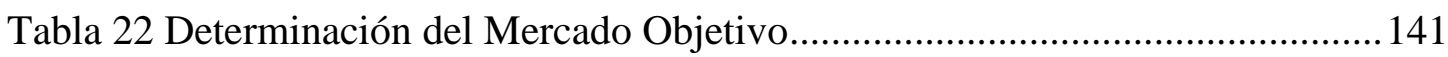

Tabla 23 Consumo Promedio Mensual de Oxigeno Industrial .................................. 143

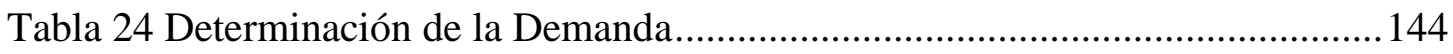

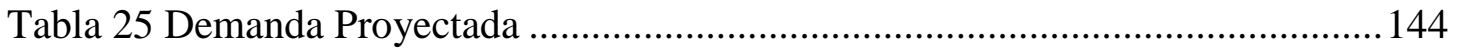

Tabla 26 Tasas de Crecimiento Referenciales ......................................................... 145

Tabla 27 Demanda Proyectada y Plan de Producción ................................................. 145

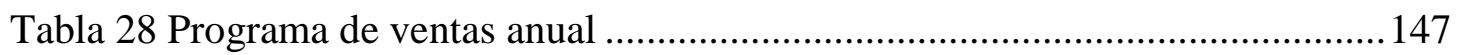

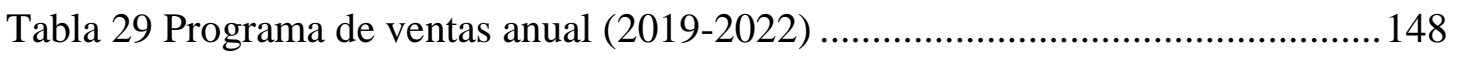

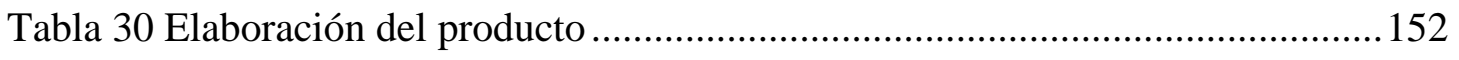

Tabla 31 Inicio del servicio de oxigeno industrial ................................................ 155

Tabla 32 Modelamiento y selección de procesos productivos..................................... 156 
Tabla 33 Procesamiento de adquisición y almacenamiento de materiales 157

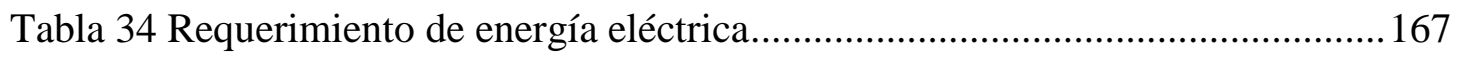

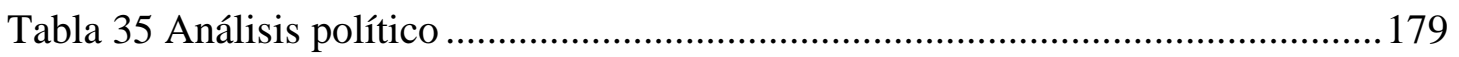

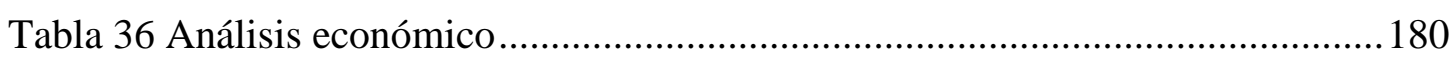

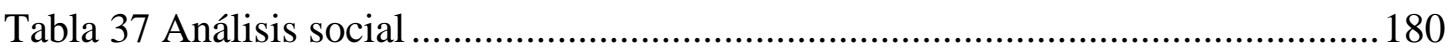

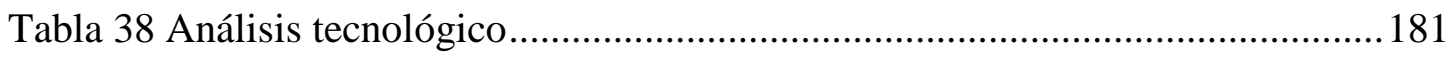

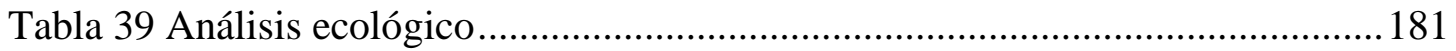

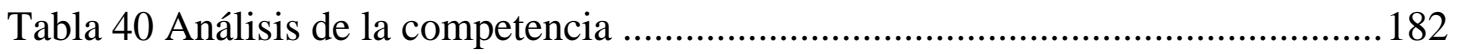

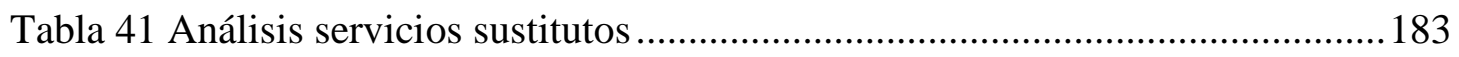

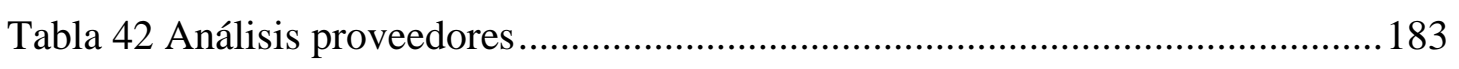

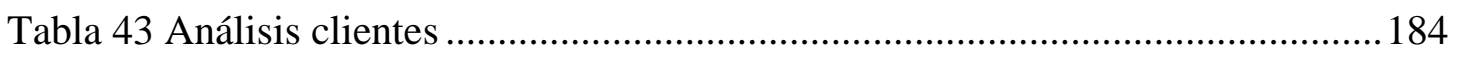

Tabla 44 Análisis gerencia ............................................................................. 188

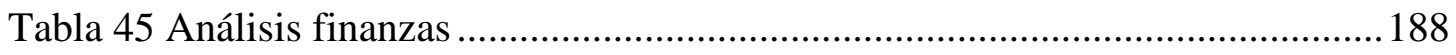

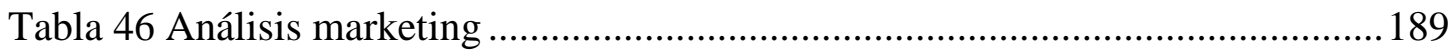

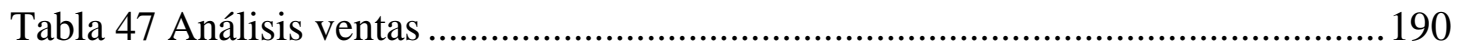

Tabla 48 Análisis operación y logística ................................................................... 190

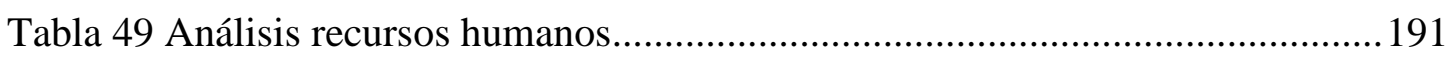

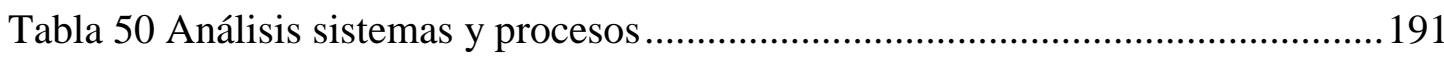

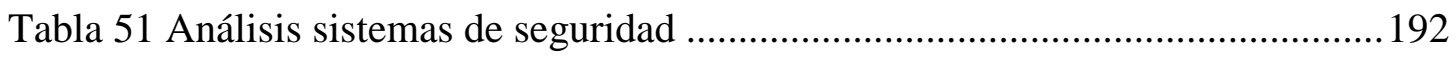

Tabla 52 Matriz de ventajas competitivas sostenibles ............................................ 196

Tabla 53 Análisis FODA de "Oxigeno del sur" (Estrategias FO, DO) ...................... 199

Tabla 54 Análisis FODA de "Oxigeno del sur" (Estrategias FA, DA) .......................201

Tabla 55 Costo de la planilla por mes...................................................................... 213

Tabla 56 Inversión en Muebles y Enseres .............................................................223

Tabla 57 Inversión en Maquinaria y Herramientas..................................................237

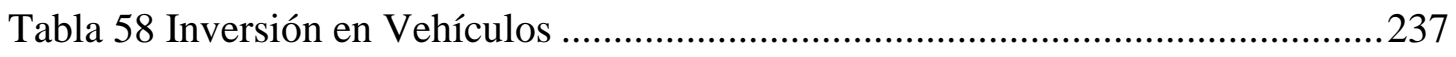

Tabla 59 Inversión en Equipos de Oficina, Comunicación y Computación................238

Tabla 60 Inversión en Terrenos, Construcciones y Obras Civiles ..............................238

Tabla 61 Programa de Inversión Fija del Proyecto....................................................2239

Tabla 62 Inversión en Activos Intangibles y Diferidos .............................................239

Tabla 63. Determinación de Costos Operacionales ..................................................241

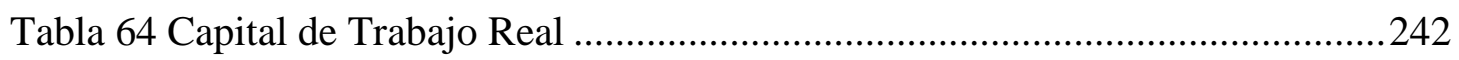

Tabla 65 Programa de Capital de Trabajo .............................................................242 
Tabla 66 Costo de Inversión del Proyecto .243

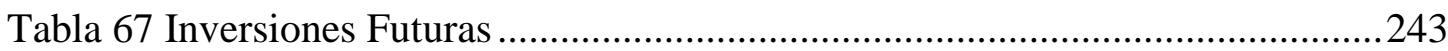

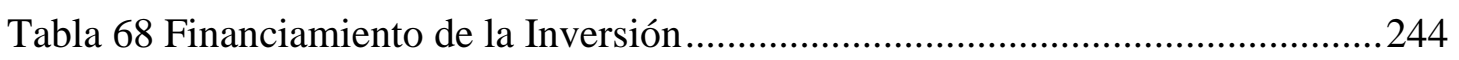

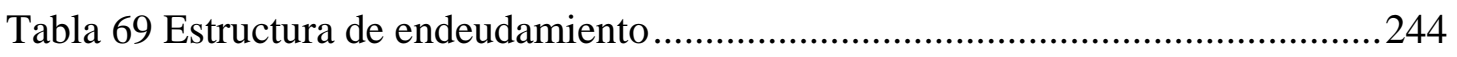

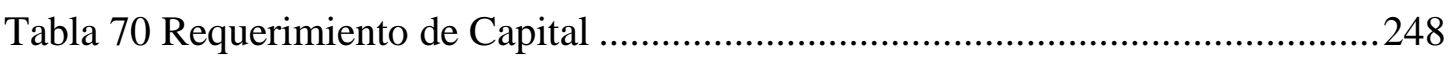

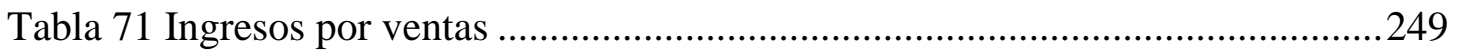

Tabla 72 Presupuesto de Costos Operacionales.....................................................249

Tabla 73 Presupuesto de adquisición de materia prima directa................................250

Tabla 74 Presupuesto de adquisición de Insumos directos ........................................250

Tabla 75 Presupuesto de Gastos por Ventas ..........................................................250

Tabla 76 Presupuesto de Gastos Administrativos ....................................................251

Tabla 77 Presupuesto de Gastos por Ventas ...........................................................251

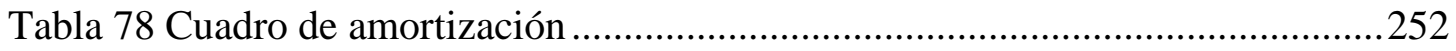

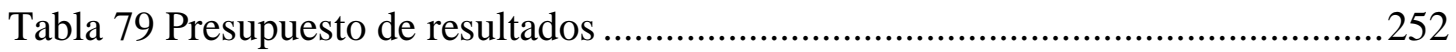

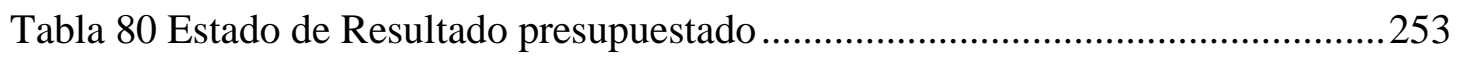

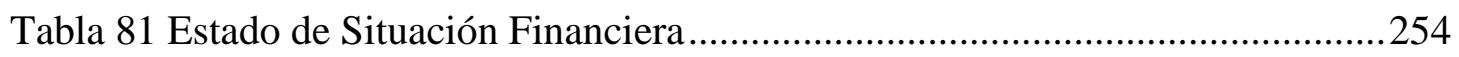

Tabla 82 Flujo de Caja Económico y Financiero.......................................................255

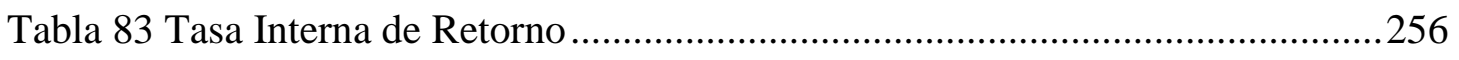

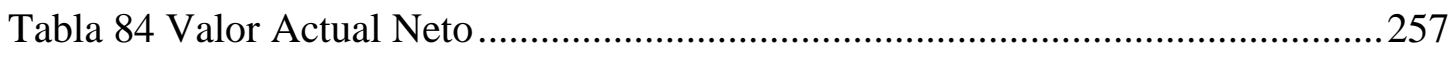

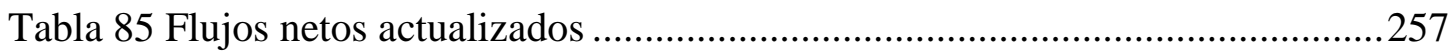

Tabla 86 Estimación del Período de Recuperación de la Inversión.............................258

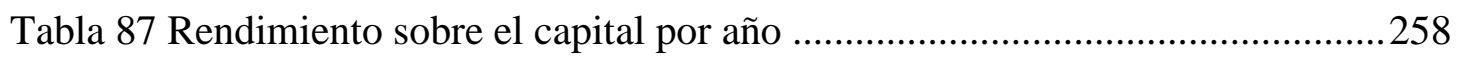

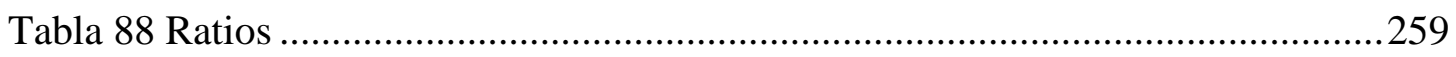

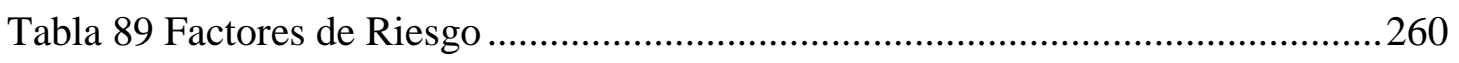

Tabla 90 Plan de Contingencia por Suceso............................................................263

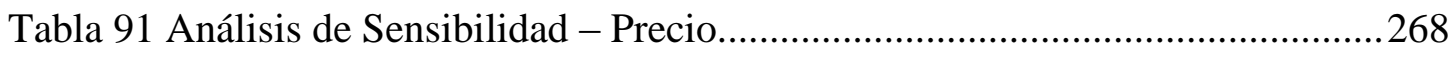

Tabla 92 Análisis de Sensibilidad - Costo ..............................................................268

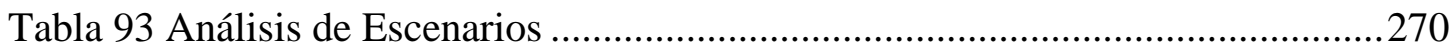




\section{Lista De Figuras}

Figura 1 Tipos de Competidores 30

Figura 2. Análisis del entorno competitivo en base a las cinco fuerzas de Porter ........38

Figura 3 Mineros Artesanales en vía de formalización. 62

Figura 4. Crecimiento del Producto Bruto Interno por actividad. .63

Figura 5. Crecimiento del Valor Agregado Bruto en la actividad de extracción ........64

Figura 6. Crecimiento del Valor Agregado Bruto en la actividad ..............................64

Figura 7 Población Ocupada en empleo informal en la Región Sur.............................65

Figura 8 Equipo para planta de oxigeno industrial ...................................................67

Figura 9 Número de empresas según la actividad económica que realizan.................77

Figura 10 Número de empresas de acuerdo a su línea de actividad económica. ..........78

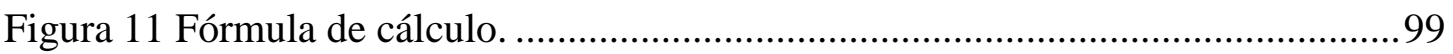

Figura 12 Ubicación de las empresas consumidoras de oxígeno industrial................104

Figura 13 Tipo de actividad que realiza su empresa............................................... 105

Figura 14 Empresa proveedora a la que accede para la adquisición del oxígeno....... 106

Figura 15 Empresa proveedora a la que accede para la adquisición del oxígeno .....107

Figura 16 La empresa que lo abastece de oxigeno industrial cubre la necesidad....108

Figura 17 Empresas satisfechas con el servicio de su proveedor actual de oxígeno. 109

Figura 18 Empresas satisfechas con su actual proveedor por actividad económica. 110

Figura 19 Empresas que les gustaría un mejor servicio sobre la adquisición del

producto.

Figura 20 Empresas que les gustaría un mejor servicio sobre la adquisición del producto.

Figura 21 Empresas dispuestas a adquirir el producto de un nuevo proveedor

Figura 22 Empresas dispuestas a adquirir el producto de un nuevo proveedor,por tipo de actividad.

Figura 23 Nivel de precios al que las empresas adquieren el oxígeno industrial. .....115

Figura 24 Nivel de precios al que las empresas adquieren el oxígeno industrial .....116

Figura 25 Nivel de pureza del oxígeno industrial requerido

Figura 26 Principales factores de decisión de compra de oxigeno industrial 118

Figura 27 Empresas que consumen oxigeno industrial y que tiene planes de expansión y un requerimiento adicional del producto. 
Figura 28 Empresas que consumen oxigeno industrial y que tiene planes de expansión y un requerimiento adicional del producto de hasta un $20 \%$................................... 120

Figura 29 Con qué frecuencia su empresa requiere de oxigeno industrial ................121

Figura 30 ¿La cantidad de oxígeno que requiere su empresa es siempre la misma?.122

Figura 31 Diagrama de Operación de ProcesosEncilindrado y envasado ................... 154

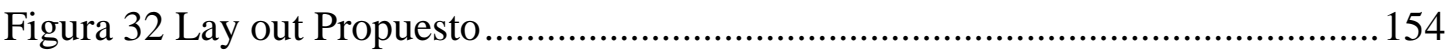

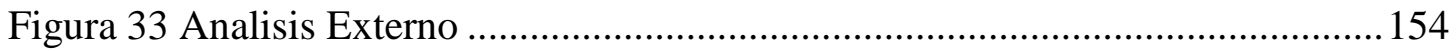

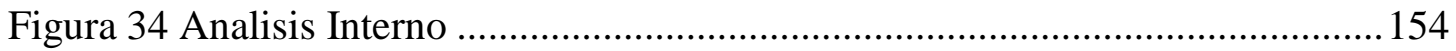

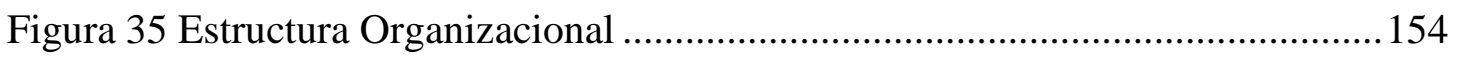

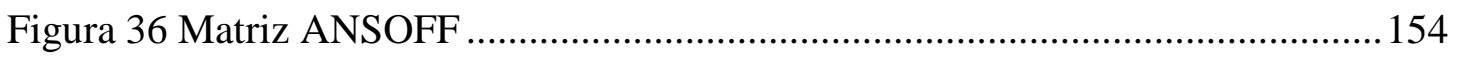

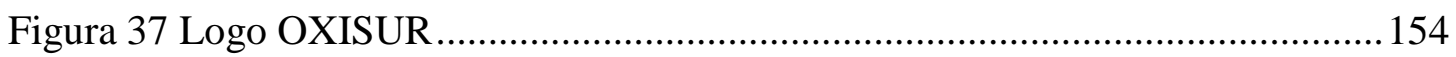




\section{INTRODUCCIÓN}

El presente trabajo de tesis tiene como objetivo realizar una investigación para determinar la factibilidad de establecer una empresa de Oxigeno industrial en el departamento de Puno. La investigación tendrá como ámbito de estudio y aplicación el distrito de Juliaca. Este proyecto consiste en implementar una planta productora y envasadora de Oxigeno industrial y ofrecer un servicio de distribución de oxigeno con calidad y seguridad, este servicio será proporcionado por “Oxigeno del Sur”, negocio planteado en el presente estudio.

Al momento de realizar la investigación de mercado, se identificó la necesidad de contar con un productor de Oxigeno industrial, para atender la demanda que se encuentra parcialmente desatendida y la demanda emergente, ya que las empresas consumidoras de oxigeno industrial solo cuentan con dos alternativas para cubrir sus requerimientos. La primera es contratar el servicio de la única planta productora de la región; sin embargo, de lo investigado determinamos que la calidad del producto ofrecido por esta planta no es la esperada por los clientes. La segunda opción son las empresas distribuidores que se encargan de suministrar el producto que le compran a terceros (usualmente Praxair), según nuestra investigación la falta de seguridad en sus operaciones crea desconfianza en los clientes, es así que la empresa propuesta tiene la oportunidad de cubrir las deficiencias y ofrecer un servicio mejorado.

El presente estudio, lo conforman nueve capítulos, enfocados en determinar la viabilidad del proyecto, siendo los siguientes:

En el capítulo I, se establece la oportunidad de negocio, seguido de la determinación del problema, justificación, objetivos y limitaciones del proyecto.

En el capítulo II, se realiza la descripción del sector al que pertenece el negocio propuesto, también se identifican las empresas que forman parte de la competencia, y que han sido agrupadas en tres categorías Grandes empresas, competidores directos y distribuidores. 
En el capítulo III, realizamos el estudio de mercado, a través del análisis cuantitativo (encuesta) y el análisis cualitativo (entrevista), identificando las preferencias de consumo de nuestro mercado potencial, respecto al producto y servicio de Oxigeno industrial.

En el capítulo IV, se intenta proyecta la posible demanda y se identifica el mercado potencial, disponible, efectivo y objetivo, del mismo modo se establece el pronóstico de ventas.

En el capítulo V, se abarca la Ingeniería del Proyecto, determinado los procesos internos de la empresa, la localización del proyecto y sus requerimientos.

En el capítulo VI, establecemos los aspectos organizacionales necesarios para lograr los objetivos propuestos, se determina también los valores, misión y visión de la empresa; de igual manera establecemos las estrategias del negocio.

En el capítulo VII, presentamos el plan de marketing, estableciendo las estrategias de marketing para producto, precio, distribución y promoción.

En el capítulo VIII, presentamos la planificación financiera del proyecto, determinando la inversión que se necesita para implementar nuestro proyecto, presupuesto de ventas, costos, etc. Necesarios para iniciar el negocio.

En el capítulo IX, Realizamos la Evaluación Económica Financiera con el fin de determinar si el proyecto es viable. 


\section{Capítulo I Generalidades}

\subsection{Antecedentes.}

Los gases industriales corresponden al grupo de gases manufacturados, los cuales se distribuyen y distribuyen en casi todos los sectores industriales, siendo variadas sus aplicaciones en campos como la medicina, la ciencia e investigación, el área metal mecánica, sector minero, etc. Dentro de los gases industriales de mayor demanda se encuentran el oxígeno, nitrógeno e hidrógeno. (Atkins, 2012)

El inventor e ingeniero alemán Carl Von Linde, sentó las bases para la producción de gases industriales. En un inicio Linde centro sus investigaciones en la creación de máquinas refrigerantes las cuales patento y comercializo en toda Europa a través de su propia fábrica. En su búsqueda por mejorar sus máquinas refrigerantes en 1894 el ingeniero Alemán descubrió la Licuefacción del aire, proceso que consiste en lograr que el aire pase de su estado gaseoso a un estado líquido y pueda ser acumulado en un recipiente colector. Posteriormente en el año 1902, Linde descubrió que el Nitrógeno y oxígeno componentes principales del aire, se evaporan a temperaturas distintas; esa característica permitió que ambos componentes al evaporarse puedan ser separados (Cabana, 2007).

El procedimiento aplicado por Linde para obtener oxígeno fue el primero en ser descubierto, pero no es el único, el oxígeno puede ser obtenido también a través de la destilación del aire líquido o por electrolisis del agua. (Cabana, 2007)

Dentro de las primeras aplicaciones que tuvo el oxígeno fue en el área de la medicina, se administró a pacientes con problemas respiratorios, inicialmente este procedimiento solo se encontraba disponible para personas que contaran con grandes recursos económicos por el alto costo que tenía. (Cabana, 2007) 
Una de las aplicaciones más importante que se le dio al oxígeno en la industria fue en la soldadura autógena de los metales, mediante el uso de un soplete se quema oxígeno y un gas combustible, como por ejemplo el acetileno (soplete oxiacetilénico) cuya llama puede alcanzar una temperatura de 3100 grados, también se puede utilizar como gas combustible el hidrogeno (soplete oxhídrico). La soldadura autógena fue un gran avance en la industria del metal. (Tamborero, n.d.)

A nivel mundial se pueden encontrar tres grandes empresas dedicadas a la producción de gases industriales la multinacional Air Liquide con su sede principal en Francia y con presencia en más de 75 países, seguida por Linde de Alemania y la Estadunidense Praxair que domina el mercado en el continente americano. Desde el año 2016 dos de estas grandes corporaciones Linde y Praxair se encuentran en conversaciones para concretar una fusión y así convertirse en los lideres absolutos dentro del mercado mundial de gases industriales (Francfort, 2016).

Una mención especial merece la corporación alemana Messer, con una fuerte presencia en el mercado de gases industriales y con más de 60 sucursales alrededor del mundo.

Hablando del espacio sudamericano tenemos a Praxair y Linde como las empresas con mayores ingresos; durante el año 2016 el 13\% de los ingresos de la empresa Praxair provinieron solo de Sudamérica, por su parte Linde se encuentra presente en Venezuela y Ecuador países donde Praxair aún no opera. (Wall, 2016)

Dentro del mercado sudamericano destaca la empresa colombiana Cryogas cuenta con más de 60 años de experiencia en el mercado de gases industriales. A partir del 2008 se une al grupo chileno INDURA principal distribuidor de gases industriales y soldadura en Chile además de operar también en Argentina, Ecuador y Perú. Uno de 
los últimos pasos realizados por la empresa Cryogas para expandirse en el mercado se dio en el año 2012 unirse al grupo Air Products compañía productora de gases industriales con fuerte presencia en el mercado internacional. (Cryogas, 2016)

En el mercado peruano se pueden encontrar empresas de reconocimiento mundial como Praxair presente en Perú hace más de 50 años, INDURA que inició sus operaciones en el Perú en el año 1996 en la ciudad de Lima y con el paso del tiempo se extendió por diferentes ciudades de nuestro país como son Trujillo, Arequipa, Talara, Cajamarca y Chiclayo. De igual manera La corporación Messer se encuentra operando en nuestro país desde el año 1960.

También están presentes empresas de capitales peruanos dedicadas a la producción y distribución de gases industriales como son Oxired, Oxigeno San Felipe, Oxyman y Oxitec.

El Perú es un país que cuenta con un gran potencial minero, gracias a la presencia de la Cordillera de los Andes principal fuente de recursos minerales. A nivel mundial nuestro país está entre los primeros productores de diversos metales como oro, cobre, plata, zinc, plomo, etc. El Perú es el segundo productor de plata a nivel mundial y el tercero en cobre; además de ser el primer productor de oro, zinc, estaño, plomo y molibdeno en América Latina. (Dirección de Promoción Minera, 2016)

En la zona sur del país, el departamento de Puno cuenta actualmente con una sola fábrica embotelladora de oxígeno industrial, la empresa denominada CIGA SA, ocupa el $50 \%$ del mercado y sus operaciones están enfocadas a cubrir principalmente los requerimientos del sector metalmecánico y minero.

En el departamento de Puno se encuentra la ciudad de Juliaca, lugar donde se tiene planeado desarrollar el presente proyecto; esta región sur del Perú tiene como 
principales actividades la agricultura, comercio, manufactura y minería, sectores importantes para la el negocio que se pretende iniciar.

La minería en el departamento de Puno se centra principalmente en la extracción de estaño, plomo, oro, plata y zinc, la exportación de estos productos mineros impulsa el crecimiento constante de la región. Debemos mencionar que gran parte de la producción minera artesanal es informal y no registra información exacta de sus niveles de extracción, además de provocar conflictos socio ambientales e inestabilidad política en esta región. Actualmente existen leyes que buscan formalizar la minería ilegal y se están aplicando gradualmente. (Dirección de Promoción Minera, 2016)

\subsection{Determinación del Problema u Oportunidad.}

Dentro de la ciudad de Juliaca, capital de la provincia de San Román-Puno, se puede encontrar una sola empresa con planta propia dedicada a la producción de oxígeno para uso industrial, también existen algunas empresas pequeñas en el mercado cuya actividad principal es distribuir oxígeno industrial dentro de los diferentes sectores. Estos distribuidores no brindan un servicio adecuado y completo con respecto al producto que ofrecen; la demanda actual carece muchas veces de información sobre las características del producto, datos sobre su manejo, manipulación y el soporte técnico para los instrumentos que los gases industriales como el oxígeno requieren.

Esta demanda además se encuentra rodeada por un ambiente de informalidad producto del crecimiento desordenado de la ciudad y el contrabando, todos estos factores ocasionan que los consumidores no puedan tener a su alcance un producto de calidad y con las características de seguridad necesarias. 
La oferta actual de oxigeno industrial en la ciudad de Juliaca está compuesta por una empresa productora de Oxigeno industrial y dos distribuidores los cuales no son suficiente para cubrir la demanda actual.

Es entonces cuando se observa la oportunidad de montar una planta de oxígeno industrial en esta región, tomando en cuenta que la única empresa productora de oxígeno industrial en la región y los distribuidores de terceros no son suficientes para cubrir la demanda de las diferentes industrias y sectores, la necesidad de contar con el oxígeno se ira incrementado conforme se vayan ejecutando los diferentes proyectos planeados para el departamento de Puno y sus provincias.

\subsection{Justificación del Proyecto.}

Este plan de negocios busca satisfacer a la demanda actual y emergente que busca un producto seguro y de calidad, además de asesoría y un servicio especializado en la manipulación de gases industriales. Debido a su constante crecimiento el sector metalmecánico será nuestro principal mercado, este sector está directamente relacionado con la actividad minería y la industria de la construcción.

El departamento de Puno experimenta actualmente un crecimiento en la industria metalmecánica, que es la encargada de transformar materia prima como el hierro, acero, aluminio, bronce, etc. Y fabricar con esa materia prima productos que se utilizan en la agricultura, construcción, comercio, minería y transporte. Ante este incremento en el rubro metal mecánico también aumenta el requerimiento de oxígeno por ser el elemento principal para realizar los trabajos de corte y soldadura.

El campo minero también está creciendo y progresando aunque muchas veces de manera informal. Existen varios proyectos mineros para la región Puno que serán desarrollados durante los próximos años. 
Para la demanda objetiva de este mercado el precio es un factor decisivo al momento de realizar la compra, se considera también de importancia la seguridad del servicio y la calidad del producto y sus características, como por ejemplo la trayectoria de la empresa, eficiencia en el servicio de entrega, servicio técnico, etc. En caso uno de estos aspectos se vea afectado, el cliente optara por comprar una segunda opción que se encuentre en el mercado, es decir que, la fidelidad del cliente, es un factor determinante para la toma de decisiones.

Ello coloca como una alternativa clara el desarrollo de este plan de negocios en el desarrollo de una empresa productora y distribuidora de gases industriales, siendo el principal elemento el oxígeno, enfocado a satisfacer necesidad de la empresa demandante, tanto en calidad precio y más, aprovechando la gran oportunidad de mercado que se presenta.

Todas las condiciones están dadas para poner en marcha este plan de negocios donde podremos aplicar las herramientas y conceptos adquiridos a través de la maestría.

\subsection{Objetivos generales y específicos.}

\section{Objetivo general.}

Determinar la factibilidad de establecer una planta de oxígeno industrial en la ciudad de Juliaca para atender la demanda de la región.

\section{Objetivos específicos.}

- Determinar la viabilidad comercial mediante la definición cuantitativa de los factores de mercado que aseguren la aceptación de nuestro producto.

- Definir el estudio técnico del proyecto determinando el tamaño, la tecnología apropiada y la localización óptima. 
- Efectuar el estudio legal y organizacional, analizando los aspectos legales inherentes al proyecto, estableciendo la forma societaria y leyes laborales que se aplican a éste tipo de empresa.

- Elaborar la evaluación del proyecto, mediante el análisis económicofinanciero del mismo, determinando el monto y estructura de la inversión, fuentes de financiamiento y niveles de ingresos y egresos; y finalmente en base a indicadores de rentabilidad.

\subsection{Alcances y limitaciones de la investigación.}

Alcances

El presente plan de negocios abarcara el sector metalmecánico del departamento de Puno, específicamente en las ciudades de Puno y Juliaca.

\section{Limitaciones}

- Acceso a la información del mercado.

- Tiempo para la entrega del proyecto.

- Disponibilidad de tomadores de decisión en las empresas para el llenado de encuestas.

- Confianza de los propietarios de las empresas al momento de realizar las entrevistas. 


\section{Capítulo II Estructura Económica del Sector}

\subsection{Descripción del estado actual de la industria.}

El crecimiento económico del país y el incremento de la inversión privada, han contribuido a la preparación de una cartera de proyectos de desarrollo para los próximos años en diferentes rubros como electricidad, ferroviario, hidrocarburos, inmuebles, irrigación, minería, etc. Estos proyectos contribuirán al ascenso de la producción metalmecánica que es continua desde el año 2010 y que contribuye al desarrollo del país de forma integral.

La importancia del sector metalmecánico radica en el apoyo que brinda a otras áreas al fabricar productos, desde herramientas hasta maquinas industriales, que facilitan el desempeño laboral a otros sectores. Sus productos se utilizan en la industria de la agricultura, comercio, minería, transporte, etc. Por lo tanto el sector metalmecánico contribuye en el desarrollo del país por ser fundamental para la producción de bienes y servicios

El oxígeno como gas industrial es uno de los principales insumos requeridos por el sector metalmecánico, este gas industrial tiene la característica de ser comburente esto lo hace indispensable para la combustión, gracias a esta propiedad, el oxígeno se utiliza en soldaduras y cortes.

\section{Oportunidad de Negocio}

El sector metalmecánico es una industria que requiere el oxígeno como gas industrial para realizar sus actividades y este sector está ligado directamente al sector minero y mucha otras industrias. En la minería los gases industriales se aplican en diferentes etapas de su proceso productivo y tienen como objetivo principal reducir costos, aumentar la capacidad de producción y disminuir el impacto ambiental. 
En la industria metalmecánica, que tiene como insumos básicos el metal y las aleaciones de hierro, el oxígeno industrial es fundamental en la producción de maquinarias y herramientas que se distribuyen a otras industrias importantes.

Con el panorama que se presenta actualmente en la región sería complicado que se intente cubrir el servicio para todos los sectores y competir de igual a igual con las empresas que ya tienen tiempo operando en el mercado. Sin embargo buscaremos posicionarnos poco a poco ofreciendo un servicio de calidad y seguridad, soporte y técnico. 
2.1.1 Segmentación de la Industria.

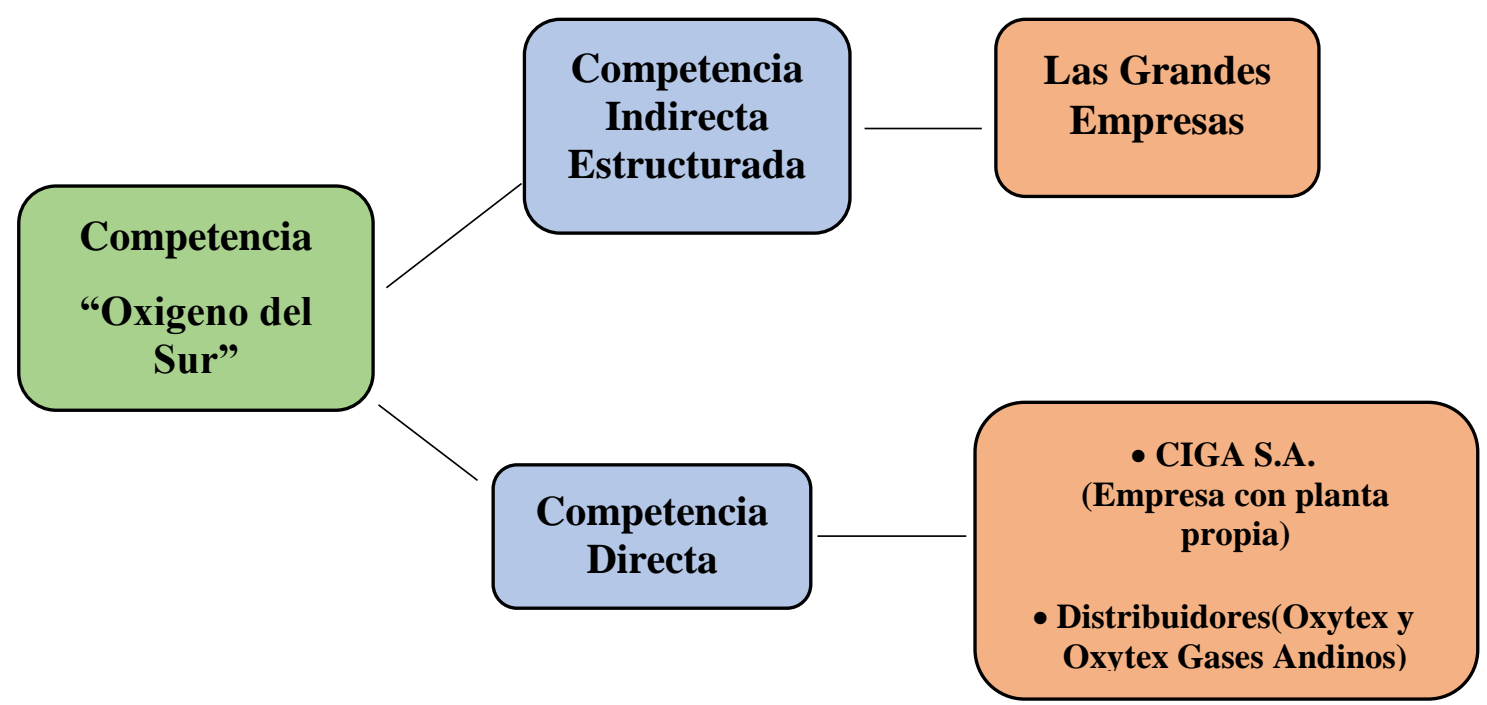

Figura 1 Tipos de Competidores.

Elaboración propia

Para el presente estudio se logró identificar dos tipos de competidores en el sector de oxígeno industrial:

Competencia Indirecta Estructurada : Grandes Empresas

Competencia Directa Estructurada : CIGA S.A. (Empresa con Planta productora de Oxigeno Industrial) y las distribuidoras como Oxytex y Oxytex Gases Andinos.

\subsubsection{Empresas que conforman la industria}

En este punto se detallara de manera general los tipos de competencia que enfrentara el negocio planteado, y a lo largo del presente estudio serán desarrollados de manera más específica.

\section{Competencia Indirecta Estructurada: Grandes Empresas}


Este conjunto lo conforman las grandes empresas con un nombre ya ganado en el ámbito internacional, y que se encuentran operando en el país desde hace muchos años, estas empresas cuentan con plantas propias para la producción de gases industriales. Dentro de este grupo se consideró a las siguientes empresas por su importancia y tiempo de operación en el país:

- Praxair

- Indura

- Messer Perú

Competencia Directa Estructurada: Competidores Directos y Distribuidores

En este grupo encontramos a la única empresa con planta propia y productora de oxígeno industrial ubicada en la ciudad de Juliaca. Dentro de este grupo encontramos a la empresa:

- CIGA S.A.

También encontramos a las empresas que se dedican solo a la distribución de oxígeno industrial. Las cuales son:

- Oxytex

- Oxytex Gases Andinos

\subsection{Tendencias de la Industria.}

Desde un análisis de la competencia. 
- Desde el punto de vista del análisis de la competencia, se pueden determinar las siguientes características para el caso de las Grandes empresas:

En el Perú encontramos tres grandes empresas de prestigio internacional Praxair, Indura y Messer Perú, cada una con su oficina principal en Lima, cuentan con sucursales a lo largo del territorio peruano en zonas estratégicas, pero ninguna de ellas tiene una planta u oficina de ventas dentro del departamento de Puno. La forma de trabajo de estas grandes empresas es la de trasladar el producto, en su transporte propio, desde sus plantas productoras de gases industriales hasta las instalaciones de las industrias que solicitan el servicio.

- En cuanto a los competidores directos, desde el punto de vista del análisis de la competencia se pude señalar:

La empresa CIGA S.A. pertenece al grupo TECNIDES, con más de 25 años de presencia en la ciudad de Juliaca, esta empresa se dedica a la producción de diversos gases industriales, dentro de ellos el oxígeno industrial, además ofrece servicios de instalación, asesoramiento y mantenimiento de instalaciones para gases industriales.

Las otras dos empresas en el mercado formalmente establecidas son Oxytec SAC y Oxytec Gases Andinos, la primera de ellas tiene casi 20 años de funcionamiento y se dedica a la distribución, aplicación e instalación de sistema de gases industriales, además cuenta con oficinas en la ciudad de Arequipa. La segunda empresa solo se dedica a la distribución de Oxigeno, ambas cuentan con oficinas en la ciudad de Juliaca. Ninguna de estas empresas produce directamente el oxígeno industrial, solo son intermediarios entre las productoras de oxígeno y los consumidores. 


\section{Desde un análisis macro económico del país.}

En cuanto al análisis macro económico del país se presentan los siguientes datos sobre el crecimiento de ciertos sectores macroeconómicos del Perú, estos datos ayudaran a determinar el escenario donde la empresa propuesta operara y cómo influirá en el mercado del oxígeno industrial.

La economía peruana durante el año 2016 creció un 3.9\%, según el Ministerio de Economía y Finanzas (2016) fue una vez más la minería la que mantuvo el avance de nuestras finanzas, las cifras señalan que El Producto Bruto Interno (PBI) registro un crecimiento superior en comparación a los años 2015 y 2014, aunque sin alcanzar el 6\% de los años 2013,2012 y 2011.

a) Con respecto al 2018, en el mes de Abril la economía peruana creció en $7,81 \%$, provocando un incremento en $4,40 \%$ en 12 meses. El mencionado incremento en la economía se debió en su mayoría a la demanda externa de productos tradicionales

Se estipula que la economía en el año 2019 el Perú se ubicará en el puesto 67 entre los países que más crecerán durante el 2019; de esta manera, su aporte representará el 0,32\% del crecimiento económico global.

El Banco de Inversión Deutsche Bank, coloco al Perú en la cima del ranking de economías emergentes menos vulnerables, por presentar características como la mejora en sus indicadores macroeconómicos, alto nivel de liquidez, buen desempeño físcal y bajo nivel de deuda externa. Estas características hacen más atractivo el entorno para captar más posibilidades de inversión (Deutsche Bank:, 2017). 
El sector minero es importante en la economía peruana, sobre todo en términos de exportaciones, de inversión, en la producción total del país, y en la generación de empleo (directo e indirecto).

Desde la segunda mitad de 2016, el crecimiento de la producción minera empieza a moderarse conforme las nuevas minas alcanzan sus máximos niveles de operación. En 2017, según nuestros estimados, la producción minera contribuirá con 0,4 puntos porcentuales al crecimiento del PIB, por debajo de lo alcanzado en 2016 (cerca de 2 puntos porcentuales).

Sector Metal Mecánico se recuperara en el 2017

Durante el año 2016 la industria metal mecánica sufrió una caída de 5.6\% afectando cuatro segmentos de su producción, equipos informáticos eléctricos y ópticos, maquinaria y equipo, materiales de transporte y productos metálicos diversos. La caída en la producción de este sector se debió principalmente al retraso en la ejecución de diversos proyectos mineros y de infraestructura, la industria metalmecánica venía creciendo desde el 2010 (Maximixe, 2016).

El PBI del subsector minero metálico creció de S/ 48,662 millones2 registrados en el 2016 a S/ 50,708 millones en el 2017. Dicho monto significó un incremento del $4.2 \%$ y se sustenta en la mayor producción anual de cobre (3.9\%), zinc $(10.2 \%)$, hierro (14.9\%) y molibdeno $(9.3 \%)$. Cabe destacar que es el tercer año consecutivo de crecimiento del PBI de la actividad minero metálica. Por su parte, el PBI nacional que ascendió a S/ 514,927 millones (a precios constantes del 2007), registró un crecimiento de $2.5 \%$ con respecto al 2016, de los cuales 0.4 puntos porcentuales fueron aportados por la actividad minero metálica. Cabe resaltar que dicho aporte fue únicamente superado por el sector Servicios. 
Asimismo, el PBI de la minería metálica representó el 9.8\% del PBI nacional en el 2017.

Sin embargo especialistas afirman que el sector metalmecánico se recuperara durante el año 2017.

b) Según los datos más recientes del Ministerio de la Producción con respecto al año 2018, indica que las exportaciones metalmecánicas entre enero-abril de 2018 ascendieron a US \$ 219 millones, lo que significó un avance de $25.1 \%$ respecto al período de 2017, dicho avance estuvo asociado a una mayor demanda generada por la recuperación del sector construcción, el trabajo de la construcción de unidades mineras, edificios y centros comerciales (Ministerio de la producción, 2018).

Sector Minero genera nueve empleos indirectos por cada empleado minero

La minería influye en el desarrollo económico del país de diferentes maneras, repercute en las inversiones, exportaciones, en la recaudación tributaria en el PBI y en la generación de empleo. Por cada empleo generado en el sector minero se generan nueve empleos indirectos.

En Latinoamérica el Perú ocupa el primer lugar en la producción de oro, plomo y zinc y el segundo lugar en la producción de plata y cobre. La inversión en el sector minero se incrementó en un 400\% entre el año 2001 y 2013, sin embargo durante el año 2014 y 2015 la inversión se redujo, a consecuencia de la caída en el precio de los metales y los constantes conflictos sociales (Direccion General de Mineria, 2016).

Sector Construcción durante el año 2017 se espera un crecimiento de 4\% 
La industria de la construcción se encarga de proyectos inmobiliarios como casas y abarca hasta proyectos de ingeniería civil de gran escala, donde intervienen los procesos de soldadura, corte y recubrimiento.

Durante el año 2016 el sector de la construcción decreció en 3.15\% debido a que el gobierno pasado no puso énfasis en las políticas de vivienda, esto ocasiono que la demanda de cemento disminuyera al igual que la ejecución de obras públicas y hubiese dificultades para implementar productos mineros. Sin embargo se espera la recuperación del sector durante el año 2017, teniendo como fortaleza las obras que se realizan en el interior del país que representan el 72\% de su producción (Rios, 2017)

c) Por otro lado el sector construcción del Perú alcanza un gran crecimiento de $7,2 \%$ en cuatro años, dicho incremento se vio beneficiado por el avance físico de obras públicas en los ámbito nacional, regional y local (17,58\%), además de un mayor consumo interno de cemento $(8.25 \%$ ) (Instituto nacional de estadística e informática. 2018)

\section{Conclusión del escenario macro económico descrito}

Los sectores que hemos detallado si bien han presentado una reducción en su producción estos últimos años, para el presente año 2017 los especialistas proyectan la recuperación de estos sectores. La industria metalmecánica, minera y de construcción necesitan del oxígeno industrial para realizar sus diversas actividades y se aplican en distintos momentos de su producción, el incremento en la producción de estos sectores generara un aumento en la demanda de oxígeno industrial. 


\subsection{Análisis Estructural el Sector - Oxígeno Industrial.}

Modelo de la Cinco Fuerzas de Porter.

El análisis realizado en base a las cinco fuerzas de Porter, se presenta como una herramienta de gestión la cual fue diseñada por el profesor y economista Michael Porter en 1979. El modelo ayuda a realizar un estudio externo de la empresa por medio del análisis del sector o industria a la que pertenece. (Porter, 2009).

Michael Porter señala la presencia de cinco fuerzas dentro de un sector o industria:

- Amenaza de entrada de nuevos competidores.

- Poder de negociación de los proveedores.

- Poder de negociación de los clientes.

- Amenaza de productos sustitutos.

- Rivalidad entre competidores.

El Modelo de las cinco fuerzas de Porter, permitirán establecer los niveles de competencia de una industria y también a diseñar estrategias que permitan que la empresa pueda sacar ventaja de las oportunidades y hacerle frente a las posibles amenazas. 


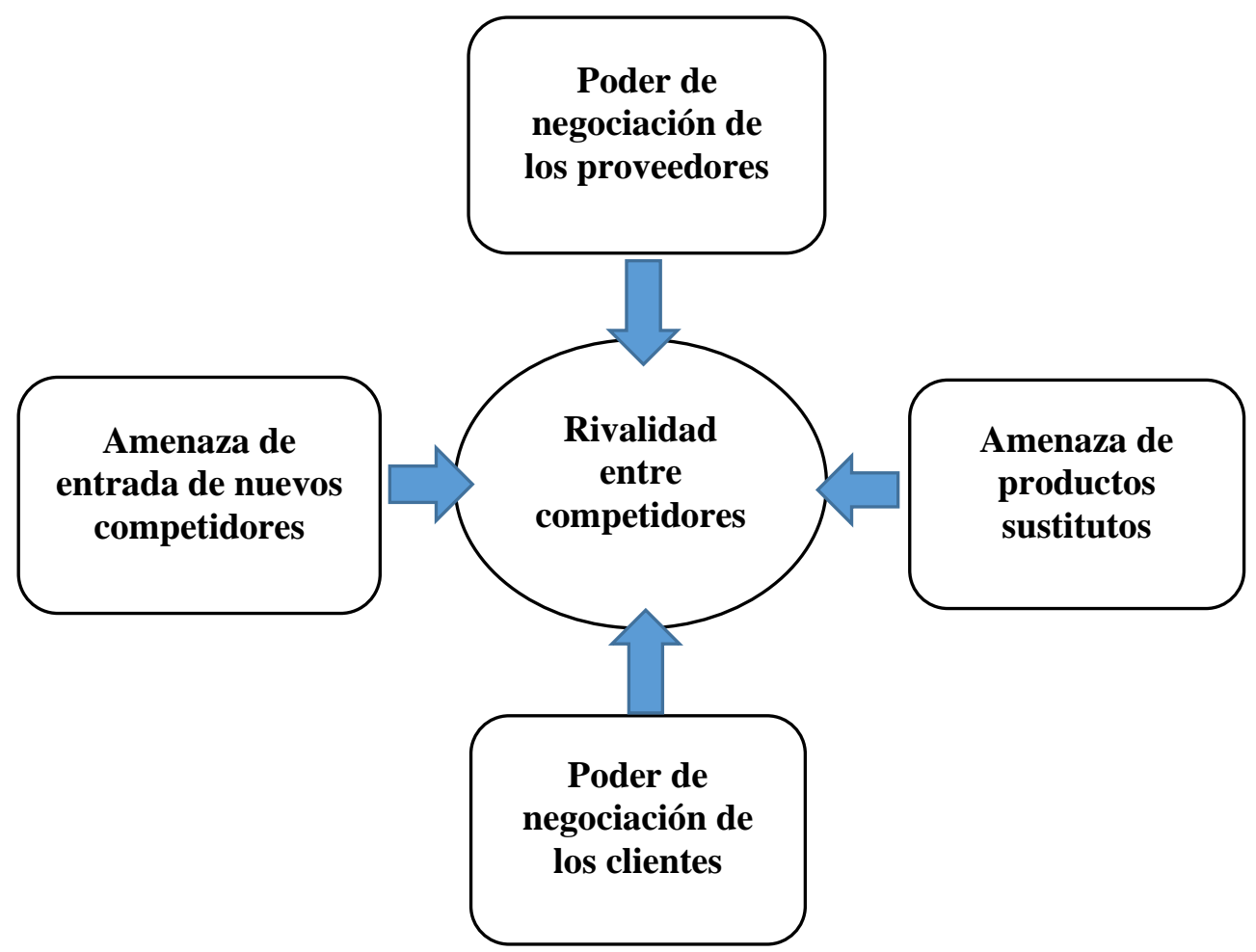

Figura 2. Análisis del entorno competitivo en base a las cinco fuerzas de Porter. Elaboración propia

Mediante la aplicación de las cinco Fuerzas de Porter se evaluara las diferentes variables concernientes con el mercado, para poder determinar el nivel de competitividad de cada fuerza descrita.

Se aplicara la siguiente escala de calificación:

Tabla 1 Escala de Calificacion

Escala Media/ Alta Media Media/Baja Baja

$\begin{array}{lllll}\text { Calificación } & 4 & 3 & 2 & 1\end{array}$

Nota. Elaboración Propia 


\subsubsection{Amenaza de los nuevos competidores.}

De acuerdo a Porter (2009) se hace uso de esta fuerza en la industria para identificar el ingreso potencial de empresas con similares características o productos al mercado.

Las empresas nuevas, al tratar de formar parte de un mercado, pueden hallar en su camino barreras complicadas de superar como la poca experiencia, el capital necesario, escases de canales de distribución, problemas para tener acceso a los insumos, pueden encontrase con un mercado saturado, etc.

Ciertas empresas, a pesar de encontrarse con estas dificultades, logran ingresar al mercado sobre todo cuando presentan productos de más alta calidad, menores precios y una publicidad mejor enfocada en comparación con las empresas que se encuentran dentro del mercado en ese momento.

La barrera de uno siempre será la oportunidad de otro.

Para analizar la fuerza de los competidores se deben contestar las siguientes preguntas:

- ¿El mercado del oxígeno industrial es considerado interesante para otras empresas?

- ¿En el mercado de oxigeno industrial existen barreras de ingreso?

- ¿Las barreras presentes son fáciles de superar?

- ¿Los competidores nuevos podrían apropiarse de una parte del mercado?

El mercado del oxígeno industrial se percibe como un sector atractivo para las nuevas empresas, considerando que son muy pocas las empresas 
dedicadas a este rubro en la región Puno y conociendo que la demanda del producto se irá incrementando por el aumento de proyectos de inversión.

A través del análisis de las fuerzas de Porter se analizará el nivel de competencia entre los competidores directos de la empresa propuesta compuestos por:

- CIGA S. A, por ser la única empresa que cuenta con una planta productora de oxigeno industrial dentro del departamento de Puno.

- Distribuidores, conformados por Oxytex y Oxytex Gases Andinos, empresas que distribuyen oxigeno industrial obtenido de grandes productoras.

Tabla 2 Amenaza entrada de nuevos competidores

\begin{tabular}{|c|c|c|c|c|c|}
\hline \multirow{3}{*}{ VARIABLE } & \multirow{3}{*}{ PESO } & \multicolumn{2}{|l|}{ CIGA S.A. } & \multicolumn{2}{|c|}{ (Oxytex y Oxytex Gases Andinos) } \\
\hline & & $\begin{array}{ll}\text { GRADO } & \text { DE }\end{array}$ & PESO & GRADO & DE $\quad$ PESO \\
\hline & & ATRACTIVIDAD & PONDERADO & ATRACTIVIDAD & PONDERADO \\
\hline Dominio en el desarrollo de la & & & & & \\
\hline actividad & 0.20 & 4 & 0.80 & 3 & 0.60 \\
\hline Necesidad permanente de & & & & & \\
\hline especialización y tecnificación & 0.15 & 4 & 0.60 & 1 & 0.15 \\
\hline Confianza del cliente & 0.50 & 4 & 2.00 & 2 & 1.00 \\
\hline Facilidad de acceso al servicio & 0.15 & 3 & 0.45 & 3 & 0.45 \\
\hline Total & & & 3.85 & & 2.20 \\
\hline Peso Ponderado Medio & & 3.025 & & & \\
\hline
\end{tabular}




\section{Interpretación}

Lo valores otorgados a la amenaza de entrada de nuevos competidores al mercado de oxígeno industrial, señalan que representa una amenaza media (3.025), por lo tanto se puede decir que si bien existen barreras para los nuevos competidores estas no son infranqueables.

Para el rubro de gases industriales específicamente de oxígeno industrial, la competencia es poca, solo existe una planta de oxígeno industrial que está más comprometida con el sector minero, también están presentes dos distribuidoras con oficinas en la ciudad de Juliaca desde donde operan y comercializan sus productos.

El mercado de oxígeno industrial como muchos otros en la región Puno, se ve tocado por la informalidad que prevalece en las ciudades de esta región del país. Si bien las grandes empresas dedicadas al rubro metalmecánico buscan un proveedor de oxígeno que cumpla con todos los requisitos necesarios para brindar un servicio de calidad, muchas pequeñas empresas prefieren contactar a los distribuidores de oxígeno sin indagar mucho acerca de la calidad del producto que reciben y de donde proviene.

Aquí se presenta una oportunidad de negocios para la empresa propuesta, al instalar una planta propia en la región se podrá brindar un servicio de calidad, que cuente con la seguridad, especialización y tecnificación que no tienen los distribuidores, además al operar en la ciudad de Juliaca se tendrá acceso a los potenciales clientes y se facilitara la distribución del producto, demostrando la capacidad de poder atender las solicitudes de empresas grandes y pequeñas. Calidad, dominio de actividades y costos bajos permitirán a la empresa ganarse la confianza de los clientes que es la barrera más difícil de superar. 


\subsubsection{Amenaza Productos Sustitutos.}

La amenaza de productos sustitutos se refiere al potencial ingreso de empresas que puedan ofrecer productos sustitutos o alternativos al planteado en el presente estudio. Se denominan productos sustitutos a aquellos que pueden ser usados en lugar de otros, llegando incluso a formar parte de la competencia directa del negocio planteado, ya que pueden cumplir la misma función y cubrir las mismas necesidades (Porter, 2009).

El análisis de esta amenaza permitirá crear estrategias que ayuden a la empresa propuesta a enfrentar a las empresas que comercializan ese tipo de productos.

Tabla 3 Amenaza productos sustitutos

\begin{tabular}{|c|c|c|c|c|c|}
\hline \multirow{3}{*}{ VARIABLE } & \multirow{3}{*}{ PESO } & \multicolumn{2}{|l|}{ CIGA S.A. } & \multicolumn{2}{|c|}{$\begin{array}{l}\text { DISTRIBUIDORES } \\
\text { (Oxytex y Oxytex Gases Andinos) }\end{array}$} \\
\hline & & $\begin{array}{ll}\text { GRADO } & \text { DE }\end{array}$ & PESO & GRADO & PESO \\
\hline & & ATRACTIVIDAD & PONDERADO & ATRACTIVIDAD & PONDERADO \\
\hline $\begin{array}{ll}\text { Disponibilidad } & \text { de } \\
\text { sustitutos cercanos } & \end{array}$ & 0.30 & 3 & 0.90 & 3 & 0.90 \\
\hline Confianza en el servicio & 0.35 & 3 & 1.05 & 2 & 0.70 \\
\hline $\begin{array}{l}\text { Predisposición del } \\
\text { comprador de consumir } \\
\text { productos sustitutos }\end{array}$ & 0.15 & 3 & 0.45 & 2 & 0.30 \\
\hline Competencia de precios & 0.20 & 3 & 0.60 & 2 & 0.40 \\
\hline Total & 1.00 & & 3.00 & & 2.30 \\
\hline Peso ponderado medio & 2.65 & & & & \\
\hline
\end{tabular}

Nota. Elaboración Propia

\section{Interpretación}

Los valores obtenidos de la amenaza de productos sustitutos dan como resultado una incidencia media/baja (2.65) en el mercado. 
El oxígeno industrial se utiliza en la industria metalmecánica principalmente en la soldadura por autógena donde se mezcla el oxígeno con acetileno, pero existen otros tipos de soldadura como la soldadura por electrodos, de igual manera el oxígeno es utilizado para el corte de diversos materiales ferrosos de considerable espesor este proceso se conoce como oxicorte, para este producto también existen sustitutos como el corte por plasma, corte por agua, etc. Estos procesos actualmente son más costosos pero podrían obtener mejores acabados en su aplicación.

Existe una variedad de sustitutos para el oxígeno industrial en el mercado, pero la calidad y la seguridad en el producto y servicio serán un valor añadido a la empresa propuesta.

\subsubsection{Poder de Negociación de Proveedores.}

El poder de negociación de los proveedores será muy importante en la situación de la industria que tiene una cantidad reducida de proveedores, porque estos podrán contar con una mayor capacidad de negociación, materializada principalmente en la capacidad de incrementar sus precios.

El análisis del poder de negociación de los proveedores ayudara a identificar si este se convierte en una posible amenaza para la empresa y elaborar estrategias para concretar acuerdos favorables con los proveedores y obtener mayor control sobre ellos.

Actualmente las diferentes industrias solicitan a sus proveedores la mejora en la calidad ambiental de sus componentes, mayor eficiencia energética, un mejor servicio en la recepción y entrega del pedido, etc. 
Tabla 4 Poder de negociación de proveedores

\begin{tabular}{|c|c|c|c|c|c|c|}
\hline \multirow{3}{*}{ VARIABLE } & \multirow{3}{*}{ PESO } & \multicolumn{2}{|l|}{ CIGA S.A. } & \multicolumn{3}{|c|}{ (Oxytex y Oxytex Gases Andinos) } \\
\hline & & GRADO DE & PESO & GRADO & $\mathrm{DE}$ & PESO \\
\hline & & ATRACTIVIDAD & PONDERADO & ATRACTIV & IIDAD & PONDERADO \\
\hline $\begin{array}{l}\text { Existencia de variedad de } \\
\text { proveedores formales y de } \\
\text { garantía }\end{array}$ & 0.25 & 3 & 0.75 & 2 & 0.50 & \\
\hline $\begin{array}{l}\text { Existencia de proveedores } \\
\text { locales }\end{array}$ & 0.25 & 2 & 0.50 & 2 & 0.50 & \\
\hline $\begin{array}{l}\text { Necesidad de productos de } \\
\text { especialización }\end{array}$ & 0.20 & 3 & 0.60 & 1 & 0.20 & \\
\hline $\begin{array}{l}\text { Necesidad de insumos por } \\
\text { mayor }\end{array}$ & 0.25 & 4 & 1.00 & 2 & 0.50 & \\
\hline Total & 1.00 & & 2.85 & & 1.70 & \\
\hline Peso ponderado medio & 2.27 & & & & & \\
\hline
\end{tabular}

Nota. Elaboración Propia

\section{Interpretación}

Del análisis del poder de los proveedores se obtiene como resultado una incidencia media/baja (2.27) en el mercado.

Los proveedores en el sector de gases industriales no cuentan con un alto poder de negociación, ya que por la composición de los productos no se necesitan de materia prima específica y los insumos que se utilizan pueden ser conseguidos en el mercado nacional o internacional.

La compañía de energía eléctrica sería uno de los pocos proveedores con alto poder de negociación, ya que este insumo participa en todo el proceso de producción y si la compañía decidiera elevar sus costos afectaría a los costos de producción, además este es un tipo de proveedor con el que no se puede negociar. 


\subsubsection{Poder de Negociación de los Compradores.}

Esta fuerza hace referencia al poder de negociación que tienen los consumidores o compradores y su capacidad de exigir mejores precios. Si la cantidad de consumidores es reducida, entonces su poder de negociación será mayor. Comúnmente en diversos mercados los consumidores cuentan con mayor poder de negociación que los vendedores (Porter, 2009).

El análisis del poder de negociación de los consumidores, permitirá diseñar estrategias que tengan como objetivo captar más clientes y obtener mayor lealtad de los mismos.

Tabla 5 Poder de negociación de los compradores

\begin{tabular}{|c|c|c|c|c|c|}
\hline \multirow{3}{*}{ VARIABLE } & \multirow{3}{*}{ PESO } & \multirow{2}{*}{\multicolumn{2}{|c|}{ CIGA S.A. }} & \multicolumn{2}{|c|}{ DISTRIBUIDORES } \\
\hline & & & & $\begin{array}{l}\text { (Oxytex } \\
\text { Andinos) }\end{array}$ & \multirow{2}{*}{$\begin{array}{ll} & \\
\text { y Oxytex Gases } \\
\text { GRADO DE }\end{array}$} \\
\hline & & ATRACTIVIDAD & PONDERADO & VALOR & \\
\hline $\begin{array}{l}\text { Importancia y necesidad } \\
\text { del cliente por el producto }\end{array}$ & 0.30 & 4 & 1.20 & 4 & 1.20 \\
\hline Disponibilidad $\quad$ de & & & & & \\
\hline $\begin{array}{l}\text { información para el } \\
\text { comprador }\end{array}$ & 0.20 & 4 & 0.80 & 3 & 0.60 \\
\hline $\begin{array}{l}\text { Satisfacción de las } \\
\text { expectativas del comprador }\end{array}$ & 0.25 & 3 & 0.75 & 3 & 0.75 \\
\hline Volumen de compra & 0.25 & 4 & 1.00 & 2 & 0.50 \\
\hline Total & 1.00 & & 3.75 & & 3.05 \\
\hline Peso ponderado medio & 3.40 & & & & \\
\hline
\end{tabular}

Nota. Elaboración Propia 


\section{Interpretación}

El resultado del análisis del poder de negociación de los compradores nos da como resultado una amenaza media (3.40), el oxígeno industrial es de primordial importancia para las actividades de la industria metalmecánica principal aliado de la industria minera y sus procesos de producción.

El mercado de oxigeno industrial en el departamento de Puno está en crecimiento, se tienen planeado la ejecución de varios proyectos en la región, los cuales incrementaran la necesidad de solicitar este producto, actualmente la oferta de oxígeno industrial es pequeña para toda la demanda existente.

Los consumidores actuales se ven en la necesidad de contactar a los distribuidores para ahorrar tiempo, ya que al existir solo una planta de oxígeno esta tarda más en atender sus pedidos.

\subsubsection{Rivalidad entre competidores.}

Esta fuerza ayuda a realizar una comparación entre las ventajas competitivas de la empresa propuesta con las ventajas competitivas de empresas que se encuentren dentro del mismo rubro, de esta forma la empresa nueva podrá elaborar estrategias que le permitan hacerle frente a la competencia (Porter, 2009). Si la cantidad de competidores es reducida la rentabilidad será mayor, el riesgo de ingresar a un mercado con varias empresas posicionadas elevara los costos y riesgos.

La rivalidad entre empresas competidoras de un mismo sector puede manifestarse de diversas formas como a través del descuento de precios, mejoras en los productos o servicios, publicidad, etc. 
Tabla 6 Rivalidad entre competidores

\begin{tabular}{|c|c|c|c|c|c|}
\hline \multirow{3}{*}{ VARIABLE } & \multirow{3}{*}{ PESO } & \multicolumn{2}{|l|}{ CIGA S.A. } & \multicolumn{2}{|c|}{$\begin{array}{l}\text { DISTRIBUIDORES } \\
\text { (Oxytex y Oxytex Gases Andinos) }\end{array}$} \\
\hline & & GRADO & PESO & GRADO & PESO \\
\hline & & ATRACTIVIDAD & PONDERADO & ATRACTIVIDAD & PONDERADO \\
\hline Confianza del cliente & 0.50 & 4 & 2.00 & 3 & 1.50 \\
\hline Servicio Especializado & 0.20 & 3 & 0.60 & 2 & 0.40 \\
\hline Oportunidad del servicio & 0.30 & 4 & 1.20 & 3 & 0.90 \\
\hline Total & 1.00 & & 3.80 & & 2.80 \\
\hline Peso ponderado medio & 3.30 & & & & \\
\hline
\end{tabular}

Nota. Elaboración Propia

\section{Interpretación}

Del análisis de la rivalidad de competidores se obtuvo como resultado un puntaje medio (3.30), siendo la confianza del cliente el punto más fuerte a considerar.

En el mercado de oxígeno industrial del departamento de Puno, los competidores son limitados, como se mencionó anteriormente, solo se puede encontrar una empresa con planta propia para la producción de oxígeno y dos intermediarios que funcionan como distribuidores.

Actualmente la rivalidad entre ellos no es intensa, ya que cada uno de ellos considera tener un sector del mercado ganado y es donde concentra todos sus esfuerzos para conservar sus clientes, se pude mencionar que la rivalidad existente entre las empresas de oxigeno industrial está marcada por el manejo de precios; las tres empresas que conforman el mercado de oxigeno industrial del departamento 
de Puno ofrece precios muy similares, si alguna de las empresas decidiera rebajar sus precios para ganar más clientes colocaría a las otras empresas en la necesidad de bajar los propios para defender su mercado, pero esto afectaría su rentabilidad. Por el momento las empresas mencionadas cuentan con precios regulados.

Las cuatro fuerzas competitivas analizadas anteriormente afectan a la rivalidad de la empresa con sus competidores, tomándolas en cuenta podemos concluir que el nivel de rivalidad competitivo es medio (3.30), puesto que la amenaza de nuevos competidores es media (3.025), la amenaza de productos sustitutos es media/baja (2.65), el poder de negociación de los proveedores es media/baja (2.27) y el poder de negociación de los compradores es media (3.40).

La empresa propuesta pretende distinguirse de la competencia brindando un producto de calidad y un servicio con seguridad, contando con una constante capacitación y tecnificación, además de colocar personal especializado para mantener satisfechos a los clientes.

\subsection{Análisis de la Competencia.}

Posteriormente al análisis de campo realizado en la ciudad de Juliaca, se obtuvo información acerca de la competencia en el mercado de oxígeno industrial, se identificó una empresa la cual cuenta con una planta de producción y brinda el mismo servicio que la empresa que proponemos en este proyecto, esa empresa lleva el nombre de CIGA S.A.

Para poder realizar el estudio de mercado se dividió a la competencia en dos grupos de acuerdo a sus características:

- Grandes Empresas

- Competidores Directos 


\section{Las Grande Empresas}

Las empresas consideradas dentro de este grupo son grandes compañías reconocidas a nivel mundial, las cuales vienen años operando dentro de nuestro país ofreciendo una gran variedad de servicios y productos relacionados a los gases industriales. Sus principales características son ofrecer productos de alta calidad y confiabilidad; además de contar con plantas de producción estratégicamente ubicadas a lo largo del territorio nacional.

Sin embargo estas empresas no vendrían a ser competidores directos ya que por el momento no cuentan con sucursales en la ciudad de Juliaca ni en ninguna otra zona de la región Puno, pero son considerados como potenciales competidores y su denominación para nuestro estudio será como el grupo de "Grandes Empresas".

\section{Competidores Directos}

Dentro de los competidores directos ubicamos a la empresa con planta propia y a los distribuidores de oxigeno industrial.

Una sola empresa cuenta con su propia planta productora de oxígeno industrial ubicada en la ciudad de Juliaca, y que comercializa su producto en todo el departamento de Puno. Esta empresa puede ser contactada a través de su página web y o personalmente en su oficia principal. Esta empresa será situada, por las semejanzas con la empresa propuesta, dentro del grupo de "competidores directos". 
Por otro lado también tenemos a los distribuidores, se identificó a un par de empresas las cuales sin ser productoras de oxígeno industrial, cubren cierta parte del mercado distribuyendo el producto que adquieren de empresas más grandes. Estas empresas no cuentan con toda la tecnificación, información y logística necesaria para la atención de grandes volúmenes de compra.

\subsubsection{Características, Semejanzas y Diferencias entre el Plan de Negocios y los tipos de competencia.}

\section{Características de la Grandes Empresas}

Conjunto conformado por las empresas que tienen un nombre reconocido a nivel internacional y cuentan con gran cantidad de años de trabajo en el mercado de gases industriales, dentro de este grupo podemos mencionar a las siguientes empresas:

- PRAXAIR

- INDURA

- MESSER

Las empresas agrupadas en esta categoría cuentan con características similares que se mencionan a continuación:

- Las empresas mencionadas, tienen localizada en la capital a su oficina principal, además cuentan con un número respetable de años operando en el Perú.

- Las tres empresas poseen plantas propias para la producción de diferentes tipos de gases industriales entre ellos el oxígeno industrial.

- Dentro de sus actividades encontramos la instalación de sistemas que permiten el suministro de gases industriales On-Site. 
- Praxair y Messer son reconocidas mundialmente, mientras tanto Indura tiene una fuerte presencia en Sudamérica y gracias a su alianza con la multinacional Air Products en el 2013 afianzara su liderazgo en el mercado latinoamericano.

- Sus principales clientes se encuentran en el sector metalmecánico y en el sector minero.

- Estas empresas, según datos de SUNAT, cuentan con más de 100 trabajadores fijos.

- Tiene los equipos y capacidad necesaria para atender considerables volúmenes de compra.

Tabla 7 Las grandes empresas

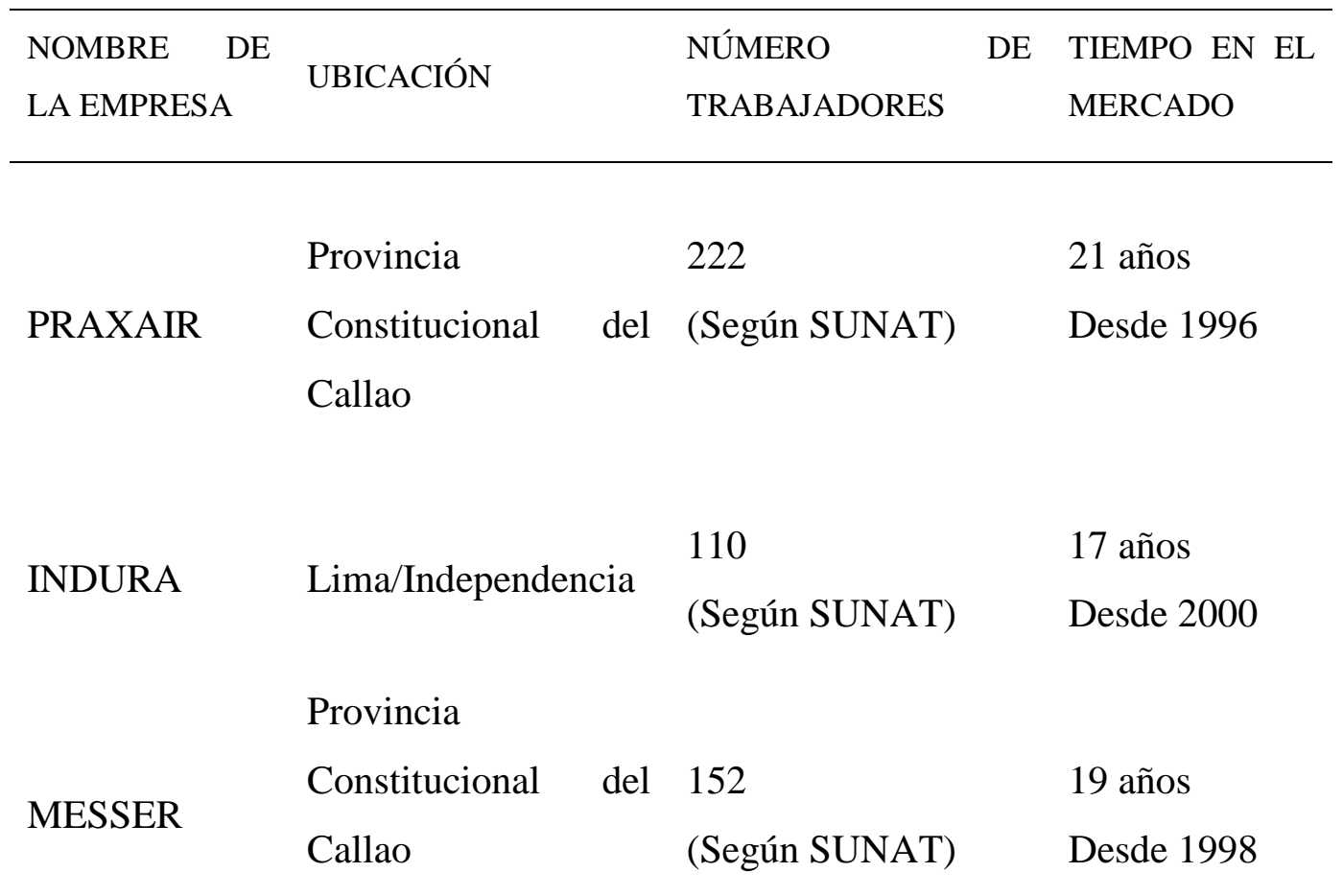

Nota. Elaboración Propia 


\section{Semejanzas y diferencias de las grandes empresas con "Oxigeno del Sur"}

Luego de haber identificado las principales características que comparten las empresas se les ha denominado como el grupo de Grandes Empresas, a continuación se señalan las semejanzas y diferencias con la empresa planteada en el presente estudio:

Semejanzas de las grandes empresas con Oxígeno del Sur:

- Las empresas señaladas están dentro de la industria de los gases industriales específicamente en la producción de oxígeno Industrial.

- Tanto las grandes empresas como la empresa que se propone ofrecen sus servicios a la industria metal mecánica y a los sectores ligados a esta industria.

Tabla 8 Diferencias entre las grandes empresas y Oxigeno del sur

\begin{tabular}{|c|c|c|}
\hline VARIABLE & GRANDES EMPRESAS & OXIGENO DEL SUR \\
\hline Servicio ofrecido & $\begin{array}{l}\text { Variedad de Gases } \\
\text { Industriales }\end{array}$ & Oxígeno Industrial \\
\hline Sede principal & Lima & Juliaca \\
\hline Instalaciones On-Site & $\mathrm{Si}$ & No \\
\hline Nro. de trabajadores & De 100 a mas & Entre 15 y 20 \\
\hline Presencia en el mercado & Más de 15 años & Iniciamos actividades \\
\hline Cobertura & A nivel nacional & Departamento de Puno \\
\hline
\end{tabular}

Nota. Elaboración Propia

Características de los Competidores Directos 
Este grupo lo conforman tres competidores el primero que es CIGA S.A., una empresa con características y actividades muy similares a la empresa propuesta:

Las principales características de la empresa CIGA son:

- La empresa CIGA S.A. está ubicada en la ciudad de Juliaca dentro del departamento de Puno.

- Pertenece al grupo TECNIDES (Técnica y Desarrollo E.I.R.L), siendo CIGA su marca para la comercialización de oxígeno industrial.

- Cuentan con una planta productora de oxígeno industrial.

- Entre sus principales clientes encontramos a empresas de la industria minera y metalmecánica.

- Cubren casi el 50\% del mercado de oxígeno industrial en el departamento de Puno.

- Cuentan con un sistema de protección ambiental.

- Tienen entre 15 a 20 trabajadores.

- Esta registrada correctamente en la SUNAT

- Su modalidad de contratación de personal es a través de contratos de trabajo. Por otro lado tenemos a dos empresas que cumplen función de distribuidores, estas empresas adquieren el oxígeno industrial de proveedores que se encuentran fuera del departamento de Puno, en este grupo encontramos a las siguientes empresas:

- OXYTEX S.A.C.

- OXYTEX GASES ANDINOS 
Las empresas agrupadas en esta categoría cuentan con características similares que nombraremos a continuación:

- Estos distribuidores cuentan con oficinas en la ciudad de Juliaca.

- Distribuyen y abastecen de oxígeno industrial a diferentes sectores.

- Realizan instalaciones de sistemas de gases.

- En algunas oportunidades y dependiendo de los costos se abastecen de grandes empresas como Praxair, Indura o Messer.

- Oxytex S.A.C. tiene una sucursal en la ciudad de Arequipa

Tabla 9 Los competidores directos

\begin{tabular}{|c|c|c|c|}
\hline $\begin{array}{l}\text { NOMBRE DE LA } \\
\text { EMPRESA }\end{array}$ & UBICACIÓN & $\begin{array}{ll}\text { NÚMERO } & \text { DE } \\
\text { TRABAJADORES } & \end{array}$ & $\begin{array}{l}\text { TIEMPO EN EL } \\
\text { MERCADO }\end{array}$ \\
\hline CIGA S.A. & $\begin{array}{l}\text { Ciudad } \\
\text { Juliaca }\end{array}$ & $\begin{array}{l}15 \text { trabajadores } \\
\text { (Según SUNAT) }\end{array}$ & $\begin{array}{l}21 \text { años } \\
\text { Desde } 1996\end{array}$ \\
\hline OXYTEX & Juliaca & $\begin{array}{l}10 \\
\text { (Según SUNAT) }\end{array}$ & $\begin{array}{l}8 \text { años } \\
\text { Desde } 2009\end{array}$ \\
\hline $\begin{array}{l}\text { OXYTEX } \\
\text { GASES } \\
\text { ANDINOS }\end{array}$ & Juliaca & $\begin{array}{ll}\text { No } & \text { registra } \\
\text { información } & \text { en la } \\
\text { SUNAT } & \end{array}$ & $\begin{array}{l}1 \text { año } \\
\text { Desde } 2016\end{array}$ \\
\hline
\end{tabular}

Nota. Elaboración Propia

Semejanzas y diferencias de Los Competidores Directos con "Oxigeno del Sur" 
Luego de identificar las principales características del principal competidor, es necesario establecer las semejanzas y diferencias del competidor directo con la empresa planteada:

Semejanzas de los competidores directos con Oxigeno del sur

- Ambas ofrecen oxígeno Industrial

- Poseen su propia planta productora

- Su sede principal se encuentra en la ciudad de Juliaca y su planta está ubicada también en esa ciudad.

- Ofrecen sus servicios a la industria metalmecánica y sectores afines.

- Tienen menos de 20 trabajadores

Tabla 10 Diferencias entre los competidores directos y Oxigeno del sur

\begin{tabular}{|c|c|c|}
\hline VARIABLE & COMPETIDORES & OXIGENO DEL \\
\hline $\begin{array}{l}\text { Posicionamiento en el } \\
\text { mercado }\end{array}$ & Nivel medio & $\begin{array}{l}\text { Plan de Marketing para } \\
\text { posicionarnos en } \\
\text { mercado }\end{array}$ \\
\hline Modalidad & & \\
\hline Contratación & Por contrato de trabajo & Trabajadores en planilla \\
\hline Atención de pedidos & Dentro de las 48 horas & Dentro de las 24 horas \\
\hline $\begin{array}{l}\text { Forma de pago por los } \\
\text { servicios }\end{array}$ & Efectivo & $\begin{array}{l}\text { Efectivo } \\
\text { Electrónico } \\
\text { Depósitos y transferencias }\end{array}$ \\
\hline
\end{tabular}

Nota. Elaboración Propia

\section{Conclusiones del análisis de competencia}

- En la ciudad de Juliaca se presenta una demanda emergente de oxígeno industrial. 
- La presencia de una sola planta productora de oxígeno para todo el departamento de Puno no es suficiente para cubrir la demanda actual.

- Los distribuidores de oxígeno industrial no siempre están disponibles y tardan más tiempo en culminar sus servicios.

- Las empresas que prefieren el servicio de los distribuidores en muchos casos desconocen la existencia de la planta productora de oxígeno o creen que sus precios son más altos.

- Es factible instalar una empresa dedicada al rubro de producción de oxígeno industrial, no se cuenta con mucha competencia directa, solo un competidor el cual no puede cubrir todo el mercado.

\subsubsection{Matriz De Perfil Competitivo}

Ponce (2006) manifiesta que "La matriz de perfil competitivo, es una herramienta que por medio de aspectos o factores internos determinados, los cuales pueden ser nuestras fortalezas y debilidades, va a permitir la identificación de los competidores de una organización" (P.113).

Para elaborar la matriz se deben seguir los siguientes pasos:

A. Tener información relevante de las empresas competidoras que estarán comprendidas en la matriz.

B. Identificar las características más importantes, las más relevantes y los aspectos más vulnerables para cada empresa.

C. Para cada una de estas características se les debe asignar un valor, para la empresa propuesta los valores designados fueron determinados por los autores del presente estudio. 
D. Se asignara una calificación a los competidores presentes en la matriz, tomando en cuenta que los únicos valores a considerar son: 1, debilidad; 2, menor debilidad; 3, menor fuerza; 4, mayor fuerza.

E. Para la obtención del peso ponderado de cada empresa se multiplicara la columna del peso. Se multiplica el peso de la segunda columna por cada una de las calificaciones de las empresas competidoras, obteniéndose el peso ponderado correspondiente.

F. Finalmente se sumaran los totales de la columna del peso (Debe ser de 1.00) y de las columnas de los pesos ponderados.

De esta manera se obtendrá una matriz de perfil competitivo, teniendo de referencia los grupos de competencia desarrollados inicialmente.

El resultado de la investigación de campo determino las claves de éxito para la empresa de Oxigeno industrial, las cuales son:

\section{Capacidad de respuesta}

Es la habilidad que tiene cada empresa para atender de manera rápida al requerimiento de un servicio, los clientes valoran el tiempo de respuesta de una empresa. Los compradores requieren obtener una respuesta inmediata a sus intereses por medio de diversos canales de comunicación con los que cuente la empresa. Contar con personal que este pendiente constantemente de los correos electrónicos, pagina web y redes sociales es un factor de éxito.

\section{Efectividad y calidad en el servicio}

En el panorama actual de la ciudad de Juliaca, muchas empresas solicitan el servicio de los distribuidores, sin embargo estas empresas distribuidoras no cuentan con las herramientas e instrumentos necesarios para ofrecer un servicio 
completo. Por lo tanto consideramos que ofrecer un servicio completo combinando calidad y seguridad es un factor de éxito.

\section{Personal especializado}

Como hemos visto el suministro de oxígeno industrial se realiza en algunos casos por personal que no está completamente capacitado en el manejo de gases industriales. Este es un servicio que solo personal capacitado puede realizar .Aquí encontramos otro factor de éxito que podemos aprovechar.

\section{Lealtad, aceptación y confianza del cliente}

Probablemente el principal desafío, para cualquier negocio nuevo que quiere incursionar en un mercado determinado, es generar la confianza de los clientes a través de la prestación de un servicio de calidad y seguridad. Por ello, la primera experiencia será fundamental, debido a que el cliente determinara su continuidad de acuerdo al nivel de satisfacción conseguido durante su primer servicio.

Se elaboró un cuadro donde se señalan los factores de éxito, se asigna un valor de acuerdo a la relevancia de cada factor; el peso para cada factor ha sido establecido por los autores del presente estudio, finalmente la sumatoria de los valores asignados dan como resultado uno.

La escala utilizada fue del 1 al 4, donde cuatro establece que la empresa se encuentra preparada para sacar ventaja del factor de éxito que está siendo evaluado y el uno establece que la empresa no se encuentra lista para beneficiarse de ese factor. 
Tabla 11 Valores Matriz de Perfil Competitiva

\begin{tabular}{ll}
\hline VALOR & DETALLE \\
\hline 1 & Debilidad Mayor \\
2 & Debilidad Menor \\
3 & Fortaleza Menor \\
4 & Fortaleza mayor
\end{tabular}

Nota. Adaptado de "La Matriz FODA: Alternativa de diagnóstico y determinación de

Estrategias de intervención en diversas organizaciones" por H. Ponce, 2006.

Posteriormente a la aplicación de la herramienta, se consiguieron los siguientes resultados: 
Tabla 12 Matriz de perfil Competitiva

\begin{tabular}{|c|c|c|c|c|c|c|c|}
\hline \multirow[b]{2}{*}{ Factores claves del éxito } & \multirow[b]{2}{*}{ Peso } & \multicolumn{2}{|c|}{ Oxígeno del Sur } & \multicolumn{2}{|c|}{ Grandes empresas } & \multicolumn{2}{|c|}{ Competidores Directos } \\
\hline & & Valor & $\begin{array}{l}\text { Peso } \\
\text { ponderado }\end{array}$ & Valor & Peso Ponderado & Valor & Peso Ponderado \\
\hline Capacidad de respuesta & 0.1 & 3 & 0.3 & 3 & 0.3 & 2 & 0.2 \\
\hline $\begin{array}{l}\text { Efectividad y calidad de } \\
\text { servicio }\end{array}$ & 0.3 & 4 & 1.2 & 3 & 0.9 & 2 & 0.6 \\
\hline Personal especializado & 0.2 & 4 & 0.8 & 3 & 0.6 & 2 & 0.4 \\
\hline $\begin{array}{l}\text { Lealtad, aceptación } \quad \text { y } \\
\text { confianza del cliente. }\end{array}$ & 0.4 & 3 & 1.2 & 2 & 0.8 & 2 & 0.8 \\
\hline Total & 1 & & 3.5 & & 2.6 & & 2 \\
\hline
\end{tabular}

Nota. El peso de cada factor fue establecido por los autores del presente estudio, en el caso de los competidores directos se hizo en base a los resultados de la encuesta y para las grandes empresas por la historia y experiencia de la empresa. Tomado de "La Matriz FODA: Alternativa de diagnóstico y determinación de Estrategias de intervención en diversas organizaciones” por H. Ponce, 2006. 
En el cuadro preliminar se aprecia que Oxígeno del Sur logro un puntaje ponderado total de 3.50 por lo tanto, no solo está apta para aprovechar los factores de éxito sino que se encuentra en mejores condiciones que sus competidores, al ofrecer un producto y servicio con calidad y seguridad.

\subsection{Análisis del Contexto Actual y Esperado}

Se realizó un análisis del entorno actual donde se desarrollara la nueva empresa:

\subsubsection{Análisis Político Gubernamental}

Dentro del aspecto político gubernamental se tendrá en cuenta la frecuente modificación de leyes, reglamentos, etc. Por eso se debe tener especial cuidado con los indicadores de regulación sobre el empleo, estabilidad gubernamental, el aumento de impuestos, leyes de defensa del medio ambiente, etc.

Actualmente el poder ejecutivo realiza diversas acciones para reactivar la economía e incentivar la formalización de las empresas, una de sus últimas acciones fue la de aprobar el Decreto Legislativo 1332 el cual busca facilitar la constitución de nuevas empresas a través de los Centro de Desarrollo Empresarial (CDE), los cuales tienen como principal objetivo facilitar la constitución de personas jurídicas, la formalización e incentivar el desarrollo empresarial.

Por otro lado en el departamento de Puno el estado y las autoridades encargadas de velar por el medio ambiente, desde hace alguno años han estado trabajando para conseguir formalizar a los mineros informales, quienes con sus actividades dañan irreversiblemente el medio ambiente. El Decreto Legislativo 1105 establece una serie de disposiciones para el proceso de formalización de la 
pequeña minería y minería artesanal que opera informalmente, estas normas son aplicadas a nivel nacional.
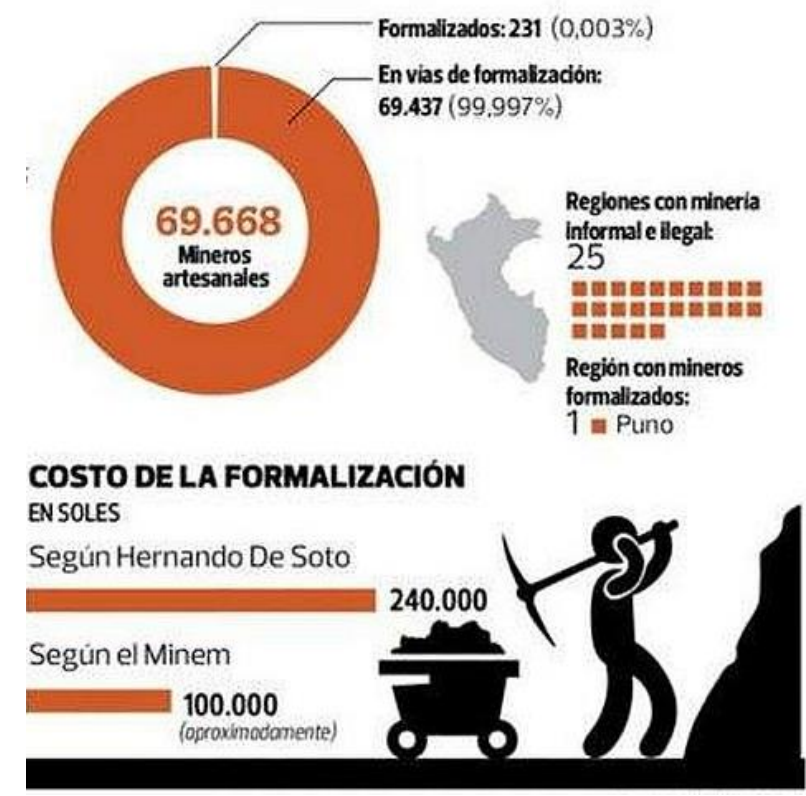

Figura 3 Mineros Artesanales en vía de formalización.Tomado del Ministerios de Energía y Minas.

\subsubsection{Análisis Económico}

Según el Fondo Monetario Internacional (2016) se proyecta un crecimiento del $2.7 \%$ para el Perú durante el año 2017, este porcentaje ha disminuido en comparación a las expectativas que se tenían a finales del 2016. El escándalo de Odebrecht y los daños ocasionados por los desastres naturales has repercutido de manera negativa en todos los proyectos que se tenían preparados para el presente periodo.

De acuerdo al Informe Tecnico Nro. 2 publicado por el Instituto Nacional de Estadistica e Informatica (2017), el PBI durante el primer trimestre del 2017 presento un incremento de $2.1 \%$, las actividades que evolucionaron positivamente fueron la pesca, telecomunicaciones,administracion publica, extraccion de 
petroleo gas y otros minerales, por el contrario el sector construccion, agricultura, seguros y pensiones decrecieron.

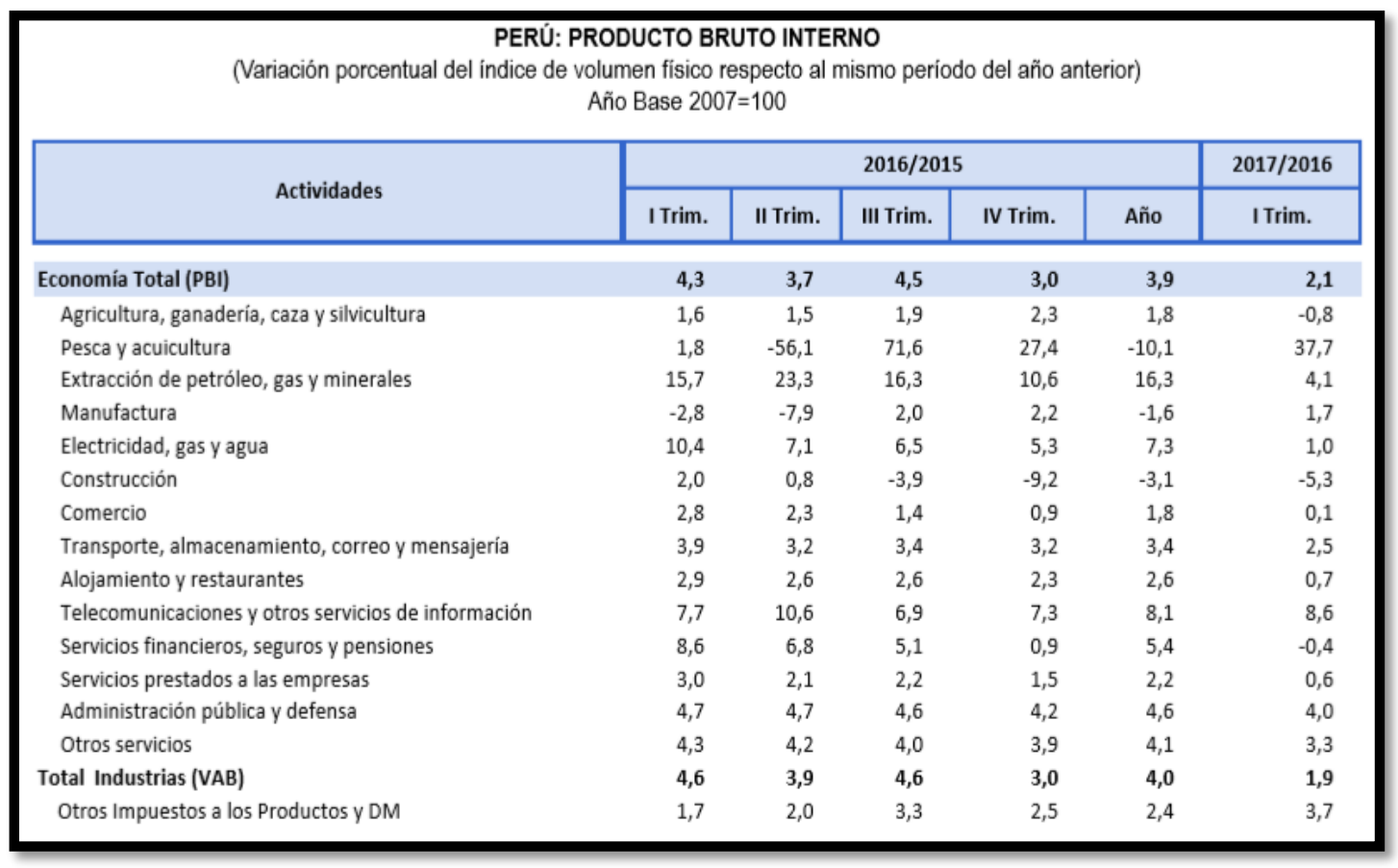

Figura 4. Crecimiento del Producto Bruto Interno por actividad.

Tomado de "Informe Técnico Nro. 2: Producto Bruto Interno Trimestral", por el Instituto Nacional de Estadística e Informática (INEI), 2017.

Según este informe el valor agregado bruto de la actividad de extracción de petróleo, gas y minerales mostro un crecimiento del 4.1\%. La extracción de minerales incremento su producción de cobre, hierro y zinc a diferencia del oro, plata, plomo y estaño que disminuyeron su producción (Instituto Nacional de Estadistica e Informatica, 2017). 


\begin{tabular}{|c|c|c|c|c|c|c|}
\hline \multirow[t]{3}{*}{$\begin{array}{l}\text { EXTRACCIÓN DE } \\
\text { Variación porcentual d }\end{array}$} & $\begin{array}{l}\text { LEO, GAS } \\
\text { de volume } \\
\text { ores a pre }\end{array}$ & $\begin{array}{l}\text { MINERAL } \\
\text { fisico resp } \\
5 \text { constant }\end{array}$ & $\begin{array}{l}\text { 8: VALOR } \\
\text { to al mismo } \\
\text { de } 2007\end{array}$ & $\begin{array}{l}\text { REGADO } \\
\text { eríodo del }\end{array}$ & $\begin{array}{l}\text { TO } \\
\text { nterior) }\end{array}$ & \multirow{3}{*}{$\begin{array}{c}2017 / 2016 \\
\text { I Trim. }\end{array}$} \\
\hline & \multicolumn{5}{|c|}{$2016 / 2015$} & \\
\hline & I Trim. & II Trim. & III Trim. & IV Trim. & Año & \\
\hline Extracción de petróleo, gas y minerales & 15,7 & 23,3 & 16,3 & 10,6 & 16,3 & 4,1 \\
\hline Petróleo, gas natural y servicios conexos & $-18,3$ & 1,7 & 7,8 & $-9,1$ & $-5,1$ & 5,3 \\
\hline Minerales y servicios conexos & 25,3 & 28,6 & 18,2 & 15,2 & 21,4 & 3,9 \\
\hline
\end{tabular}

Figura 5. Crecimiento del Valor Agregado Bruto en la actividad de extracción del petróleo, gas y minerales.

Tomado de "Informe Técnico Nro.2: Producto Bruto Interno Trimestral", por el Instituto Nacional de Estadística e Informática (INEI), 2017.

El sector de la construcción disminuyo un $5.3 \%$ en su valor agregado bruto, debido a la paralización de diversos proyectos inmobiliarios y obras de ingeniería civil en el sector público y privado (Instituto Nacional de Estadistica e Informatica, 2017).

CONSTRUCCIÓN: VALOR AGREGADO BRUTO

(Variación porcentual del índice de volumen fisico respecto al mismo periodo del año anterior) Valores a precios constantes de 2007

\begin{tabular}{|l|c|c|c|c|c|c|}
\hline \multirow{2}{*}{ Actividad } & \multicolumn{5}{|c|}{$2016 / 2015$} & $2017 / 2016$ \\
\cline { 2 - 7 } & I Trim. & II Trim. & III Trim. & IV Trim. & Año & ITrim. \\
\hline
\end{tabular}

Figura 6. Crecimiento del Valor Agregado Bruto en la actividad del sector construcción.

Tomado de "Informe Técnico Nro. 2: Producto Bruto Interno Trimestral", por el Instituto Nacional de Estadística e Informática (INEI), 2017.

Como se aprecia anteriormente, se observa un crecimiento en diversos sectores que a su vez traerán beneficios al sector metalmecánico el cual requerirá un mayor consumo de oxigeno industrial. Siendo el sector minero nuestro principal mercado 
debemos tocar el tema de los proyectos que se pondrán en marcha en poco tiempo dentro de la región Puno, los cuales incrementaran la demanda considerablemente.

De acuerdo al Ministerio de Energía y Minas se proyectan para el año 2017 la ejecución de 12 proyectos mineros a nivel nacional los cuales ya cuentan con un estudio de impacto ambiental aprobado, unos de estos proyectos con mayor probabilidad de ejecutarse a corto plazo es el de Ollachea en el departamento de Puno. El proyecto Ollachea está ubicado a $250 \mathrm{~km}$ del lago Titicaca donde se planea extraer oro, la compañía Minera IRL está a cargo del proyecto.(Calderon,2016)

\subsubsection{Análisis Legal}

De acuerdo al Gobierno Regional de Puno la informalidad laboral alcanza casi el 90\% en el departamento de Puno, solo 3 de cada 10 trabajadores cuenta con todos sus derechos laborales, es la ciudad de Juliaca donde se concentra la mayor cantidad de trabajadores informales, el gobierno regional en conjunto con la Superintendencia Nacional de Fiscalización Laboral contantemente está realizando campañas dirigidas a los jóvenes así como a los empleadores para promover la formalidad.

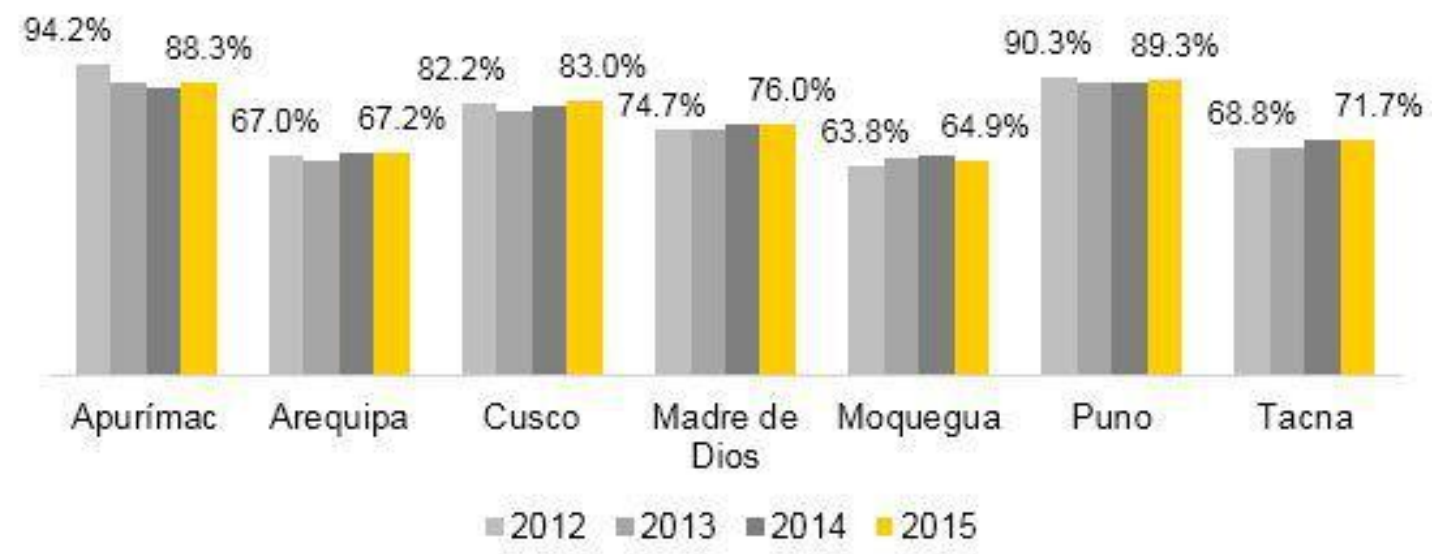

Figura 7 Población Ocupada en empleo informal en la Región Sur. Tomado del Instituto Nacional de Estadística e Informática. 
En el aspecto legal es importante tener en regla toda la documentación y permiso necesarios para que la nueva empresa y planta de producción pueda operar sin ningún problema y no sea observada por ninguna entidad fiscalizadora. También hay que preocuparse por la situación laboral de los empleados, se debe cumplir con lo que exige la ley y brindarles todos sus beneficios laborales.

\subsubsection{Análisis Cultural}

La población de Juliaca y en general de todo el departamento de Puno, se han desarrollado en un ambiente donde la informalidad está presente en su vida diaria y en muchos casos lo aceptan como algo común y natural. El contrabando es una de las actividades que se encuentra más presente en la vida diaria de las personas de la región, situación que afecta de muchas maneras a diversos negocios, si bien es una actividad irregular que aún no impacta significativamente en la comercialización de oxigeno industrial trae consigo una idea de desconfianza por los nuevos productos que ingresan al mercado.

Se debe ganar la confianza y lealtad del cliente brindado un producto de alta calidad que les haga ver que una empresa informal no es la mejor opción y que a la larga lo barato sale caro.

\subsubsection{Análisis Tecnológico}

El avance tecnológico genera que como empresa dedicada a la producción de gases industriales se esté a la vanguardia de los últimos adelantos tecnológicos, tratando de mejor continuamente las herramientas e insumos. 


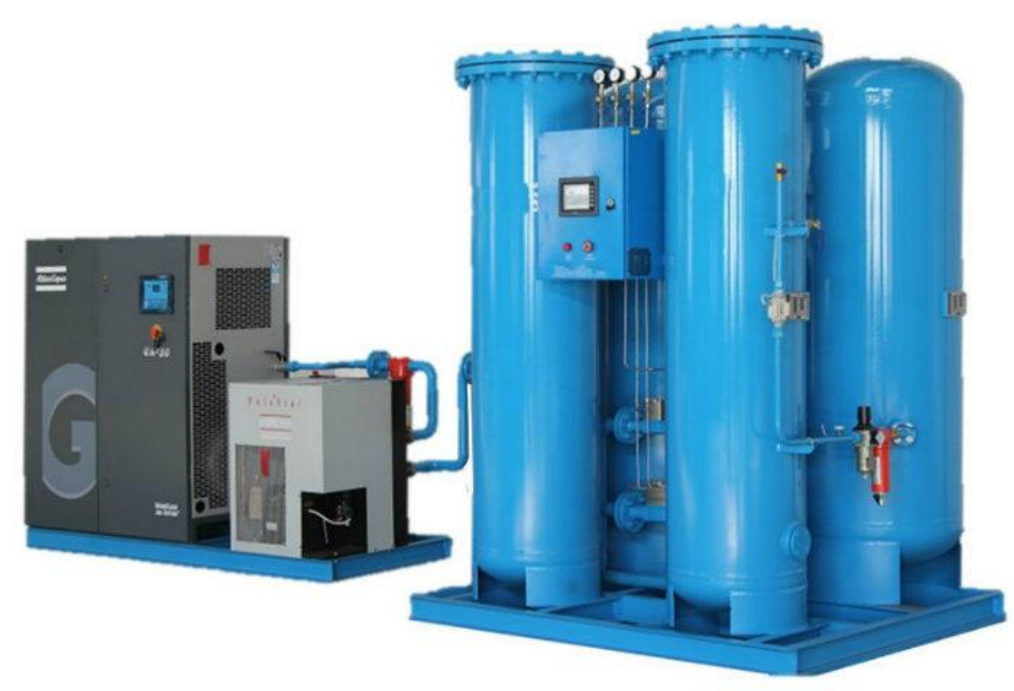

Figura 8 Equipo para planta de oxigeno industrial

Al existir dentro del departamento de Puno antecedentes de una planta productora de Oxigeno industrial como lo es CIGA, permite conocer que existen las herramientas ,tecnología y mano de obra calificada necesaria en la región para llevar a cabo una empresa similar dentro del mismo espacio geográfico.

\subsubsection{Análisis Ambiental}

Por el rubro al que pertenece la empresa propuesta y por los insumos con los que trabajara es importante contar con un sistema de protección ambiental que aseguro la calidad del producto sin causar daños al medio ambiente.

La Municipalidad Provincial de San Román (2015) describe los principales problemas ambientales de la ciudad de Juliaca:

- El Aeropuerto de Manco Cápac, representa una fuente de contaminación sonora. 
- La planta de tratamiento de agua potable, ubicada muy cerca del rio Coata a un costado del casco urbano de la ciudad lugar propenso a la contaminación.

- Lagunas de oxidación, muy cercanas también a la zona urbana.

- Relleno Sanitario Primario, su ubicación es el principal problema ya que se encuentra muy cercano a diversas áreas agrícolas.

- Camal Municipal, contamina de diversas formas el medio ambiente olores, ruidos y residuos orgánicos.

\subsection{Oportunidades}

A continuación se desarrolla la Matriz de Impacto (Oportunidades y Amenazas) tomando en cuenta las variables del contexto actual y esperado, con el propósito de conocer si el efecto de cada variable es positivo o negativo con relación al cliente y a la empresa de oxígeno industrial. Finalmente se determinara si las variables son una oportunidad o amenaza para nuestro proyecto. 
Tabla 13 Matriz de Impacto

\begin{tabular}{|c|c|c|c|c|c|}
\hline \multirow{5}{*}{$\begin{array}{l}\text { Análisis } \\
\text { Político } \\
\text { Gubernamental }\end{array}$} & Variable & Cliente & Empresa & Oportunidad & Amenaza \\
\hline & $\begin{array}{l}\text { Regulación } \\
\text { sobre el empleo }\end{array}$ & $\begin{array}{l}\text { Percepción de seriedad } \\
\text { respecto a la empresa } \\
\text { de Oxigeno }\end{array}$ & $\begin{array}{lll}\text { Formalidad en } & \text { la } \\
\text { contratación } & & \text { de } \\
\text { empleados } & & \end{array}$ & $\begin{array}{l}\text { Percepción } \\
\text { formalidad respecto a la } \\
\text { empresa de Oxigeno } \\
\text { industrial }\end{array}$ & \\
\hline & $\begin{array}{l}\text { Estabilidad } \\
\text { Gubernamental }\end{array}$ & $\begin{array}{l}\begin{array}{l}\text { Sostenibilidad para } \\
\text { invertir en gases } \\
\text { industriales }\end{array} \\
\end{array}$ & $\begin{array}{l}\text { Incremento en } \\
\text { solicitudes de servicio }\end{array}$ & $\begin{array}{l}\text { Aumento en la cartera } \\
\text { de clientes }\end{array}$ & \\
\hline & $\begin{array}{l}\text { Incremento de } \\
\text { impuestos }\end{array}$ & $\begin{array}{l}\text { Incrementos en el costo } \\
\text { del servicio }\end{array}$ & $\begin{array}{l}\text { Los clientes optarían } \\
\text { por otra opción }\end{array}$ & & $\begin{array}{l}\text { Reducción en el } \\
\text { margen de ganancia de } \\
\text { incrementarse los } \\
\text { impuestos }\end{array}$ \\
\hline & $\begin{array}{ll}\text { Ley } & \text { de } \\
\text { Protección } & \\
\text { Ambiental } & \end{array}$ & $\begin{array}{l}\text { Exigencias de un } \\
\text { Sistema de protección } \\
\text { ambiental }\end{array}$ & $\begin{array}{l}\text { Capacitación del } \\
\text { personal para aplicar } \\
\text { correctamente el SPA }\end{array}$ & $\begin{array}{ll}\text { Percepción } & \text { de } \\
\text { responsabilidad con el } \\
\text { medio ambiente }\end{array}$ & $\begin{array}{l}\text { Posible incremento en } \\
\text { el precio de insumos }\end{array}$ \\
\hline \multirow{2}{*}{$\begin{array}{l}\text { Análisis } \\
\text { Económico }\end{array}$} & $\begin{array}{l}\text { Crecimiento } \\
\text { del PBI }\end{array}$ & Poder adquisitivo & $\begin{array}{l}\text { Posibilidad del } \\
\text { incremento de } \\
\text { solicitudes de servicio }\end{array}$ & $\begin{array}{l}\text { Aumento en la cartera } \\
\text { de clientes por el } \\
\text { crecimiento económico } \\
\text { del país }\end{array}$ & \\
\hline & $\begin{array}{l}\text { Crecimiento de } \\
\text { los sectores } \\
\text { minería y } \\
\text { construcción }\end{array}$ & $\begin{array}{l}\text { Capacidad para invertir } \\
\text { y solicitar más } \\
\text { servicios }\end{array}$ & $\begin{array}{l}\text { Posibilidad del } \\
\text { incremento de } \\
\text { solicitudes de servicio }\end{array}$ & $\begin{array}{l}\text { Crecimiento de } \\
\text { cartera de clientes }\end{array}$ & \\
\hline
\end{tabular}




\begin{tabular}{|c|c|c|c|c|c|}
\hline Análisis Legal & $\begin{array}{l}\text { Documentación } \\
\text { y permisos al } \\
\text { día. }\end{array}$ & $\begin{array}{l}\text { Confianza en la } \\
\text { seguridad al manipular } \\
\text { el Oxígeno industrial }\end{array}$ & $\begin{array}{l}\text { Los costos pueden } \\
\text { incrementarse }\end{array}$ & & $\begin{array}{l}\text { Menor rentabilidad } \\
\text { por perder la imagen } \\
\text { de empresa seria y } \\
\text { segura }\end{array}$ \\
\hline $\begin{array}{l}\text { Análisis } \\
\text { Cultural }\end{array}$ & $\begin{array}{l}\text { Sociedad } \\
\text { rodeada de } \\
\text { informalidad }\end{array}$ & $\begin{array}{l}\text { Aceptar una empresa } \\
\text { formal }\end{array}$ & $\begin{array}{l}\text { Informar sobre las } \\
\text { ventajas de trabajar con } \\
\text { una empresa formal }\end{array}$ & $\begin{array}{l}\text { Fortalecimiento de la } \\
\text { imagen de la empresa } \\
\text { ante los clientes } \\
\text { evitando el empleo } \\
\text { informal. }\end{array}$ & \\
\hline $\begin{array}{l}\text { Análisis } \\
\text { Tecnológico }\end{array}$ & $\begin{array}{l}\text { Mejora } \\
\text { tecnológica } \\
\text { constante }\end{array}$ & $\begin{array}{l}\text { Mantener una } \\
\text { constante capacitación } \\
\text { tecnificación }\end{array}$ & $\begin{array}{l}\text { Invertir en tecnología y } \\
\text { en la capacitación del } \\
\text { personal. }\end{array}$ & $\begin{array}{l}\text { Lealtad por parte de los } \\
\text { clientes al contar con } \\
\text { equipos de última } \\
\text { generación. }\end{array}$ & \\
\hline $\begin{array}{l}\text { Análisis } \\
\text { Ecológico }\end{array}$ & $\begin{array}{l}\text { Aplicación de } \\
\text { un Sistema de } \\
\text { protección } \\
\text { ambiental }\end{array}$ & \begin{tabular}{llr}
\multicolumn{2}{l}{ Requerimiento } & de \\
productos que & no \\
generen & & daño \\
ambiental & &
\end{tabular} & $\begin{array}{l}\text { Uso de insumos que no } \\
\text { generen contaminación }\end{array}$ & & $\begin{array}{l}\text { Incremento en el } \\
\text { precio de los insumos. }\end{array}$ \\
\hline
\end{tabular}

Nota. Elaboración propia 


\section{Matriz de Evaluación e los Factores Externos (EFE)}

La Matriz de Evaluación de los Factores Externos tiene como principal función relacionar las oportunidades con las amenazas, esta matriz permite juntar y evaluar la información de los diversos análisis políticos gubernamentales, económicos, legales, etc. De acuerdo a esta matriz una empresa puede obtener como máximo hasta un total ponderado de 4 , y como mínimo puede obtener un 1 siendo el valor promedio ponderado de 2.5 (Arias, 2012)

Tabla 14 Matriz EFE

\section{MATRIZ EFE}

FACTOR EXTERNO CLAVE

FACTOR EXTERNO CLAVE

PESO

RATING PROMEDIO PONDERADO

\section{Oportunidades}

Percepción de formalidad respecto a la $\mathbf{0 . 1 5}$

4

0.60

empresa de Oxigeno industrial

Aumento en la cartera de clientes por el $\mathbf{0 . 1 5}$

3

0.45

crecimiento económico del país

Percepción de responsabilidad con el medio

0.15

4

0.60

ambiente

Fortalecimiento de la imagen de la empresa

0.10

4

0.40

ante los clientes evitando el empleo informal.

Lealtad por parte de los clientes al contar con

0.15

4

0.60

equipos de última generación.

\section{Amenazas}

Reducción en el margen de ganancia de

0.10

2

0.20

incrementarse los impuestos

Posible incremento en el precio de insumos

0.10

1

0.10

Menor rentabilidad de perder la imagen de

0.10

2

0.20

empresa seria y segura

Total

1

Nota. Elaboración propia 


\section{Capítulo III Estudio de Mercado}

\subsection{Descripción De Producto}

El oxígeno es un metaloide gaseoso, primordial para la respiración de los seres vivos. Es un gas de características insípido, inodoro, e incoloro; es más pesado que el aire y parte integrante de él. Puesto que el aire atmosférico está compuesto aproximadamente de $21 \%$ de oxígeno a condiciones normales.

OXIGENO DEL SUR S.A. se propone como una empresa que se dedicará a la producción y comercialización del gas industrial conocido como oxígeno industrial. El producto está dirigido al sector industrial y minero de la región Puno, siendo uno de los pilares el brindar la seguridad alrededor del servicio que involucra la venta del producto, así como un compromiso constante por la preservación medioambiental.

El producto denominado "Oxigeno Industrial" ha de ser destinado al sector metal mecánico y minero, dejando de lado al sector que hace uso de oxígeno para consumo medicinal, y es que, a pesar de que existe una demanda de oxígeno para el uso medicinal por ser uno de los principales usos que se le da al producto, este requiere un estudio adicional sobre demanda y licencias para el ámbito regional de Puno. Entonces, ha sido decisión oportuna el concentrarse sobre los sectores de mayor representatividad sobre el consumo del oxígeno industrial y que una manera u otra se encuentran mejor organizados y es mucho más fácil destinar las estrategias de captación de clientes, de forma tal que la inversión y los esfuerzos sean destinados a mercados más conocidos, y dejando a futuro el análisis de mercados emergentes "océanos azules".

Así el producto que el proyecto presenta a oferta es oxígeno puro, el cual se obtendrá con un nivel de pureza de mínimo $99.5 \%$, en forma gaseosa y con métodos 
más sofisticados que los métodos tradicionales (proceso criogénico), lo cual permitirá un ahorro importante.

Para el producto en particular del presente proyecto, este se caracteriza como un bien normal, dado que; la relación funcional entre el precio y cantidad demandada es una de tipo inversa, como lo refleja el análisis histórico de la demanda y los precios, donde en periodos de reducción de precios por algún oferente se tenía consecuentemente un incremento de la cantidad demandada de oxígeno, al mismo al ser mayor la restricción presupuestaria de los consumidores, es mayor también el nivel de consumo de este bien en particular.

Respecto a los sustitutos del producto que oferta el presente proyecto, se debe mencionar que no existen mayores sustitutos sobre el bien principal, más sin embargo, si existen sustitutos sobre los bienes complementarios al uso del oxígeno industrial, como puede ser el acetileno, carburo, gas propano.

Así entonces al no existir sustituto al bien principal, la capacidad de fijar el precio del producto y manejar la demanda y oferta, estará determinada principalmente por la elasticidad-precio del bien condicionada a la estructura propia que se identifique en el mercado de destino.

\section{Características del Oxígeno:}

- Gas oxidante

- Comburente

- Utilizado en cobre, bronce aleaciones de níquel y acero.

- El oxígeno industrial debe contar por lo menos con $99.5 \%$ de pureza

- Utilizado en la industria y talleres con equipos oxicorte 
- Los cilindros utilizados para el transporte del oxígeno industrial deben ser transportados y almacenados en forma vertical y de manera fija.

\section{Propiedades}

El oxígeno se mezcla casi con todos los elementos, excepto los gases inertes, comúnmente para producir óxidos, reacción que varía de acuerdo a la temperatura, gracias a esta característica el oxígeno es usado en aplicaciones dentro de la siderurgia, industria electrónica y química. También posee la propiedad de ser comburente, mezclado con acetileno $\mathrm{u}$ otros gases combustibles para ser aplicado en soldadura y cortes.

\section{Formas de Producción y Abastecimiento}

Existen dos métodos industriales más comunes para obtener oxígeno en estado gaseoso, uno es la electrolisis del agua y el otro es la destilación fraccionada del aire liquido donde se licua el aire hasta que llegue al estado líquido y posteriormente se evapora, como el nitrógeno, componente del aire, es más volátil se evapora rápidamente y nos queda el Oxígeno en estado líquido para su posterior evaporación. El oxígeno se almacena y se transporta.

\section{Condiciones generales}

El producto del presente proyecto es prestado bajo las siguientes condiciones generales:

- El producto es un gas inodoro e incoloro bajo las temperaturas y presiones ordinarias de $15^{\circ} \mathrm{C}$ y $101,3 \mathrm{KPa}$ de presión y bajo una densidad de 1,346 $\mathrm{Kg} / \mathrm{m} 3$.

- El producto es suministrado como un gas comprimido. 
- El producto es abastecido en envases denominados cilindros de una capacidad de 3, 6, 8 y $10 \mathrm{~m}^{3}$, los cuales no llevarán soldadura o reparación alguna, ni defecto de tipo alguno que ponga en riesgo la seguridad de los agentes y clientes.

\subsection{Selección del Segmento de Mercado}

Para Patricio Bonta y Mario Ferber, se define el segmento de mercado como; "Aquella parte del mercado definida por diversas variables específicas que permiten diferenciarla claramente de otros segmentos. A medida que se considera una mayor cantidad de variables para definir cualquier segmento de mercado, el tamaño dl segmento se reduce y las características de este son más homogéneas”.

Entonces a partir de la definición propuesta por Patricio Bonta y Mario Ferber sobre el segmento de mercado, el presente proyecto ha definido su segmento de mercado a partir de una desagregación del mercado y la diferenciación de las partes, donde a través de un proceso continuo y en función a una serie de variables y criterios de segmentación de mercados, se ha logrado definir consecuentemente un mercado potencial, un mercado disponible, un mercado efectivo, y finalmente un mercado objetivo, que es aquel segmento de mercado final hacia el cual se dirigen todos los esfuerzos para la consecución de la demanda.

Entonces en función a la teoría de segmentación de mercado, se ha definir en primera instancia el mercado potencial, para luego en función de una serie de variables y criterios ir desagregando este segmento hasta llegar el mercado objetivo; por lo tanto, el primer paso ha sido definir el universo de estudio a investigar, a fin de caracterizar a las diferentes unidades que lo componen y seguir con proceso de segmentación de mercado. 
Para empezar a conocer el universo de estudio, en función al cual se extraerá una muestra para simplificar el análisis de mercado a realizar, se parte de la primicia de que el universo de estudio para la presente investigación está conformado por todas aquellas empresas que integran el sector industrial en la región de Puno, y que hacen uso del oxígeno industrial para sus operaciones. Así, se tiene entonces un universo de estudio integrado por el total de empresas de producción metálica, y las empresas mineras.

Así entre los principales tipos de empresas que cumplen con estas características y que se encuentran en marcados del sector industrial, se tiene:

- Sector minero - metalúrgico

- Factorías (sector metalúrgico)

- Talleres (Sector Minero y metalúrgico)

Cada uno de estos sectores industriales está considerado como un cliente potencial, porque requieren del oxígeno industrial en procesos de manufactura, fabricación y/o transformación, teniendo en cuenta que no existe un registro actualizado, exacto y fiable sobre los talles y factorías, con un número concreto de los mismo; por lo que se ha visto por conveniente adoptar cifras fiables de documentos de gestión provistos por el sector público y de fuentes secundarias como lo es el BCRP.

De acuerdo a datos proporcionados por el Plan de Desarrollo Regional Concertado al 2021- Región Puno, el número de empresas de acuerdo a la actividad económica que realizan es el siguiente: 


\begin{tabular}{|c|c|c|c|}
\hline $\mathbf{N}^{0}$ & ACTIVIDAD ECONÓMICA & TOTAL & $\%$ \\
\hline 1 & Agricultura, ganadería, caza y silvicultura & 1294 & 2,440 \\
\hline 2 & Pesca & 129 & 0,240 \\
\hline 3 & Explotación de minas y canteras & 192 & 0,360 \\
\hline 4 & Industria manufacturera & 7850 & 14,820 \\
\hline 5 & Electricidad gas y agua & 34 & 0,060 \\
\hline 6 & Construcción & 4540 & 8,570 \\
\hline 7 & Comercio & 8334 & 15,740 \\
\hline 8 & Hoteles y restaurantes & 996 & 1,880 \\
\hline 9 & Transportes almacén y comunicaciones & 2528 & 4,770 \\
\hline 10 & Intermediación financiera & 91 & 0,170 \\
\hline 11 & Actividad inmobiliaria empresarial y alquiler & 12009 & 22,680 \\
\hline 12 & Administración pública & 2288 & 4,320 \\
\hline 13 & Enseñanza & 3117 & 5,890 \\
\hline 14 & Servicios sociales y de salud & 2927 & 5,530 \\
\hline 15 & Otras actividades. Servicios comunitarios & 6618 & 12,500 \\
\hline 16 & Hogares privados Servicios domésticos & 5 & 0,010 \\
\hline 17 & Organismos y órganos extraterritoriales & 1 & 0,002 \\
\hline \multicolumn{2}{|c|}{ TOTAL } & 52953 & 100,0 \\
\hline
\end{tabular}

Figura 9 Número de empresas según la actividad económica que realizan.

Tomado del Plan de Desarrollo Regional Concertado al 2021 - Región Puno

En la figura 9, se puede apreciar que 192 empresas se dedican a la explotación minera, por otro lado 7850 empresas se encuentran dentro del rubro de industria manufacturera y finalmente otro sector de interés para el desarrollo del presente trabajo es el de la construcción con 4540 empresas dedicadas a esa actividad. 
En cuanto al sector manufacturero está conformado por empresas dedicadas a diversas líneas de actividad económica, detalladas a continuación:

\begin{tabular}{|l|l|l|r|c|}
\hline Nro. & CIIU & D E T A L L E & TOTAL EMPRESA & $\%$ \\
\hline 1 & 1810 & Fabricación de prendas de vestir, excepto prendas de piel & 1453 & 18,5 \\
2 & 1541 & Elaboración de productos de panaderia & 920 & 11,7 \\
3 & 1730 & Fabricación de tejidos y articulos de punto y ganchillo & 770 & 9,81 \\
4 & 2811 & Fabricación de productos metálicos para uso estructural & 562 & 7,16 \\
5 & 3610 & Fabricación de muebles & 450 & 5,73 \\
6 & 2221 & Actividades de impresión & 394 & 5,02 \\
7 & 1920 & Fabricación de calzado & 299 & 3,81 \\
8 & 1551 & Destilación, rectificación y mezcla de bebidas & & \\
& & alcohólicas, producción & 279 & 3,55 \\
9 & 2010 & Aserrado y acepilladura de madera & 252 & 3,21 \\
10 & 1511 & Producción, procesamiento y conservación de carne & & \\
& & y productos cárnicos & 227 & 2,89 \\
11 & 3699 & Otras industrias manufactureras N.C.P. & 2244 & 28,5 \\
\hline \multicolumn{2}{|l|}{ TOTAL } & & 7850 & 100 \\
\hline
\end{tabular}

Figura 10 Número de empresas de acuerdo a su línea de actividad económica.

Tomado del Plan de Desarrollo Regional Concertado al 2021 - Región Puno.

Se aprecia que dentro del sector de industrias manufactureras, la línea de actividad económica de interés para los investigadores del presente trabajo es la de fabricación de productos metálicos para uso estructural, de acuerdo a la figura Nro. 10 un total de 562 empresas se dedican a esta actividad.

Cabe mencionar, que el sector construcción donde de alguna manera se utiliza el oxígeno industrial en sus actividades, no ha sido tomado dentro del universo de estudio, dado que; luego de una serie de análisis, a razón principal que existe una gran dispersión de los datos respecto al sector, así como que el gran tamaño de este segmento frente al poco consumo del producto oxigeno industrial, terminan por generar distorsiones al momento del diseño del muestreo; limitando a fin de cuentas obtener la mayor cantidad de información de los sectores que precisamente tienen un mayor consumo concentrado y sobre los cuales debe de basarse la búsqueda de una información más precisa y con contenido de valor. 
Por otro lado un dato anecdótico, está dado así por el hecho de que la gran mayoría de empresas de construcción no involucran en sus procesos de producción de manera directa al oxigeno industrial, sino más bien se dedican netamente a la construcción a partir de insumos que ya no requieren oxigeno industrial

Así entonces, para el caso en particular del presente trabajo de tesis, y teniendo en cuenta las cifras presentadas por entidades fiables, es que se concluye en las siguientes cifras como la mejor aproximación del número de las empresas que podrían conformar el universo potencial de consumidores para la presente empresa.

Referencia del universo de mercado:

- Empresas de en la actividad de Explotación Minera; 192.

- Empresas en la actividad de la fabricación de productos metálicos 562.

Debemos señalar que el universo de mercado señalado, es a partir del cual se obtuvo el mercado potencial real, el mercado disponible, el mercado efectivo y finalmente el mercado objetivo, que es el segmento de mercado que la empresa direcciona sus ventas. Para ello se seguirán una serie de criterios lógicos a partir de la información de mercado obtenido por la propia investigación de mercado, c y por información provista por expertos en el rubro de este tipo empresas.

La meta a futuro es alcanzar un mayor porcentaje del mercado actual, a partir de la diversificación, disminución de costos, tiempo de distribución, etc. Todo como parte de las estrategias de comercialización, todo lo cual surge en base a los resultados provistos en el estudio de mercado. 


\subsection{Análisis Cualitativo}

Un análisis cualitativo como parte de una investigación de mercado, es aquella que evita una cuantificación precisa, y que logran un conjunto de registros narrativos de los fenómenos que son estudiados a partir de técnicas como la observación participante y las entrevistas no estructuradas.

Este análisis cualitativo es a la vez importante, ya que, permite obtener información muy relevante para poder guiar de manera mucho más oportuna el estudio cuantitativo del análisis del mercado.

En cuanto al análisis cualitativo se utilizó una de las herramientas más habituales, como lo es la entrevista como técnica, dirigida principalmente a obtener información de expertos y representantes de empresas relacionadas al rubro de producción, comercialización y distribución de oxígeno industrial en el departamento de Puno; y a partir de la cual se buscó obtener información sobre el perfil de los consumidores, características de los oferentes, y definición de la estructura de mercado particular para el universo de estudio.

\subsubsection{Proceso de Muestreo}

Para el caso en particular de la investigación cualitativa, y la aplicación de la técnica de entrevista, se optó por un muestreo por conveniencia - no probabilístico; dado que, ha sido de vital importancia el conocer información más relevante posible a cerca del mercado, y que nos permita obtener referencias precisas que guíen la investigación cuantitativa.

Así para las entrevistas se escogió a los representantes de tres de las empresas más significativas del departamento de Puno, empresas que fueron seleccionadas por conveniencia bajo el criterio de mayor experiencia en el 
mercado, ya que por su experiencia proporcionaron información muy relevante respecto al conocimiento del mercado.

La entrevista a los expertos permitió identificar las oportunidades y factibilidad que tiene la producción de oxígeno industrial en el departamento de Puno, al mismo tiempo que la información lograda ha permitido guiar de manera más precisa la investigación de mercado.

Las empresas seleccionadas son:

Empresa: Cori Puno S.A

Contacto: $\quad$ Elmer Castillo Rojas

Cargo: $\quad$ Jefe de compras

Ubicación: Juliaca

Empresa: A\&T ingenieros

Contacto: Carlos Ramos Chambi

Cargo: Jefe de logística

Ubicación: Puno

Empresa: Grupo Carwill

Contacto: Gutiérrez Will

Cargo: Gerente general

Ubicación: Juliaca 


\subsubsection{Diseño de instrumento}

El instrumento utilizado para el estudio cualitativo de la presente investigación fue la entrevista, la cual estuvo orientada a obtener información de manera oral y personalizada en base a un grupo de preguntas abiertas, la cuales fueron aplicados a los expertos y representantes de las empresas seleccionadas para este proceso. 


\subsubsection{Análisis y Procesamiento de datos: La entrevista}

A continuación se plasman los resultados de las entrevistas realizadas al grupo de tomadores de decisiones respecto a la información de mercado, así como un análisis de los principales puntos en convergencia, puntos que bajo consenso permiten tener una referencia más precisa sobre algunos aspectos fundamentales del mercado.

Tabla 15 Análisis de la entrevista

\begin{tabular}{|c|c|c|c|}
\hline PREGUNTAS & $\begin{array}{l}\text { ELMER CASTILLO ROJAS } \\
\text { Jefe de compras de Cori Puno S.A }\end{array}$ & $\begin{array}{l}\text { CARLOS RAMOS CHAMBI } \\
\text { Jefe de logística de A\&T ingenieros }\end{array}$ & $\begin{array}{l}\text { GUTIÉRREZ WILL } \\
\text { Gerente general del Grupo Carwill }\end{array}$ \\
\hline $\begin{array}{l}\text { ¿A su criterio cuál es la } \\
\text { característica entre los } \\
\text { usuarios de oxígeno } \\
\text { industrial en el } \\
\text { departamento de Puno? }\end{array}$ & $\begin{array}{l}\text { En los últimos diez años se ha vuelto un } \\
\text { mercado competitivo por lo tanto las } \\
\text { empresas son exigentes y buscan no solo } \\
\text { precios acorde a sus necesidades, sino la } \\
\text { calidad del insumo, sobre todo entre el } \\
\text { sector minero e industrial. }\end{array}$ & $\begin{array}{l}\text { La variedad de industrias en el departamento de } \\
\text { Puno, así como comercios de mediana escala ha } \\
\text { generado una alta demanda de oxígeno industrial, } \\
\text { por lo que el consumidor, a mi criterio busca tres } \\
\text { cualidades básicas: precio, calidad y disponibilidad, } \\
\text { es en estos tres ejes que se centra y caracteriza los } \\
\text { consumidores, por lo que las empresas productoras } \\
\text { y distribuidoras deben adaptarse a estas exigencias. }\end{array}$ & $\begin{array}{l}\text { La característica marcada entre las } \\
\text { empresas y usuarios que requieren } \\
\text { oxígeno industrial está relacionada con el } \\
\text { precio, ello porque mucho de los usuarios } \\
\text { son de pequeñas y medianas empresas y } \\
\text { siempre buscan insumos más baratos que } \\
\text { se adapten a sus necesidades. }\end{array}$ \\
\hline $\begin{array}{l}\text { ¿Usted cree que se cubre } \\
\text { toda la demanda de }\end{array}$ & $\begin{array}{l}\text { El crecimiento exponencial de las } \\
\text { industrias, tanto como las Mypes }\end{array}$ & $\begin{array}{l}\text { En la actualidad hay sectores que no se puede cubrir, } \\
\text { ello porque el departamento de Puno es accidentado }\end{array}$ & $\begin{array}{l}\text { No percibo grandes sectores por cubrir ya } \\
\text { que las principales empresas productoras y }\end{array}$ \\
\hline
\end{tabular}




\begin{abstract}
oxígeno industrial en el industriales ha incrementado el consumo
departamento de Puno?

de oxígeno industrial, teniendo en cuenta

que Puno cuenta con una intensa actividad

industrial y minera, sectores que

requieren de grandes cantidades de este

insumo. Ello ha generado que no se pueda

cubrir toda la demanda en ciertas
\end{abstract}

temporadas. y muchas empresas mineras se encuentran en zonas distribuidoras han podido cumplir con la

alejadas lo que limita la distribución de este insumo. demanda del mercado, lo que sí es

Falta acercar y mejorar los canales de distribución, evidente es que aún no se formaliza la lo cual garantizaría la distribución de oxígeno industrial.

calidad en la distribución y producción de oxígeno industrial entre las empresas, es ahí donde hay un nicho por cubrir, para lo cual es necesario contar con un sistema de gestión eficiente que cumpla con las necesidades y exigencias del consumidor.

Entre las fortalezas destaco su

versatilidad para adaptarse a los diversos

¿Podría usted precisar escenarios en que se ha desenvuelto el

cuáles serían las fortalezas mercado de oxígeno industrial en el

y debilidades entre los departamento de Puno, tratando de

principales distribuidores cumplir con las necesidades de los

de oxígeno industrial en el clientes.

departamento de Puno? En cambio entre las debilidades más resaltantes es que aún es deficiente en contar con canales de distribución que
La fortaleza más importante es la diversificación de los productos, orientándolos a diversos segmentos y sectores, hace años solo daban prioridad al sector industrial y minero, ahora otras industrias y organizaciones tienen las mimas facilidades de contar con este insumo.

Su principal debilidad es la calidad del servicio, el cual es deficiente y limitado, lo que genera insatisfacción y quejas de los clientes, ello es una
La fortaleza de este rubro radica en la experiencia de las empresas que se han instalado en este departamento, ya que cuenta con varios años fabricando $\mathrm{y}$ distribuyendo oxígeno industrial, cuentan con una cartera importante de clientes estratégicos y conocen las necesidades y sus particularidades.

La debilidad más resaltante y que podría generar una disminución en sus ventas es 


\begin{tabular}{llll}
\hline $\begin{array}{l}\text { llegue a todos los lugares del desventaja, teniendo en cuenta que pueden llegar que no cuentan con una adecuada } \\
\text { otras empresas con otra visión de trato al cliente. }\end{array}$ & $\begin{array}{l}\text { distribución, los pedidos no siempre llegan } \\
\text { en la fecha y hora convenida, ello debido a } \\
\text { que muchas de las empresas distribuidoras }\end{array}$ \\
& no cuentan con la movilidad y personal & necesario, lo cual genera atrasos en la \\
& distribución.
\end{tabular}

Se ha podido observar un incremento

porcentual de nuevas empresas en el sector Mype y Pyme relacionados a la

¿Cuál es la nueva

industria, si bien es cierto su nivel de tendencia entre los

usuarios de oxígeno

industrial en el

departamento de Puno?

el

consumo es mucho menor a las grandes

industrias, la cantidad de este tipo de unidades comerciales abre un campo significativo para las empresas que distribuyen oxígeno industrial y un nicho interesante para nuevas empresas que desean emprender en este rubro.
Es la expansión del mercado fuera de las Los usuarios de por sí son exigentes y buscan productos de calidad, ello se ve no solo en los clientes estratégicos e importantes como el sector minero e industrial, sino en las pequeñas empresas,

lo cual exige a los productos de oxígeno industrial de contar con productos y un servicio de calidad. principales ciudades del departamento, antes no había mayor consumo de otras comunidades del departamento, con los años el crecimiento de las industrias ha generado un mayor consumo y demanda de oxígeno industrial. 
Inicialmente si es una empresa nueva debe
¿Qué
cualidades
y La calidad del producto y servicio, a partir
Contar con una filosofía de calidad y que a su vez,
contar con un estudio de mercado, que le
características debe contar
de estas dos fortalezas podría incorporar
establezca canales de distribución, acercando así el
permita conocer las características
una empresa productora de
nuevos clientes y fidelizar a los que ya
producto a los usuarios, de tal forma que los clientes
especiales del cliente, así brindarle el
oxígeno industrial para tiene, muchos clientes no solo buscan
no esperen más de lo debido por el producto
producto y servicio que requiere. Para ello
posicionarse en un precios accesibles y bajos, sino que
solicitado. Si una empresa se empeña fortalecer esta
debe contar con personal capacitado y con
mercado como
el desean un producto y servicio a la altura
característica, podría muy fácilmente posicionarse
experiencia que permita perfilar una
departamento de Puno?
de sus exigencias.
en el mercado.
empresa con visión de calidad en el
servicio, así crecer dentro de este mercado.

Nota. Elaboración Propia 
Para reforzar el análisis cualitativo basado en las entrevistas realizadas a tres de las principales empresas consumidoras, se vio por pertinente llevar a cabo también una entrevista con uno de los miembros de mayor jerarquía de la empresa de mayor valor en el mercado de oxigeno industrial, refiriéndonos a la empresa CIGA S.A.

La empresa CIGA S.A., es la empresa que posee mayor experiencia sobre el mercado, dado que, fue la primera en iniciarse y al mismo es la empresa que cuenta con los mejores resultados sobre el mercado, una gran aceptación y una importante cuota de mercado de cerca del $50 \%$, además de ser la única que cuenta con una planta de producción, a diferencia de la competencia que únicamente se dedican a la comercialización, por lo que, sin duda alguna es el referente más importante que se puede tener al alcance.

Entonces se procedió a elaborar un cuestionario de preguntas respecto a información de mercado que se consideró de relevancia su conocimiento, luego este cuestionario fue enviado vía email, bajo el concepto de consulta amiga.

Debe de señalarse, que el denominado agente de consulta, es no solo uno de los miembros de mayor jerarquía de la empresa CIGA S.A., sino que también existe un vínculo de relaciones profesionales y de amistad para con los tesistas, por lo que, existió una amplia y favorable disponibilidad para contestar las consultas elaboradas.

Se presenta a continuación un extracto de las principales preguntas realizadas y las respuestas otorgadas, a fin de tener información de mayor utilidad que sirva de guía en el diseño de la investigación cuantitativa, así entonces se presenta a continuación los resultados de la consulta amigable llevada a cabo. 
Consulta Amigable sobre el mercado de Oxígeno Industrial en la región de Puno - Empresa CIGA S. A.

\section{Apartado I - Conocimiento de la Oferta}

1. Por favor, señale concretamente la forma y el tipo de usos que se le da al oxígeno industrial en la región de Puno

Respuesta:

En Puno generalmente se comercializa el oxígeno gaseoso comprimido, al menos en el rubro industrial y metalmecánico, la concentración de oxigeno gaseoso para el uso metalmecánico debe ser de $99.5 \%$. En el rubro medicinal se comercializa también el oxígeno líquido.

2. De lo señalado anteriormente, ¿Cuáles son las 3 formas y usos principales de oxigeno industrial que se produce y vende en la región de Puno? (Especifique por orden prioritario y señale un valor que refleje su relevancia).

Respuesta:

Para el oxígeno industrial solo estaríamos hablando de una forma, la cual es en estado gaseoso y los usos principales se dan en procesos de soladura oxiacetilénica, procesos de oxicorte, y procesos de fundición.

- Proceso de Oxicorte: $50 \%$

- Proceso de soldadura oxiacetilénica: $30 \%$

- Proceso de fundición: $20 \%$ 
3. ¿Quiénes son los principales productores, vendedores o distribuidores "oferentes" de los diferentes formas de oxigeno industrial que se expide en la región de Puno? Señale el nombre completo de las empresas que corresponde, distinguiéndolas según el tipo de oxígeno que ofrecen. (Especifique por orden prioritario y señale un valor o cualidad que refleje su relevancia).

Respuesta:

Todas las empresas distribuyen oxigeno industrial sin distinguir tipos para el presente caso.

-Comercial Leo (Distribuidor de Praxair): Distribuidor que cuenta con el respaldo de Praxair Perú.

-Praxair: empresa transnacional con producción en Lima, no posee local propio en Puno, cuentan con certificación ISO 9001-2008 y BPM

-Oxytex: Distribuidor con más de 10 años de experiencia se provee de varias empresas, no cuentan con stock permanente.

-CIGA SA.: Productor de oxigeno gaseoso con las de 25 años en el mercado cuenta con certificación ISO 9001-2015.

4. Otorgue una cuota de participación para las empresas oferentes de oxigeno industrial en la región de Puno.

Respuesta:

-Oxitex y Gases Andinos: $30 \%$

-Oxytex: $20 \%$

-CIGA SA.: 50\% 
5. ¿Cuáles son las principales deficiencias y/o debilidades de las empresas que conforman la actual oferta de gas industrial en sus diferentes formas y usos?

Respuesta:

Las principales deficiencias están dadas por que la mayoría son distribuidores esto hace de que ellos estén sujetos a sus proveedores y añadiendo el costo y riesgo del transporte propio que implica comprar el oxígeno. La mano de obra poco calificada para este tipo de negocio que no es muy común es uno de los principales factores en contra. El personal requiere entrenamiento constante ya que el oxígeno comprimido manipulado por un personal poco capacitado podría terminar fácilmente en una desgracia.

6. ¿Cuáles son las principales amenazas para las empresas que conforman la actual oferta de gas industrial en sus diferentes formas y usos?

\section{Respuesta:}

Los aspectos principales que influyen en el mercado de puno están guiados principalmente por el precio, tiempo de entrega y la flexibilidad de cada organización, en palabras sencillas los clientes tanto corporativos como no corporativos no simpatizan mucho con la burocracia de algunas empresas como Praxair y otras.

7. ¿Cuáles son las principales fortalezas de las empresas que conforman la actual oferta de gas industrial en sus diferentes formas y usos? 
Respuesta:

Las fortalezas de las empresas distribuidoras a excepción de CIGA S.A. están dadas por el precio y el tiempo de atención. En cuanto a la empresa CIGA SA., esta cuenta con producción propia lo que permite una independencia total en el aprovisionamiento del oxígeno.

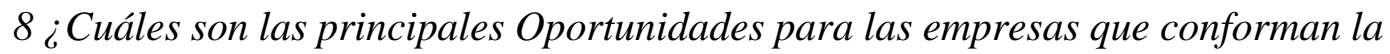
actual oferta de gas industrial en sus diferentes formas y usos?

Respuesta;

-Crecimiento en la industria metalmecánica

-Crecimiento de la minería informal

-Crecimiento de la minería formal

9. Señale el precio o rango de precios por unidad de producción que existe en el actual mercado de oferentes de oxigeno industrial en la región de Puno.

Respuesta:

Los precios son manejados de acuerdo al volumen de consumo y la relevancia del cliente. Los precios oscilan entre 16 y 6.90 soles por metro cubico.

10. Señale las principales formas de comercialización del producto final, realizado por las empresas oferentes de oxigeno industrializado, en la región de Puno.

Respuesta:

Básicamente es una venta directa al $100 \%$. 
11. Señale algunas características relevantes sobre la distribución del oxígeno industrializado, llevado a cabo por las principales empresas oferentes en la región de Puno. ¿La venta incluye el costo del cilindro que almacena el producto, se da un alquiler de los cilindros y cuál el costo asociado?

Respuesta:

La venta es netamente por el contenido (oxigeno). El precio de los cilindros para clientes usuarios es de aproximadamente 1,800 soles. Y el alquiler de la botella (cilindro) tiene un costo de 8 soles por día, con una previa garantía por el cilindro de 1000 soles.

12. Mencione las principales estrategias de marketing y venta utilizadas usualmente por las empresas oferentes de oxigeno industrial en la región de Puno.

Respuesta:

La única estrategia de marketing adoptada por la mayoría de empresas es el pintado de la marca en el cilindro para la promoción de la misma.

13. Mencione y explique si considera que existe alguna potencial oportunidad de obtener una ventaja competitiva o algún tipo de riesgo a partir de la relación con los proveedores de los insumos claves.

Respuesta:

Definitivamente si, en referente al costo de la energía. En nuestro caso, estamos trabajando estrategias corporativas para disminuir ese costo.

\section{Apartado II - "Identificación de la demanda, y Tipo de Mercado"}


1. Por favor, señale concretamente cuál es el tipo de oxigeno industrial que es demandando en la región de Puno. Asocie la relevancia del tipo a un valor numérico.

Respuesta:

La forma de oxigeno de mayor demanda es el oxígeno industrial para el sector metal mecánico y minero. Oxigeno gaseoso envasado en cilindros de acero de 10, 8, 6 metros cúbicos.

2. Enumere el tipo de consumidores que adquieren el producto de oxigeno industrial en la región Puno. Otorgue una cuota de demanda según el tipo de consumidor

Respuesta:

$-50 \%$ empresas metalmecánicas

$-30 \%$ empresas de fundición (mayormente dentro de mineras)

$-20 \%$ Soldadores.

3. Mencione los principales usos que le dan los actuales consumidores al producto oxigeno industrializado.

Respuesta:

Procesos de oxicorte, procesos de fundición de oro, procesos de soldadura oxiacetilénica. 
4. Señale las expectativas de crecimiento sobre la demanda del producto oxigeno industrializado en la región de Puno. Mencione una tasa de crecimiento de la demanda esperada.

Respuesta:

La tasa esperada es de $10 \%$

5. Señale los principales factores determinantes sobre la decisión de compra por parte de los consumidores (Precio, calidad, otros). Tome en consideración la forma y el tipo de uso que le dan los consumidores sobre el oxígeno industrial.

Respuesta:

Precio, oportunidad o tiempo de entrega

6. Mencione la frecuencia temporal de demanda del producto oxigeno industrial en la región de Puno.

Respuesta:

La demanda de oxigeno industrial es por mes un aproximado de 4000 metros cúbicos.

7. Describa aquellos elementos que pueden denotar una importante variación (Incremento o reducción, estancamiento) sobre el comportamiento de la demanda del producto oxigeno industrializado. 
Respuesta:

Precio y oportunidad de entrega o atención.

8. Por favor, si considera algún otro aspecto relevante respecto al análisis de la demanda y que deba ser tomado en cuenta, mencione este(os) en la siguiente parte.

Respuesta:

Tienen que tener en cuenta es que el mercado industrial es informal casi al $80 \%$, entonces a ellos no les interesa más que el precio y la atención oportuna, dado esto es un poco difícil sacar un ratio de demanda esperada, ya que hay clientes que aparecen y desaparecen justamente por la informalidad que se maneja en este tipo de segmento y mercado.

Por tanto se recomienda, que para su estudio cuantitativo de demanda, se tome el criterio de evaluar a consumidores que tienen un consumo representativo sobre el oxígeno industrial, es decir, un nivel de consumo de cierta manera estable, a fin de centrarse en la búsqueda de un mercado sólido y ya establecido, sobre el cual se puede ganar un segmento no satisfecho, adoptando entonces una postura de riesgo moderado en un principio. 
Nota: No se realiza un análisis de la consulta amigable realizada y presentada en este segmento anterior, debido a que las respuestas expresan de manera explícita la información relevante para guiar el estudio de mercado cuantitativo y para la investigación en general.

\subsection{Análisis Cuantitativo}

El enfoque del análisis cuantitativo como parte de la investigación de mercado, se encuentra caracterizado porque se basa en un proceso más preciso que el estudio cualitativo, y que en base a números concretos y un análisis estadístico del mismo, permite establecer patrones de comportamiento sobre la o las variables de estudio de mercado.

Así el enfoque del análisis cuantitativo llevado a cabo se caracteriza por la recolección de datos fundamentados por la medición, datos que son expresados en números concretos y que gracias al proceso del diseño de la investigación se ha buscado controlar y minimizar el error o sesgo de información probable. El análisis e interpretación de los resultados se lleva a cabo de manera objetiva, logrando resultados cuantificables y extrapolables para el universo de estudio.

Para el estudio cuantitativo del mercado, en la presente investigación, se ha tomado en cuenta las principales conclusiones logradas en el estudio cualitativo y que han guiado la elaboración del instrumento utilizado para este apartado, esperando corroborar las principales conclusiones del estudio cualitativo y profundizar aún más en aspectos de conocimiento del mercado, de forma tal que permita identificar aspectos relevantes para definir el mercado de destino. 
Así mismo se ha considerado las premisas logradas a partir de la consulta amigable realizada al agente de la principal empresa oferente de oxigeno industrial en la región de Puno, como lo es CIGA S.A.

Esta parte de la investigación radica en establecer no solo la percepción de los clientes que adquieren oxígeno industrial en el departamento de Puno, sino también en conocer cifras concretas que caractericen sus patrones de consumo. Para ello se elaboró y aplico una encuesta estructurada de preguntas cerradas, centrada en explorar los datos obtenidos de forma numérica y exponencial, lo cual permitió a los investigadores aproximarse a su objeto de estudio, que consiste en establecer la viabilidad del proyecto, a través de la respuesta de los consumidores (mercado).

Se recalca que el principal objetivo de la investigación cuantitativa es contar con los datos y cifras precisas que permitan conocer la realidad desde el punto de vista del consumidor, tales como; el tipo de consumidor existente, la percepción sobre la oferta existente, el tipo de mercado que caracteriza a la industria de oxigeno industrial, los principales factores que mueven la demanda, la existencia de segmentos de mercado insatisfechos, segmentos de mercado emergentes, la caracterización de los precios, distribución y marketing sobre el producto de oxigeno industrial, entre otros, todo a partir de lo cual será la base para el análisis posterior de la viabilidad del proyecto, ya que, es la existencia de un mercado desatendido o mal atendido lo que posibilidad el funcionamiento de una unidad de producción y la viabilidad de un proyecto.

\subsubsection{Proceso de Muestreo}

Corbetta (2003) manifiesta que "Población o Universo es todo conjunto o grupo de individuos, cosas u objetos con ciertos atributos comunes (p.17). 
Para determinar la población de estudio, con base en la que se obtendrá la muestra, primeramente se determinó el número de empresas según su actividad económica que se consideraron para realizar el presente estudio, quedando su distribución de la siguiente manera:

Tabla 16 Empresas según su actividad económica

\begin{tabular}{|l|c|c|}
\hline \multicolumn{2}{|c|}{ Empresas según su actividad económica } \\
\hline Actividad Económica & $N^{\circ}$ de Empresas & Frec. Relativa \\
\hline Explotación minera & 192 & $25 \%$ \\
\hline Fabricación de productos metálicos & 562 & $75 \%$ \\
\hline Total & 754 & $100 \%$ \\
\hline
\end{tabular}

Por lo tanto la población de estudio está conformada por 754 empresas. Así mismo cabe destacar que la distribución sobre la cantidad de empresas que conforman el universo según tipo de actividad, se ha mantenido en correspondencia para la determinación del muestreo por estratos, permitiéndonos así obtener una mayor cantidad de información valiosa de aquel sector que refiere un mayor consumo del producto y que por tanto resulta conveniente estudiar a mayor profundidad.

De esta forma se aplicó un muestreo estratificado uniforme a fin de poder mantener las propiedades estadísticas del muestreo más apropiado, al mismo tiempo que se logra capturar más información del conjunto de la población que dada su naturaleza de un nivel de consumo más alto, es una mayor fuente de información. Así, se justifica la aplicación de un muestreo estatificado uniforme, dada la referencia del estudio cualitativo sobre la presencia de dos sectores 
conformantes del universo de estudio, donde cada uno tiene su la naturaleza propia sobre el consumo de oxigeno industrial.

\subsubsection{Muestra}

Corbetta (2003) coincide en definirla como "el sub- conjunto de la población”(p.10). Ya que la muestra es seleccionada o extraída de la población, pasa hacer una parte de ella.

Se obtuvo la muestra mediante la aplicación de la fórmula para problemas fortuitos la cual sirvió para determinar el número de usuarios que serán encuestados.

Para que sea posible hallar la muestra de la población se realiza la siguiente fórmula:

$$
n=\frac{N Z^{2} p q}{e^{2}(N-1)+Z^{2} p q}
$$

Figura 11 Fórmula de cálculo.

Tomado de Estadística aplicada a la investigación, (p.3), por Ramos Anthony, 2009, Venezuela: Editorial UNEFM. 2012

$\mathrm{N}$ = Población o universo

$\mathrm{Z}=$ Valor del nivel de confianza

$\mathrm{p}=$ Proporción de individuos que poseen las características del estudio

$\mathrm{q}$ = Proporción de individuos que no poseen las características del estudio

$\mathrm{e}=$ Porcentaje o margen de error

Los valores de la formula son los siguientes: 
$\mathrm{N}=754$

$\mathrm{Z}=95 \%---1,96$

$\mathrm{p}=50 \%$

$q=50 \%--0,5$

$\mathrm{E}=5 \%---0,05$

Remplazando:

$n=$

$754 *\left(1.96^{2}\right) *(0.5 * 0.5)$

$\left(0.05^{2}\right) *(754-1)+\left(1.96^{2}\right) *(0.5 * 0.5)$

$n=$

255

Se obtuvo entonces una muestra final, según la aplicación de la fórmula fue de 255 empresas, las cuales por el tipo de actividades que realizan requieren de oxígeno industrial en el departamento de Puno.

Ahora entonces, ha sido de correspondencia determinar la muestra de manera estratificada, y para ello se utiliza un muestreo proporcionado de acuerdo al porcentaje de consumo de oxigeno industrial que tienen las empresas según su actividad económica, por lo tanto la muestra ha sido establecida de la siguiente manera:

Tabla 17 Cantidad de empresas a encuestar segun rubro

\begin{tabular}{|l|c|c|c|c|}
\hline Actividad Económica & Población & Fijación & Muestra & Proporción \\
& & Muestral & estratificada & Muestral \\
\hline Explotación minera & 192 & $34 \%$ & 65 & $25 \%$ \\
\hline
\end{tabular}




\begin{tabular}{|l|c|c|c|c|}
\hline Fabricación de & 562 & $34 \%$ & 190 & $75 \%$ \\
productos metálicos & & & & \\
\hline Total & $\mathbf{7 5 4}$ & $34 \%$ & 255 & $100 \%$ \\
\hline
\end{tabular}

Como se puede apreciar, la determinación del tamaño muestral de cada estrato que compone la muestral en su conjunto, ha sido determinado por un muestreo estratificado uniforme, con una fijación muestral del 34\% para cada estrato, obteniendo un tamaño del estrato muestral del sector Minero de 65 empresas a ser entrevistadas y de 190 empresas del sector Metal Mecánico.

Por otro lado, ha sido de mucho provecho la aplicación de un muestreo estratificado uniforme que ha hecho posible que del total de la muestra conjunta, el 75\% de las entrevistas (190 de 255 empresas) sean realizadas al sector que se refiere con el mayor nivel de consumo del oxígeno industrial, tal como lo refieren las consultas amigables llevadas a cabo a uno de los principales miembros del staff de la empresa CIGA S.A. ; empresa que tiene más dominio en el mercado, y que cuenta con una amplia experiencia del funcionamiento real de este tipo de industria, por lo cual este elemento ha permitido dotar a la presente investigación de una importante y significativa información, contribuyendo con su conocimiento de manera explícita y técnica.

Es importante mencionar que si bien es cierto, se ha aplicado un muestreo estratificado para la determinación del tamaño de muestra global y de cada una de las partes de los estratos que lo integran, al momento de 
la determinación de los elementos muéstrales, es decir, de las empresas que fueron seleccionadas para el estudio cuantitativo de mercado, tales empresas fueron seleccionadas no bajo un muestreo probabilístico, sino por el contrario bajo un muestreo por conveniencia, dada las limitaciones de poder contar con el padrón completo y actualizado respecto del total de empresas que conforman de manera real cada uno de los estratos del universo de estudio.

Así se ha tomado en consideración una de las principales premisas de mercado obtenidas a partir del análisis cualitativo, la cual señala la distinción de dos segmentos de mercado con características peculiares; el sector de producción metálica y el sector minero, en donde los consumidores relevantes son aquellos quienes tienen niveles de consumo significativo, consumidores sobre los cuales se debe de realizar el estudio cuantitativo a fin de obtener información precisa de un segmento de mercado más establece que guarde relación con la recomendación de los expertos de adoptar una postura moderada de riesgo y por consecuente centrarse en aquellos consumidores con consumos significativos y estables de oxigeno industrial.

\subsubsection{Diseño de instrumento}

Por el tipo de negocio se consideró realizar la recolección de datos en base a una encuesta personal con preguntas cerradas. Para lo cual se intentó acordar un encuentro entre encuestador y encuestado, bajo la modalidad de encuesta en establecimiento. 
Se hizo uso del cuestionario como instrumento, elaborado en forma de escala con ítems, los cuales serían contestados de acuerdo a las apreciaciones del encuestado, el cuestionario se elaboró de acuerdo a las cualidades y características del producto (oxígeno industrial), tales como: costo, distribución, calidad, envase, forma de pago, etc., y teniendo en consideración las principales premisas logradas en el estudio cualitativo sobre la caracterización del mercado.

Tabla 18 Ficha tecnica de encuesta

754 empresas consumidoras de

Población

oxigeno industrial

\begin{tabular}{lc}
\hline Ámbito Geográfico & $\begin{array}{c}\text { Departamento de Puno } \\
\text { Unidad muestral }\end{array}$ \\
Cuestionarios Validos & 255 \\
Error Muestral & 0.05 \\
Nivel de confianzantes de las empresas
\end{tabular}

Nota. Elaboración propia.

\subsubsection{Análisis y procesamiento de datos}

A continuación se presentan los principales resultados obtenidos del estudio de mercado: 


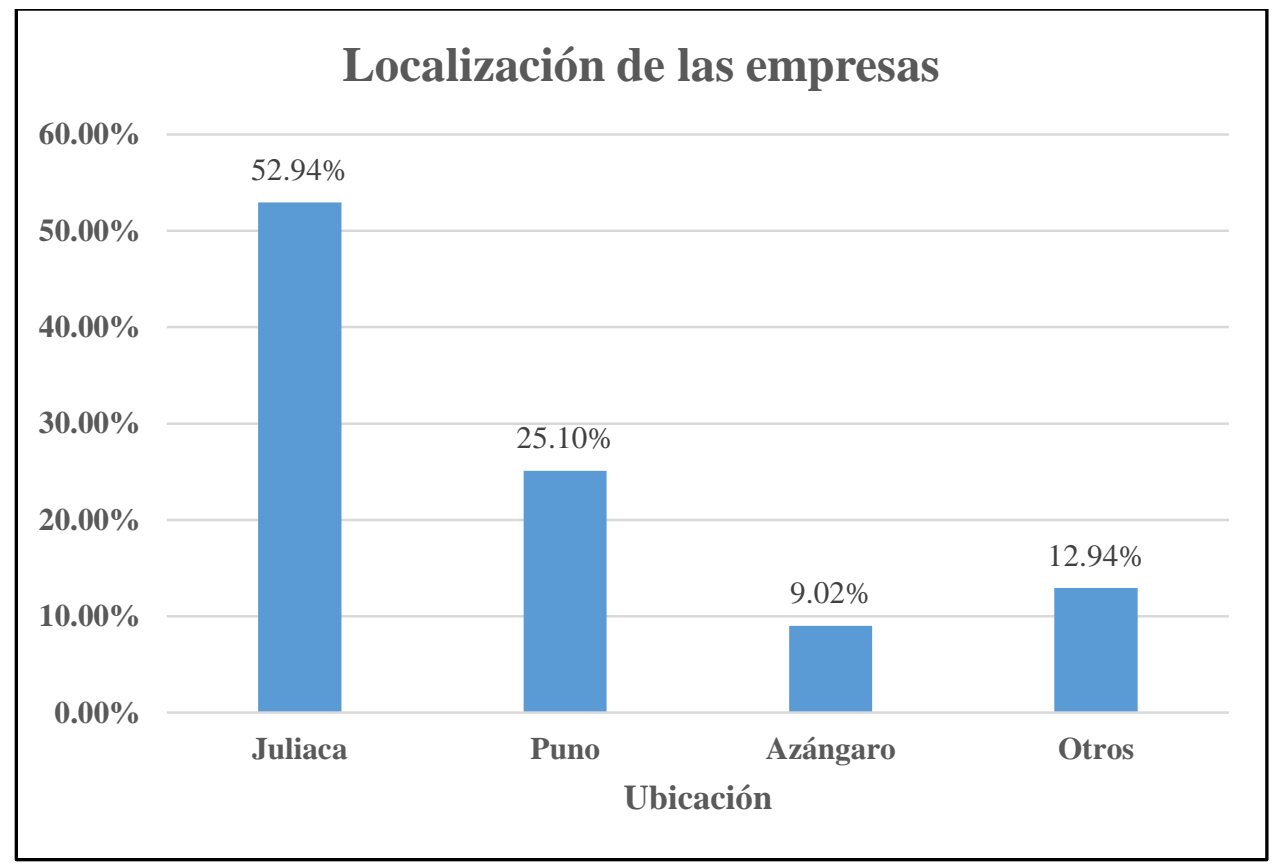

Figura 12 Ubicación de las empresas consumidoras de oxígeno industrial Elaboración propia.

Interpretación:

Del $100 \%$ de los encuestados, el $53 \%$ respondió que su empresa se encuentra ubicada en la ciudad de Juliaca, el $25 \%$ contesto que su empresa se ubica en la ciudad de Puno y un $9 \%$ señalo que se encuentra en la ciudad de Azángaro; el resto de ciudades del departamento de Puno en conjunto representan el $13 \%$ del total.

En el caso de la empresas mineras muchas de ellas tienen sus oficinas principales en ciudades como Juliaca, Puno, Azángaro, etc. Mientras que sus centros de operaciones se sitúan comúnmente en zonas alejadas del área urbana, esto ha sido considera al momento de establecer las estrategias de marketing necesarias para la distribución apropiada del producto. 


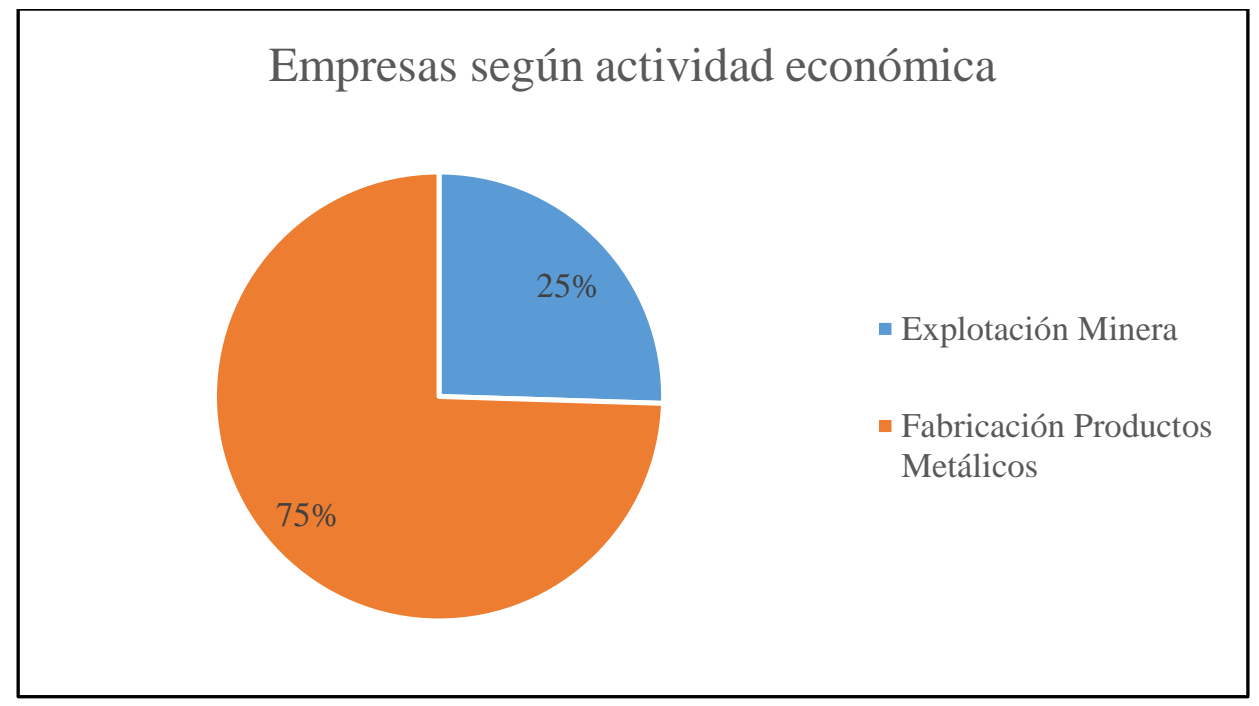

Figura 13 Tipo de actividad que realiza su empresa.

Elaboración propia

Interpretación:

Se puede apreciar que son las empresas dedicas a la fabricación de productos metálicos quienes tienen la mayor participación de mercado, en lo que respecta al consumo de oxigeno industrial. Así estas representan cerca del $75 \%$, y las empresas de explotación minera un $25 \%$.

Es importante notar, que el muestreo estratificado uniforme ha permitido mantener una correspondencia aproximada entre la representatividad porcentual de cada sector sobre la muestra conjunta, un $75 \%$ y $25 \%$ sobre sobre la muestra conjunta, en relación similar a la tasa de consumo referente de oxigeno industrial proveniente de cada uno de los sectores. Misma referencia que señala que entre un $50 \%$ a $60 \%$ de la demanda de oxigeno industrial de la región de Puno proviene de las empresas de fabricación de productos metálicos y de igual manera entre un $25 \%$ a $60 \%$ la demanda que proviene de las empresas mineras, siendo apenas la referencia de entre $10 \%$ a $15 \%$ aquella que provenía del sector construcción, empresas que no han sido tomadas en cuenta, dada el tipo de 
distorsiones que genera sobre el muestreo y la propia naturaleza de los datos de dicho sector.

Así mismo el sector minero, es un importante mercado, dado que, es uno de los sectores con mayor capacidad de pago, aunque no tengan una importante representatividad en la cantidad de empresas sobre el total del universo; mientras que el sector al que pertenecen las empresas que se dedican a la producción de productos metálicos son quienes mayor oxigeno industrial exigen.

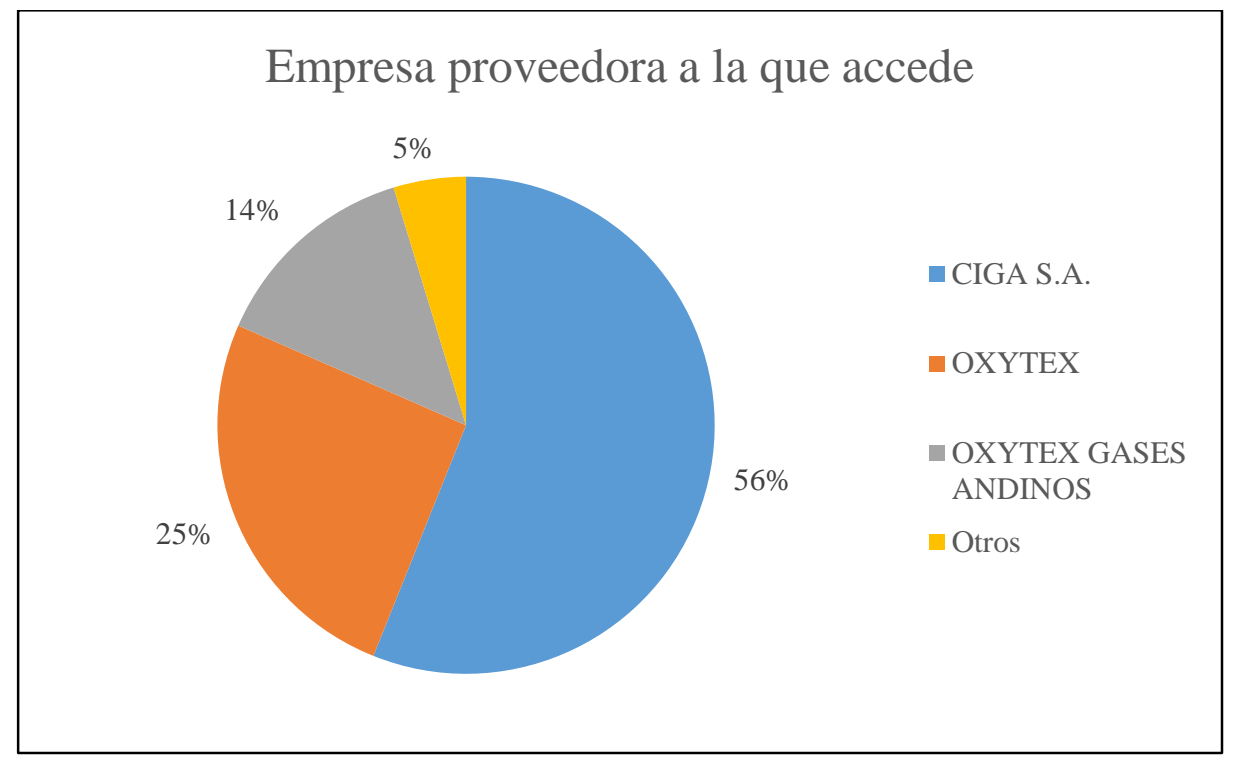

Figura 14 Empresa proveedora a la que accede para la adquisición del oxígeno industrial.

Elaboración propia

Interpretación:

Se aprecia que la empresa CIGA S.A. es quién domina el mercado de oxigeno industrial en la región de Puno, logrando una participación del 56\%, seguido por OXITEX con un 25\%; es decir, del total de 255 empresas encuestadas ,143 empresas tienen como proveedor a CIGA S.A. y 65 empresas 
a OXITEX, logrando en conjunto un dominio de cerca de $81 \%$ sobre el mercado, sin duda alguna las dos empresas de mayor importancia y referencia.

Como puede apreciarse, CIGA S.A. es la empresa con mayor dominio en el mercado, además de su amplia experiencia ya en el sector industrial, motivo por el cual se tomó con mucha relevancia la información provista por las consultas amigables realizadas a uno de los miembros más importante del staff de trabajadores de tal empresa.

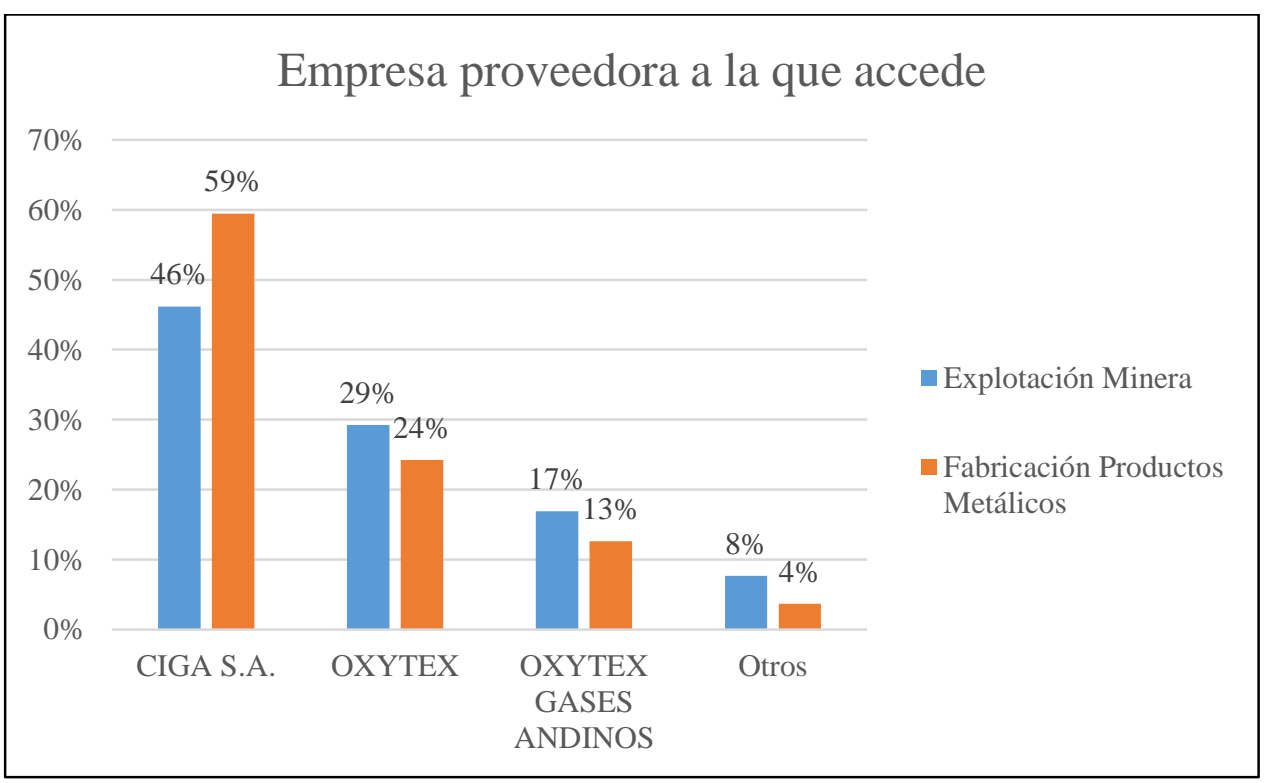

Figura 15 Empresa proveedora a la que accede para la adquisición del oxígeno industrial, según tipo de actividad.

Elaboración propia

Interpretación:

Sabiendo que es la empresa CIGA S.A. quién domina el mercado de oxigeno industrializado, se puede apreciar también que su mayor tipo de clientes son las empresas de explotación minera y de la fabricación de productos metálicos, hecho que se repite en las otras empresas proveedoras. 
Se tiene así por ejemplo que, cerca del 59\% (113 de 190) de las empresas entrevistadas del rubro de fabricación de productos metálicos y el 46\% (30 de 65) de empresas del rubro minero, le compran a CIGA SA el producto oxigeno industrial;, mientras que para la empresa OXITEX 29\% y 24\% de las empresas de cada sector la recurren para la adquisición de oxigeno industrial, por lo que; los mayores clientes son sin duda alguna las empresas dedicadas a la fabricación de productos metálicos en mayor cuantía, seguidos por el sector minero también en una cuantía importante, resultados en coherencia con las principales referencias de consumos para ambos sectores.

\section{Empresas cuyo proveedor cubre todo su volúmen de requerimiento}

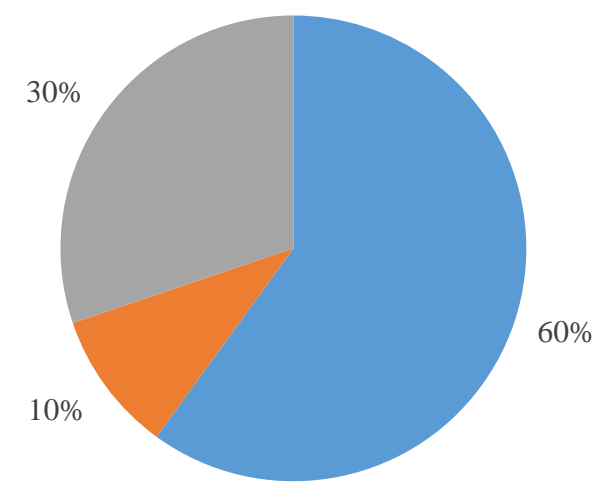

$\square \mathrm{Si}$

A veces

No

Figura 16 La empresa que lo abastece de oxigeno industrial cubre todos sus requerimientos en cuanto a cantidades del producto.

Elaboración propia

Interpretación:

En la figura anterior se puede observar que, en su mayoría de veces, cerca del $70 \%(60 \%+10 \%)$ de las empresas encuestadas mencionan que su actual proveedor tiene la capacidad para cumplir con los volúmenes de compra requeridos, mientras que un $30 \%$, es decir, 77 empresas de empresas 
encuestadas mencionan que sus proveedores no son capaces de proveer el requerimiento de compra necesario. Así estas cifras reflejan el hecho de que al no existir muchos proveedores de oxigeno los existentes no se dan abasto y se les dificulta atender pedidos de gran volumen, generando una oportunidad aún latente para nuevos oferentes.

Así al ser un porcentaje de alrededor del $30 \%$, las empresas que no llegan a cubrir completamente sus requerimientos de compra, es claro que la empresa emergente a proponerse como parte de la presente investigación, tendrá estrategias de venta que están orientadas en parte a cubrir este porcentaje de empresas, así como otras fracciones de la población, según otros criterios logrados de los resultados posteriores del análisis de la información más adelante mencionados.

\section{Empresas que se encuentran satisfechas con su actual proveedor}

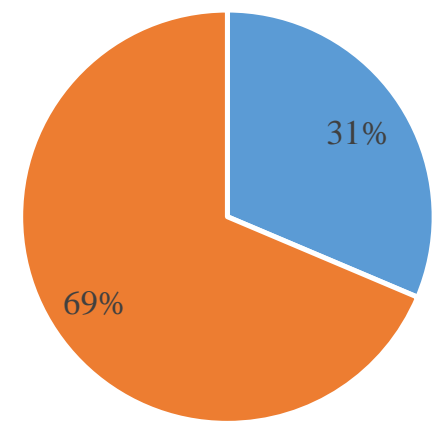

Figura 17 Proporción de empresas que están satisfechas con el servicio de su proveedor actual de oxígeno.

Elaboración propia

Interpretación: 
Como se aprecia en la figura anterior, cerca de un $69 \%$ de empresas no se encuentran satisfechas con el actual proveedor que tienen, una cifra relevante para la determinación del segmento de mercado a atender por parte de la empresa de la presente investigación.

Entre algunos de los comentarios sugeridos por los entrevistados, se mencionó que es la misma estructura de oferta, un tipo de monopolio en gran proporción, lo que les obliga a continuar con la adquisición del oxígeno industrial aun cuando exista un descontento con los proveedores, así mismo los encuestados mencionaron que en su mayoría el descontento es por ciertos factores sobre la distribución, la capacidad de entrega, entre otros, que son principalmente propios de las empresas distribuidoras únicamente y que no tienen una planta de producción en la zona, caso que no se cumple para la empresa CIGA S.A.

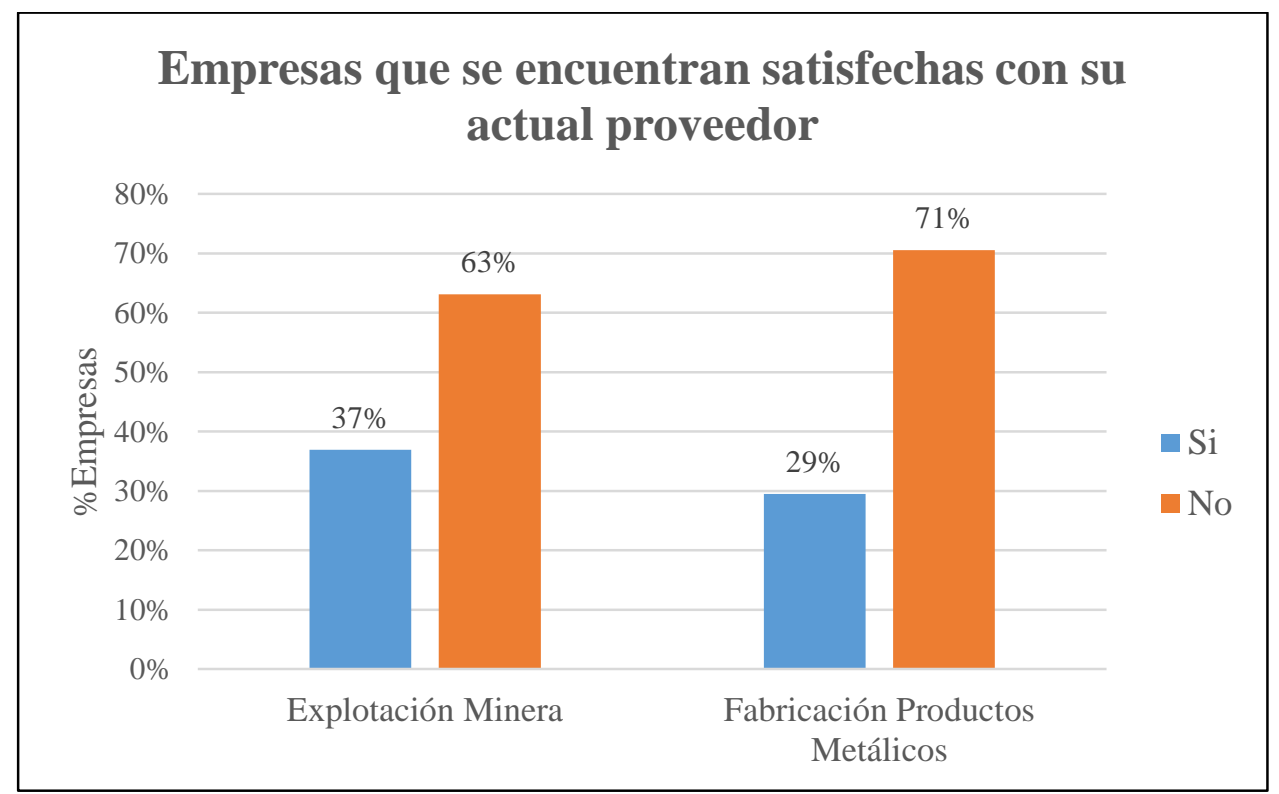

Figura 18 Empresas que se encuentran satisfechas con su actual proveedor por actividad económica.

Elaboración propia 
Interpretación:

Se aprecia en la figura que, independientemente del tipo de empresa según su actividad económica que realice, estas en su mayoría cerca de un $67 \%$ en promedio no se encuentran satisfechas con el actual proveedor que tienen, una cifra relevante para la determinación del segmento de mercado a atender por parte de la empresa de la presente investigación.

Aquí es importante resaltar que, en el caso de las empresas de rubro minero y aquellas de producción metálica, quienes son las que compran en su mayoría a CIGA S.A., mencionaron entre sus comentarios que, la insatisfacción es debida más que todo al hecho del tiempo de entrega, es decir, muchas veces es la burocracia administrativa sobre los requerimientos de compra.

\section{Empresas que les gustaría un mejor servicio sobre la adquisición del producto}

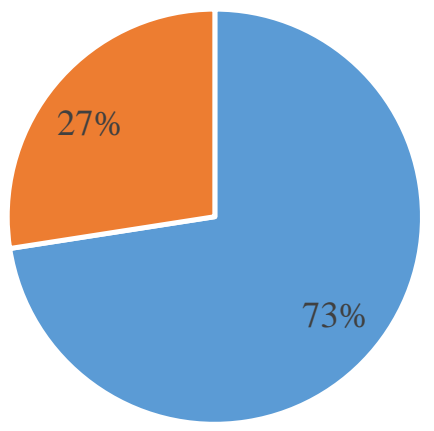

Figura 19 Empresas que les gustaría un mejor servicio sobre la adquisición del producto. Elaboración propia

Interpretación: 
Como se observa en la figura anterior, $73 \%$ de las empresas encuestadas respondieron que les gustaría un mejor servicio, cifra muy coherente con el $69 \%$ de empresas que mencionaron su insatisfacción.

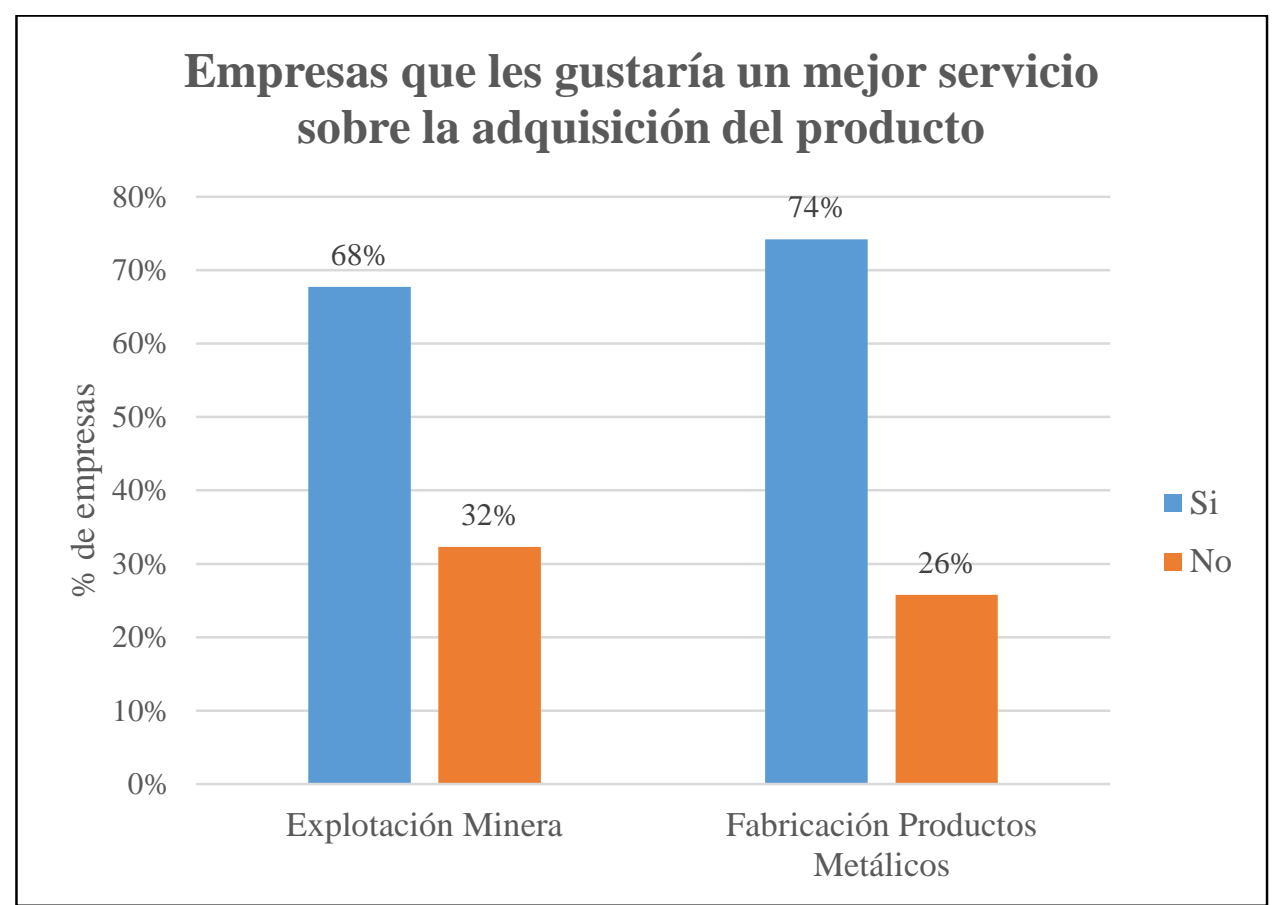

Figura 20 Empresas que les gustaría un mejor servicio sobre la adquisición del producto, según tipo de actividad.

Elaboración propia

Interpretación:

De manera coherente con los niveles de insatisfacción encontrados previamente, se tiene que independientemente del tipo de actividad que realicen las empresas, están quieren un mejor servicio, ya sea, basado en reforzar o solucionar alguno de los causantes de esa insatisfacción.

Es muy interesante notar que las empresas dedicadas a la explotación minera y a la fabricación de productos tienen cifras relevantes de $74 \%$ y $68 \%$, valores muy significativos para la determinación del mercado potencial que encontrará y buscará atender. 
Disposición a adquirir el producto a un nuevo proveedor

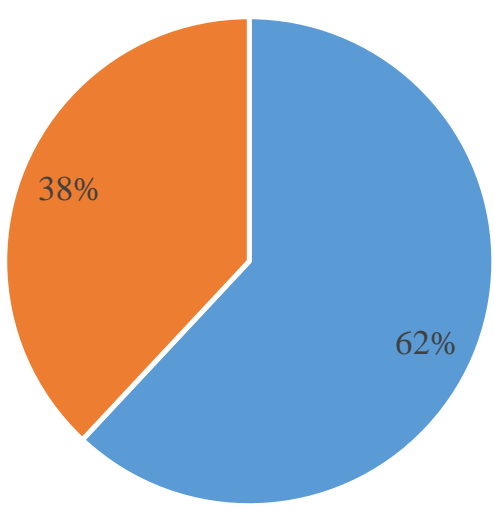

Figura 21 Empresas que se encuentran dispuestas a adquirir el producto de un nuevo proveedor.

Elaboración propia

Interpretación:

Los resultados de la figura que se muestra, señalan que un $62 \%$ de las empresas encuestas estarían dispuestas a adquirir el oxígeno industrial de un nuevo proveedor, es decir, de un total de 255 encuestadas, 158 empresas muestran cierta disposición a un nuevo proveedor.

Cifra anecdótica, dado que anteriormente se señaló que en promedio el $69 \%$ de las empresas estaban insatisfechas y les gustaría un mejor servicio, sin embargo; al ser una industria compleja la dedicada a la producción de oxigeno industrial y con una demanda muy exigente, cubierta en su mayoría por el dominio que tiene la empresa CIGA SA., muchos de los entrevistados mencionaron que el factor decisivo que impulsa esta cifra sorpréndete, es el gran descontento sobre la capacidad de entrega de los oferentes, además de señalar que la confianza en su proveedor actual permanecería en gran grado estable, y 
su referencia de compra a un nuevo proveedor estaría basada en que aún tienen requerimientos de compra que no son del todo cubierto y que dotarían de confianza a este nuevo proveedor sobre estos faltantes, probando una pequeña cuota a uno nuevo hasta lograr un nivel de confianza suficiente que los lleve a cambiar en su mayoría el requerimiento del producto hacia un nuevo proveedor.

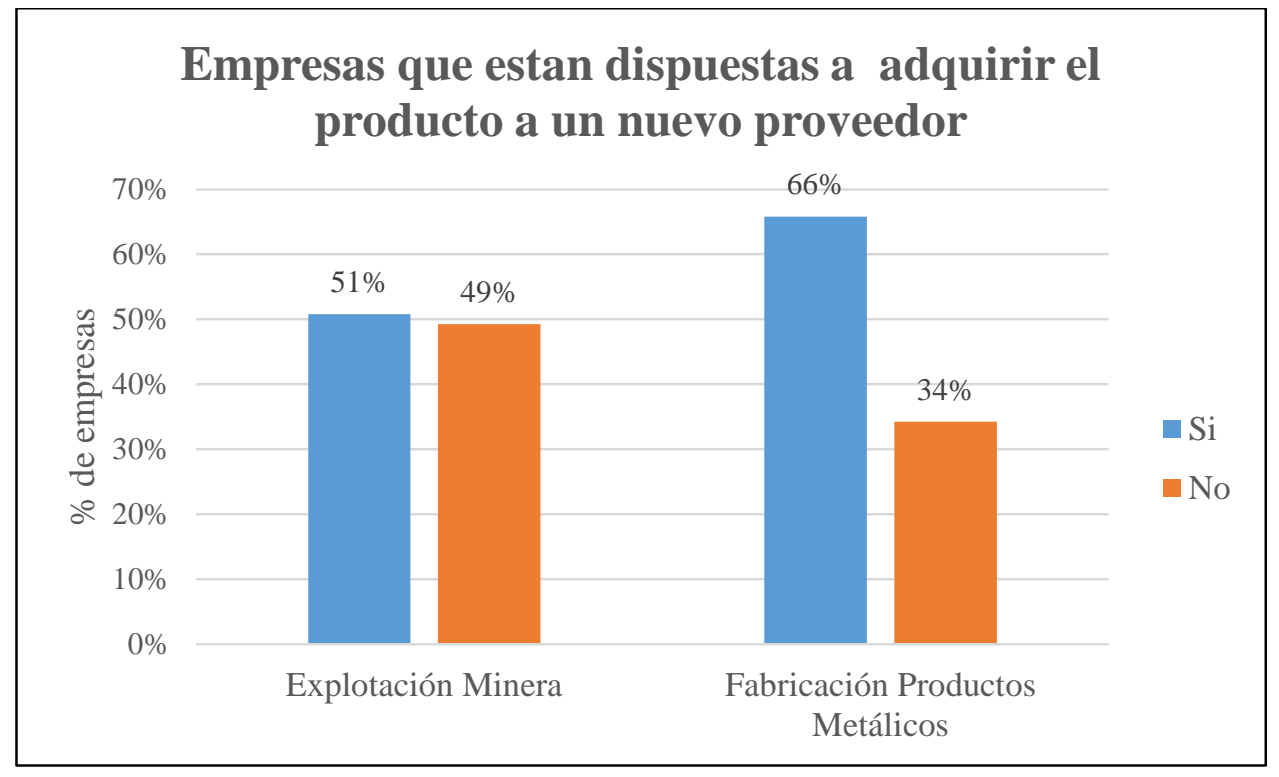

Figura 22 Empresas que se encuentran dispuestas a adquirir el producto de un nuevo proveedor, según tipo de actividad.

Elaboración propia

Interpretación:

En la presente figura, cabe destacar que el tipo de empresas que estaría dispuesta a destinar parte de sus requerimientos del producto hacia un nuevo proveedor, son aquellas en el rubro de producción de productos metálicos en su mayor parte y de la fabricación de la explotación minera en un porcentaje menor. Así se tienen cifras de un 51\% de empresas (33 de 65) dedicadas a la explotación que accederían a un nuevo proveedor y un 66\% (125 de 190) de empresas de fabricación de productos metálicos que también accederían a un nuevo proveedor. 
Debe recordarse que precisamente son las empresas dedicadas a la fabricación de productos metálicos, seguido por las del rubro minero, quienes se llevan una mayor cuota de consumo del mercado del producto de oxigeno industrializado y son estas quienes plantean la posibilidad de acceder a un nuevo proveedor. Así mismo debe notarse que el porcentaje de las empresas del sector minero tienen una menor disposición a un nuevo proveedor, ya que, tal y como lo sugieren los comentarios de los entrevistados, son sus propios procedimientos de carácter más riguroso lo que les obliga en buena manera a mantener el grado de confianza bilateral conseguido con sus actuales proveedores.

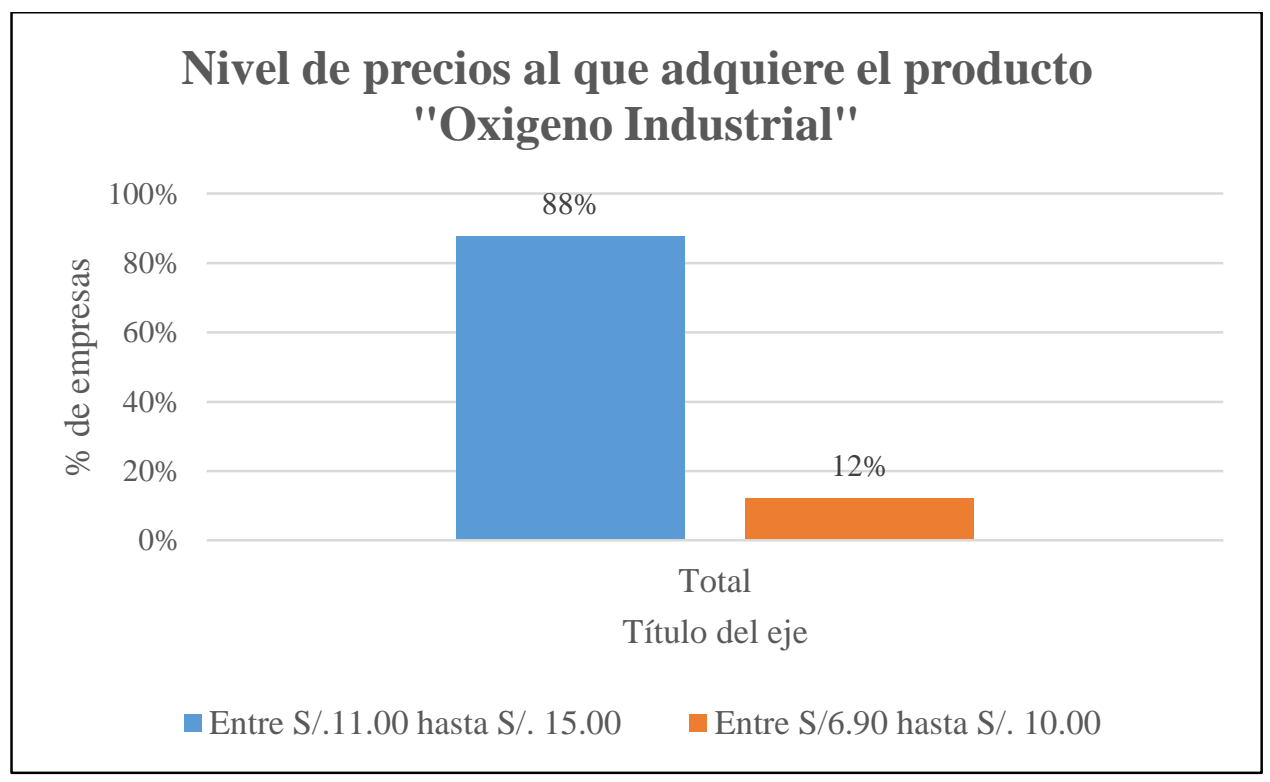

Figura 23 Nivel de precios al que las empresas adquieren el oxígeno industrial.

Elaboración propia

Interpretación:

Como puede apreciar el rango de precios por unidad de $\mathrm{m} 3$, existentes para el producto de oxigeno industrial en la región de Puno, oscila entre S/. 6.90 a S/. 15.00, aunque el $88 \%$ de las empresas entrevistadas adquieren el producto a un precio que oscila entre los S/. 11.00 a S/. 15.00 como máximo; por lo que 
la empresa a la que hace referente la presente investigación tomará como segmento de mercado a este universo de empresas que adquieren el producto en el rango de precios con un mínimo de S/. 11 hasta un máximo de S/15.00.

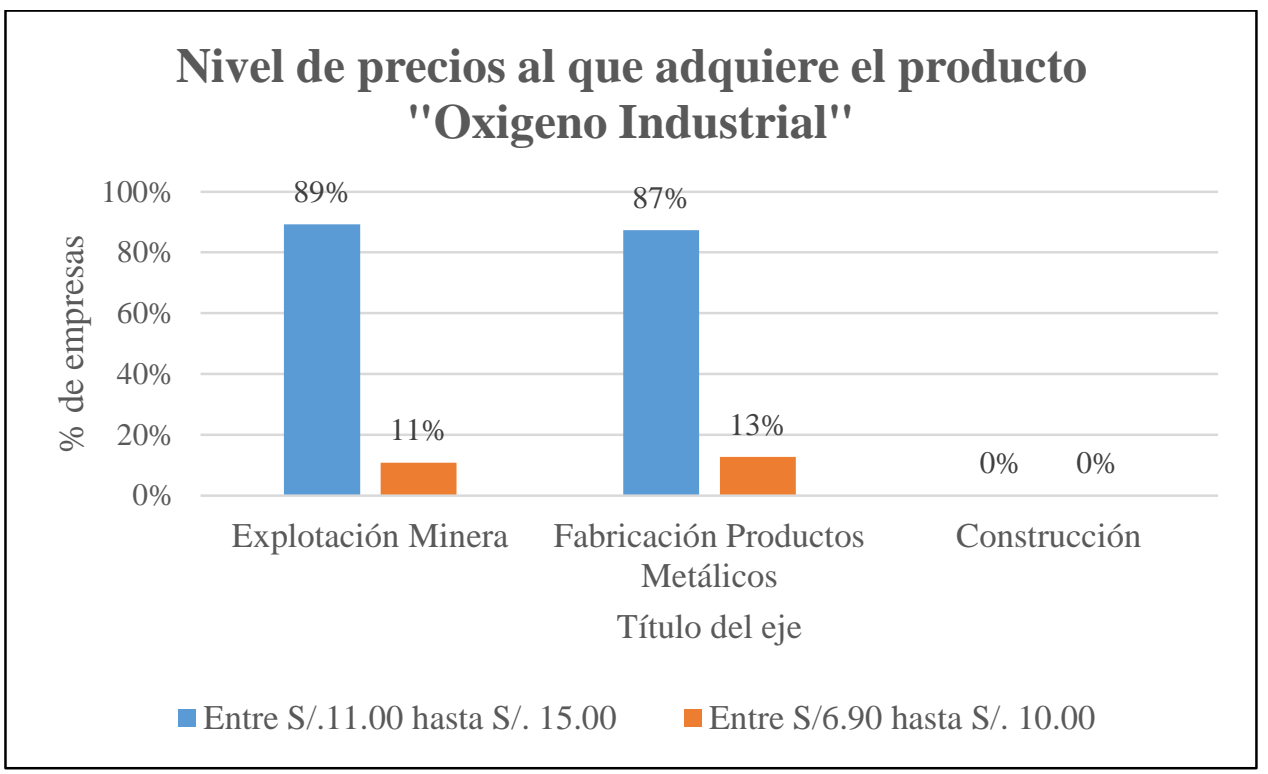

Figura 24 Nivel de precios al que las empresas adquieren el oxígeno industrial, según tipo de actividad. Elaboración propia

Interpretación:

Para reforzar lo señalado en el párrafo anterior, en la presente figura se puede observar que en promedio un $88 \%$ de las empresas adquieren el producto de oxigeno industrial a un precio mínimo de S/11.00 el m3 hasta un máximo de S/. 15.00 el m3, cifras coherentes con el tipo de sectores que se han considerado en el estudio, como lo son las empresas de explotación minera con buena capacidad de adquisición, y las empresas de producción metálica qué aunque algunas no lo deseen, dado el tipo de estructura de mercado de la industria de oxigeno industrial en la región de Puno, no tienen muchas otras opciones, además de que son los oferentes con estos niveles de precios quienes les proveen 
el oxígeno industrial bajo las características técnicas que ellos demandan, como por ejemplo el nivel de pureza del oxígeno.

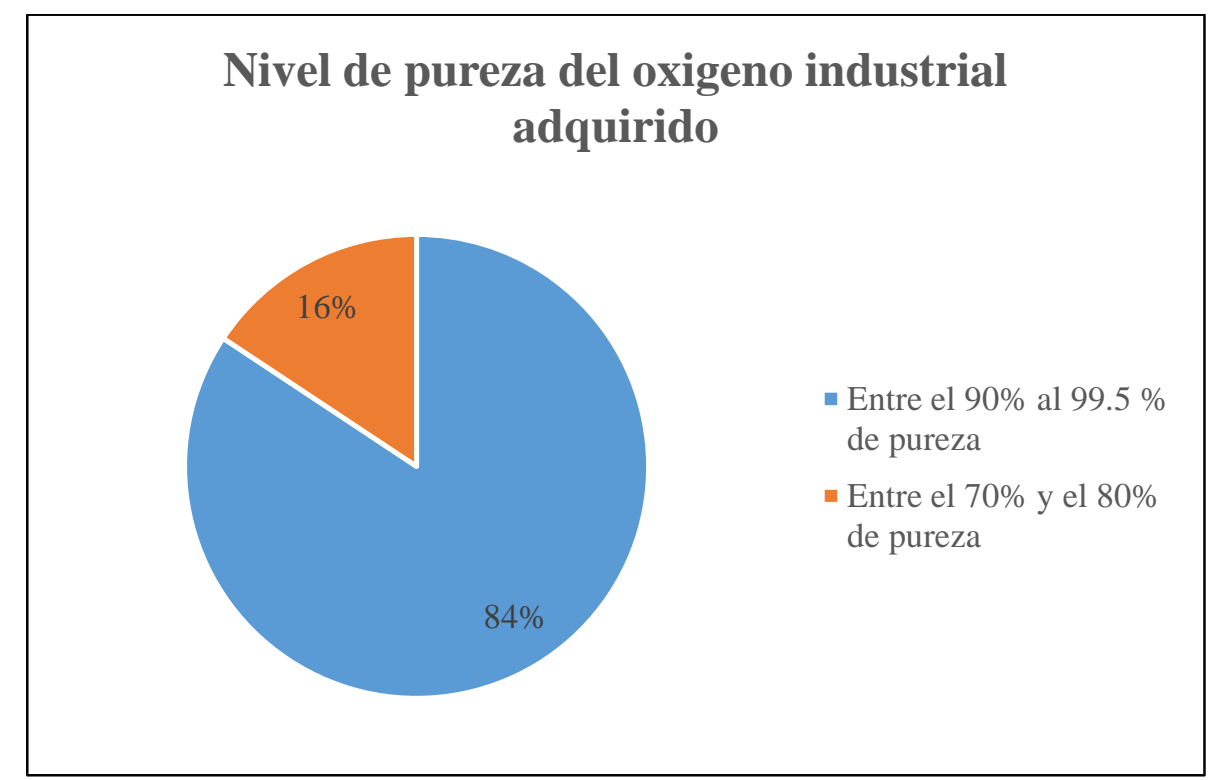

Figura 25 Nivel de pureza del oxígeno industrial requerido

Elaboración propia

Interpretación:

Se aprecia que, el nivel de pureza del producto oxigeno industrial, es requerido en un nivel de entre el $90 \%$ a $95 \%$ de pureza en un total del $84 \%$ de las empresas entrevistadas, y el restante a un nivel de pureza inferior. Cabe mencionar que ese porcentaje restante está cubierto en su mayoría por algunas pequeñas factorías de otro tipo que brindan servicios al sector metalúrgico.

Entonces, queda claro que el nivel de pureza de oxígeno que ha de proponer la empresa del presente estudio, es una que ofrezca un producto de oxigeno industrial con un nivel de entre $90 \%$ a $95 \%$ de pureza. 


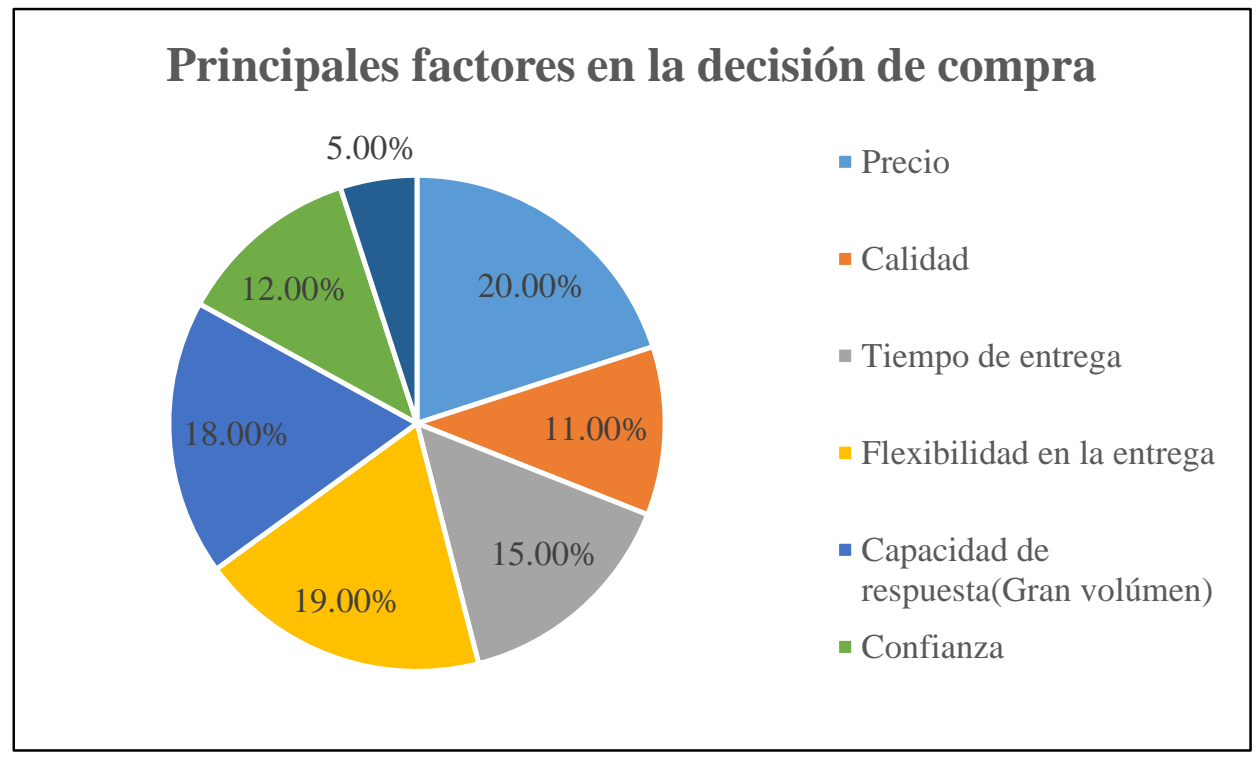

Figura 26 Principales factores de decisión de compra de oxigeno industrial. Elaboración propia

Interpretación:

Entre los principales factores en la decisión de compra, se identificó que el precio es el principal factor con una respuesta de un $20 \%$ (51 de 255 empresas), seguido por el factor de la flexibilidad de entrega con una respuesta de $19 \%$ ( 49 de 255 empresas) y en tercer lugar está la capacidad de entrega con una respuesta de $18 \%$ (45 de 358 empresas) y muy importante también el factor de la confianza con una respuesta del 12\% (30 de 255 empresas).

A partir de las cifras presentadas, se han establecido importantes propuestas de mejora sobre estos factores para la empresa del presente estudio, conformadas como estrategias de marketing. 


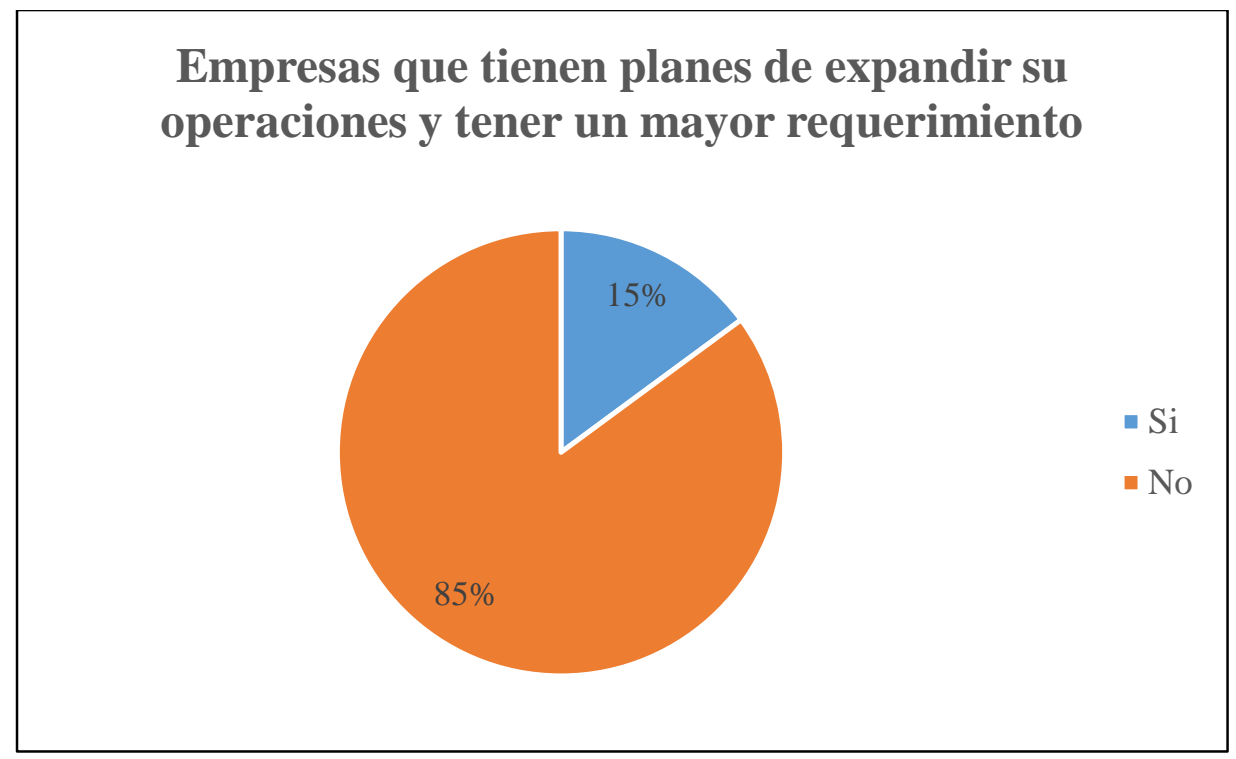

Figura 27 Empresas que consumen oxigeno industrial y que tiene planes de expansión y un requerimiento adicional del producto

Elaboración propia

Interpretación:

Se les preguntó también a las empresas si estas tenían algún plan de expansión sobre sus niveles de producción, obteniendo una respuesta de solo un 15\% (38 de 255) del total de empresas con planes de expansión de sus operaciones y por lo tanto con una necesidad de incrementar sus requerimientos de oxigeno industrial.

Esta cifra es muy importante y ha sido tomado en cuenta para la determinación de la demanda, ya que la empresa presente del estudio pretende captar dichos nuevos requerimientos como una parte de su cuota de mercado. 


\section{Empresas que planean expandir sus requerimientos de oxigeno industrial}

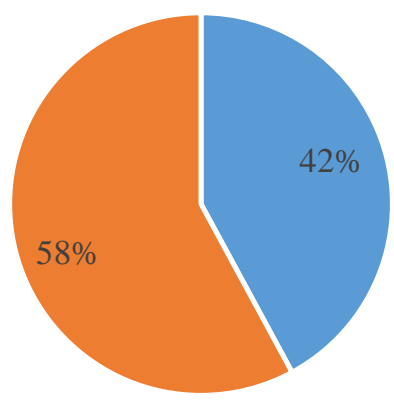

- Hasta un $20 \%$ sobre el volúmen mensual

- Más de un $20 \%$ sobre el volúmen mensual

Figura 28 Empresas que consumen oxigeno industrial y que tiene planes de expansión y un requerimiento adicional del producto de hasta un $20 \%$.

Elaboración propia

Interpretación:

Como se puede apreciar también en la presente figura, de las 38 empresas que señalaron tener planes de un incremento sobre sus operaciones y por tanto un requerimiento adicional sobre el producto de oxigeno industrial, $42 \%$ de dichas empresas mencionaron que tenían planes de incrementar su producción y tener un requerimiento adicional del oxígeno industrial hasta un $20 \%$ más de su actual volumen de requerimiento, es decir, 16 empresas de las 38 que afirmaron incrementos de hasta máximo un $20 \%$ sobre su plan de producción , mientas que el 58\% de empresas restantes, es decir; 22 de las 38, señalaron planes de incrementar sus producción y tener un requerimiento adicional de más del $20 \%$ de su actual volumen de compra.

Es importante señalar que únicamente se ha tomado la cifra correspondiente a las empresas que señalaron que tienen planeado incrementar 
su producción y tener un requerimiento adicional de a lo sumo $20 \%$ más de lo actualmente producido, ya que, considerar el porcentaje restante de empresas con planes de un requerimiento adicional de más del $20 \%$ de su actual volumen de pedido, sería incluir un factor inestable, dado la temporalidad y el tipo de industria en el que se trabaja.

\section{Frecuencia de requerimiento de compra del oxígeno industrial}

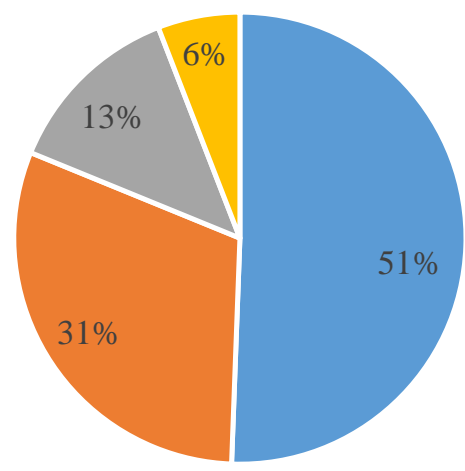

- Mensual

- Quincenal

- Semanal

- Otros

Figura 29 Con qué frecuencia su empresa requiere de oxigeno industrial Elaboración propia Interpretación:

En la figura anterior se puede apreciar que el $51 \%$ de las empresas realiza sus pedidos de manera mensual, seguido por un $31 \%$ que los hace de manera quincenal, reflejando la propiedad de estabilidad sobre la demanda del oxígeno industrial, tal y como lo comentaron algunos de los entrevistados.

En cuanto a la frecuencia con el que este tipo de empresas requiere del oxígeno industrial, por tratarse de empresas con una producción estandarizada, solicitan el oxígeno mensualmente previendo sus actividades a realizar durante 30 días. 


\section{¿Tiene frecuentemente el mismo nivel de requerimiento del producto?}

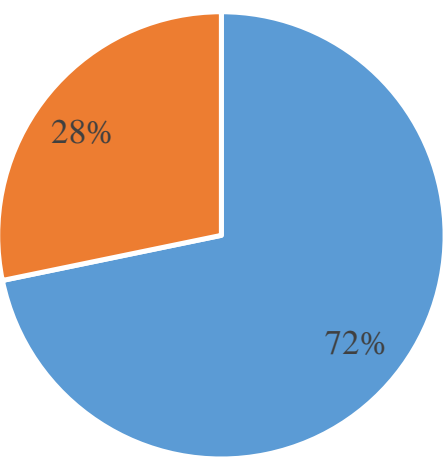

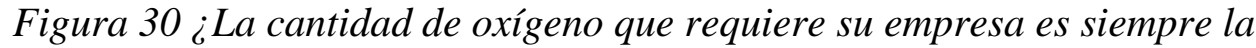
misma?

Elaboración propia

Interpretación:

En la figura anterior se puede apreciar que el $72 \%$ de las empresas ha manifestado que la cantidad de oxígeno que requieren es comúnmente la misma, siendo esta cifra muy relevante para el estudio, ya que, dota a los resultados obtenidos de una gran estabilidad para la realización de las proyecciones sobre el mercado objetivo y sobre la formulación de las estrategias a planteadas. 


\subsection{Conclusiones Y Recomendaciones Del Estudio Cualitativo y Cuantitativo}

\subsubsection{Análisis del estudio cualitativo}

- Los expertos concuerdan en señalar que el mercado bajo estudio, es un mercado competitivo con una creciente demanda, de características exponenciales, ya que el consumo está incrementándose de manera congruente con la expansión de una intensa actividad industrial y minera en la región de Puno, motivo por el cual se hace un polo atractivo para nuevas inversiones.

- Entre los principales factores de valoración por parte de los consumidores, se encuentran; la calidad, disponibilidad y adecuada distribución, la flexibilidad y el tiempo de entrega, el precio; factores que han de ser tomados en cuenta para el diseño de la investigación cuantitativa y para el conjunto de la investigación del proyecto.

- Entre los principales elementos de insatisfacción señalados se encuentran; la no adecuada distribución del producto, explicada principalmente por los limites sobre los canales de distribución, la calidad sobre el servicio de distribución, la deficiente capacidad para cumplir con los plazos y volúmenes de entrega en algunas ocasiones; elementos que de ser subsanados por la presente empresa generan oportunidades de captación de mercado, ya que, al lograr que los canales de distribución sean establecidos adecuadamente para que el producto pueda llegar sin problemas y no haya retraso al centro de operaciones de cada empresa, generaría una importante fuente de clientes.

- Una de las principales fortalezas de las empresas oferentes en el mercado de estudio, señalan, es sin duda alguna el tiempo de experiencia en el mercado que le permite poder contar con una importante cartera de clientes, ya que, los 
consumidores valoran mucho que el oferente cuente con varios de experiencia fabricando y distribuyendo el oxígeno industrial, elemento que les permite dotar de un vínculo de confianza.

- Dentro de la fortalezas con las que debe contar una empresa de oxigeno industrial según la opinión de los propios clientes se encuentran también; la versatilidad, diversificación del producto y la experiencia.

- Las debilidades detectadas por los consumidores fueron la calidad del producto y deficiencias en los canales de distribución, estos puntos deben de tenerse en cuenta para convertirlos en ventajas para nuevos oferentes.

- Se señala que actualmente existe una demanda emergente conformada en parte por la pequeña y mediana empresa en los sectores metal mecánico y minero, así como una reciente expansión a nuevos sectores, sin embargo se cuenta con bajo nivel de conocimiento respecto a esta demanda emergente.

\subsubsection{Conclusiones del estudio cualitativo}

- Se ha reflejado de forma eminente una gran probabilidad de encontrar una demanda que se pueda ser captada por nuevo oferente, premiso que ha de ser refutada a partir del estudio cuantitativo.

- Existen elementos de insatisfacción que deben de analizarse a mayor profundidad en el estudio cuantitativo a fin de dar solidez a la existencia de un importante mercado insatisfecho al que pueden basarse las estrategias de captación de clientes, elementos tales como; la calidad, disponibilidad y adecuada distribución, la flexibilidad y el tiempo de entrega, el precio. 
- Uno de los elementos críticos que ha de buscarse construir es la confianza que estreche vínculos consumidor-oferente, por lo que; es importante que las empresas productoras y distribuidoras de oxígeno industrial en el departamento de Puno se adapten a las necesidades de los clientes, tanto en el servicio y producto que ofrecen.

- A pesar de mencionarse la existencia de nuevos mercados emergentes conformados por las micro y pequeñas empresas, se debe analizar lo oportuno de destinar esfuerzos e inversiones en el estudio de estas unidades productivas frente el estudio de empresas de consumos más sólidos sobre el producto.

- Uno de los principales elementos a tener en cuenta para cualquier nuevo oferente debe ser implementar y mejorar constantemente los canales de distribución hará que el producto y servicio cumpla con las expectativas del cliente.

\subsubsection{Conclusiones del estudio cuantitativo}

Luego del análisis de las encuestas y de su exposición de manera numérica se concluyó lo siguiente:

o Gran parte de las empresas consumidoras de oxígeno ubican sus oficinas principales, encargadas de coordinar sus suministros, en la ciudad de Juliaca, lugar donde se ubicará la planta de producción de la empresa propuesta.

o Las empresas que tienen mayor participación en el consumo agregado del oxígeno industrial en la región de Puno, son en primer lugar, aquellas dedicadas a la fabricación de productos metálicos, seguidos por las empresas de explotación minera, con una participación de alrededor del $72 \%$ y $28 \%$ correspondientemente sobre el consumo promedio de oxigeno industrial, cifras coherentes con la 
referencia de las cifras de $60 \%$ y $25 \%$ del consumo proveniente de dichas empresas sobre el total de la demanda.

o La forma de mercado existente para la industria del oxígeno industrial, es una de tipo oligopólica, donde la empresa dominante es CIGA S.A. con una cuota sobre la oferta del 56\%, seguido por OXITEX, OXITEX GASES ANDINO, y a pesar de tal estructura sobre la oferta del mercado del oxígeno industrial, con pocos oferentes, no existe un rotundo poder sobre la determinación de los precios, aunque sin duda alguna es CIGA SA., quien establece el umbral de precios a tener como benchmarking.

o No más del $30 \%$ de empresas mencionaron que no tienen cubiertos de manera completa sus requerimientos de compra usualmente, así mismo, en un promedio cerca del $69 \%$ de las empresas no se encuentran satisfechos con sus actuales proveedores y les gustaría que el servicio mejore.

o Más del $50 \%$ de las empresas encuestadas se encuentran dispuestas a adquirir el producto oxigeno industrial a un nuevo proveedor en el mercado, una cifra explicada por el hecho principal del gran descontento que existe en los consumidores ante la falta de capacidad de los oferentes de cubrir completamente los requerimientos de compra, además de la burocracia y ciertas gestiones administrativas que entorpecen y demoran el proceso de adquisición de oxigeno industrial por parte de las empresas.

o Entre las características básicas del producto de oxigeno industrial, se encuentra que este debe tener un nivel de pureza de entre $90 \%$ a $95 \%$ y debe oscilar en un precio de entre S/. 11.00 a S/. 15.00., siendo un total de $88 \%$ de las empresas entrevistadas quienes acceden actualmente a este nivel de precios y en estas 
condiciones. Así mismo la frecuencia de requerimiento es usualmente de manera mensual y en segundo lugar quincenal, por otro lado el $71 \%$ de las mismas empresas encuestadas mencionan tener un nivel de requerimiento estable de forma periódica.

o La mayoría de consumidores de oxígeno industrial ubicados en la región de Puno, consideran como los principales factores de decisión de compra; el precio, la flexibilidad sobre la entrega, la capacidad de respuesta y finalmente la confianza, con porcentajes de preferencia de $20 \%, 19 \%, 18 \%$ y $12 \%$ respectivamente

o Existe un $15 \%$ de empresas que señalan que tienen planes de incrementar sus operaciones y requerir un adicional sobre sus volúmenes de pedido de oxigeno industrial de hasta un $20 \%$ sobre lo usual.

o El mercado de oxígeno industrial del departamento de Puno solo cuenta con una planta productora de oxígeno y dos distribuidoras, las cuales no son suficientes para atender toda la demanda emergente asegurando la calidad del producto.

o La empresa CIGA es el principal competidor directo por contar con muchas características similares a la empresa que se propone, entre ellas el poseer una planta propia; actualmente CIGA abarca la mitad del mercado de oxígeno industrial.

\subsubsection{Convergencia del estudio cualitativo y cuantitativo}

Como se puede deducir a partir de las conclusiones del estudio cualitativo y cuantitativo, se encuentran elementos de convergencia, entre los principales se encuentra; la existencia de un segmento de mercado con un nivel importante de insatisfacción que de cumplir con sus expectativas se puede lograr captar como 
importante fuente de demanda, y como elementos de decisión de compra se tiene; la flexibilidad sobre la entrega, la capacidad de respuesta, y la confianza, elementos críticos que se tomaron en cuenta en la formulación de estrategias de marketing para la consecución de la demanda.

Se ha encontrado también convergencia sobre la opinión de los expertos respecto el precio del bien "oxigeno industrial" como precios de rango superior, además de una muestra pequeña pero significativa de expectativas de crecimiento sobre la producción y por ende demanda del oxígeno industrial.

\subsubsection{Recomendaciones del estudio cualitativo cuantitativo}

- Se recomienda que el segmento de mercado de la presente propuesta de proyecto se dirija sobre el segmento de mercado insatisfecho que ha sido identificado, dado la relevancia y significancia del nivel de insatisfacción encontrado sobre los actuales consumidores de oxigeno industrial.

- La empresa debe de tomar en consideración las principales deficiencias identificadas sobre los factores críticos de compra de los consumidores de forma tal que se sea necesario que toda la empresa brinde calidad en todos los aspectos, tanto en el servicio, trato al cliente y el producto que ofrece, así lograra posicionarse en el mercado frente a otras empresas que no cumplen con los estándares esperados.

- Se debe de considerar un precio de introducción basado en el rango inferior de precios del mayor grueso de demanda actual sobre el consumo de oxigeno industrial, así para ingresar a un nuevo mercado es necesario que los precios sean accesibles y puedan competir con los de la competencia, sin que esto represente disminuir la calidad del producto, ni afectar la rentabilidad de la empresa. 
- Toda empresa que desee incursionar en un nuevo mercado debe hacer un estudio previo, así conocer las necesidades de los clientes y las fortalezas y debilidades de la competencia, con ello buscar diferenciarse y empezar a posicionarse en el mercado.

- Se recomienda que los nuevos oferentes del mercado industrial rubro de gases industriales deben contar con la capacidad necesaria para cubrir grandes volúmenes de compra dentro de los plazos establecidos, a fin de lograr cumplir las altas exigencias de los actuales consumidores y lograr lazos de confianza que permitan estrechar relaciones de largo plazo.

- Es importante que las empresas productoras y distribuidoras de oxígeno industrial en el departamento de Puno se adapten a las necesidades de los clientes, tanto en el servicio y producto que ofrecen.

- Implementar y mejorar constantemente los canales de distribución hará que el producto y servicio cumpla con las expectativas del cliente.

\subsection{Perfil Del Consumidor Tipo y Sus Variantes}

Basados en el análisis cuantitativo y cualitativo se puede señalar que el perfil del consumidor de oxígeno industrial en el departamento de Puno es:

- Consumidor que busca las condiciones óptimas sobre la entrega del producto y precios accesibles.

- El consumidor busca una empresa que ofrezca un servicio integrador sobre el producto, es decir, que antes, durante y después del servicio cumpla con sus expectativas durante todo el proceso. 
- Consumidor que es estricto con los plazos de entrega y a las facilidades sobre la entrega del producto.

- Consumidor critico en su decisión de compra, es decir, por buscar la flexibilidad y a la vez la confianza en el producto y servicio, este tipo de consumidor puede dejar de comprar a su distribuidor que no cumple con ese perfil y escoger a otro que si le garantiza un buen servicio. 


\section{Capítulo IV Proyección del Mercado}

\section{Objetivo}

\subsection{El ámbito de la proyección}

Para la determinación de la proyección del mercado, se ha de seguir primero un proceso ordenado que permita la identificación del mercado potencial, disponible, efectivo, y finalmente del mercado objetivo, sobre el cual se aplicarán una serie de técnicas de proyección a fin de estimar valores futuros con base a criterios lógicos y técnicos.

\subsection{Selección del método de proyección}

Malhotra (2008) señala que "La proyección es un estudio que estima cómo será el crecimiento de la economía en diferentes escenarios futuros" (p. 25)

Para conseguir la proyección del mercado se pueden emplear dos métodos para alcanzar la proyección:

- Métodos cuantitativos de proyección.

- Métodos cualitativos de proyección.

\section{Métodos cuantitativos de proyección.}

Comprenden modelos matemáticos que tienen como base datos históricos importantes como por ejemplo: promedio móvil, promedio móvil simple, promedio móvil ponderado, serie de tiempo, etc.

\section{Métodos cualitativos de proyección}

Estos modelos se diferencian de los cuantitativos por que no haces uso de los datos históricos ni formulas, ellos se basan en entrevistas realizadas a expertos del tema a discusión. 
Por las características del presente proyecto se decidió establecer la proyección del mercado objetivo que ha sido determinado en forma consecuente luego de encontrar cada uno de los segmentos de mercado precedentes, por medio de una proyección basada en tasas de crecimiento histórico sobre la demanda y tasa de crecimiento definidas a partir de la entrevista a expertos en el rubro de oxígeno industrial, calculando la demanda basados en la experiencia y en las cifras de relevancia encontrados en la encuesta aplicada al universo de clientes.

\subsubsection{Mercado Potencial}

Rodríguez (2013) señala que "El mercado potencial está compuesto por todas aquellas personas e instituciones que tienen o pueden llegar a tener la necesidad que satisface el producto en cuestión. Es posible que parte de este mercado satisfaga su necesidad, comprando a la competencia, pero eso no quiere decir que en algún momento llegue a cambiar y comprar otra marca” (p. 43)

Por otra parte, el mercado potencial se encuentra también definido como; el conjunto de consumidores al que se puede llegar a vender el producto o servicio en cuestión, dado que, estos necesitan o podrían llegar a necesitar el producto o servicio, es decir; por aquellas personas o unidades empresariales que consumen y también por los que no consumen el producto o servicio que se pretende ofrecer, y que por su propia naturaleza de operación los lleva a exigir el consumo de dicho bien o servicio, o de ser el caso de no consumirlo actualmente, llegarían a exigir su consumo en coherencia con su propia naturaleza de operación.

Esta definición guarda coherencia con la propuesta por Rivera (2007, p.79), Escribano y otros (2006) y López y otros (2010) quienes convergen en definir al mercado potencial como "el número máximo de compradores al cual se 
puede dirigir la oferta comercial de la empresa", siendo este número máximo dado por el total de empresas que por su propia naturaleza de operación necesitan o exigirían en algún momento determinado el producto en cuestión.

Así, para la determinación del mercado potencial, se ha tomado en cuenta el universo total de empresas que por su naturaleza de su actividad requieren la utilización del producto de oxigeno industrial. Se tiene entonces los siguientes resultados.

Tabla 19 Mercado Potencial

\begin{tabular}{lcc}
\hline \multicolumn{3}{c}{ Determinación del Mercado Potencial } \\
\hline $\begin{array}{l}\text { Empresa por tipo de actividad } \\
\text { económica }\end{array}$ & $\begin{array}{c}\mathrm{N}^{\circ} \text { Empresas en } \\
\text { la Región }\end{array}$ & $\begin{array}{l}\text { Mercado } \\
\text { Potencial }\end{array}$ \\
\hline $\begin{array}{l}\text { Explotación Minera } \\
\text { Fabricación Productos Metálicos }\end{array}$ & 192 & 192 \\
Total & 562 & 562 \\
\hline
\end{tabular}

Como se aprecia en la Tabla $\mathrm{N}^{\circ}$ 21, la cantidad de empresas que conforman el mercado potencial, según su actividad económica, es el universo de las empresas que han sido tomadas en consideración para el presente estudio, ya que, por su propia naturaleza utilizan el oxígeno industrializado como parte de sus procesos de producción.

Se tiene así, un mercado potencial conformado por un grupo de 754 empresas, siendo las de mayor participación las empresas de fabricación de productos metálicos.

Una aclaración importante que ya fue explicada en el apartado del proceso de muestreo, es la de mencionar que los resultados obtenidos en el análisis cuantitativo, se basaron en un muestreo por conveniencia, aun cuando el tamaño 
muestral fue determinado de manera probabilística, al momento de la selección de los elementos muéstrales se llevó a cabo bajo criterios de preferencia de las empresas seleccionadas para el estudio de mercado, dada las limitaciones de poder contar con el padrón completo y actualizado respecto del total de empresas que conforman de manera real cada uno de los estratos del universo de estudio.

Así se ha tomado en consideración una de las principales premisas de mercado obtenidas a partir del análisis cualitativo, la cual señala la distinción de dos segmentos de mercado con características peculiares; el sector de producción metálica y el sector minero, en donde los consumidores relevantes son aquellos quienes tienen niveles de consumo significativo, consumidores sobre los cuales se debe de realizar el estudio cuantitativo a fin de obtener información precisa de un segmento de mercado más establece que guarde relación con la recomendación de los expertos de adoptar una postura moderada de riesgo y por consecuente centrarse en aquellos consumidores con consumos significativos y estables de oxigeno industrial.

\subsubsection{Mercado Disponible}

Rodríguez (2013) dice que "Conjunto de consumidores que tienen el deseo, renta y el acceso (que no exista alguna restricción legal o alguna restricción física, etc.) a una determinada oferta de mercado y el mercado cualificado disponible es una vez tenida en cuenta las restricciones de acceso". (p. 44)

Así mismo, el mercado disponible se encuentra definido por varios autores como, una parte del mercado potencial que se encuentra representado por el conjunto de consumidores que tienen la necesidad especifica de adquirir el producto o servicio que ofrece el nuevo oferente. Esto no quiere decir que todas 
estas personas o empresas comprarán el producto o adquirirán el servicio a este nuevo oferente, ya que, de este total, una parte podría seguir adquiriendo el bien a sus actuales proveedores o por el contrario podría brindar la posibilidad de acceder a nuevos oferentes, sin embargo, el rasgo característico de este mercado disponible es el hecho de que los consumidores si adquieren el producto al momento de hoy, pasando de ser consumidores potenciales a consumidores reales, denominados disponibles por el hecho de que se encuentran en disponibilidad de optar por nuevos oferentes para cubrir sus actual consumo del bien.

Para el cálculo del mercado disponible para el oxígeno industrial, se ha tomado como base el número de empresas que conforman el mercado potencial y se considera ahora el criterio sobre el porcentaje de respuesta afirmativa de consumo, obtenida de las empresas que han sido entrevistadas a partir de la muestra.

En coherencia con la segunda definición presentada sobre la concepción del mercado disponible, que señala que este está integrado por consumidores que al momento de hoy consumen el bien, el presente estudio adoptó la tasa de respuesta afirmativa de consumo de oxigeno industrial, es decir, el porcentaje de empresas del total del mercado potencial, que ya no únicamente consumen oxigeno industrial por su propia naturaleza de operación, sino que además tienen un nivel consumo significativo sobre el bien, lo cual define a este como un consumo más estable y significativo, que pone a dichas empresas con una mayor disponibilidad sobre la decisión de adquirir el bien a nuevos oferentes, y por tanto integran el mercado disponible sobre el bien en cuestión. 
Para la obtención de la tasa de respuesta afirmativa de consumo, y en coherencia con las recomendaciones de los expertos, en el momento inicial de la selección de las empresas que integraron el conjunto de empresas entrevistadas, estas fueron seleccionadas por conveniencia en función al criterio del nivel de consumo significativo del oxígeno industrial.

Luego de seguir un procedimiento riguroso, basado en una primera prueba piloto y la aplicación estratégica sobre las entrevistas al momento de un primer acercamiento a este conjunto de empresas, se logró identificar únicamente a aquellas empresas con consumos significativos de oxigeno industrial, dejando de lado aquellas con niveles poco significativos, y de esta manera la tasa de respuesta afirmativa hace referencia a la proporción de empresas del total entrevistadas, que si señalaron un consumo significativo del oxígeno industrial en comparación a aquellas que señalaron bajos niveles de consumo del bien en cuestión.

Así, para la presente investigación en particular, y en similitud con la definición teórica de un mercado disponible conformado por el conjunto de personas que si adquieren el producto al momento de hoy frente a quienes no lo hacen, se tiene al grupo de empresas que al momento de hoy si presentan un consumo de oxigeno industrial significativo y mucho más estable, frente a las empresas con niveles poco significativos, guardando la congruencia con la postura de riesgo medio sugerida por los expertos al señalar que se debe de enfocar sobre el segmento de mercado con un consumo de oxigeno significativo y estable, para luego capturar a quienes presentan condiciones de insatisfacción y sobre los cuales se identifica el mercado efectivo.

Se tiene entonces, los siguientes resultados: 
Tabla 20 Mercado Disponible

\begin{tabular}{lccc}
\hline \multicolumn{3}{c}{ Determinación del Mercado Disponible } \\
\hline $\begin{array}{l}\text { Empresa por tipo de actividad } \\
\text { económica }\end{array}$ & $\begin{array}{c}\text { Mercado de Respuesta } \\
\text { Potencial } \\
\text { afirmativa de } \\
\text { consumo de oxígeno } \\
\text { industrial }\end{array}$ & $\begin{array}{c}\text { Mercado } \\
\text { disponible }\end{array}$ \\
\hline Explotación Minera & 192 & $79 \%$ & 152 \\
Fabricación Productos Metálicos & 562 & $83 \%$ & 464 \\
Total & 754 & - & 616 \\
\hline
\end{tabular}

Es importante mencionar que, al tener los porcentajes de manera desagregada de la respuesta afirmativa sobre el consumo de oxigeno industrial, para efectos del cálculo del mercado disponible no se ha considerado la tasa promedio del total, sino por el contrario se ha trabajado con los porcentajes que se obtuvo para cada tipo de empresa, a fin de continuar dotándole de mayor relevancia al conjunto de empresas que efectivamente tienen una mayor representatividad y participación del consumo de oxigeno industrial sobre la demanda.

Se tiene así entonces un universo del mercado disponible de 616 empresas.

\subsubsection{Mercado Efectivo}

"Es una parte del mercado disponible y está formado por el conjunto de consumidores que tienen además de la necesidad, la intensión de comprar el bien o servicio que ofrece el proyecto. Este también es definido a través del resultado de la encuesta" (Rodríguez, 2013, p 52) 
Para muchos autores modernos en la teoría de la investigación de mercado, se presenta una convergencia en señalar una definición del mercado efectivo como, una parte del mercado disponible que se encuentra formado por el conjunto de consumidores que además de la necesidad específica, tienen la intención de comprar el bien o servicio que ofrece el nuevo negocio.

En coherencia con la segunda definición del mercado efectivo y para efectos de la determinación del mercado efectivo, se toma como base el universo de empresas que conforman el mercado disponible, así también los criterios como, el porcentaje de empresas que se encuentran insatisfechas con el servicio brindado por su actual proveedor, el porcentaje de empresas que están dispuesto a destinar sus requerimientos de compra a un nuevo proveedor, y que aquellas que adquieren el producto al nivel de precios de mayor homogeneidad en el mercado.

El sentido tras la identificación del mercado efectivo, es encontrar aquellos consumidores del mercado disponible, que adquieren el bien al día de hoy y que presentan una disposición real - lógica de adquirir el bien a un nuevo oferente.

Para el presente estudio en particular, se ha definido la disposición de adquisición del bien a un nuevo oferente, a partir del criterio lógico de que aquellos consumidores que se encuentren insatisfechos con los actuales oferentes tienen una mayor disposición a adquirir el bien a nuevos oferentes que subsanen dicha insatisfacción, así mismo para reforzar esta disposición por un nuevo oferente, se adopta también el criterio de identificar aquellos consumidores que no solo expresan su insatisfacción y la posibilidad de acceder a nuevos 
proveedores, sino específicamente a aquella proporción de empresas que están insatisfechas y señalan tácitamente su clara disposición por aceptar un nuevo oferente que cumpla sus expectativas. Finalmente, como otro elemento de filtro, se ha tomado el criterio de precios, es decir, las empresas que conforman el mercado efectivo, son aquellas que se encuentran insatisfechas y expresan tácitamente su descontento y su disposición puntual a dar cabida a un nuevo oferente, y oferente que tenga precios competitivos, es decir, precios similares a los oferentes actuales, con la diferencia de que bajo el mismo rango de precios, se ofrezca un bien mejorado a fin de cumplir con las expectativas de los consumidores.

Se tiene así los siguientes resultados: 
Tabla 21 Determinacion del Mercado Dsiponible

Determinación del Mercado Disponible

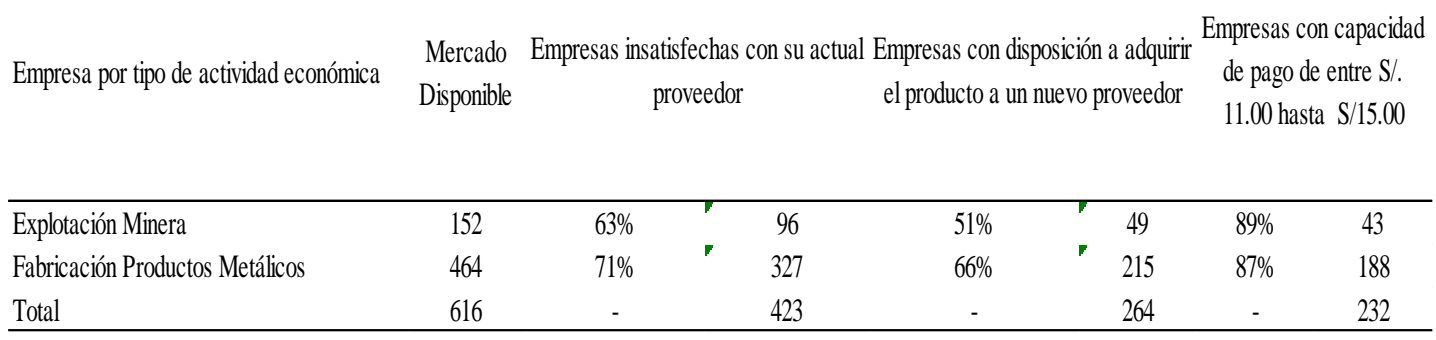

Nota. Elaboración propia

Es importante notar nuevamente que se ha trabajado con los respectivos porcentajes para cada estrato, dada la relevancia importante de la cuota de consumo que tiene cada tipo de empresas sobre la demanda.

Así, se tiene entonces un mercado efectivo final conformado por un universo de 232 empresas.

Puede parecer un número pequeño, sin embargo debe resaltarse la coherencia con la realidad, y en similitud con la empresa dominante del mercado como lo es CIGA SA., quien actualmente abastece a un promedio de 348 empresas, es claro con una mayor participación de las empresas de productos metálicos, por lo que, al ser una empresa dominante y con amplia experiencia en el mercado, es esta el mejor benchmarking que se tiene y seguirla es una estrategia interesante. 


\subsubsection{Mercado Objetivo}

Luego de hallar el mercado efectivo, se necesita conocer el mercado objetivo cuyo resultado nos dice cuanto mercado se capta aproximadamente cada año.

Refiere Stanton (2005, p.674) que un mercado objetivo es el grupo de personas y organizaciones al que la empresa dirige su programa de productos, es decir, el segmento del mercado efectivo que se encuentra integrado por el grupo de consumidores a los cuales la empresa quiere llegar.

El mercado efectivo conforma a la vez el mercado objetivo de manera agregada, entendiendo que el mercado objetivo es la proporción del mercado efectivo que ha de atenderse para cada año según la meta establecida.

Se tiene entonces los siguientes resultados:

Tabla 22 Determinación del Mercado Objetivo

\begin{tabular}{cccc}
\hline \multicolumn{3}{c}{ Determinación del Mercado Objetivo } \\
Año & $\begin{array}{c}\text { Mercado Efectivo } \\
\text { Final }\end{array}$ & \%Participación & Mercado Objetivo \\
& 232 & $25 \%$ & 58 \\
Año 1 & 232 & $35 \%$ & 81 \\
Año 2 & 232 & $50 \%$ & 116 \\
Año 3 & 232 & $50 \%$ & 116 \\
Año 4 & 232 & $50 \%$ & 116 \\
Año 5 & 232 & $65 \%$ & 151 \\
Año 6 & 232 & $75 \%$ & 174 \\
Año 7 & 232 & $75 \%$ & 174 \\
Año 8 & & & \\
& 232 & $85 \%$ & 197 \\
Año 9 & & & \\
Año 10 & 232 & $90 \%$ & 209 \\
\hline
\end{tabular}

Nota. Elaboración propia 
Como toda empresa, una que recién ingrese en el mercado, tiene un ciclo de adaptación, y mucho más en una industria relacionada al producto de oxigeno industrial, por lo que, no puede pretenderse captar a todos los clientes en un solo año, así que se establecieron cuotas de captación o participación sobre el mercado efectivo, de manera anual.

Cabe resaltar que los porcentajes de participación propuestos, fueron recomendación de una consulta amigable y técnica, por parte de uno de los miembros con mayor experiencia en la empresa dominante CIGA S.A., quién conoce el funcionamiento de esta empresa desde sus orígenes y tiene el entendimiento suficiente sobre el funcionamiento real de la industria, también, mencionando que estos porcentajes fueron la experiencia del ciclo de adaptación de dicha empresa.

Se tiene así entonces que de un conjunto de 232 empresas, se buscará atender a un grupo de 58 empresas el primer año de operación, 81 como meta para el segundo año, y así sucesivamente como puede apreciarse en la tabla anterior sobre el mercado objetivo.

Ahora corresponde pasar a la determinación de la demanda en las unidades de consumo, es decir, en m3 de oxígeno que el mercado demande, por lo que se obtuvo los siguientes resultados a partir de los criterios que han sido explicados en párrafos siguientes.

Se tiene primero, el consumo promedio agregado de oxigeno industrial en m3, por tipo de empresas en la región de Puno, tal y como sigue: 
Tabla 23 Consumo Promedio Mensual de Oxigeno Industrial

\section{Consumo Promedio Mensual de Oxígeno Industrial}

\begin{tabular}{lcc}
\hline Tipo de Empresa & $\mathrm{m} 3$ & Participación \\
\hline Explotación Minera & 1400 & $28 \%$ \\
Fabricación Productos & 3570 & $72 \%$ \\
Metálicos $\quad$ Total & 4970 & $100 \%$ \\
\hline
\end{tabular}

Nota. Elaboración propia

Estas cifras han sido establecidas a partir de información que se ha podido obtener de la encuesta llevada a cabo y en correspondencia con la información histórica de carácter secundario, así como de las consultas amigables realizadas al miembro ya mencionado de la empresa dominante.

Puede notarse que en coherencia con lo mencionado en los resultados del estudio de mercado, son las empresas dedicas a la fabricación de productos metálicos quienes consumen un mayor volumen del oxígeno industrial ofertado en la región de Puno.

A partir de dichas cifras y del porcentaje de empresa que de acuerdo al estudio de mercado, tienen planes de incrementar sus producción y tener requerimientos den no más del $20 \%$ del volumen usual, es que se lograr establecer los resultados de la demanda, tal y como se aprecia en la siguiente tabla. 
Tabla 24 Determinación de la Demanda

\begin{tabular}{lcccc}
\hline \multicolumn{5}{c}{ Determinación de la demanda } \\
$\begin{array}{l}\text { Empresa por tipo de actividad } \\
\text { económica }\end{array}$ & $\begin{array}{c}\text { Consumo promedio } \\
\text { menmsual agregado } \\
\text { (unidades de m3) }\end{array}$ & $\begin{array}{c}\text { Consumo Anual } \\
\text { agregado } \\
\text { (unidades de m3) }\end{array}$ & $\begin{array}{c}\text { Posibilidad de hasta un } \\
\text { 20\% de incremento del } \\
\text { volúmen mensual } \\
\text { requeido }\end{array}$ & $\begin{array}{c}\text { Demanda Anual } \\
\text { Base } \\
\text { (unidad en m3) }\end{array}$ \\
\hline Explotación Minera & 1400 & 16800 & $8 \%$ & 18092 \\
Fabricación Productos Metálicos & 3570 & 42840 & $6 \%$ & 45320 \\
Total & 4970 & 59640 & - & 63413 \\
\hline
\end{tabular}

Nota. Elaboración propia

Se concluye entonces como demanda base para la realización de la proyección a los 10 años, un volumen total de 63413 m3 de oxigeno industrial.

Se muestra a continuación los resultados de la proyección de la demanda.

Tabla 25 Demanda Proyectada

\begin{tabular}{ccc}
\hline \multicolumn{3}{c}{ Demanda Proyectada } \\
\hline Año & $\begin{array}{c}\text { Tasa de Crecimiento } \\
\text { Esperada }\end{array}$ & $\begin{array}{c}\text { Demanda } \\
\text { Esperada ( m3) }\end{array}$ \\
\hline Año 1 & - & 63413 \\
Año 2 & $5.98 \%$ & 67205 \\
Año 3 & $5.98 \%$ & 71223 \\
Año 4 & $6.33 \%$ & 75735 \\
Año 5 & $6.33 \%$ & 80532 \\
Año 6 & $7.00 \%$ & 86169 \\
Año 7 & $6.44 \%$ & 91716 \\
Año 8 & $6.44 \%$ & 97621 \\
Año 9 & $9.92 \%$ & 107306 \\
Año 10 & $9.92 \%$ & 117951 \\
\hline
\end{tabular}

Nota. Elaboración propia

Las tasas de crecimiento esperada, han sido determinadas tomando en consideración la tasa de crecimiento encontrada en datos históricos de la industria de oxigeno industrial, presentado en dos trabajos de investigación de similar índole para la región de Puno, también se toma en cuenta la tasa de crecimiento 
sugerida por expertos en la industria en particular, así como las tasa de crecimiento del producto bruto del sector minero y construcción.

Tabla 26 Tasas de Crecimiento Referenciales

\begin{tabular}{lcc}
\hline \multicolumn{2}{c}{ Tasa de crecimeinto referenciales } \\
\hline Tasas de Crecimiento & Min & Max \\
\hline $\begin{array}{l}\text { Por similitud Histórica del tipo } \\
\text { de producto en la región }\end{array}$ & $\mathbf{5 . 9 8 \%}$ & $\mathbf{7 . 6 2 \%}$ \\
$\begin{array}{l}\text { Tasa del sector industrial } \\
\text { sugerida por expertos }\end{array}$ & $\mathbf{7 . 0 0 \%}$ & $\mathbf{1 5 . 0 0 \%}$ \\
$\begin{array}{l}\text { Tasa de Crecimiento Historica } \\
\text { interanual del Sector Minero }\end{array}$ & $4.90 \%$ & \\
Tasa de crecimiento Promedio & $\mathbf{5 . 9 6 \%}$ & $\mathbf{9 . 7 7 \%}$ \\
\hline
\end{tabular}

Nota. Elaboración propia

Cada una de estas tasas de referencia tiene un mínimo y un máximo, adoptándose los rangos mínimos de cada una para ser menos volubles a este criterio. Se tienen así finalmente, la siguiente tabla:

Tabla 27 Demanda Proyectada y Plan de Producción

\begin{tabular}{ccccc}
\hline \multicolumn{5}{c}{ Demanda Proyectada y Plan de Producción } \\
\hline Año & $\begin{array}{c}\text { Tasa de } \\
\text { Crecimiento } \\
\text { Esperada }\end{array}$ & $\begin{array}{c}\text { Demanda Esperada } \\
(10 \mathrm{~m} 3)\end{array}$ & $\begin{array}{c}\text { Plan de } \\
\text { Producción } \\
(10 \mathrm{~m} 3)\end{array}$ & $\begin{array}{c}\text { Uso de la } \\
\text { capacidad } \\
\text { Instalada }\end{array}$ \\
\hline 1 & - & 6341.30 & 5678.84 & $59.41 \%$ \\
2 & $5.98 \%$ & 6720.51 & 6110.23 & $63.93 \%$ \\
3 & $5.98 \%$ & 7122.40 & 6541.21 & $68.44 \%$ \\
4 & $5.98 \%$ & 7548.32 & 6972.19 & $72.95 \%$ \\
5 & $7.00 \%$ & 8076.70 & 7403.17 & $77.46 \%$ \\
6 & $7.00 \%$ & 8642.07 & 7834.15 & $81.96 \%$ \\
7 & $5.96 \%$ & 9157.13 & 8265.13 & $86.47 \%$ \\
8 & $5.96 \%$ & 9702.90 & 8696.11 & $90.98 \%$ \\
9 & $9.77 \%$ & 10651.20 & 9127.09 & $95.49 \%$ \\
10 & $9.77 \%$ & 11692.17 & 9558.07 & $100.00 \%$ \\
\hline
\end{tabular}

Nota. Elaboración propia

Se observa en la tabla anterior, no solo la demanda esperada, sino el plan de producción establecido por la empresa que propone la presente investigación, 
y se destaca el uso de la capacidad instalada en planta sobre la demanda de mercado insatisfecho o esperado atendida por la empresa, iniciando con un uso de $60 \%$ sobre la capacidad de planta el primer año, así hasta llegar al $100 \%$ a lo largo del horizonte temporal.

Se tiene que mencionar que no se ha adoptado la propuesta de un $100 \%$ de cuota sobre la demanda esperada, debido a que se adopta una postura moderada sobre la demanda y al mismo tiempo en base al plan de uso de capacidad instalada que se adopta, por recomendación de los expertos en este tipo de industria. Recordemos que para la estimación de la demanda base, se tomó en cuenta el que las empresas tenían en mente hasta un incremento de $20 \%$ sobre sus requerimientos de oxigeno industrial, por planes de incremento de operaciones, hecho que puede resultar susceptible, así que se adopta una postura moderada sobre la cuota de participación en la demanda esperada, además de recomendación de los expertos.

\subsection{Pronóstico de Ventas}

El pronóstico de ventas del primer año de manera mensual, se halló primeramente fijando las ventas por mes, teniendo en cuenta la estacionalidad del producto. Para averiguar la estacionalidad, se preguntó a vendedores, empresarios y clientes de oxígeno industrial. Y estos nos indicaron que hay una mayor venta de este insumo, en los meses de Julio y Diciembre. Las ventas empiezan a subir en febrero, y luego aumenta un poco más en marzo, manteniéndose el mismo crecimiento hasta el mes de mayo. A su vez, se ha considerado el mes de diciembre porque muchas medianas y pequeñas empresas realizan diversos servicios en las fechas navideñas. 
Por ser el primer año, la empresa será conservadora y teniendo en cuenta que no se llega al $100 \%$ de ventas proyectadas, se hará lo siguiente: el primer mes, venderemos el $33 \%$ de las ventas regulares, el siguiente mes el $40 \%$, el tercer mes el $50 \%$ aproximadamente; los siguientes dos meses se venderá el $65 \%$ de las ventas regulares, el sexto mes se venderá el $78 \%$ de las ventas regulares; y a partir del séptimo mes, se venderá el 100\% de las ventas regulares. Como vemos en el siguiente cuadro:

Tabla 28 Programa de ventas anual

\begin{tabular}{lccc}
\hline \multicolumn{4}{c}{ Programa de Ventas del primer año en forma mensual } \\
(En unidades) & \multicolumn{2}{c}{} \\
\hline MESES & $\%$ Ventas Regulares & $\%$ de Ventas & Ventas Totales \\
ENERO & $6 \%$ & $2 \%$ & 128 \\
FEBRERO & $6 \%$ & $2 \%$ & 128 \\
MARZO & $8 \%$ & $4 \%$ & 257 \\
ABRIL & $8 \%$ & $6 \%$ & 385 \\
MAYO & $12 \%$ & $8 \%$ & 514 \\
JUNIO & $10 \%$ & $7 \%$ & 449 \\
JULIO & $12 \%$ & $12 \%$ & 771 \\
AGOSTO & $6 \%$ & $6 \%$ & 385 \\
SETIEMBRE & $6 \%$ & $5 \%$ & 321 \\
OCTUBRE & $6 \%$ & $6 \%$ & 385 \\
NOVIEMBRE & $8 \%$ & $8 \%$ & 514 \\
DICIEMBRE & $12 \%$ & $12 \%$ & 771 \\
TOTAL & $100 \%$ & $78 \%$ & 5,008 \\
& & &
\end{tabular}

Nota. Elaboración propia

En el cuadro anterior se aprecia que durante el primer año la empresa llegará a un $78 \%$ de sus ventas proyectadas, lo que hace una venta de 5,008 unidades de balones de oxígeno industrial.

Programa de Ventas del Segundo al Quinto año (2019 - 2022), en porcentajes, desagregado en forma mensual 
A continuación se presenta el cuadro donde se apreciara el programa de ventas para los cuatro años siguientes.

Se consideró como meses de mayor venta: febrero, marzo, abril, mayo y diciembre.

Tabla 29 Programa de ventas anual (2019-2022)

Programa de ventas (2019 - 2022)

(Expresado en unidades y porcentajes)

\begin{tabular}{lrrrrr}
\hline \multirow{2}{*}{ MESES } & \multicolumn{2}{c}{$\%$ de } & & & \\
& Ventas & 2019 & 2020 & 2021 & 2022 \\
ENERO & $6 \%$ & 555 & 752 & 979 & 1110 \\
FEBRERO & $6 \%$ & 555 & 752 & 979 & 1110 \\
MARZO & $8 \%$ & 740 & 1002 & 1306 & 1481 \\
ABRIL & $8 \%$ & 740 & 1002 & 1306 & 1481 \\
MAYO & $12 \%$ & 1110 & 1503 & 1958 & 2221 \\
JUNIO & $10 \%$ & 925 & 1253 & 1632 & 1851 \\
JULIO & $12 \%$ & 1110 & 1503 & 1958 & 2221 \\
AGOSTO & $6 \%$ & 555 & 752 & 979 & 1110 \\
SETIEMBRE & $6 \%$ & 555 & 752 & 979 & 1110 \\
OCTUBRE & $6 \%$ & 555 & 752 & 979 & 1110 \\
NOVIEMBRE & $8 \%$ & 740 & 1002 & 1306 & 1481 \\
DICIEMBRE & $12 \%$ & 1110 & 1503 & 1958 & 2221 \\
TOTAL & $100 \%$ & 9,248 & 12,528 & 16,320 & 18,508 \\
\hline
\end{tabular}

Nota. Elaboración propia

\subsection{Aspectos críticos que impactan el pronóstico de ventas}

Son aquellos que pueden modificar el pronóstico de las ventas y deben ser considerados en el proceso de planeación; se pueden clasificar como:

- Factores externos. Dentro de los cuales se encuentran el Producto Bruto Interno, Ingreso per cápita, Precios en un mercado libre de insumos y 
productos, Poder adquisitivo de la moneda, Modificaciones en cuanto a la oferta del producto en el mercado, Incremento de impuestos, entre otros.

- Factores internos.

Los factores de mayor riesgo son los externos, porque no dependen directamente de la administración de la empresa, estos factores son independientes, de igual manera se deben tomar las acciones necesarias para que no afecte el crecimiento esperado de la empresa. Es importante gestionar de manera adecuada todo lo que hace referencia al pago de impuestos y tributos, para evadir problemas con los entes recaudadores.

En el caso de los factores internos que puede dañar el pronóstico de ventas se encuentran:

- De ajuste, son ajustes a las estimaciones futuras por variaciones experimentadas en anteriores años.

- De cambio en las operaciones, que pueden ser por cambios en:

$\checkmark$ El proceso de producción.

$\checkmark$ La mezcla de materiales y mano de obra.

$\checkmark \quad$ La calidad del producto.

$\checkmark$ La estrategia de comercialización y mercadeo.

$\checkmark$ De crecimiento

\section{Capítulo V Ingeniería del Proyecto}

\subsection{Estudio de ingeniería}

La ingeniería de proyectos es la etapa del proyecto donde se determinan los recursos necesarios para la ejecución y desarrollo de las actividades o planes del proyecto. (Universidad de Barcelona, s.f.) 
El estudio técnico o ingeniería del proyecto constituye la etapa en la cual se busca determinar si es factible física o materialmente llevar a cabo un proyecto, determinación que es realizada generalmente por los expertos propios del área en la que si sitúa el mismo. Sapag, N. (2011). Tal como lo señala Sapag y Sapag (2000), “su objetivo es llegar a determinar la función de producción óptima para la utilización eficiente y eficaz de los recursos disponibles para la producción del bien o servicio deseado", (p.21)

De la selección de la función óptima se derivarán las necesidades de equipos y maquinarias que junto con la información relacionada con el proceso de producción, permitirá cuantificar el costo de operación.

Dentro de los principales temas que abarca el estudio de ingeniería están:

- Localización y tamaño del proyecto

- Distribución de la planta

- Ingeniería (Modelamiento y selección del proceso productivo).

- Aspectos legales relacionados al proyecto planteado.

\subsubsection{Modelamiento y selección de procesos productivos}

Dado que el oxígeno es un elemento que compone, junto con el nitrógeno, el aire atmosférico en un $99 \%$. Y siendo el aire una materia prima abundante sin coste alguno. Se vuelven más convenientes las técnicas que permiten obtener oxígeno a partir del aire y no del agua. El proceso de electrolisis del agua puede ser muy caro y no suele aplicarse en la industria, su uso esta mayormente en laboratorios.

Dentro de estas técnicas, para obtener oxígeno a partir del aire, las más comunes son las ASU y PSA. La técnica ASU (Air Separation Unit) que busca 
separar el oxígeno del nitrógeno en la destilación fraccionada, teniendo en cuenta una diferencia en la temperatura de ebullición considerable $\left(12^{\circ} \mathrm{C}\right)$. Y la adsorción de oxígeno, denominada PSA, por sus siglas en ingles Pressure Swing Adsortion. Dado el requerimiento en la pureza del oxígeno, de más del 98.5\% en la aplicación industrial (principalmente en el corte oxiacetilénico), es que solo consideramos la tecnología de destilación fraccionada, también conocida como el proceso criogénico o el método de Georges Claude. Se descarta el proceso PSA dado que no puede alcanzar niveles tan altos de pureza, para el plan de negocios.

A continuación pasaremos a detallar el proceso de destilación fraccionada con la tecnología criogénica:

Proceso 1 - Compresión del aire:

La operación requiere aire comprimido a 200 atmósferas o 3000 psi, para lo cual, el aire atmosférico pasa por unas compresoras especiales de alta presión que funcionan sin aceite (pistones con anillos grafitados) o sino compresoras de pistones con aparatos desecadores de aire y filtros especiales que eliminan las partículas de polvo, agua líquida y residuos de aceite.

Proceso 2 - Secado y Recepción del aire:

A continuación el aire ingresa a una tubería concéntrica interior (una tubería dentro de otra de gran longitud arrollada en un haz de espirales apretados y encerrada en una caja llena de material aislante (lana de vidrio) donde el tubo termina en un depósito para el aire líquido donde una válvula regula la salida del aire bajando la presión de 200 a 20 atmósferas. 
El brusco descenso de esta presión produce frío cerca de $40^{\circ} \mathrm{C}$, el aire así enfriado regresa hacia fuera por la tubería externa concéntrica saliendo del recipiente. Va enfriando el aire que va entrando por la tubería interior hasta $190^{\circ} \mathrm{C}$ y comienza a caer gotas de aire líquido en el depósito refrigerado, este líquido contiene $78 \%$ de nitrógeno, $21 \%$ de oxígeno y $0.9 \%$ de gases inertes.

\section{Proceso 3 - Generación del Oxígeno:}

En esta parte recién se produce la separación del oxígeno del nitrógeno; para esto se toma en cuenta que el punto de ebullición del nitrógeno es $-195^{\circ} \mathrm{C}$ y el del oxígeno es $-182.5^{\circ} \mathrm{C}$, que da una diferencia de $12.5^{\circ} \mathrm{C}$ y que permite la separación de ambos gases mediante la evaporación en una columna fraccionadora. En esta columna el nitrógeno siendo más volátil (en su mayoría aun gas) se evaporará primero mientras que en la otra columna se va concentrando el oxígeno hasta una pureza de $99.5 \%$, dado que ya se encuentra en estado líquido.

Proceso 4 - Comprensión y envasado del oxígeno:

Ya teniendo oxígeno líquido, este deberá pasar por un intercambiador de calor para regresar a su estado gaseoso y por un proceso de comprensión para poder ser embotellado en los cilindros (botellas de gas) especiales para su transporte y comercialización.

Tabla 30 Elaboración del producto

Operario de Producción

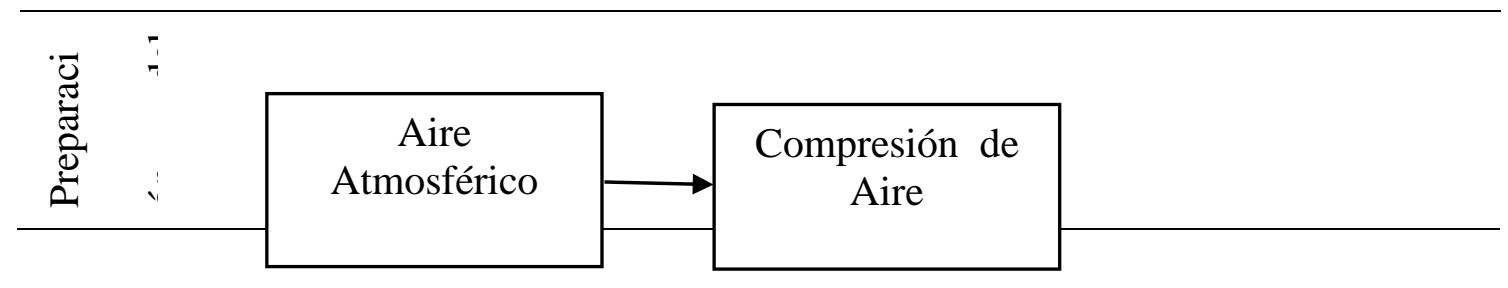




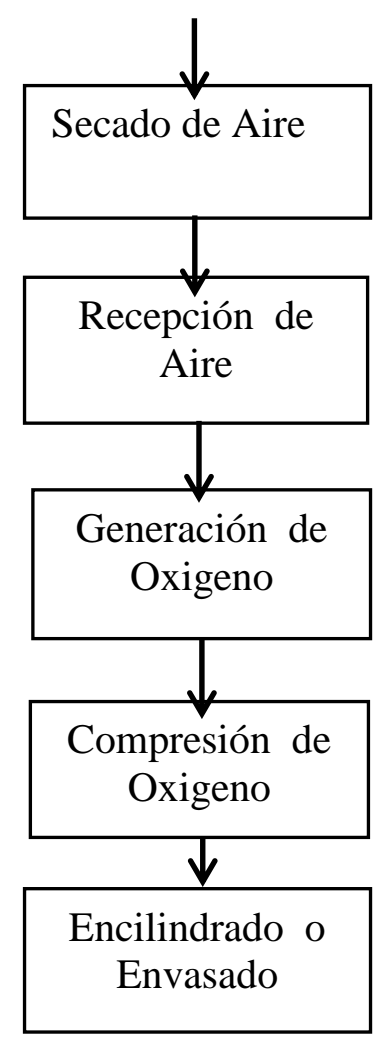

Nota. Elaboración propia

Diagrama de Operación de Proceso

Empresa : Oxigeno del Sur

Producto : Oxigeno Industrial

Fecha : 27/08/2017

Aire Atmosférico

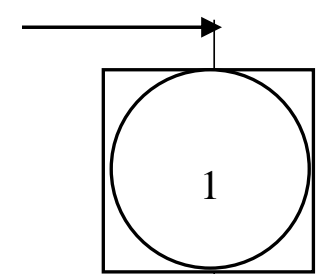




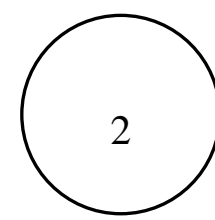

Secado de Aire

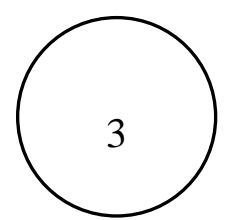

Recepción de Aire

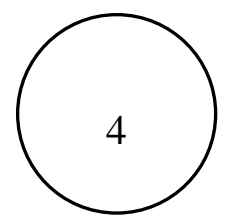

Generación de oxigeno

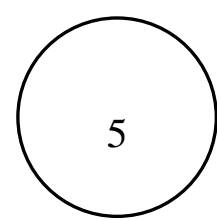

Comprensión de oxigeno

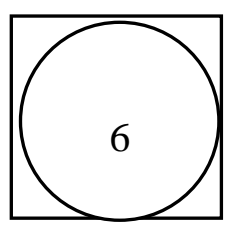

Encilindrado y envasado

Figura 31 Diagrama de Operación de Procesos 
Tabla 31 Inicio del servicio de oxigeno industrial

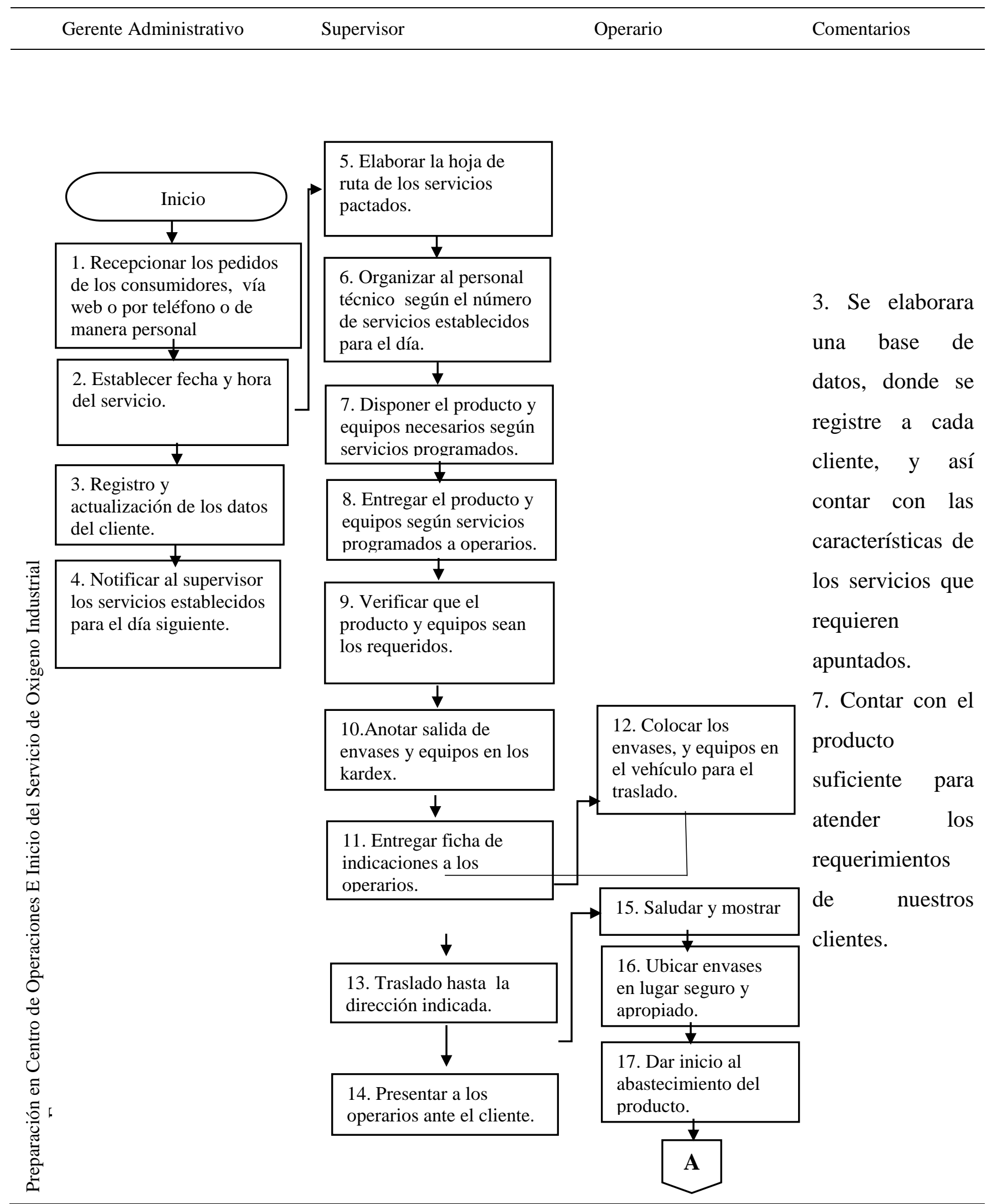

Nota. Elaboración propia 
Tabla 32 Modelamiento y selección de procesos productivos

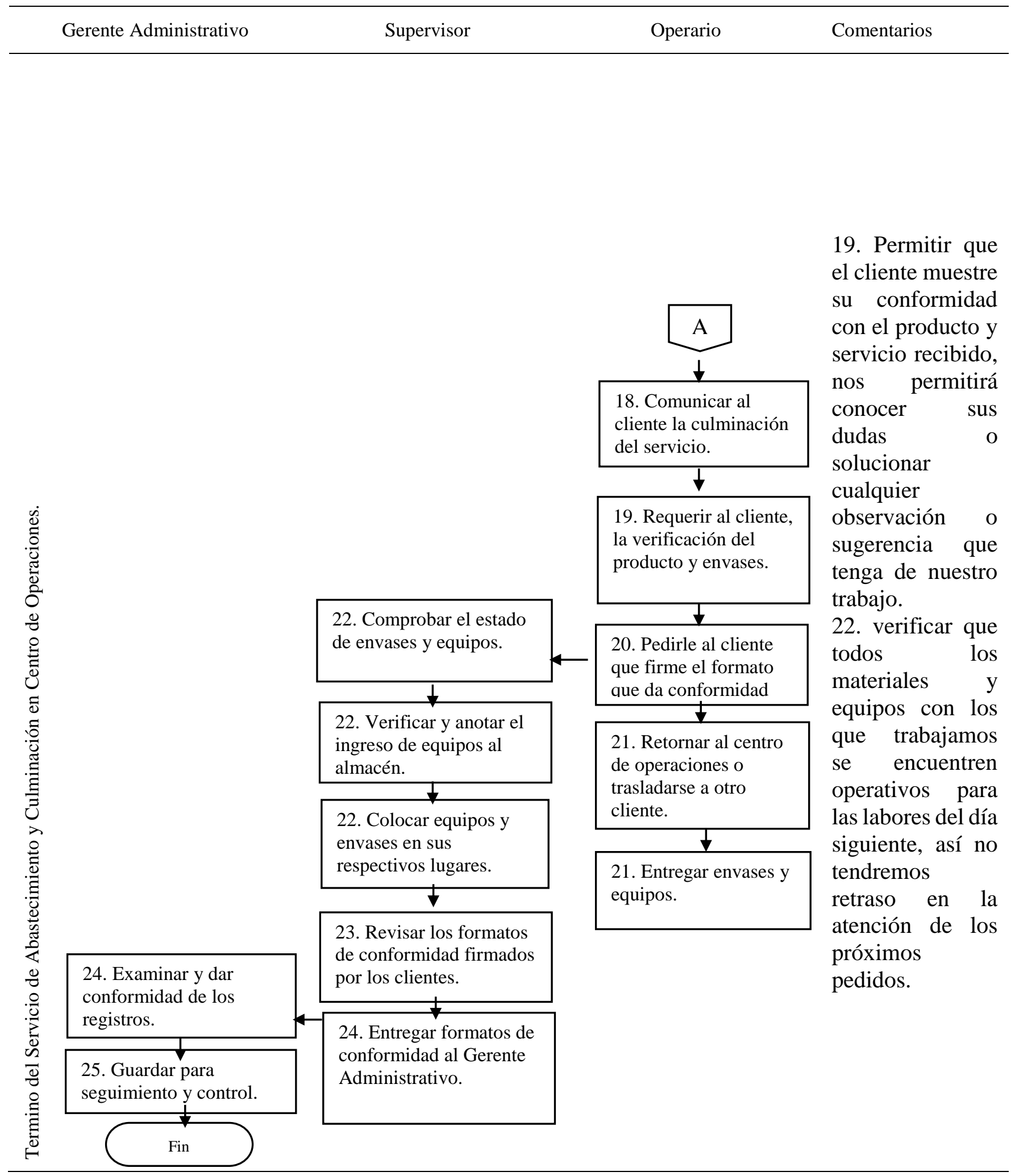

Nota. Elaboración propia 
Tabla 33 Procesamiento de adquisición y almacenamiento de materiales

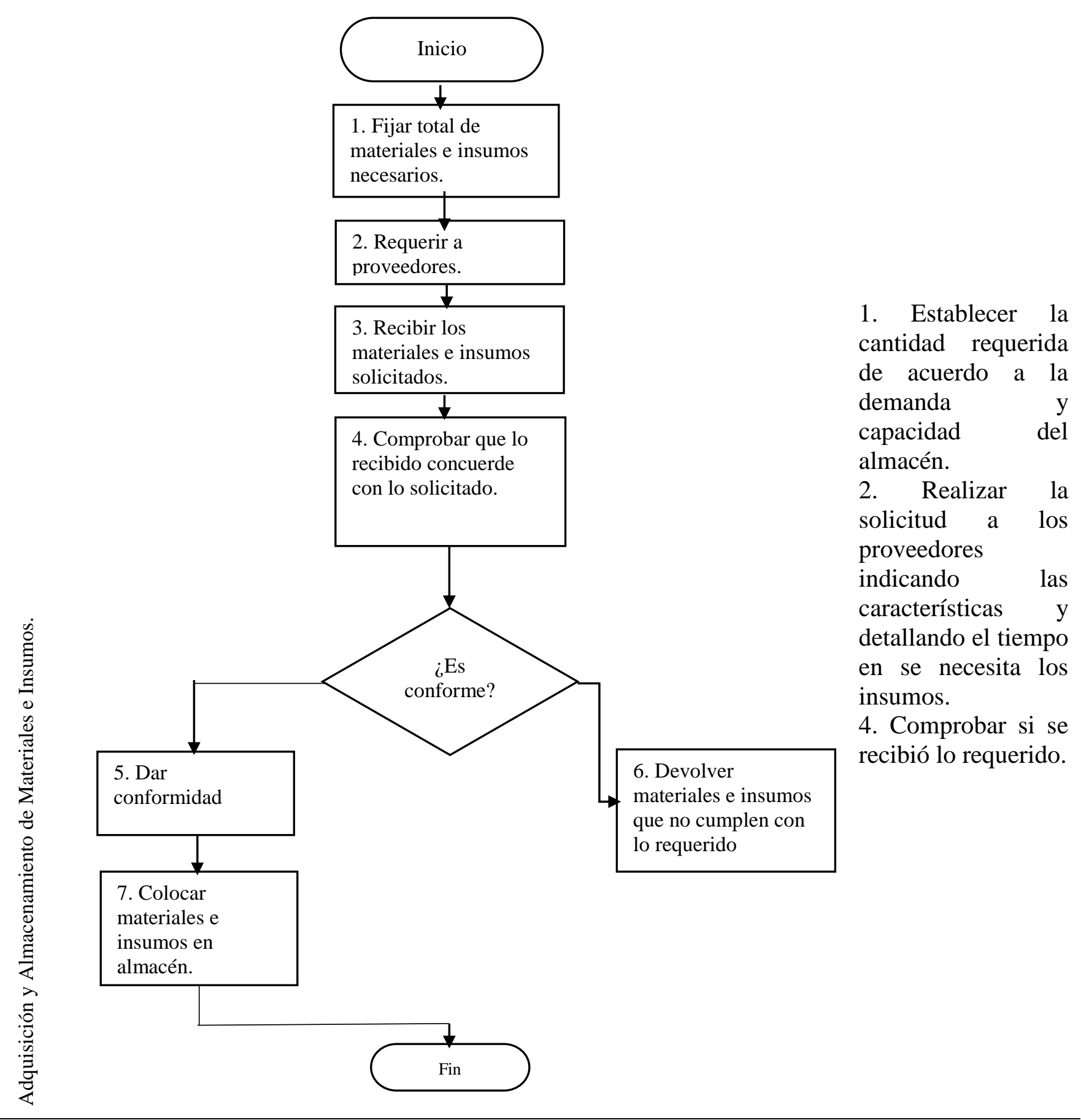

Nota. Elaboración propia 


\subsubsection{Selección Del Equipamiento.}

Se consideraron las siguientes características para los equipos y materiales, duración y confiabilidad, calidad y servicio postventa.

\section{Maquinaria y Equipos de Operaciones}

- 01 Comprensión de Alta Presión Atlas Copco

- 01 Soplador de oxígeno (equipo para cubrir el déficit de $\mathrm{O} 2$ en altura)

- 01 Torre de purificación de aire (equipo que limpia las impurezas de polvo, agua y partículas otras en el aire). Marca Aid Products

- 01 Generador de Oxigeno que incluye las torres de destilación fraccionada y el serpentín de enfriamiento, por donde pasará el oxígeno líquido hasta volverse nuevamente gaseoso. Marca Aid Products

- 01 equipo Servomex para el análisis de oxígeno que sale del generador.

- 01 camión de 7-8 toneladas de capacidad acondicionado para el transporte de gases embotellados.

02 camiones de 3-4 toneladas de capacidad acondicionados para el transporte de gases embotellados.

\section{Equipos de Oficina}

- 03 Computadoras para uso de escritorio

- 02 Teléfonos fijos

- 03 impresora

\section{Materiales de Oficina (de uso anual)}

- 10 Paquetes de hojas bond (de medio millar) 
- 10 Cajas de lapiceros (2 rojos y 8 azules)

- 02 Engrampadora

- 02 Saca grapas

- 10 Folders

- 04 resaltadores

- 02 perforadores

- 10 Archivadores

- 06 Cintas adhesivas

\section{Uniformes para operarios}

- 11 Mamelucos

- 11 Cascos

- 11 Pares de zapatos de protección

- 11 Protectores respiratorios (con filtro anti gases)

- 11 Pares de Guantes especiales

\subsubsection{Lay Out}

La empresa planteada requerirá de un área aprox. de $1900 \mathrm{~m}^{2}$, para que cada uno de los ambientes pueda contar con el espacio necesario, además de tener espacio suficiente para las vías de circulación requeridas por los estándares de seguridad sobre todo en las zonas de producción y almacenamiento.

\section{Distribución:}

Se ubicaría de la siguiente manera:

- Recepción, Lugar donde se atenderá a nuestros clientes.

- Oficina del Supervisor, área destinada para el supervisor de la empresa. 
- Oficina de Gerente Administrativo, espacio diseñado para el Gerente administrativo.

- Cochera, área destinada a albergar las unidades de transporte con los que cuente la empresa.

- Área de producción, zona ambientada adecuadamente para el proceso de elaboración de Oxigeno industrial.

- Almacenamiento, espacio con medidas y características necesarias para resguardar los materiales y equipos.

- Vestuario de Operarios, zona donde los operarios puedan colocarse el uniforme y los implementos de seguridad necesarios.

- Baños, emplazados y dirigidos para el uso de los empleados de la empresa y los clientes.

\subsubsection{Distribución de Equipos y maquinarias}

Se distribuirán los equipos y maquinarias de forma que se pueda lograr que el proceso de elaboración y distribución del producto se produzca de manera fluida y de acuerdo los criterios de seguridad establecidos. 


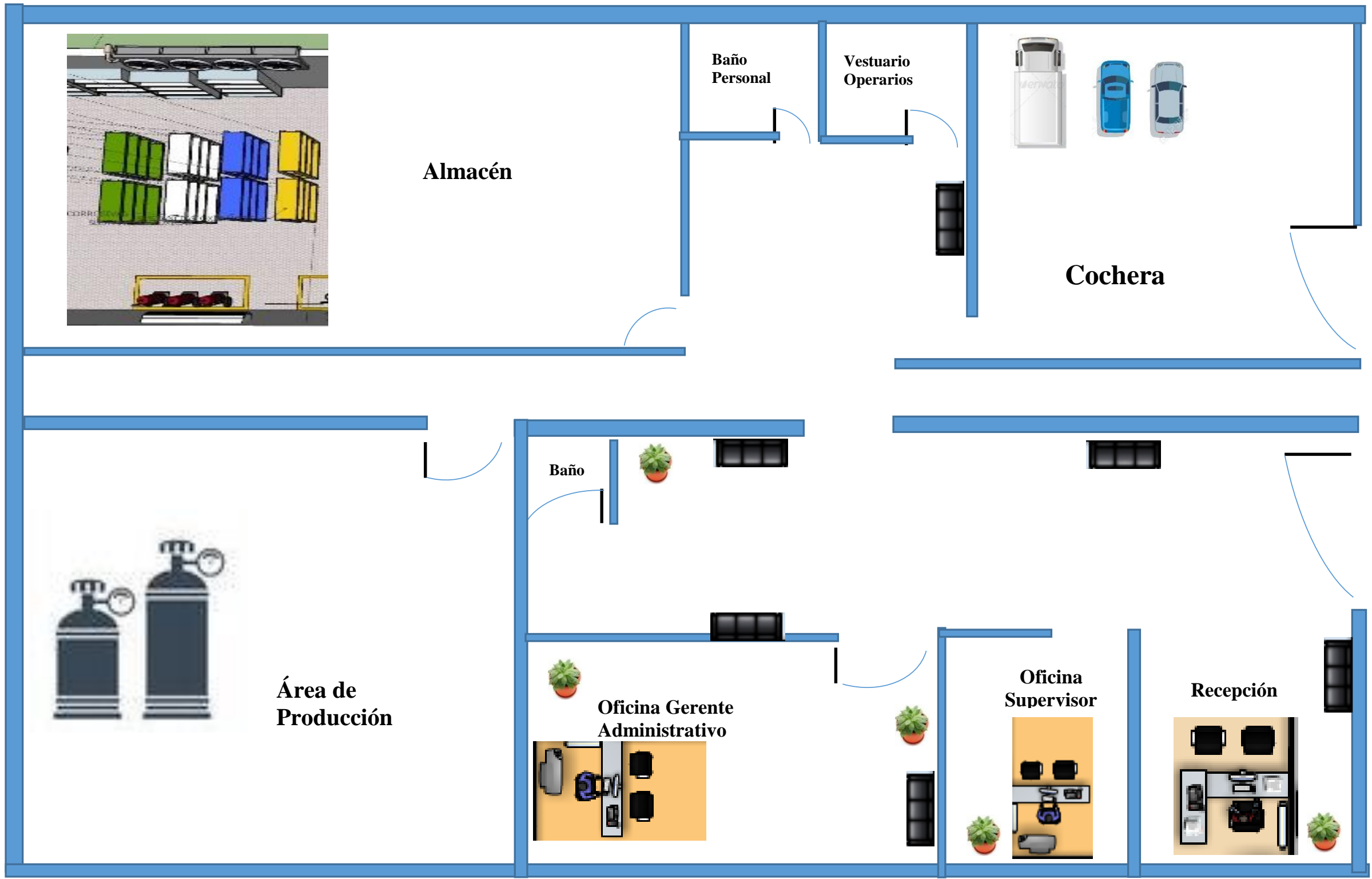

Figura 32 Lay out propuesto. Elaboración propia 


\subsection{Determinación del Tamaño}

\subsubsection{Proyección de crecimiento}

\section{Capacidad Inicial}

El presente estudio estima que se producirá al $68 \%$ de su capacidad durante el primer año, es decir: 56,780 $\mathrm{m}^{3} / \mathrm{año}$, al final del planeamiento de horizonte que es en el año 10 llegaremos al 100\% con una producción de $95,580.00 \mathrm{~m}^{3} /$ año de oxígeno industrial.

\section{Capacidad Instalada}

La capacidad instalada de producción del proyecto es de 95,580.00 m /año de Oxigeno industrial, equivalente a una producción diaria de $306.35 \mathrm{~m}^{3} /$ día con una producción de $30,64 \mathrm{~m}^{3}$ / hora, operando en un turno de 10 horas y durante 312 días de funcionamiento anual.

La maquinaria y equipos están planteados para poder lograr ese nivel de producción, funcionando al 100\% de su capacidad instalada.

\subsubsection{Recursos}

\section{Requerimientos de Máquinas y/o Equipos}

La tendencia actual de las plantas de producción de oxígeno industrial modernas es la automatización y el control electrónico. Esto asegura un servicio largo, preciso y seguro de los motores, y en caso de fallas de fluido eléctrico o cualquier otro inconveniente que podría ocurrir durante el funcionamiento del equipo seria informado rápidamente, para poder buscar soluciones inmediatas que no detengan el proceso de producción. 


\section{Compresor de Aire}

Es un compresor Atlas Copeo sueco, tiene un tablero de control con lo siguiente:

- Interruptores de arranque - parada y manual - automático, en el primer caso el compresor puede funcionar indefinidamente y en el segundo se detiene cuando el resto de la planta se ha paralizado por alguna razón.

- Contador de horas de trabajo (cuenta el tiempo que la máquina ha estado funcionando desde su fabricación).

- Arranque del motor; los motores corrientes tienen un sistema de arranque mecánico o por condensadores que dan el impulso inicial, pero como este motor es de potencia viene provisto de una bobina de arranque con disipador eléctrico si en diez segundos no marcha el motor por baja corriente o carga de aire comprimido, se detiene la partida.

- Control automático de parada, si la máquina de cargar el oxígeno en los cilindros se completa y no hay capacidad para más aire comprimido, el compresor en el término de cinco minutos se detiene y con ella toda la planta de producción, ahora si se retiran los cilindros cargados y se conectan otros vacíos la máquina en forma automática arrancará de nuevo.

- Control de arranque, son dispositivos que impiden el arranque cuando el voltaje de corriente es muy bajo o alto aún durante su funcionamiento si las variaciones son muy amplias, esto evita un daño al motor eléctrico por sobrecarga. 
- Control de sobrecarga térmica, en los días calurosos, la prolongada carga de aire comprimido y bajo voltaje puede ocasionar el calentamiento del motor eléctrico y que al sobrepasar los límites fijados por el fabricante este dispositivo térmico detiene la marcha del compresor y lo mantiene desconectado hasta que alcance los límites tolerables.

Con todos los dispositivos descritos podríamos pensar que la maquinaria puede funcionar sin supervisión, pero no es así, siempre es necesaria la presencia de los operarios, quienes pueden detectar fallas en los aparatos de seguridad

\section{Enfriador de Aire}

El aire comprimido que sale del compresor está caliente y contaminado con vapor de agua, aceite y partículas de polvo atmosférico que se debe eliminar antes de que pase al generador de oxígeno. Este equipo es similar a una refrigeradora, consta de una unidad enfriadora con serpentín y líquido refrigerante accionado por una bomba y motor - ventilador que enfría el aire hasta $7^{\circ} \mathrm{C}$ de modo que la humedad y el aceite se condensan en las paredes de la tubería siendo recolectado y eliminado con una válvula de alivio; a la salida del enfriador el aire pasa por un filtro especial que completa la limpieza separando hasta $0,5 \mathrm{mg} / \mathrm{m} 3$. De agua y aceite, el $100 \%$ de partículas sólidas hasta un micrón y el $18 \%$ de partículas hasta de 0,3 micrones.

El enfriador también va provisto de controles eléctricos lámparas y medidores que indican la marcha de los motores, temperatura de enfriamiento y un dispositivo que impide el paso del aire sí la máquina falla o no se ha encendido por olvido. 


\section{Generador de Oxígeno}

Este aparato descrito consta de dos tanques cilíndricos verticales de acero que contienen granos de zeolita, el aire que ingresa por la parte inferior está controlado por una válvula accionada por un sistema electrónico de circuito integrado que controla el tiempo de apertura (20 segundos) al gas en su ascenso hacia arriba, las zeolitas retienen el nitrógeno por adsorción de modo que el oxígeno, puro llega al techo y sale por una válvula justo cuando la válvula inferior cierra la entrada de más aire; después de 14 segundos la válvula inferior se abre y el nitrógeno vuelve hacia atrás y escapa al espacio hasta que la presión se iguales al de la atmósfera.

Mientras el primer tanque va eliminando el nitrógeno el segundo tanque se llena de aire y comienza el ciclo anterior de tal manera que los dos tanques trabajan en forma alternativa; la producción cíclica y pulsante de oxígeno pasa a un tanque de almacenamiento hasta una presión de 60 PSI; en este lugar un analizador determina el porcentaje de pureza del gas expulsándolo por una presión de 60 PSI; en este lugar un analizador determina el porcentaje de pureza de gas expulsándolo por una válvula si la calidad no es adecuada para su uso industrial.

El tablero de control consta de un interruptor de corriente arranque parada y otro automático - manual, el primero cuando se conecta a los demás aparatos y el segundo manual cuando se desea que el generador funcione en forma continua o independiente; un manómetro de presión indica el aire que ingresa y otro la presión dentro de los tanques de trabajo; dos filtros de agua y aceite accionados por la tarjeta eléctrica que los purga cada 90 segundos mediante una electroválvula, finalmente un contador eléctrico de las horas de 
trabajo; a la salida del tanque de almacenamiento se halla una válvula reguladora que permite la salida del gas a la presión de 25 PSI al compresor de oxígeno.

\section{Insumos (soda cáustica)}

La soda cáustica, será utilizada como insumo para la obtención de oxígeno purificado. Según el ingeniero químico experto, se requieren $7 \mathrm{Kg}$ de este insumo para la producción de $1000 \mathrm{~m} 3$ de oxígeno. Este insumo se compra en sacos de $42.5 \mathrm{Kg}$ a un costo aproximado de S/. 297.50

Por lo tanto, haciendo una comparación con nuestra capacidad instalada de $307 \mathrm{~m} 3$ de oxígeno/día podemos calcular un costo de 2.3 centavos de sol por cada m3 de oxígeno [S/. 297.5 / (42.5*307)]

\section{Requerimiento de Agua}

La empresa planteada no utiliza agua como un insumo para la producción de oxígeno, sin embargo si requerirá del agua para el funcionamiento de los servicios higiénicos, y para el mantenimiento de las plantas, siendo la cantidad requerida por mes de $15 \mathrm{~m}^{3}$, lo que anualmente hacen $180 \mathrm{~m} 3$. 
La cantidad de energía eléctrica requerida por la planta de oxígeno, para el primer año de funcionamiento, sobre la base de 312 días de operación y un turno de 10 horas diarias, se presenta a continuación en el siguiente cuadro:

Tabla 34 Requerimiento de energía eléctrica

\begin{tabular}{|l|r|r|}
\hline \multicolumn{1}{|c|}{ Equipo } & \multicolumn{1}{|c|}{$\begin{array}{c}\text { Potencia } \\
(\mathrm{KW})\end{array}$} & Energía (Kwh/año) \\
\hline Área de Producción & 18.625 & $58,110.00$ \\
\hline Compresor de Aire & 2.98 & $9,297.60$ \\
\hline Soplador de aire & 0.75 & $2,324.40$ \\
\hline Servomex & 7.45 & $23,244.00$ \\
\hline Generador de Oxigeno & 0.48 & $1,497.60$ \\
\hline Iluminación General & & $1,560.00$ \\
\hline Área Administración & 0.50 & 499.20 \\
\hline Computadoras & 0.32 & $1,123.20$ \\
\hline Iluminación General & 0.15 & $97,656.00$ \\
\hline Impresora & Total & \\
\hline & & \\
\hline
\end{tabular}

Nota. Elaboración propia

Considerando que el costo por Kw-h es de S/. 0.58, podemos indicar que el costo de energía por $\mathrm{m}^{3}$ para el área de operaciones es de $\mathrm{S} / .0 .99$. Sobre el consumo estimado de energía para el primer año de producción, de 94,473 Kwh, multiplicado por su precio $\mathrm{S} / .0 .58$ y dividido entre el total de $\mathrm{m}^{3}$ proyectados (de 56,780 $\mathrm{m}^{3}$ ) es que obtenemos este valor de S/.0.99 aproximado del costo de energía en la producción. 


\subsubsection{Tecnología}

La tecnología criogénica es la que se utilizara en el presente proyecto, ya que como se explico anteriormente es la más segura para alcanzar la calidad y pureza del producto final.

\subsubsection{Flexibilidad.}

Si se presenta la situación que la demanda de oxigeno supere lo proyectado, se debe estar prevenido para afrontar esa posible situación. La solución es mantener el almacén suministrado correctamente, realizando mantenimiento continuo a los equipos y maquinarias, y además contar con personal capacitado para poder proceder ante el posible escenario de ampliar las horas de operación por turno a 12 o 14 por día.

\subsubsection{Selección del Tamaño Ideal.}

Se estableció que las áreas necesarias para la empresa propuesta son; recepción, garaje, vestidores, oficinas del área administrativa, servicios higiénicos, almacén y área de producción. Se calcula que el tamaño necesario para ejecutar el proyecto es de $1900 \mathrm{~m}^{2}$, el área permitirá la realización de todas las tareas de la empresa.

\subsection{Estudio de localización.}

El estudio de localización tendrá como principal objetivo establecer la mejor zona para ubicar el centro de operaciones de la empresa propuesta.

\subsubsection{Definición de Factores locacionales.}

- Cercanía a los potenciales clientes, es importante que los clientes puedan ubicar fácilmente la empresa. 
- Precio de arrendamiento y arbitrios municipales.

- Vías de comunicación y transporte, la empresa por sus características requiere ubicarse cerca de las principales avenidas que permiten que las unidades de transporte puedan movilizarse fácilmente.

- Precio de servicios públicos, se debe conocer el gasto mensual aproximado de los servicios básicos como el agua y luz.

- Disponibilidad de predios, se debe ubicar un local que se acomode a los requerimientos del proyecto en cuanto al área y a la seguridad que ofrezca la zona.

\subsubsection{Consideraciones legales.}

\subsubsection{Identificación del marco legal:}

Por la clase de operaciones que realizara la empresa propuesta, está ubicada dentro de las actividades económicas como Fabricación de Sustancias químicas básicas, de acuerdo a la SUNAT con el código 24116 según la Clasificación Industrial Internacional Uniforme.

\subsubsection{Ordenamiento Jurídico de la empresa:}

Tipo de Sociedad: Se revisó la información acerca de los tipos de constitución de una empresa existente, se acordó que la empresa propuesta debe conformarse como una Sociedad de Responsabilidad Limitada por los siguientes motivos:

Por contar con tres socios se debe convertir en una sociedad, y la Sociedad de Responsabilidad Limitada no debe contar con más de 20 socios.

El capital se divide en participaciones iguales. 
Por ser una sociedad los socios no responden por las deudas de la empresa con su patrimonio personal.

\section{Tipos de Contratos de Trabajo a utilizar}

Se identificó que la principal competencia contrata a sus operarios haciendo uso de contratos temporales, ese tipo de contratos tienen un tiempo de duración de 3 o 6 meses. Para que la empresa de oxigeno industrial se diferencie de sus competidores y poder reflejar una imagen seria y de formalidad se contratara al personal de manera indeterminada y brindando todos los beneficios de acuerdo a ley.

Régimen de contribución de la empresa

De acuerdo a las características de la empresa y por la decisión de conformarla como una sociedad de responsabilidad limitada, le corresponde a la empresa pertenecer al Régimen General del Impuesto a la Renta.

Dentro de las obligaciones que tienen las empresas que pertenecen a este régimen se encuentra el pago mensual del impuesto a la renta y el impuesto general a las ventas (IGV).

\section{Licencia de Funcionamiento}

La municipalidad Provincial de San Román, donde pertenece la ciudad de Juliaca, solicita los siguientes requisitos para otorgar la licencia de funcionamiento dentro de su jurisdicción:

- $\quad$ Formato de solicitud de licencia de funcionamiento

- Copia de vigencia de poder del representante legal en caso de personas jurídicas.

- Recibo de pago por derecho de trámite. 
- Declaración jurada de inspección técnica de seguridad en edificaciones.

\subsection{Determinación de la localización optima:}

Se determinó la localización de la empresa en base a todos los factores detallados anteriormente, llegando a la conclusión que el lugar más óptimo está en el distrito de Juliaca, ya que cuenta con las vías de acceso y los servicios requeridos, además de que el distrito de Juliaca posee predios de la dimensión que se requiere, para el desarrollo del proyecto, además de ser el centro comercial más importante del departamento de Puno, también fue considerado el hecho que nuestros principales competidores y las oficinas de nuestros potenciales clientes se encuentran en este distrito. 


\section{Capítulo VI Aspectos Organizacionales}

\subsection{Caracterización de la cultura organizacional deseada.}

La cultura organizacional es aquel intangible compuesto por el grupo de características compartidas por una empresa y que la diferencian de otras; mostrando actitudes, valores y creencias que comparten las partes de una organización.

Schein (2004) manifiesta que para él la cultura organizacional comprende la manera de arreglar dificultades internas y externas, y que son útiles para el aprendizaje de los nuevos miembros.

La cultura organizacional está formada por las normas y pautas que rigen una organización. Las normas de la empresa se elaboraran con el fin de influir en cada miembro de la empresa, por ello, es fundamental que todo colaborador de la compañía acepte y aplique estas normas.

Oxigeno del Sur debe contar con una cultura organizacional que permita que cada miembro de la empresa se identifique y se comprometa con la empresa y sus clientes, se debe tener en cuenta que la empresa propuesta pertenece a un sector donde los clientes requieren sentirse seguros con el producto y servicio que van a recibir.

Oxigeno del Sur debe manejar una cultura que permita a cada miembro de la empresa proyecte confianza y seguridad con los clientes.

\section{Aspectos de la Cultura Organizacional de "Oxigeno del Sur".-}

Los aspectos que conforma cada empresa son:

\section{Forma de comunicación rutinaria}

Comunicación del cliente con la empresa 
La empresa les brindara a los clientes la opción de comunicarse a través de diferentes medios desde los más tradicionales como el teléfono así como por las redes sociales. Sin importar el medio por el que los clientes se comuniquen con la empresa, siempre deben ser atendidos de manera profesional, y así puedan disipar sus dudas. Cualquier comunicación debe caracterizarse por la amabilidad y predisposición de ayudar al cliente.

\section{Comunicación entre los Colaboradores}

Todos los miembros de la empresa deben mantener una comunicación constante, sobre todo cuando se trata de los requerimientos de algún cliente. También se debe mantener información registrada de cada cliente y sus particularidades.

\section{Comunicación entre nuestro colaborador y el cliente}

La comunicación entre los miembros de la empresa y los clientes es probablemente la comunicación más importante que se efectuara en la empresa. Los operarios que realizan los servicios y tienen contacto directo con los consumidores deberán seguir un protocolo de atención al cliente el cual será establecido por la empresa con anterioridad.

\section{Reglas compartidas por la organización}

Reglas de Seguridad

$\checkmark$ Seguridad del colaborador, todos los miembros de la empresa tienen la obligación de seguir las normas de seguridad que dicta la empresa y los manuales de manipulación de gases industriales.

Seguridad del Cliente, es primordial asegurar la seguridad de los clientes y las empresas, se debe solicitar a los clientes que realicen el mantenimiento 
de sus instalaciones e instrumentos para el mejor funcionamiento del producto.

$\checkmark$ Seguridad de la Información, se debe garantizar la protección de los datos proporcionados por los clientes y sus empresas.

Reglas de entrada, saludar educadamente a todo el personal.

Reglas de vestimenta, todo miembro de la empresa y según al área a la que pertenece, debe asistir aseado y con el uniforme (y/o equipo de seguridad) que impone la empresa. Reglas de salida, todo miembro de la empresa que tenga contacto con los clientes deberá despedirse educadamente de ellos.

\section{Valores Principales de la empresa}

$\checkmark$ Amabilidad, los trabajadores deben mostrase cordiales al momento de atender a los clientes.

$\checkmark$ Respeto, respetar las normas de la organización y todos los miembros de la misma.

$\checkmark$ Honestidad, es fundamental que todo miembro de la empresa actué de manera honesta durante el desarrollo de sus tareas.

$\checkmark$ Disciplina y puntualidad, cada miembro de la organización debe ejecutar sus labores en el tiempo estimado.

$\checkmark$ Excelencia en el servicio, todos los miembros de la empresa deben estar comprometidos en realizar un buen trabajo.

\section{Toma de decisiones}

En el caso de la empresa propuesta, el supervisor es el encargado de organizar los servicios de acuerdo a las características de cada cliente. Si durante el servicio sucediera algún inconveniente, que el operario no esté en la capacidad de solucionar, 
deberá comunicárselo inmediatamente al supervisor quien se acercará a las instalaciones de la empresa del cliente para buscar una solución. Debe registrarse el hecho y luego ser comunicado al gerente administrativo.

\section{Clima Organizacional}

\section{Políticas Generales}

Proporcionar un clima laboral sano es responsabilidad de la gerencia y en este caso del supervisor, ambos partes deben concertar para poder ofrecer un ambiente saludable para todos.

Los factores que componen el clima laboral son:

$\checkmark$ Condiciones físicas del área de trabajo

Oficina principal, la oficina debe estar distribuida adecuadamente, la iluminación debe ser la adecuada para el trabajo que se realizara en ese ambiente, de igual manera la ventilación. La empresa contara baños destinados para el área administrativa.

El almacén de productos y equipos, deberá contar con los espacios necesarios para albergar los productos y equipos, según las reglas de seguridad establecidas.

El Vehículo de servicios, debe contar con capacidad necesaria para el traslado de productos y trabajadores que realizar el servicio.

Dentro de las empresas donde se realiza el servicio:

El respeto es fundamental durante la ejecución de un servicio, el respeto debe ser mutuo entre operarios y clientes, si los clientes en algún momento le faltan el respeto a los operarios será el supervisor el que deberá intervenir para solucionar el impase. 
Estructura de la Cadena de Mando

La cadena de mando está presente en todo tipo de organizaciones, cada colaborador de la empresa debe respetarla sin que esto signifique reprimir sus opiniones o ganas de dar su punto de vista. Oxigeno del Sur, a través de una caja de sugerencias promoverá que los miembros de la empresa manifiesten sus opiniones.

Comunicación dentro de la empresa

Cada miembro de la empresa tendrá un trato amable y cordial con el resto de trabajadores sin importar su jerarquía. Para facilitar este proceso todo colaborador llevara una identificación siempre que se encuentre dentro de la empresa.

$\checkmark$ Personalidad de los jefes de equipo

Los colaboradores que ocupen un puesto superior deben mostrar siempre una actitud positiva y de liderazgo que ayude a mantener un clima laboral saludable.

\subsubsection{Visión de Oxigeno del Sur.}

Convertirse en el largo plazo en el líder regional en gases industriales, ofreciendo un producto y servicio que se caracterice por su calidad y seguridad. Estar pendiente siempre de nuevas tecnologías y su aplicación en el ámbito de los gases industriales.

\subsubsection{Misión de Oxigeno del Sur.}

Cubrir las necesidades de los clientes brindando un producto y servicio con valor agregado, mediante el trabajo de un grupo profesional comprometido con sus valores. 


\subsubsection{Valores de la empresa.}

Los valores de una organización son los cimientos que conforman a la empresa.

Nosnik (2005) manifiesta que "Los valores son conceptos que sintetizan y comunican estándares de conducta, crean una normatividad tanto de políticas institucionales como de una ética profesional y moral personal en el desempeño de los colaboradores de una organización. Los valores dan pie a criterios con los que se reconoce y premia; en otros casos, sanciona y reprime la conducta de una organización" (P. 51-52)

Los valores que predominaran en la empresa propuesta son:

- Honestidad, proceder siempre con honestidad.

- Integridad, todas las acciones deben caracterizarse por estar dentro de un marco justo.

- Sostenibilidad, preocupación por futuras generaciones.

- Respeto, respetar a todos los miembros de la empresa sin excepción.

\subsection{Formulación de las estrategias del negocio}

La empresa "Oxigeno del Sur", en búsqueda de sus estrategias realizara un análisis interno y externo de la empresa, para así poder identificar sus fortalezas, debilidades, oportunidades y amenazas. 


\subsubsection{Análisis Externo}

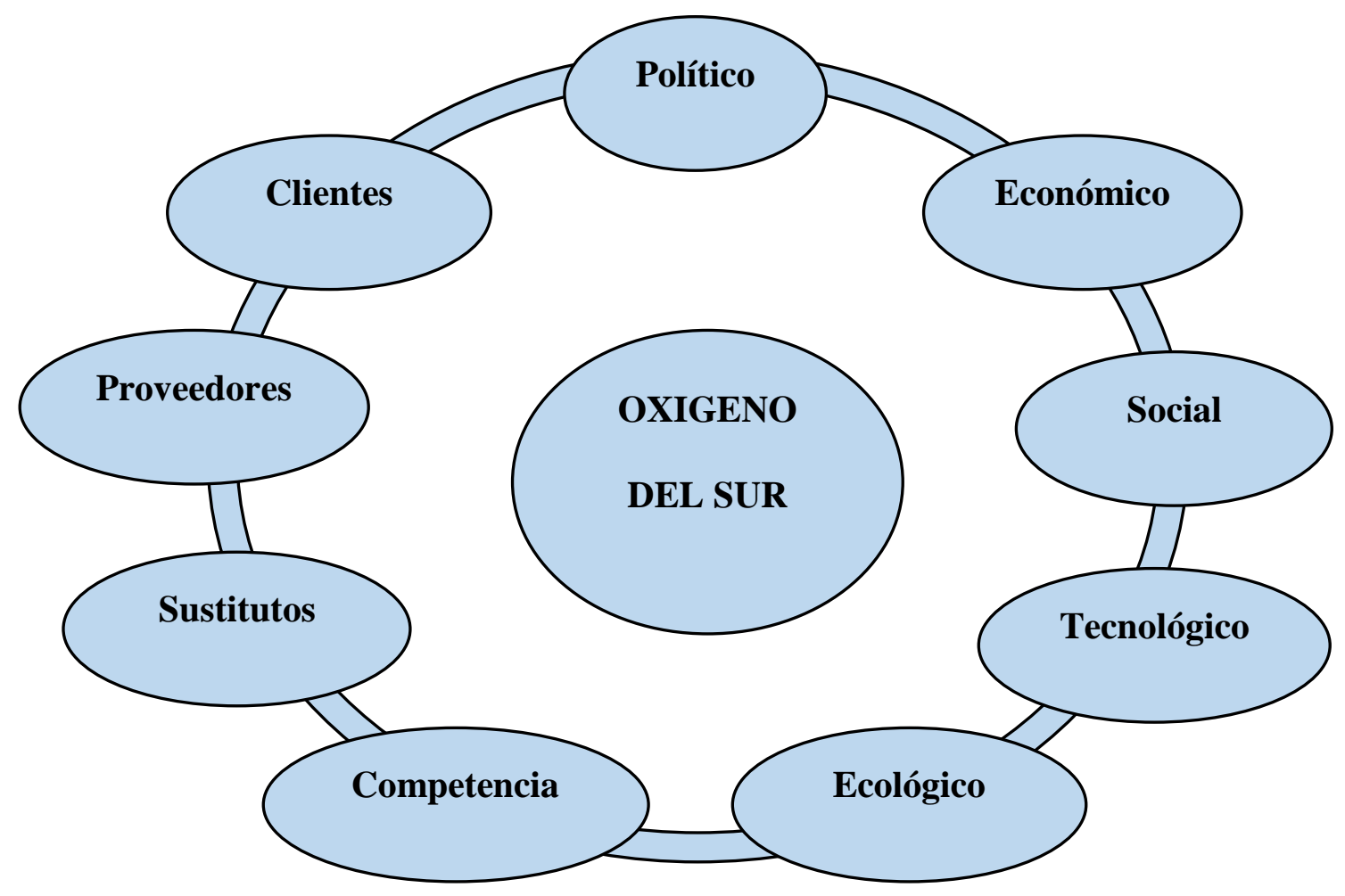

Figura 33 Análisis Externo. Elaboración propia

El análisis externo abarca todos los aspectos sobre los cuales la empresa no tiene influencia, pero que de igual manera pueden afectar a la empresa.

\section{Análisis Político}

El gobierno busca constantemente realizar acciones que le ayuden a reactivar la economía por medio de la formalización de las empresas informales, busca alcanzar este fin por medio de la reestructuración de leyes y reglamentos que les permitan regular a los miembros de una empresa.

Según un estudio realizado durante el año 2015 el 85\% de las Mypes eran informales, de acuerdo a esto el gobierno ejecuto un plan para lograr que estas 
empresas puedan formalizarse. Una empresa que desea proyectarse como una empresa seria debe cumplir con todos los requerimientos de ley.

Tabla 35 Análisis político

\begin{tabular}{|c|c|c|}
\hline Oportunidades & Amenazas & \\
\hline $\begin{array}{l}\text { - Reflejar la imagen de empresa } \\
\text { seria y responsable. }\end{array}$ & 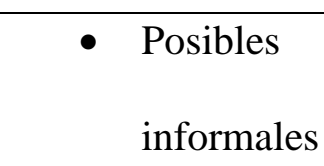 & competidores \\
\hline
\end{tabular}

Nota. Elaboración propia

\section{Análisis Económico}

Durante los últimos años dos sucesos importantes han traído como consecuencia la detención de una serie de proyectos inmobiliarios y de ingeniería civil en todo el país.

El niño costero, fenómeno natural que ha destruido varias zonas del país cuya reconstrucción superaría el presupuesto proyectado para el presente año.

El caso Odebrecht, por su magnitud trajo como consecuencia la paralización de diversos proyectos de importancia a nivel nacional, esto ha repercutido en la economía Peruana de manera negativa.

Sin embargo la minería sigue siendo uno de los sectores principales que aporta al desarrollo económico del país. La elaboración de diversos proyectos en el sector minero muestra que la minería sigue siendo uno de los puntos fuertes de la economía peruana. 
Tabla 36 Análisis económico

\section{Oportunidades}

- Cartera de proyectos mineros

a corto y largo plazo.
Amenazas

- Inmovilización de proyectos

inmobiliarios y de ingeniería

civil a nivel nacional.

Nota. Elaboración propia

\section{Análisis Social}

La ciudad de Juliaca, como otras del departamento de Puno, han crecido de manera desordenada, a consecuencia de esto la informalidad y el contrabando están presente en casi todas sus actividades comerciales, hasta el momento nuestro rubro está libre de contrabando debido a las características que debe tener el producto como es el Oxígeno industrial.

Tabla 37 Análisis social

Oportunidades Amenazas

- Informalidad y contrabando.

Nota. Elaboración propia

\section{Análisis Tecnológico}

La empresa dedicada a la producción de gases industriales debe estar a la vanguardia de los últimos adelantos tecnológicos, tratando de mejorar continuamente nuestras herramientas e insumos. La tecnología que utilizaremos en nuestra planta, será la tecnología criogénica, ya que esta es la más segura para alcanzar la calidad de nuestro producto final que será el oxígeno gaseoso para uso industrial. 
Tabla 38 Análisis tecnológico

\begin{tabular}{lll}
\hline \multicolumn{2}{c}{ Oportunidades } & Amenazas \\
\hline Se aplicara la Tecnología & \\
Criogénica para obtener un \\
producto de más alta calidad y \\
pureza
\end{tabular}

Nota. Elaboración propia

\section{Análisis Ecológico}

El tema ecológico es una tendencia actual en todo el mundo que trata de buscar productos que no causen daño al medio ambiente. Las empresas productoras de gases industriales deben buscar constantemente maneras de minimizar el impacto ambiental que derivan de sus operaciones.

Tabla 39 Análisis ecológico

\begin{tabular}{ll}
\hline Oportunidades & Amenazas \\
\hline$\bullet$ & Tendencia de buscar productos \\
que no causen daño al medio & \\
ambiente. &
\end{tabular}

Nota. Elaboración propia

\section{Análisis de la competencia}

Se dividió anteriormente a los competidores en dos grupos, el primero "las grandes empresas", compañías reconocidas a nivel internacional con muchos años de experiencia y de presencia en el país como Praxair, Messer e Indura, pero que sin embargo no son una competencia directa ya que ninguna de ellas posee plantas u oficinas en el departamento de Puno. El segundo grupo está conformado por los competidores directos, donde se ubica la empresa CIGA S.A., marca que pertenece 
al Grupo Tecnides y que es la única empresa con planta propia productora de Oxigeno industrial en el departamento de Puno y que abarca el 50\% del mercado, en este grupo también se ubican a los distribuidores, pequeñas empresas que como su nombre lo dice solo se dedican a distribuir Oxigeno industrial, el cual adquieren de otras empresas que pueden ser en algunos casos las grandes empresas.

Tabla 40 Análisis de la competencia

\begin{tabular}{|c|c|}
\hline Oportunidades & Amenazas \\
\hline 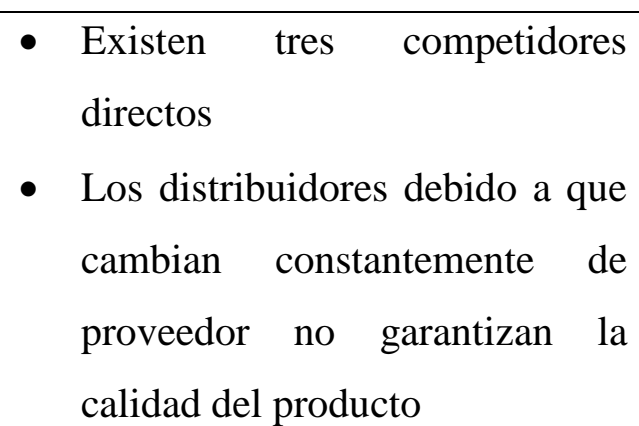 & $\begin{array}{l}\text { - Posible ingreso de las } \\
\text { grandes empresas al } \\
\text { mercado }\end{array}$ \\
\hline
\end{tabular}

Nota. Elaboración propia

\section{Análisis de los servicios sustitutos}

El Oxigeno industrial se utiliza en la industria metalmecánica principalmente en la soldadura por autógena donde se mezcla el oxígeno con acetileno, pero existen otros tipos de soldadura como la soldadura por electrodos, de igual manera el oxígeno es utilizado para el corte de diversos materiales ferrosos de considerable espesor este proceso se conoce como oxicorte, para este producto también existen sustitutos como el corte por plasma, corte por agua, etc. Estos procesos actualmente son más costosos pero podrían obtener mejores acabados en su aplicación. 
Tabla 41 Análisis servicios sustitutos

\begin{tabular}{llll}
\hline \multicolumn{3}{l}{ Oportunidades } & Amenazas \\
\hline$\bullet$ & Los costos de los & $\bullet$ & Productos \\
productos sustitutos & & sustitutos presentan \\
& son más elevados & & mejores acabados
\end{tabular}

Nota. Elaboración propia

\section{Análisis de los proveedores}

Oxigeno del Sur, por la composición de sus productos no requiere de materia prima específica, todos los insumos requeridos podrán ser encontrados tanto en el mercado nacional como internacional.

En cuanto a los proveedores de los servicios básicos como son el agua y la energía eléctrica, tienen sus propias reglas así que sus costos no se pueden negociar.

Tabla 42 Análisis proveedores

\begin{tabular}{lll}
\hline Oportunidades & \multicolumn{2}{l}{ Amenazas } \\
\hline$\bullet$ Proveedores de insumos & $\bullet$ & No se tiene poder para \\
a nivel nacional e & negociar con las compañías \\
internacional & & de servicios básicos.
\end{tabular}

Nota. Elaboración propia

\section{Análisis de los clientes}

El mercado de Oxigeno industrial, como ya se ha mencionado, se encuentra actualmente cubierto por una sola empresa que cuenta con su propia planta de producción de Oxigeno industrial y por dos distribuidores, empresas que no se dan abasto para cubrir todos los requerimientos de los consumidores de Oxigeno 
industrial, además existe una demanda emergente de Oxigeno en el departamento de Puno debido a todos los proyectos mineros y de infraestructura que se tienen preparados para esta región.

Tabla 43 Análisis clientes

\begin{tabular}{lll}
\hline Oportunidades & Amenazas \\
\hline$\bullet$ & Demanda emergente por todos & \\
los proyectos planificados para la & \\
& región Puno \\
\hline
\end{tabular}

Nota. Elaboración propia

\section{Consolidado de Oportunidades y Amenazas}

\section{Oportunidades}

- Formalizar la empresa para proyectar una imagen de empresa formal y responsable, cumplir con todas las normas y reglas vigentes fortalecerá la imagen de nuestra empresa, y permitirá que nuestros clientes nos perciban como una empresa preocupada por cumplir con todas sus obligaciones y sus estándares de calidad.

- Cartera de proyectos mineros, dentro del territorio peruano se encuentran listos 12 proyectos mineros, los cuales ya cuentan con un estudio de impacto ambiental aprobado, dentro de estos planes encontramos al proyecto minero Ollachea, zona con recursos auríferos, ubicado en la provincia de CarabayaPuno.

- Aprovechar la Tecnología Criogénica para obtener un producto de alta calidad y pureza, la tecnología Criogénica consigue la separación del aire utilizando 
temperaturas criogénicas, esta tecnología permite conseguir productos de alta pureza y calidad.

- Tendencia de buscar productos que no dañen el medio ambiente, contar con un sistema de protección ambiental o un manual de procedimientos ambientales nos convierte en una empresa con responsabilidad social y que se preocupa por la sostenibilidad, todo esto ayuda a la imagen de la empresa.

- Solo existe un competidor directo, el estudio de mercado nos reveló que solo tenemos un competidor directo, el cual no es suficiente para cubrir la demanda existente y emergente.

- Los distribuidores debido a que cambian constantemente de proveedor no garantizan la calidad del producto, los distribuidores captan el Oxigeno industrial que distribuyen de la empresa que en ese momento le ofrezca un mejor precio, sin importarles mucho la calidad del producto.

- Los costos de los productos sustitutos son más elevados, existen productos sustitutos para actividades como la soldadura y el corte de materiales ferrosos, donde principalmente se aplica el oxígeno industrial, sin embargo sus costos representan una inversión mayor que no todas las empresas están dispuestas a aceptar.

- Proveedores de insumos a nivel nacional e internacional, los insumos que se requieren son fáciles de hallar en el mercado nacional e internacional.

- Demanda emergente por todos los proyectos planificados para la región Puno, los proyectos mineros, de infraestructura, inmobiliarios y de ingeniería civil planificado para el departamento de Puno representaran un incremento en la demanda de Oxigeno industrial.

\section{Amenazas}


- Posibles competidores informales, como ya lo hemos mencionado anteriormente en el departamento de Puno existe mucha informalidad y en cualquier momento podría extenderse al mercado de Oxigeno industrial.

- Paralización de proyectos inmobiliarios y de ingeniería civil a nivel nacional, los últimos acontecimientos podrían retrasar el inicio de algunos proyectos de inversión tanto en el departamento de Puno como en el resto del país.

- Informalidad y contrabando, si bien un producto como el Oxigeno industrial sería muy difícil de falsificar y comercializar, los envases y otros instrumentos utilizados sí podrían verse afectados por el contrabando.

- Potencial ingreso de las grandes empresas al mercado de oxigeno industrial, empresas reconocidas internacionalmente podrían ingresar en cualquier momento a la ciudad de Juliaca y con su reconocimiento y publicidad podrían restarnos clientes.

- Productos sustitutos presentan mejores acabados, los productos sustitutos representan una mayor inversión por parte de los consumidores, sin embargo sus acabados pueden resultar superiores a los del Oxigeno industrial.

- No se cuenta con poder para cambiar o negociar con las compañías de servicios básicos, la empresa propuesta requerirá grandes cantidades de energía eléctrica y su precio no es negociable. 


\subsubsection{Análisis Interno}

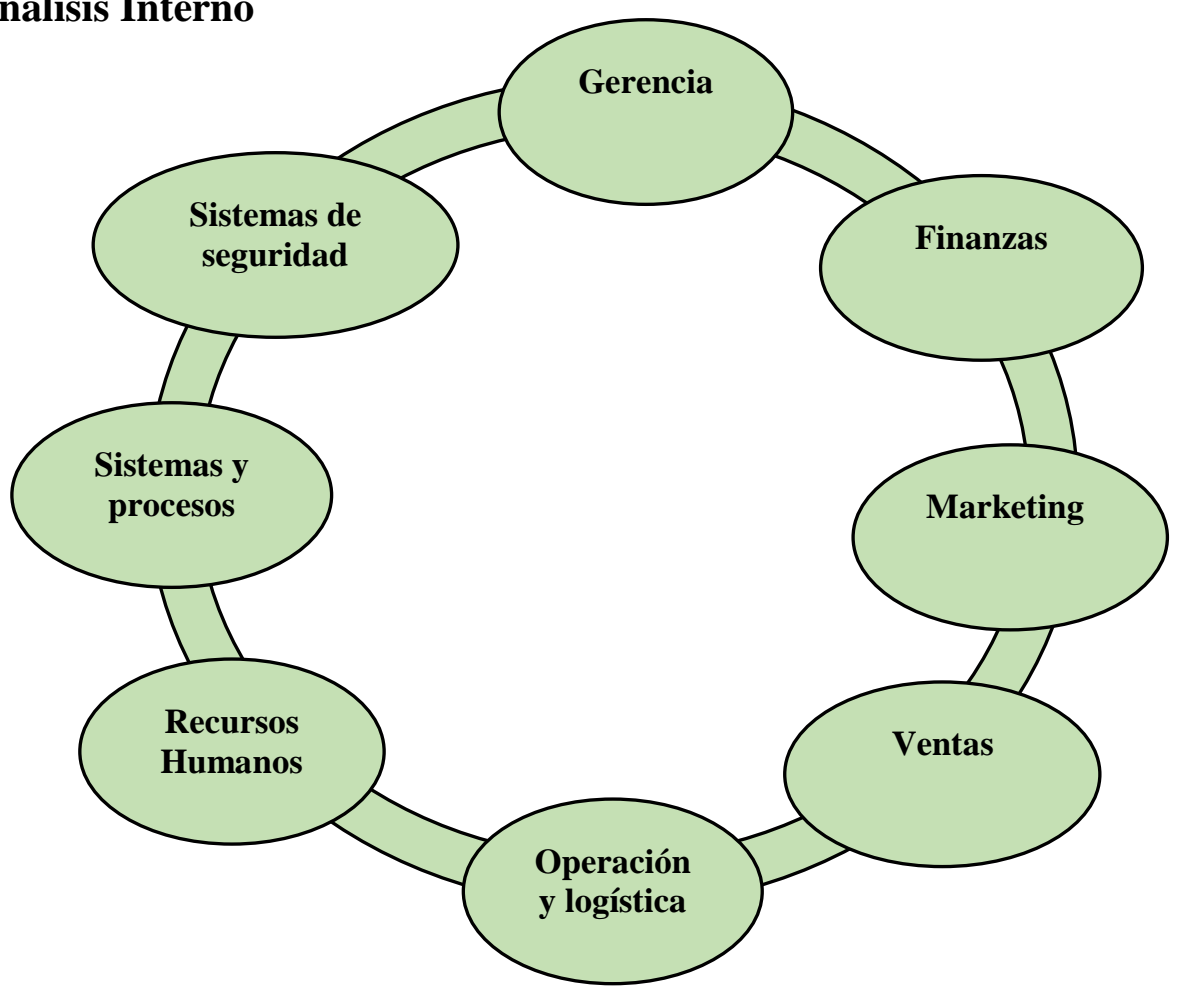

Figura 34 Análisis Interno. Elaboración propia

En cuanto al análisis interno de la empresa, abarca aspectos sobre los cuales la organización puede influenciar por formar parte de la misma empresa:

\section{Análisis de la Gerencia}

La empresa debe contar con un Gerente administrativo capacitado en la dirección de empresas especializadas en la producción y distribución de gases industriales, el ocupante del puesto debe sentirse comprometido en alcanzar resultados positivos para la empresa, teniendo siempre presente los objetivos de la empresa.

El Gerente administrativo deberá contar con habilidades de liderazgo necesarias para proporcionar un clima laboral agradable. 
Tabla 44 Análisis gerencia

\begin{tabular}{l} 
Fortalezas \\
\hline Gerente que cuente con \\
experiencia en regir empresas de \\
gases industriales. \\
Gerente comprometido con el \\
negocio y los resultados. \\
\hline Nota. Elaboración propia
\end{tabular}

\section{Análisis de las Finanzas}

Las empresas que comprenden el mercado objetivo, son empresas serias preocupadas por sus procesos, por lo que consideramos que el pago por el servicio ofrecido se realizara dentro de los plazos pactados.

El producto y servicio serán pagados a través de depósitos y transferencias bancarias, de este modo se evitan riesgos para la empresa propuesta y para los clientes.

Durante el inicio de las operaciones se dependerá financieramente de los socios o entidades financieras que permitan sostener las actividades de la empresa hasta conseguir un equilibrio.

Tabla 45 Análisis finanzas

\begin{tabular}{|c|c|}
\hline Fortalezas & Debilidades \\
\hline 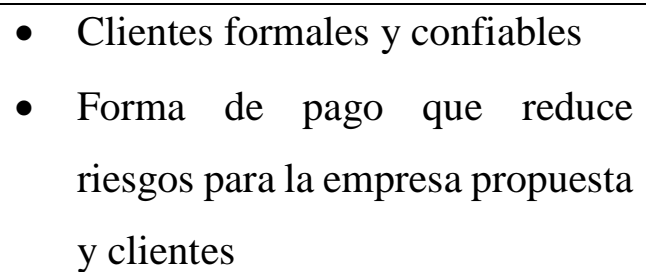 & $\begin{array}{l}\text { - Por tratarse de una empresa } \\
\text { nueva no se cuenta con historial } \\
\text { crediticio que permita acceder a } \\
\text { créditos con intereses bajos. }\end{array}$ \\
\hline
\end{tabular}

Nota. Elaboración propia 


\section{Análisis de Marketing}

La empresa propuesta tratara siempre de posicionarse como líder en el mercado del Oxigeno industrial en el departamento de Puno, realizando visitas a nuestros potenciales clientes para ofrecerles nuestros productos y publicitándonos en medios escritos y redes sociales.

Aprovechando que las empresas consumidoras de Oxigeno debe conformarse con el servicio que le ofrece la única planta instalada en Juliaca y los distribuidores que compran el oxígeno industrial a otras empresas.

La empresa debe proyectar siempre una imagen de asociada a la calidad y seguridad de sus servicios.

Tabla 46 Análisis marketing

\section{Fortalezas \\ Debilidades}

- Acceso a canales de difusión económicos como las redes sociales.

- Por ser una empresa nueva el plan

- Puesta en marcha de un plan de marketing que logre fidelizar al de marketing se acomodara a un presupuesto reducido. cliente.

Nota. Elaboración propia

\section{Análisis de Ventas}

“Oxigeno del Sur" ofrece el producto y servicio de Oxigeno industrial, sus características principales son la calidad y seguridad, por lo tanto se determinó que los operarios, sobre todo los que distribuyen el producto, son la mejor carta de presentación de la empresa y deben proyectar siempre profesionalismo, capacidad 
y amabilidad para generar una imagen adecuada de la empresa que se manifieste en su rentabilidad.

Tabla 47 Análisis ventas

Fortalezas Debilidades

- Existencia de canales - No se contara con impulsadores de económicos de difusión. ventas.

Nota. Elaboración propia

\section{Análisis de la Operación y logística}

La empresa registrara a todos los clientes, así se podrá responder oportunamente a sus requerimientos, se tendrán registrados no solo los datos de facturación de los clientes, sino también las cantidades de producto que normalmente requieran y cualquier otra exigencia que tengan.

Se contara también con una zona de almacenaje adecuadamente distribuida y organizada de manera adecuada para almacenar el producto envasado y contar con las posibilidades de atender cualquier pedido imprevisto que se presente.

Tabla 48 Análisis operación y logística

\section{Fortalezas \\ Debilidades}

- Elaboración de una base de datos delos clientes.

- Capacidad de respuesta ante cualquier imprevisto. 
- Operarios de almacén capacitados.

Nota. Elaboración propia

\section{Análisis de los Recursos Humanos}

Cada área de la empresa estará conformada por personal capacitado y con experiencia. Cada miembro del personal será seleccionado de manera estricta.

Todo colaborador, será capacitado antes de ingresar al puesto y durante su permanencia en el. Cada trabajador deberá cumplir los estándares establecidos por la empresa.

Tabla 49 Análisis recursos humanos

Fortalezas Debilidades

- Personal capacitado.

- Personal seleccionado bajo un estricto régimen.
- Poca presencia de personal con experiencia en el rubro en el departamento de Puno

Nota. Elaboración propia

\section{Análisis de los Sistemas y procesos}

Oxigeno del Sur será capaz de responder de forma inmediata cuando se trate de cubrir un servicios, de forma que se pueda atender las solicitudes planeadas y no planeadas dentro de los plazos determinados basados en un protocolo de atención.

Tabla 50 Análisis sistemas y procesos

Fortalezas Debilidades


- Respuesta inmediata de toda solicitud.

Nota. Elaboración propia

\section{Análisis de los Sistemas de Seguridad}

Oxigeno del Sur tendrá diseñados protocolos de seguridad, que comprenderán las características de la empresa, todo trabajador deberá ingresar a su zona de trabajo utilizando el uniforme e implementos de seguridad correspondiente a sus labores.

Tabla 51 Análisis sistemas de seguridad

Fortalezas Debilidades

- Se contara con un protocolo de seguridad dentro y fuera de la empresa.

Nota. Elaboración propia

\section{Consolidado de Fortalezas}

- Gerente administrativo con la suficiente experiencia en gestionar empresas de gases industriales, se tendrá una persona con experiencia en el manejo de una empresa de este tipo, que conozca el proceso de producción del oxígeno industrial, sus condiciones de almacenamiento y las condiciones para su distribución, así como las labores administrativas propias de su cargo.

- Gerente administrativo enfocado en el negocio y la obtención de resultados. 
- Clientes formales y confiables, se buscara hacer tratos con empresas serias, formadas de acuerdo a ley y que tengan los conocimientos necesarios para la manipulación del Oxigeno industrial.

- Forma de pago que disminuye riesgos para la empresa y clientes, luego de recibir la solicitud del producto por parte del cliente, se enviara una liquidación y los clientes deben cancelarla antes de realizarse el servicio efectuando un depósito a las cuentas de la empresa.

- Acceso a canales de difusión económicos como las redes sociales, la empresa estará presente en las redes sociales como Facebook desde donde podremos llegar al mercado objetivo.

- Elaboración de un plan de marketing que busque fidelizar al cliente, se tendrá un plan de marketing que incluya publicidad en medios escritos, redes sociales, además de visitas a nuestros potenciales clientes para explicarles los beneficios de los productos.

- Procesamiento de una base de datos de los clientes, contar con un registro de los clientes mantendrá informada a la empresa acerca de sus requerimientos y exigencias.

- Capacidad de respuesta, trabajadores capacitados para afrontar situaciones adversas durante su desenvolvimiento.

- Almaceneros capacitados, personal en constante capacitación para manejar adecuadamente el almacén.

- Personal elegido de manera rigurosa, se realizaran las acciones necesarias para seleccionar al personal adecuado, dando prioridad aquellos que demuestren experiencia y presenten referencias positivas de trabajos anteriores 
- Contamos con un protocolo de seguridad, contaremos con un protocolo de seguridad para el manejo del producto.

Consolidado de Debilidades

- Oxigeno del Sur contara con historial crediticio limitado por tratarse de una empresa nueva, la empresa en sus inicios solo podrá a acceder a créditos reducidos.

- El plan de marketing será también reducido por que se le asignara un presupuesto pequeño. Posterior al inicio de las operaciones y cuando la empresa este establecida en el mercado y sea más rentable se pretende incrementar su presupuesto.

- Oxigeno del Sur no contara con impulsadores de ventas, durante los inicios de la empresa su prioridad será cubrir los puestos más importantes y necesarios.

- Poca presencia de personal con experiencia en el rubro en el departamento de Puno, al realizar la selección de personal se pudo notar que en el departamento de Puno, específicamente la ciudad de Juliaca no se encuentran personas con experiencia en manipulación de gases industriales.

\subsubsection{Matriz de Ventajas Competitivas Sostenibles}

Se hará uso de una matriz de ventajas competitivas sostenibles para identificar las fortalezas de la empresa, se debe establecer cuáles son las fortalezas realmente importantes, en la matriz de ventajas competitivas sostenibles se colocara todas las fortalezas y se procederá a responder las siguientes preguntas:

- ¿Esa fortaleza es valiosa?

- ¿La fortaleza es irreemplazable?

- ¿La fortaleza es rara? 
- ¿La fortaleza es complicada de imitar?

- ¿La fortaleza es una competencia nuclear?

Luego de contestar esas preguntas se determinara si se trata de:

- Ventaja Competitiva Sostenible; ventaja propia de la empresa tiene y difícil de imitar.

- Ventaja Competitiva Temporal; ventaja con la que cuenta la empresa pero que es sencilla de imitar.

- Paridad Competitiva; ventaja competitiva compartida con la competencia.

Se obtuvieron los siguientes resultados: 
Tabla 52 Matriz de ventajas competitivas sostenibles

\section{MATRIZ DE VENTAJAS COMPETITIVAS SOSTENIBLES}

\begin{tabular}{|c|c|c|c|c|c|c|}
\hline Fortalezas & ¿Valioso? & ¿Raro? & $\begin{array}{l}\text { ¿Difícil de } \\
\text { imitar? }\end{array}$ & ¿Insustituible? & $\begin{array}{l}\text { ¿Competencia } \\
\text { nuclear? }\end{array}$ & $\begin{array}{l}\text { Ventaja } \\
\text { Competitiva }\end{array}$ \\
\hline $\begin{array}{l}\text { Gerente administrativo con experiencia en } \\
\text { gestionar empresas de gases industriales }\end{array}$ & SI & SI & $\mathrm{NO}$ & $\mathrm{NO}$ & SI & $\begin{array}{l}\text { Ventaja } \\
\text { Competitiva } \\
\text { Sostenible }\end{array}$ \\
\hline $\begin{array}{l}\text { Gerente comprometido con el negocio y sus } \\
\text { objetivos }\end{array}$ & SI & $\mathrm{NO}$ & $\mathrm{NO}$ & $\mathrm{NO}$ & SI & $\begin{array}{l}\text { Paridad } \\
\text { Competitiva }\end{array}$ \\
\hline Clientes formales y confiables & SI & SI & $\mathrm{NO}$ & $\mathrm{NO}$ & NO & $\begin{array}{l}\text { Ventaja } \\
\text { Competitiva } \\
\text { Temporal }\end{array}$ \\
\hline $\begin{array}{l}\text { Forma de pago sin riesgos para la empresa } \\
\text { y clientes }\end{array}$ & SI & $\mathrm{NO}$ & $\mathrm{NO}$ & $\mathrm{NO}$ & $\mathrm{NO}$ & $\begin{array}{l}\text { Paridad } \\
\text { Competitiva }\end{array}$ \\
\hline $\begin{array}{l}\text { Acceso a canales de difusión económicos } \\
\text { como las redes sociales }\end{array}$ & SI & $\mathrm{NO}$ & $\mathrm{NO}$ & $\mathrm{NO}$ & $\mathrm{NO}$ & $\begin{array}{l}\text { Paridad } \\
\text { Competitiva }\end{array}$ \\
\hline $\begin{array}{l}\text { Elaboración de un plan de marketing que } \\
\text { fidelice al cliente }\end{array}$ & SI & SI & SI & $\mathrm{NO}$ & SI & $\begin{array}{l}\text { Ventaja } \\
\text { Competitiva } \\
\text { Sostenible }\end{array}$ \\
\hline
\end{tabular}


Elaboración de una base de datos de los clientes

Capacidad de respuesta ante cualquier inconveniente

Almacenero capacitado

Personal elegido de manera rigurosa

La empresa cuenta con un protocolo de seguridad
SI

SI

SI

NO

NO

$$
\text { NO }
$$

NO

SI

SI

SI

SI

SI

SI
Ventaja

NO

NO Competitiva

Temporal

Ventaja

SI Competitiva

Sostenible

Paridad

Competitiva

Ventaja

SI Competitiva

Sostenible

Ventaja

SI Competitiva

Sostenible

Nota. Elaboración propia 


\subsubsection{Matriz FODA}

Luego de efectuar el análisis externo e interno de la empresa, se procederá a elaborar una matriz FODA, que ayudara a determinar las estrategias de la empresa tomando en cuenta las oportunidades, amenazas, fortalezas y debilidades detectadas.

\section{Importancia del FODA para un plan de negocios}

La importancia del FODA como parte de la elaboración de un plan de negocios radica en que la información obtenida durante el análisis permitirá a los investigadores plantear estrategias, metas y planes de acción que ayudaran a conocer la dirección que va a tomar la empresa propuesta dentro del mercado.

El FODA ayuda a determinar esos aspectos que pueden favorecer a una empresa nueva (fortalezas y oportunidades) así como también ayuda a detectar aquellos factores o aspectos que pueden obstaculizar el desarrollo de una nueva empresa (debilidades y amenazas). (Borello, 1994) 
Tabla 53 Análisis FODA de "Oxigeno del sur" (Estrategias FO, DO)

\section{FODA}

O1 Formalizar la empresa para proyectar

una imagen seria.

O2 Cartera de proyectos mineros

O3 Aprovechar la Tecnología Criogénica para obtener un producto de alta calidad y pureza.

O4 Tendencia de buscar productos que no dañen el medio ambiente.
Debilidades

F1 Gerente administrativo con la experiencia necesaria para dirigir empresas de gases industriales

F2 Elaboración de un plan de marketing que fidelice cliente

F3 Capacidad de respuesta ante cualquier inconveniente.

F4 Personal elegido de manera estricta.

F5 Contar con un protocolo de seguridad

$$
\text { Estrategias (FO) }
$$

1.-El profesionalismo del personal fortificará

la imagen de la empresa.(F1,F4,O1)

2.-El plan de marketing estará enfocado en captar a la demanda insatisfecha actualmente cubierta solo por un competidor directo y dos distribuidores. (F2,O5,O6)

D1 Por tratarse de una empresa nueva no se contara con historial crediticio que permita acceder a créditos grandes.

D2 Por tratarse de una empresa nueva el presupuesto del plan de marketing será reducido.

D3 La empresa no contara con impulsadores de ventas.

D4 Poca presencia de personal con experiencia en el rubro en el departamento de Puno.

Estrategias (DO)
4.- Se aprovechara la insatisfacción actual de la demanda potencial para introducir el producto resaltando las virtudes de nuestro producto y servicio (D2, D3, O5, O6).

3.- Las cualidades de la forma de trabajo,

como la capacidad de respuesta y el 
O5 Solo existe un competidor directo.

O6 Los distribuidores debido a que

cambian constantemente de proveedor no garantizan la calidad del producto.

O7 El precio de los productos sustitutos son elevados a comparación del oxígeno industrial.

O8 Proveedores de insumos a nivel nacional e internacional.

O9 Demanda emergente de acuerdo a los proyectos planeados para la región Puno. cumplimiento de los protocolos de seguridad y atención al cliente, en conjunto con el plan de marketing y la tecnología usada para la obtención del producto volverá a la empresa más llamativa ante la demanda emergente.

(F2, F3, F5, O2, O3, O9)

Nota. Elaboración propia 
Tabla 54 Análisis FODA de "Oxigeno del sur" (Estrategias FA, DA)

\section{Fortalezas \\ FODA \\ F1 Gerente administrativo con experiencia en dirigir empresas de gases industriales \\ F2 Elaboración de un plan de marketing que fidelice al cliente \\ F3 Capacidad de respuesta ante cualquier incidencia. \\ F4 Personal elegido de manera estricta \\ F5 Se cuenta con un protocolo de seguridad}

Amenazas

Debilidades

D1 Por tratarse de una empresa nueva no se contara con historial crediticio que permita acceder a créditos grandes.

D2 Por tratarse de una empresa nueva el presupuesto del plan de marketing será reducido.

D3 La empresa no contara con impulsadores de ventas.

D4 Poca presencia de personal con experiencia en el rubro en el departamento de Puno.

Estrategias (DA)

A1 Posibles competidores informales. 5.- Contar con un gerente enfocado en los A2 Paralización de proyectos objetivos de la empresa y con personal inmobiliarios y de ingeniería civil a nivel seleccionado rigurosamente permitirá sobresalir nacional.

A3 Informalidad y contrabando en el ambiente de informalidad que impera en la ciudad de Juliaca y de esta manera poco a poco A4 Potencial ingreso de grandes fidelizar al cliente y superar a los productos empresas al mercado de oxigeno sustitutos y estar preparados para enfrentar un industrial. $\quad$ potencial ingreso de grandes empresas de
6.- Sacar provecho de manera efectiva los canales de comunicación, para transmitir una imagen de calidad y seguridad de la empresa Oxigeno del Sur y así poder captar al mercado objetivo para poder competir con otras empresas que se presenten en el futuro. (D2, A4) 
A5 Productos sustitutos presentan oxigeno industrial al mercado (F1, F2, F4, A3,

mejores acabados.

A5, A4).

A6 No se cuenta con poder para negociar

con las empresas de servicios básicos.

Nota. Elaboración propia 


\subsubsection{Estrategias del negocio}

Luego de elaborar la matriz FODA, presentamos las siguientes estrategias:

- El profesionalismo del personal fortificará la imagen de la empresa.(F1,F4,O1)

- El plan de marketing estará enfocado en captar a la demanda insatisfecha actualmente cubierta solo por un competidor directo y dos distribuidores. $(\mathrm{F} 2, \mathrm{O} 5, \mathrm{O} 6)$

- Las cualidades de la forma de trabajo, como la capacidad de respuesta y el cumplimiento de los protocolos de seguridad y atención al cliente, en conjunto con el plan de marketing y la tecnología usada para la obtención del producto volverá a la empresa más llamativa ante la demanda emergente. (F2, F3, F5, O2, O3, O9)

- Se aprovechara la insatisfacción actual de la demanda potencial para introducir el producto resaltando las virtudes de nuestro producto y servicio (D2, D3, O5, O6).

- Contar con un gerente enfocado en los objetivos de la empresa y con personal seleccionado rigurosamente permitirá sobresalir en el ambiente de informalidad que impera en la ciudad de Juliaca y de esta manera poco a poco fidelizar al cliente y superar a los productos sustitutos y estar preparados para enfrentar un potencial ingreso de grandes empresas de oxigeno industrial al mercado (F1, F2, F4, A3, A5, A4).

- Sacar provecho de manera efectiva los canales de comunicación, para transmitir una imagen de calidad y seguridad de la empresa Oxigeno del Sur y así poder captar al mercado objetivo para poder competir con otras empresas que se presenten en el futuro. (D2, A4) 


\subsection{Determinación de las Ventajas Competitivas Críticas.}

Se realizó un análisis previo del ambiente interno de Oxigeno del Sur concentrándose en factores relacionados a la gerencia, finanzas, marketing, etc. El determino las fortalezas de la empresa, las cuales fueron ingresadas a la matriz de ventajas competitivas que ayudan a establecer si son ventajas competitivas sostenibles, temporales o de paridades competitiva.

Posteriormente se identificaron las siguientes ventajas competitivas para Oxigeno del Sur:

- Gerente General encargado de toma decisiones de la empresa, responsable de liderar, coordinar y generar ganancias. Gerente enfocado en el negocio y en alcanzar sus objetivos.

- Gerente administrativo con suficiente experiencia en gestionar empresas de gases industriales.

- Clientes serios y confiables.

- Forma de pago que reduce riesgos para la empresa y sus clientes.

- Acceso a canales de difusión económicos como las redes sociales.

- Elaboración de un plan de marketing que fidelice al cliente.

- Elaboración de una base de datos de los clientes

- Capacidad de respuesta ante cualquier incidencia.

- Almacenero capacitado

- Personal elegido bajo un riguroso régimen de selección

- Se contara con un protocolo de seguridad 


\subsection{Diseño De La Estructura Organizacional Deseada}

Se presentara un esquema organizacional que muestre el nivel jerárquico de cada puesto de trabajo de acuerdo a sus obligaciones.

La distribución muestra a la ubicación de los colaboradores de la empresa:

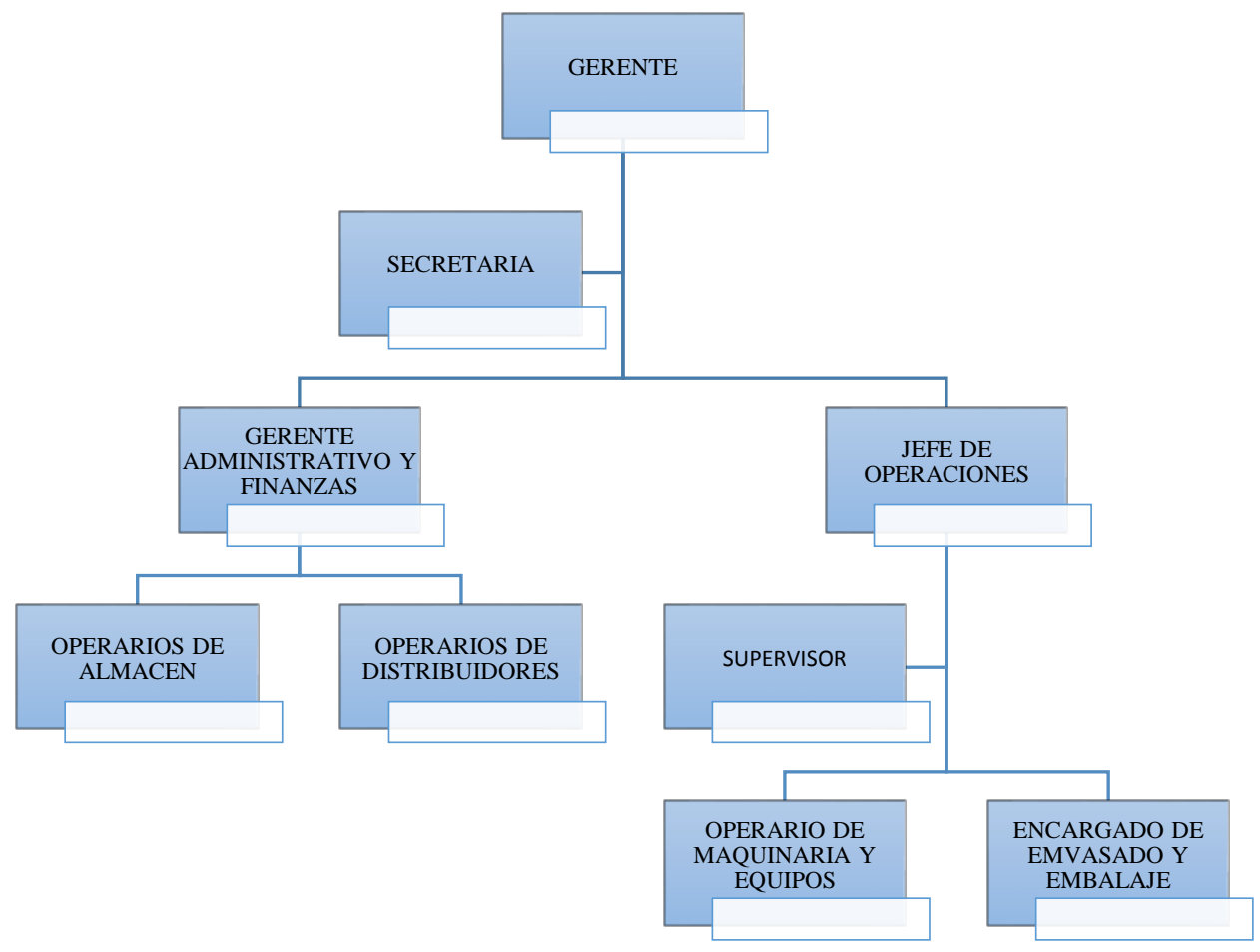

Figura 35. Estructura Organizacional. Elaboración propia

\subsection{Diseño de Los Perfiles en Puestos Claves:}

En esta etapa del estudio, se definirán las obligaciones y responsabilidades que se asignarán a los diversos puestos de la organización. Esto permitirá dar los lineamientos necesarios para la adecuada gestión del negocio. Para definir las funciones y puestos que requerirá la empresa debemos considerar aspectos tales como:

- Actividades a realizar. 
- Aspectos legales, tributarios y técnicos requeridos.

- Tamaño del proyecto.

- Consideraciones de los anteriores estudios.

Según estos criterios podemos definir las funciones que se requerirán en cada una de los puestos de la organización. De esta manera, tenemos el perfil de puestos:

Puesto

Área

Supervisado por : Accionistas

Supervisa a

Coordina con

\section{: Gerente General}

: Gerencia de Administrativo

funciones.

Finalidad del puesto : Planear, dirigir y administrar la empresa, tomar decisiones en forma oportuna para lograr los objetivos de la empresa.

\section{Funciones}

: Gerente administrativo, Jefe de Operaciones

: Jefes, clientes y toda persona ligada a la ejecución de sus

Ejecuta la planeación estratégica de la empresa.

$\checkmark$ Diseña los planes comerciales de la empresa

Controla el funcionamiento de las áreas que conforman a la empresa.

$\checkmark$ Fiscaliza la dirección financiera de la empresa

$\checkmark$ Diseña el plan de marketing

$\checkmark$ Promueve el clima laboral saludable

$\checkmark$ Solicita financiamiento de acuerdo a los requerimientos de la empresa 
$\checkmark$ Escucha y busca soluciones para las quejas del personal

Responsabilidad directa sobre activos: equipos de cómputo, teléfonos móviles, escritorio, etc.

Puesto : Supervisor

Área : Producción

Supervisado por : : Gerente Administrativo

Supervisa a : Operarios de almacén, de producción y distribución.

Coordina con $\quad$ : Gerente administrativo, clientes y toda persona ligada a la ejecución de sus funciones.

Finalidad del puesto: Certificar el cumplimiento de las labores por parte de los operarios de producción, almacén y distribución, controlando las labores antes durante y después del servicio.

\section{Funciones :}

$\checkmark$ Elaborar la hoja de ruta para los operarios distribuidores diariamente.

$\checkmark$ Estar en contacto con los operarios distribuidores durante todo el servicio

$\checkmark$ Registrar la asistencia del personal, tardanzas, faltas, etc.

$\checkmark$ Demanda y controla el uso del uniforme e implementos de seguridad

$\checkmark$ Promueve un buen clima laboral

$\checkmark$ Se hace cargo de revisar los inventarios de almacén 
$\checkmark$ Dispone diversas acciones con los proveedores.

Responsabilidad directa sobre activos: equipos de operaciones y cómputo, teléfonos móviles, escritorio, etc.

Puesto : Operario de producción

Área : Producción

Supervisado por : Supervisor

Coordina con : Supervisor y toda persona ligada a la ejecución de sus funciones.

Finalidad del puesto: Operar los equipos de producción de Oxigeno industrial, así como supervisar la calidad del producto.

Funciones :

$\checkmark$ Supervisión del proceso de producción del Oxigeno industrial

$\checkmark$ Manejo de los equipos y utensilios del área de producción según los protocolos de seguridad.

$\checkmark$ Procurar una relación amables con el resto de colaboradores

$\checkmark$ Manejar el manual de manipulación de gases industriales

$\checkmark$ Conservar un comportamiento adecuado dentro y fuera de la empresa. 
Responsabilidad directa sobre activos: equipos de producción de oxígeno, teléfonos móviles, material de apunte, etc.

\author{
Puesto : Operario de almacén \\ Área : Producción \\ Supervisado por : Supervisor \\ Coordina con : Supervisor y toda persona ligada a la ejecución de sus \\ funciones.
}

Finalidad del puesto : Gestionar la adecuada distribución del producto, equipos y materiales de la empresa.

\title{
Funciones
} :

$\checkmark$ Inspeccionar la cadena de suministros.

$\checkmark$ Conservar el orden dentro del almacén.

$\checkmark$ Verificar que la salida de los envases se haga en el tiempo estimado.

$\checkmark$ Utilizar el software de control logístico

$\checkmark$ Tener una relación cordial con el resto de operarios

$\checkmark$ Manejar el manual de manipulación de gases industriales

$\checkmark$ Conservar un comportamiento adecuado 
Responsabilidad directa sobre activos: equipos materiales e insumos.

Puesto

Área

Supervisado por

Coordina con funciones.

\section{: Operario Distribuidor}

: Distribución

: Supervisor y toda persona ligada a la ejecución de sus

Finalidad del puesto: Abastecer a los clientes del producto, de acuerdo a sus requerimientos, brindando un servicio regido por las normas de seguridad establecidas.

\section{Funciones}

:

$\checkmark$ Revisar al momento de la entrega del producto en almacén que los envases estén en buen estado.

$\checkmark$ Inspeccionar que el transporte de la empresa se encuentre operativo para el servicio del día siguiente.

$\checkmark$ Atender a los clientes con cortesía y amabilidad durante todo el servicio 
$\checkmark$ Resolver cualquier inconveniente que se presente durante el servicio, de persistir el problema comunicarlo al supervisor.

$\checkmark$ Hacer que el cliente llene la hoja de conformidad del servicio

Responsabilidad directa sobre activos: equipos, envases y producto.

$\begin{array}{ll}\text { Puesto } & \text { : Secretaria } \\ \text { Área } & \text { : Administrativa }\end{array}$

Supervisado por : : Gerente Administrativo

Coordina con : Gerente administrativo, Supervisor y toda persona ligada a la ejecución de sus funciones.

Finalidad del puesto : Recepcionar los requerimientos de los clientes y resolver las dudas que puedan tener, respecto al producto y servicio que se ofrece.

\section{Funciones :}

$\checkmark$ Responder a las solicitudes de los clientes, que lleguen a la oficina ya sea de manera presencial, por teléfono, correo electrónico, etc.

$\checkmark$ Renovar constantemente la base de datos de los clientes

$\checkmark$ Notificar al Gerente Administrativo acerca de los servicios que se ejecutaran diariamente

$\checkmark$ Estar pendiente de la correspondencia 
$\checkmark$ Proporcionar informes sobre el producto y servicio que ofrece Oxigeno del Sur

Responsabilidad directa sobre activos: equipo de cómputo, teléfono móvil, escritorio, etc.

\subsection{Remuneraciones e Incentivos}

\subsubsection{Objetivo General}

Calcular las remuneraciones del personal de acuerdo al orden jerárquico de la empresa, conservando las remuneraciones acorde con las labores de cada trabajador.

\subsubsection{Objetivos Específicos}

$\checkmark$ Establecer la remuneración básica para cada trabajador, teniendo en cuenta sus beneficios de ley.

$\checkmark$ Delimitar los parámetros que permitan establecer el monto de las remuneraciones.

$\checkmark$ Estimular la eficiencia de los trabajadores

Considerando los objetivos del plan de remuneraciones, es que calculamos los sueldos brutos del personal (por mes), incluyendo el costo del contador (que es personal tercerizado). 
Tabla 55 Costo de la planilla por mes

Personal

\begin{tabular}{l}
\hline Gerente \\
Gerente administrativo y finanzas \\
Jefe de operaciones \\
Supervisor \\
Secretaria \\
Operario de maquinaria y equipos \\
Encargado de envasado y embalaje \\
Operarios de almacén \\
Operarios de distribuidores \\
Contador (Externo)
\end{tabular}

Cantidad Sueldo Bruto

\section{Total/mes}

\begin{tabular}{ccc}
1 & $3,300.00$ & $3,300.00$ \\
1 & $2,500.00$ & $2,500.00$ \\
1 & $2,500.00$ & $2,500.00$ \\
1 & $1,800.00$ & $1,800.00$ \\
1 & $1,300.00$ & $1,300.00$ \\
4 & $1,200.00$ & $4,800.00$ \\
2 & $1,200.00$ & $2,400.00$ \\
1 & $1,200.00$ & $1,200.00$ \\
4 & $1,700.00$ & $6,800.00$ \\
1 & 500 & 500.00 \\
\hline $\mathbf{1 7}$ & & $\mathbf{2 7 , 1 0 0 . 0 0}$
\end{tabular}

Esta tabla no incluye el costo de carga social, que se toma en cuenta al momento de proyectar los egresos anuales en el plan financiero. La carga social, se adecua a las normas laborales vigentes en el país y al tamaño de negocio (Pyme). De tal forma, tenemos los siguientes aportes del empleador para con sus colaboradores:

- Compensación por tiempo de servicio (CTS). A pesar que es un beneficio de las pequeñas empresas depositar media CTS al año. Se seguirá trabajando con la provisión mensual del $\mathbf{9 . 7 2 \%}$ de la remuneración afecta, es decir, para pagar la CTS completa, como parte de los incentivos de la empresa.

- Régimen de Prestación de Salud (ESSALUD). Es igual al 9\% de la remuneración del trabajador.

- Seguro Complementario de Trabajo de Riesgo (SCTR). Que otorga una cobertura adicional en caso de accidentes de trabajo y enfermedades profesionales. Aunque suele aplicarse solo a trabajadores que desempeñen actividades de riesgo; la compañía, al ver que todo su personal puede encontrarse en situaciones de riesgo ocupacional, prefiere otorgar este beneficio a todos. El aporte es igual al $\mathbf{0 . 5 3 \%}$ de la remuneración del trabajador. 
- Provisiones por vacaciones del empleado. La compañía por estar en el régimen de pequeñas empresas, solo tiene que provisionar 15 días de vacaciones para sus colaboradores al año. De tal forma, que la provisión mensual se calcula sobre un 4.17\% de la remuneración afecta.

- Gratificaciones (en los meses de Julio y Diciembre). Para tal fin, se provisionara en forma mensual el $\mathbf{1 6 . 6 7 \%}$ de la remuneración afecta de cada colaborador.

\subsection{Política de Recursos Humanos}

La Política de Recursos Humanos debe funcionar como una pauta para gerencia en su búsqueda de alcanzar los objetivos propuestos de la empresa Oxigeno del Sur.

Basu (2014) señala que "La política de recursos humanos de una compañía es una serie de reglas, procedimientos y lineamientos que rigen las interacciones de la compañía con sus empleados. Se desprenden del plan estratégico general de la compañía, y son usualmente desarrolladas con la participación de los mandos medios y otros empleados. El director o el departamento de recursos humanos es responsable por la compilación, el mantenimiento y la administración de las políticas de recursos humanos de una organización"

\section{Importancia}

La Política de Recursos Humanos se basa en diferentes gestiones como la elección del personal, su posterior capacitación y finalmente su compensación. 
Facilita a la empresa las normas para la elaboración de un programa que promueva el desarrollo de los trabajadores.

\subsubsection{Política de Reclutamiento}

Para el reclutamiento del personal, se hará uso de dos fuentes de información:

- Bolsa de trabajo promovida por el Ministerio de Trabajo

- Publicación de avisos en medios escritos

\subsubsection{Política de Ingreso}

El personal seleccionado deberé tener cumplir con los requerimientos de cada puesto, y sobre todo deben estar dispuestos a identificarse y comprometerse con los objetivos de la empresa. Así se garantizara el reclutamiento de personal honesto y comprometido con la empresa.

\subsubsection{Estrategias de Selección}

- Pruebas Psicológicas, que permitan reconocer formas de comportamiento inadecuado en los postulantes.

- Presentación de documentación relacionada a los antecedentes policiales y penales.

- Documentos que certifique el buen estado de salud de los postulantes.

- Declaración jurada de domicilio.

\subsubsection{Política de Capacitación y Entrenamiento}

Es importante brindar a todos los seleccionado la capacitación y entrenamiento necesarios para fortalecer sus conocimientos y destrezas, para la administración del personal de la empresa propuesta fue necesario establecer las siguiente estrategias de capacitación y entrenamiento. 


\section{Estrategias de Entrenamiento}

- Cuando se realice el ingreso de nuevo personal a la empresa se brindara un recorrido por las diferentes áreas de la empresa para que se familiarice con los diferentes sectores y con sus compañeros de trabajo, buscando que se sienta parte de un equipo.

- Por otro lado de acuerdo al área a la que corresponda el nuevo personal se le adiestrara en el manejo y cuidado de los equipos que tendrá a su cargo.

\section{Capacitación en Protocolo de Seguridad y Servicio al Cliente}

- El personal será constantemente capacitado acerca de las medidas de seguridad que deben seguirse dentro y fuera de las instalaciones, todo de acuerdo a los manuales de manipulación de gases industriales.

- Guía de Atención, el objetivo principal de esta capacitación es lograr que aquellos colaboradores que tengan contacto con nuestros clientes cuenten con los lineamientos necesarios para satisfacer los requerimientos y disipar todas las dudas de nuestros clientes.

\subsubsection{Política de Seguridad Y Bienestar de Personal}

Los principios en los que se basa la Política de Seguridad y Bienestar Social de la empresa son:

- Clima laboral saludable

- Fomentar estilos de vida sanos

- Ofrecer a todos los miembros de la empresa ambientes y condiciones adecuadas. 


\subsubsection{Política de Retención de Personal de "OXIGENO DEL SUR"}

Para poder retener al personal de la empresa Oxigeno del Sur, se ejecutaran una serie de acciones detalladas a continuación:

- Política de Retención: esta política se iniciara desde el momento de la selección del nuevo personal, donde la empresa se asegurar de contratar personal que tenga la intención de avanzar y progresar dentro de la empresa, de esta manera se asegura de no tener una rotación alta de personal.

- Garantizar un Buen Clima Laboral: otra forma de retener al personal es ofreciéndole un clima laboral agradable y saludable, si el colaborador se siente como en la empresa dará lo mejor de sí para obtener buenos resultados, de esta manera también se evita una posible fuga de talentos.

- Línea de Carrera: a pesar de que se trata de una empresa pequeña, se ofrecerá la oportunidad de hacer una línea de carrera dentro de la empresa si así lo desean los trabajadores y si muestran las condiciones necesarias.

- Política de Contratación: "Oxigeno del Sur" se compromete en brindar a sus trabajadores contratos indeterminado sujetos obviamente a las normas de conducta de la empresa, por otro lado la empresa busca diferenciarse de sus competidores los cuales, como se mencionó anteriormente solo ofrecen contrataos no mayores de seis meses.

- Política Remunerativa: los trabajadores de la empresa contaran con sus beneficios de acuerdo a ley sin excepción. Los miembros de la empresa deberán contar con la remuneración por encima de la mínima vital, 15 días de vacaciones, seguro en ESSALUD, compensación por tiempo de servicios y gratificaciones. 


\section{Capítulo VII Plan de Marketing}

\subsection{Introducción}

El plan de marketing es una herramienta esencial para cualquier negocio, para la comercialización eficaz y rentable de un producto o servicio. Proporciona una visión clara de los objetivos que se quieren alcanzar y especifica los objetivos, estrategias, acciones y el tiempo de ejecución, utilizando las 4 p's del marketing mix, producto, precio, plaza, y promoción (Cohen, 2010).

McCarthy y Perrault (2001) también señalan El Plan de Marketing es la formulación escrita de una estrategia de marketing y de los detalles relativos al tiempo necesario para ponerla en práctica; deberá contener la descripción detallada de lo siguiente, ¿qué combinación de marketing se ofrecerá y durante cuánto tiempo?, ¿qué recursos de la compañía será necesarios y con qué periodicidad? y ¿cuáles son los resultados que se esperan? El plan de marketing debe incluir también medidas de control (P.56)

En el presente capitulo se detallaran las estrategias y acciones del plan de marketing, haciendo uso de las 4P del mix de marketing mencionadas por Choen, 2010: Precio, Plaza, Promoción y Producto. El plan de marketing de nuestra empresa será utilizado como una guía para alcanzar los objetivos necesarios para cubrir nuestra proyección de ventas.

\subsubsection{Objetivos}

- Establecer una estrategia de Posicionamiento sostenible acorde al mercado.

- Lograr una participación del mercado objetivo del $25 \%$ por ciento en el primer año de operación. 
- Plantear un programa de seis meses para lograr que el producto sea reconocido por su calidad y seguridad y así cubrir la demanda insatisfecha.

- Incrementar el índice de ventas en un $4 \%$ anual.

- Establecer, en el mediano plazo, rangos de precios por tipo de cliente creando paquetes según sus necesidades.

- Tener con un cronograma de visitas post venta para medir la satisfacción, intereses y aplicación de posibles nuevas estrategias.

\subsubsection{Nombre de la marca:}

Los asociados sostuvieron una reunión donde propusieron una serie de nombres, al final del debate los asociados eligieron como su preferido "OXIGENO DEL SUR S.R.L.", por lo tanto, proponemos que la empresa lleve como razón social el nombre indicado. Se determinó también utilizar el nombre “OXISUR" como nombre comercial.

\subsubsection{Servicios:}

La empresa propuesta, ofrecerá el producto y servicio de Oxigeno industrial para todo el departamento de Puno, nuestro producto será elaborado con moderna maquinaria y equipos que nos permitirán obtener un producto de alta pureza cuya característica principal será la calidad, ofreceremos también el servicio de distribución de Oxigeno hasta las instalaciones o centros de operaciones de los consumidores. Nuestro personal estará capacitado en el manejo de gases industriales y seguirá un estricto protocolo de seguridad que brindada tranquilidad a nuestros clientes. 


\subsection{Estrategias de Marketing}

\subsubsection{Estrategias de Producto}

Para nuestro plan de negocios se implementara una estrategia de diferenciación de servicio, la solución para la guerra de precios es el desarrollo de una oferta innovadora, entrega e imagen diferenciada (Kotler \& Amstrong, 2012).

El principal valor con el que contara nuestro producto será la calidad de nuestro producto y servicio, a nuestra oferta se suma la presencia de personal capacitado en la manipulación de gases industriales como el Oxígeno y en la atención al cliente. Todas estas características hacen más atractivos nuestro producto y servicio en comparación con la competencia. Se hará uso de la estrategia de diferenciación (Según la matriz de Ansoff), por tratarse de una empresa nueva enfocado a un mercado ya existente.

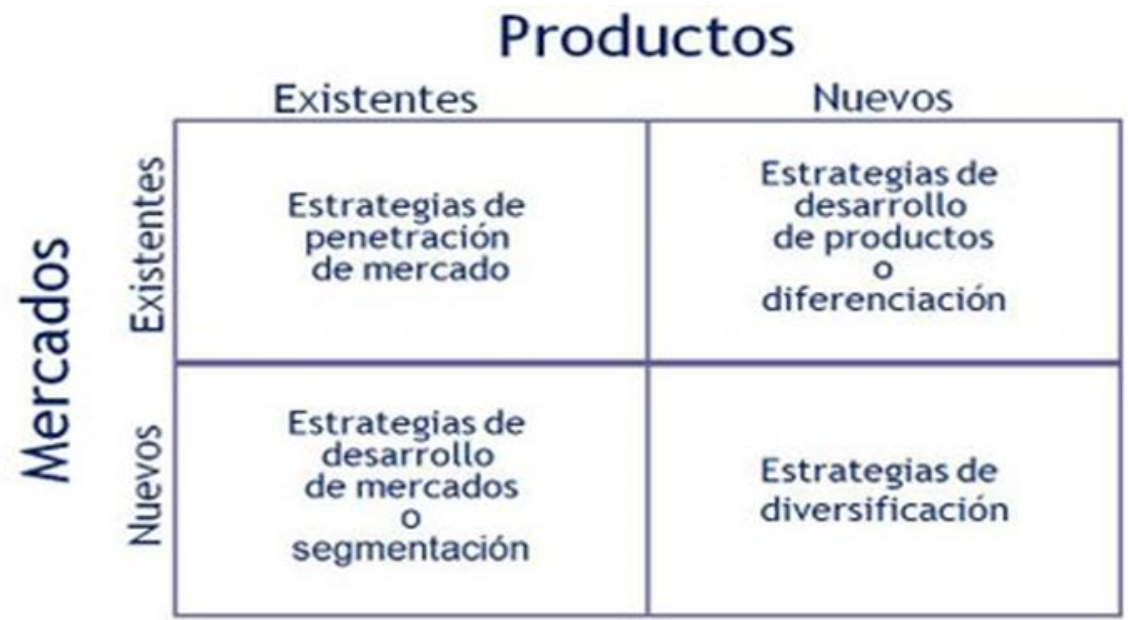

Figura 36 Matriz de Ansoff. Tomado de "Estrategia Empresarial", por Departamento Académico de Ciencias Administrativas de la Pontificia Universidad Católica del Perú (PUCP), 2006 
La estrategia de diferenciación del proyecto está basada en un servicio de calidad, de alta creatividad y asesoramiento a lo largo de todo el proceso venta y post venta, implementando un CRM eficaz, una web actualizada que nos posicione como expertos en el mercado y desarrollando anuncios publicitarios en redes sociales creativos para la propia empresa demostrando el nivel de profesionalismo. La empresa industrial tomará las medidas necesarios para garantizar que el cliente esté informado de todos los servicios que se brinda, el gerente general al momento de gestionar una futura cuenta debe hacer un resumen explicativo con el cliente para conocer sus exigencias y crear una propuesta, que al ser aprobada por el cliente se ponga en marcha según los tiempos ofrecidos.

"La diferenciación consiste en crear diferencias en la oferta de productos o servicios de la empresa mediante la creación de característica o atributo que es percibido como único y valorado por los consumidores con respecto al sector de actividad".

Para quedar grabados en el recuerdo de nuestro público objetivo debemos destacarnos de nuestra competencia, demostrar ese atributo que nos hace únicos y que nos diferencia del resto.

Para definir las estrategias de diferenciación, se deben responder las siguientes interrogantes:

- ¿Qué busca el cliente del producto y servicio?

- ¿Qué requerimiento del mercado potencial cubre los servicios?

- ¿Qué tipo de producto y servicio ofrece la competencia?

- ¿Qué hace que la empresa propuesta sea mejor que la competencia? 
Luego de responder las preguntas planteadas podemos se podrá determinar las estrategias de diferenciación:

- Producto: Se ofrece un producto de calidad y un servicio con seguridad, el Oxigeno industrial será conseguido a través del uso de maquinaria moderna y especializada que garantizara la pureza del gas industrial, de esta manera vamos a satisfacer las expectativas de nuestros clientes.

- Asimismo contar con personal capacitado y responsable en cuanto al cumplimiento del protocolo de seguridad garantizara obtener siempre buenos resultados del servicio bridado a los consumidores de Oxigeno Industrial.

- Imagen: Ofrecemos un servicio diferenciado dirigido a las empresas del sector metalmecánico o empresas que dentro de sus labores requieran de Oxigeno industrial para el desarrollo de sus actividades. Contamos con reglas de conducta que deben seguir todos los trabajadores tanto operarios como ejecutivos, además de un protocolo de seguridad aplicable dentro y fuera de la empresa, todo esto fortifica la imagen de la empresa demostrando profesionalismo y seguridad al momento de realizar nuestra labor.

- Canal: A diferencia de nuestra competencia, ofrecemos nuestro servicio a través de diversos medios de comunicación, desde los más comunes para el mercado hasta los más modernos como redes sociales.

\subsubsection{Estrategias de Precio}

En el presente proyecto se implementará una estrategia de fijación de precios de línea de productos, este tipo de estrategia fija escalas de precios entre diferentes tipos de producto con base en los diferencia de costo entre los 
productos, según la evaluación de cliente y los precios que tiene la competencia (Kotler \& Amstrong, 2012).

La determinación del precio del producto y servicio se determinó en base al estudio de mercado, obteniendo información acerca de cuanto es el monto que en la actualidad paga el mercado por este tipo de producto y servicio, y cuanto se dispondría a pagar por un servicio con calidad y seguridad como lo ofrece la presente propuesta, de esta manera se fijaron los precios de nuestro producto que van desde de los $\mathrm{S} / 11.00$ hasta los $\mathrm{S} / 15.00$ soles por $\mathrm{m}^{3}$ de Oxigeno industrial. Los precios variaran de acuerdo al volumen de compra de cada cliente.

\section{Objetivos de Estrategia de Precio}

- Incrementar las utilidades a largo plazo

- Ampliación de la participación de mercado

- Afrontar a la competencia

- Reconocer a la marca como una de las mejores

Se debe relacionar el precio a las cualidades del producto y servicio, resaltando sus cualidades y de esta manera brindarle al cliente la impresión de que por el precio que pagara recibirá un mejor producto.

\subsubsection{Estrategias de Precio}

El sistema de distribución, afecta en el éxito de la empresa por lo cual se debe crear una red que mejore la entrega de valor al cliente donde se considere a todos los proveedores. La planificación de esta cadena, debe asegurar la entrega del servicio al cliente, que implica el análisis de las necesidades y preferencias de los clientes (Kotler \& Amstrong, 2012). 
Las estrategias de distribucion consisten en la forma como el cliente tendra acceso a nuestro servicio, en el caso de nuestros clientes podran contactar a la empresa atraves del contacto telefonico, pagina web, fan page (facebook) o visitandonos directamente en nuestras oficinas. En un inicio dirigiremos nuestro servicio exclusivamente al sector metalmecanico y por encontrarnos en una zona minera como es el departamento de Puno tambien nos enfocaremos al sector minero. En una seguda etapa, cuando la empresa haya incrementado sus ventas, desarrollaremos una distribucion mas intensiva aplicando una estrategia de marketing mas agresiva para poder cubrir mas sectores que dentro del desarrollo de sus operaciones requieran del uso y aplicación de Oxigeno industrial.

La promocion de los servicios de la empresa serán de forma B2B, mediante la web el cliente podrá tener acceso a la información, podrá interactuar por la web, comunicar las dudas y preguntas que pueda tener en cuanto los servicios y le permita adquirir los servicios industriales, también se podrá pagar vía web los servicios que vaya adquiriendo para acelerar los tiempos y dar las facilidades de pago.

\subsubsection{Estrategias de Promoción}

Nuestra empresa "Oxigeno del Sur” buscara promocionarse a través del uso de herramientas publicitarias que le permitan acceder a una comunicación directa con el cliente fomentando así una relación empresa-cliente.

\section{Plan Publicitario}

"Consiste en la combinación específica de herramientas de publicidad, promoción de ventas, relaciones públicas, ventas personales y marketing directo que la empresa utiliza para alcanzar sus objetivos de publicidad y marketing". 
Se hará uso de la promoción de ventas, realizaremos visitas a nuestros potenciales clientes para explicares los beneficios de nuestro producto y servicio y publicidad en medios escritos especializados en diferentes industrias.

\section{Objetivos Publicitarios}

Posicionar nuestra marca como la primera opción de las empresas del sector metalmecánico y de las empresas de otros sectores que para el desarrollo de sus actividades necesitan del Oxígeno industrial.

Fidelizar a nuestros clientes poco a poco demostrando la calidad y seguridad de nuestro servicio, logrando así incrementar nuestra perspectiva de ventas.

\section{Branding}

Healey (2009) señala que "El branding hace referencia a la creación, desarrollo y gestión de la marca. Por tanto, no se limita, ni mucho menos, al diseño del logo símbolo o de la identidad visual, a pesar de que es frecuente caer en esta equivocación; es una tarea muy compleja que exige conocer la identidad corporativa de una organización y la forma más adecuada de transmitirla a su público" (p. 23).

En esta etapa estableceremos las características fundamentales de nuestra marca, estas características determinaran la personalidad de nuestro producto y servicio, en nuestros caso la personalidad de nuestra empresa está definida por la calidad y seguridad del servicio que ofrecemos. También estableceremos la identificación visual de la marca y el mensaje emocional que conectara nuestra marca con el público. 
El Branding comprende la formación de una marca, desde sus características básicas hasta la parte visual que buscara reflejar los valores de la empresa. La empresa ofrecerá un servicio representado en todo momento por la calidad y seguridad presente en todos nuestros procesos, además como valor agregado contara con personal capacitado para enfrentar y resolver cualquier problema que se presente.

“OXIGENO DEL SUR" se proyecta como una empresa con personalidad seria, responsable, profesional y comprometida con la atención al cliente. Tenemos al trabajo en equipo como el principal parámetro que nos permitirá obtener resultados de calidad.

Logo y Marca

Cuadrado (2007) dice "Un logotipo no es más que una palabra diseñada. El diseño es lo que confiere a la palabra que se haya elegido su originalidad, su carácter distinto y único. Estos aspectos son esenciales ya que el logotipo es la expresión de la "marca", que, a su vez, es la abstracción de todo lo que representa la empresa o producto. El logotipo define simbólicamente la imagen de la empresa que previamente se ha establecido. Aparecerá en todos y cada uno de los elementos del marketing publicitario con el objeto de reforzar la imagen de marca y establecer unos vínculos entre empresa y público, mediante la fácil y rápida asociación del logotipo a la empresa en cuestión" (p.25). 
Proponemos para nuestra empresa de Oxigeno industrial el siguiente logotipo:

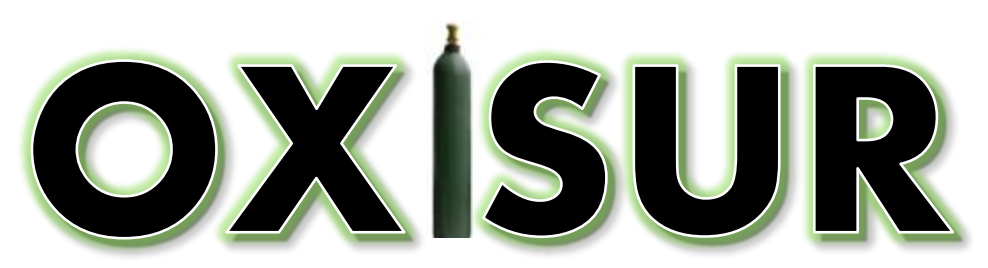

Oxigeno del Sur, seguridad y calidad para todo el Perú

Figura 37 Logo Oxigeno del Sur. Elaboración propia

Papelería Corporativa:

Utilizaremos papel membretado con el logo de la empresa para todos los formatos impresos que se utilicen dentro y fuera de la empresa.

Nuestro personal ejecutivo contara con tarjetas de presentación, con el logo y datos de la empresa, que podrán entregar a nuestros clientes para que ellos puedan comunicarse con la empresa cuando lo requieran.

Se entregaran catálogos con información relevante de la empresa así como de los productos y servicios que ofrecemos a todos nuestros potenciales clientes durante las visitas que realizaremos.

\section{Sitio WEB}

La empresa contara con una página web, donde nuestros clientes podrán encontrar información sobre la empresa así como la misión y visión de la misma, también podrán encontrar información sobre nuestros producto, los manuales de manipulación para este tipo de gases industriales y las clases de servicios que ofrecemos. 


\section{Redes Sociales}

Actualmente la tecnología nos permite tener alcance a diversos medios de comunicación masivos, en muchos casos más eficientes y económicos que los comunes. Estos medios son conocidos como redes sociales, que actualmente son usadas por empresas grandes y pequeñas para acercarse más a su público objetivo.

“Oxigeno del Sur" hará uso de las redes sociales para acercarse a su mercado objetivo, detallando y ofreciendo información sobre los servicios de Oxigeno industrial.

\section{Facebook}

Empresas grandes y pequeñas se encuentran en esta red social haciendo conocer su negocio y las bondades de sus productos y servicios.

La empresa también usara Facebook para acercarse al público objetivo y dar a conocer los beneficios que ofrece la empresa, al principio de las operaciones el gerente administrativo será el encargado de manejar el Facebook de la empresa, posteriormente cuando se incremente nuestras utilidades se contratara un comunity manager para este fin.

\section{Publicidad Exterior}

La empresa no solo hará uso de los medios publicitarios mencionados anteriormente, también utilizara publicidad tradicional como: 
Publicidad en el punto de venta

La oficina de ventas contara con material publicitario como trifoliados, volantes, además entregaremos a los potenciales clientes que se apersonen a nuestras oficinas folletos que contengan información detallada sobre nuestro producto y servicios.

\section{Visitas}

Realizaremos visitas a nuestros potenciales clientes, donde podremos explicarles detalladamente lo beneficios de nuestro producto y servicio, entregaremos información minuciosa de nuestra oferta en catálogos y folletos. Al realizar las visitas buscaremos recolectar datos de la empresa que estamos visitando para poder armar una base de datos de nuestros posibles clientes con las características de su empresa.

\section{Merchandising}

Proponemos la entrega de merchandising durante las visitas que realizaremos a nuestros potenciales clientes. Los elementos que se entregen contaran con el logo de la empresa, la frase que caracteriza nuestra marca y los numeros de contacto de la empresa. Los objetos que entregaremos son:

- Llaveros

- Lapiceros

- Cuadernillos 
Con el objetivo de alcanzar a una gran cantidad de empresas que conformen el mercado objetivo, se decidio realizar publicaciones en revistas especializadas en sectores como metalmecanico, mineria, construccion,etc. Una oportunidad para promocionar nuestro servicio seria la convencion minera que se realiza cada dos años en la ciudad de Arequipa, en este evento se entrega gran cantidad de material impreso como revistas donde podriamos anunciar.

\section{Valla Publicitaria}

Con el fin de llegar a mas empresas pertenecientes a nuestro mercado objetivo, se optara por la colocacion de un anuncio publicitario en el centro de la ciudad de Juliaca, especificamente en la Av. Pumacahua, avenida muy concurrida y de alto transito.

\subsection{Estrategia de ventas}

Las estrategias de ventas que aplicaremos, tendran como principal finalidad crear un vinculo empresa - cliente, demostrando que no solo ofrecemos un producto elaborado bajo altos estandares de calidad sino tambien brindamos las medidas de seguridad necesarias durante la distribucion del producto para tranquilidad de nuestros clientes y bienestar de sus instalaciones.

Proponemos las siguientes estrategias de ventas:

- Realizar descuentos a nuestros clientes frecuente de acuerdo al volumen de compra de oxigeno industrial que requieran.

- Capacitacion a los vendedores

- Ofrecer servicios de capacitacion para su personal sobre manipulacion de gases industriales y diferentes actualizaciones sonre el uso del Oxigeno industrial. 
- Al termino de cada servicio ofrecer pequeños obsequios a la empresa contratante, los regalos serian los mismo que se pensaron en el merchandising.

\subsubsection{Política de servicios}

Una de las principales características de nuestro servicio es la seguridad, la cual debe imperar durante la elaboración del producto así como durante su distribución. Hemos establecido una política preventiva y otra reparadora para tranquilidad de los clientes.

\section{Política preventiva}

Seleccionar personal capacitado en el manejo de gases industriales, en base a un estricto proceso de selección, y continuar con constantes capacitaciones sobre avances y novedades en la manipulación del oxígeno industrial.

\section{Política reparadora}

Para brindar tranquilidad a nuestros clientes contaremos con un seguro contra accidentes el cual cubrirá los daños que puedan ser ocasionados por alguna negligencia.

\section{Política para manejo de cuentas}

El gerente general será el encargado del manejo de las cuentas junto con el gerente administrativo, además será el encargado de capacitar a los colaboradores de los servicios que se ofrece y de la propuesta de valor que tiene el producto. 


\subsection{Modelo de las 7 S de Mc. Kinsey}

Establecimos el Plan de Marketing considerando el modelo de las $7 \mathrm{~S}$ de Mc. Kinsey, compuesto por siete factores independientes clasificados en dos grupos fuertes (hard) y blandos (soft).

\subsubsection{Estrategia (Strategy)}

"Estrategia de presentación del producto y servicio Oxigeno del Sur"

Realizaremos el lanzamiento de nuestra empresa inicialmente dentro del entorno conformado por las empresas que logramos visitar para promocionar nuestro producto y servicio. Al inicio de nuestras operaciones ofreceremos un descuento del $15 \%$ para aquellas empresas que soliciten más de $50 \mathrm{~m}^{3}$ de Oxigeno industrial en su primera compra, también ofreceremos un descuento del $20 \%$ si el volumen de compra es mayor a los $100 \mathrm{~m}^{3}$. Esta oferta estará vigente durante los dos primero meses de operaciones y el objetivo de esta estrategia es la de captar nuevos clientes.

Otra estrategia que aplicaremos inicialmente será la de facilitar la visita a nuestras instalaciones a todos aquellos potenciales clientes que lo requieran.

Por ultimo utilizaremos un formato impreso donde los clientes que hayan experimentado nuestro servicio podrán calificar el servicio y dejar sus opiniones y sugerencias.

\subsubsection{Estructura (Structure)}

Nuestra empresa será una Sociedad de Responsabilidad Limitada (S.R.L.) inscrita en el Régimen General, nuestra oficina principal estar ubicada en la ciudad de Juliaca, dentro del departamento de Puno. Contaremos con un gerente Administrativo encargado de establecer las políticas administrativas y 
de ventas, además de controlar el desarrollo de actividades dentro de la empresa. También tendremos un supervisor encargado de monitorear y supervisar a los operarios y el cumplimiento de sus labores. Por ultimo tendremos un grupo de operarios capacitados para realizar las labores de acuerdo al área a la que pertenecen.

\subsubsection{Sistemas (System)}

La empresa implementara los siguientes sistemas operativos que brindaran soporte a la gestión:

- Sistema Financiero: Comprenderá la parte financiera que incluirá las cuentas por pagar tanto a proveedores, personal, etc. La información que nos proporcione el sistema financiero será consultada antes de tomar cualquier decisión que afecte a la empresa.

- Base de datos de clientes: Cada servicio que realicemos será registrado en una base de datos con información sobre el cliente y las características de sus requerimientos. La base será actualizada constantemente.

- Protocolos de seguridad y atención al cliente: La empresa contara con un protocolo de seguridad que debe ser respetado por todos los operarios al momento de manipular el Oxígeno industrial. De igual manera el protocolo de atención al cliente debe ser respetado y aplicado correctamente por los operarios distribuidores quienes son los que tienen contacto directo con los clientes. 


\subsubsection{Estilo (Style)}

El estilo de administración que se aplicara en la empresa propuesta será la administración participativa la cual consiste en escuchar y tomar en cuenta las opiniones y experiencias de todos nuestros colaboradores sin importar el rango. Este estilo de administración permitirá que los trabajadores se sientan parte de un equipo, puedan identificarse y comprometerse con los objetivos de la empresa.

\subsubsection{Personal (Staff)}

El personal de nuestra empresa estará conformado por profesionales con la formación necesaria para los diferentes puestos de trabajo, además nuestros colaboradores serán constantemente capacitados tanto en la parte operativa como en la atención al cliente.

\subsubsection{Habilidades (Skills)}

Los colaboradores de nuestra empresa trabajaran bajo la consigna del trabajo en equipo, donde la búsqueda de la calidad del producto y servicio será su principal objetivo. El supervisor deber ayudar a fomentar el trabajo en equipo y deberá informar al gerente administrativo acerca de los logros y debilidades de los trabajadores.

Nuestros trabajadores deben contar con habilidades específicas para el desarrollo de sus labores, las estrategias para garantizar y fortalecer estas habilidades son:

- Identificación de conocimientos previos durante la selección del personal.

- Aplicar estrategias de entrenamiento en el manejo de equipos y manipulación de gases industriales. 


\subsubsection{Valores Compartidos (Shared values)}

Los valores institucionales son el eje principal para el desarrollo de actividades de "Oxigeno del Sur". Establecemos los siguientes valores institucionales dirigidos al servicio y atención al cliente:

- Honestidad, se debe actuar de manera honesta ante cualquier situación.

- Cordialidad, se deberá demostrar predisposición al momento de atender a los clientes.

- Respeto, demostrar respeto por todos

- Disciplina y puntualidad, los servicios se atenderán evitando retrasos

- Excelencia en el servicio, buscar la mejora continua. 


\section{Capitulo VIII Planificación Financiera}

Esta parte del estudio, consiste de acuerdo a Baca (2010), en "expresar en términos monetarios todas las determinaciones hechas en el estudio técnico (y organizacional)".

Este capitulo se inicia con la determinación de los costos totales y de la inversión inicial, cuya base son los estudios de ingeniería, ya que ambos dependen de la tecnología seleccionada. Continúa con la determinación de la depreciación y amortización de toda la inversión inicial; así como el cálculo del capital de trabajo, que aunque también es parte de la inversión inicial, no está sujeto a depreciación y amortización, dada su naturaleza líquida.

Los aspectos que sirven de base para el siguiente capitulo, que es la evaluación de la rentabilidad económica-financiera, serán la determinación de la base de rendimiento mínima aceptable y el cálculo de los flujos netos de efectivo. Ambas, tasas y flujos, se calculan con o sin financiamiento; los flujos provienen del estado de resultados proyectado para el horizonte de tiempo seleccionado.

\subsection{Inversión}

La determinación de las inversiones iniciales, se obtiene el valor a partir de tres subdivisiones; los costos de la inversión fija, los costos operacionales y los costos de capital de trabajo.

Esta sección en particular comprende el análisis de los costos de inversión fija, la cual se clasifica en inversiones tangibles; como terrenos y obras civiles, maquinaria; equipos y herramientas; muebles y enseres; vehículos; equipos de oficina, comunicación y computación. 
Tabla 56 Inversión en Muebles y Enseres

\begin{tabular}{|c|c|c|c|c|c|c|}
\hline Descripción & Cantidad & Unidad & Valor Unitario & Valor Total & Vida Util & Depreciación \\
\hline Escritorio tipo gerente & 1 & Global & S/. 600.00 & S/. 600.00 & 10 & S/. 60.00 \\
\hline Silla tipo gerente & 1 & Global & S/. 400.00 & S/. 400.00 & 10 & S/. 40.00 \\
\hline Escritorio sencillo & 3 & Global & S/. 300.00 & S/. 900.00 & 10 & S/. 90.00 \\
\hline Sillas giratorias & 6 & Global & S/. 150.00 & S/. 900.00 & 10 & S/. 90.00 \\
\hline Sillón tres cuerpos & 2 & Global & S/. 500.00 & S/. $1,000.00$ & 10 & S/. 100.00 \\
\hline Extintor & 6 & Global & S/. 100.00 & S/. 600.00 & 10 & S/. 60.00 \\
\hline Muebles porta archivadores & 4 & Global & S/. 250.00 & S/. $1,000.00$ & 10 & S/. 100.00 \\
\hline Juego de muebles para juntas(incluye acrilico) & 1 & Global & S/. 400.00 & S/. 400.00 & 10 & S/. 40.00 \\
\hline
\end{tabular}

Tabla 57 Inversión en Maquinaria y Herramientas

\begin{tabular}{|c|c|c|c|c|c|c|}
\hline Descripción & Cantidad & Unidad & Valor Unitario & Valor Total & $\begin{array}{l}\text { Tasa Anual } \\
\text { de Deprec. }\end{array}$ & $\begin{array}{c}\text { Depreciación } \\
\text { Anual }\end{array}$ \\
\hline Comprensión de Alta Presión & 1 & Global & S/. $84,000.00$ & S/. $84,000.00$ & $20 \%$ & S/. $16,800.00$ \\
\hline Soplador de Aire & 1 & Global & S/. $34,420.00$ & S/. $34,420.00$ & $20 \%$ & S/. $6,884.00$ \\
\hline Torre de purificación & 1 & Global & S/. $41,000.00$ & S/. $41,000.00$ & $20 \%$ & S/. $8,200.00$ \\
\hline Generador de Oxigeno & 1 & Global & S/. $86,000.00$ & $S / .86,000.00$ & $20 \%$ & S/. $17,200.00$ \\
\hline Servomex & 1 & Global & S/. $14,040.00$ & SI. $14,040.00$ & $20 \%$ & S/. $2,808.00$ \\
\hline Total & & & & S/.259,460.00 & & $S / .51,892.00$ \\
\hline
\end{tabular}

Tabla 58 Inversión en Vehículos

\begin{tabular}{ccccccc}
\hline Descripción & Cantidad & Unidad & Valor Unitario & Valor Total & $\begin{array}{c}\text { Tasa Anual } \\
\text { de Deprec. }\end{array}$ & $\begin{array}{c}\text { Depreciación } \\
\text { Anual }\end{array}$ \\
\hline Camión de 8 toneladas & 1 & Global & $S / .155,500.00$ & $S / .155,500.00$ & $20 \%$ & $S / .31,100.00$ \\
Camión de 3-4 toneladas & 2 & Global & $S / .67,250.00$ & $S / .134,500.00$ & $20 \%$ & $S / .26,900.00$ \\
\hline \multicolumn{1}{c}{ Total } & & & $S / .290,000.00$ & & $S / .58,000.00$ \\
\hline
\end{tabular}


Tabla 59 Inversión en Equipos de Oficina, Comunicación y Computación

\begin{tabular}{|c|c|c|c|c|c|c|}
\hline Descripción & Cantidad & Unidad & Valor Unitario & Valor Total & Vida Util & Depreciación \\
\hline Laptop HP & 1 & Global & $\mathrm{S} / 4,000.00$ & $S / 4,000.00$ & 5 & S/ 800.00 \\
\hline Computador & 1 & Global & $S / 2,500.00$ & $S / 2,500.00$ & 5 & S/ 500.00 \\
\hline Impresora HP & 1 & Global & $S / 1,500.00$ & $S / 1,500.00$ & 5 & S/ 300.00 \\
\hline Estabilizador & 1 & Global & S/ $\quad 100.00$ & S/ 100.00 & 5 & S/ $\quad 20.00$ \\
\hline Scanner & 1 & Global & 150.00 & 150.00 & 5 & 30.00 \\
\hline Línea Telefónica & 1 & Global & 600.00 & 600.00 & 5 & S/ 120.00 \\
\hline Software Contable & 1 & Global & 250.00 & S/ 250.00 & 5 & S/ $\quad 50.00$ \\
\hline Calefacción & 1 & Global & 500.00 & S/ 500.00 & 5 & S/ 100.00 \\
\hline Ventilador & 1 & Global & 300.00 & $S / 300.00$ & 5 & S/ $\quad 60.00$ \\
\hline
\end{tabular}

Tabla 60 Inversión en Terrenos, Construcciones y Obras Civiles

\begin{tabular}{lccrrr}
\hline \multicolumn{1}{c}{ Descripción } & Cantidad & Unidad & Valor Total & $\begin{array}{c}\text { Tasa Anual de } \\
\text { Deprec. }\end{array}$ & \multicolumn{1}{c}{$\begin{array}{c}\text { Depreciación } \\
\text { Anual }\end{array}$} \\
\hline Terreno & - & $\mathrm{m} 2$ & $\mathrm{~S} / .0 .00$ & $0 \%$ & $\mathrm{~S} / .0 .00$ \\
Construcción de Planta & - & Global & $\mathrm{S} / .0 .00$ & $0 \%$ & $\mathrm{~S} / .0 .00$ \\
Remodelación & 1 & Global & $\mathrm{S} / .35,000.00$ & $20 \%$ & $\mathrm{~S} / .7,000.00$ \\
\hline \multicolumn{1}{c}{ Total } & & & $\mathrm{S} / .35,000.00$ & $\mathrm{~S} / .7,000.00$ \\
\hline
\end{tabular}

Nota: Se señala que no existe inversión en terreno y obras civiles, dado que; los inversionistas escogieron el tema de alquiler del inmueble, dada la ventaja económica que esta proporciona.

Despues de haber descrito cada uno de los componentes de la inversión fija, a continuación se presenta una tabla de resumen con los respectivos valores, mencionando al mismo tiempo que los gastos pre operativos son incluidos a la vez como parte de la inversión fija. 
Tabla 61 Programa de Inversión Fija del Proyecto

\begin{tabular}{lr}
\hline \multicolumn{1}{c}{ Detalle de la Inversión } & \multicolumn{1}{c}{ Año 0} \\
\hline Activos Fijos Intangibles & \\
Muebles y Enseres & $\mathrm{S} / .5,800.00$ \\
Maquinaria y Herramientas & $\mathrm{S} / .259,460.00$ \\
Vehiculos & $\mathrm{S} / .290,000.00$ \\
Terreno y Obras Civiles & $\mathrm{S} / .35,000.00$ \\
\hline Subtotal & $\mathrm{S} / .590,260.00$ \\
\hline Activos Fijos intangibles o Diferidos & \\
Gastos preoperativos & $\mathrm{S} / .9,560.25$ \\
\hline Subtotal & $\mathrm{S} / .9,560.25$ \\
\hline Total & $\mathrm{S} / .599,820.25$ \\
\hline
\end{tabular}

\subsubsection{Inversión Pre-Operativa}

En este apartado se tiene aquellos activos intangibles que son necesarios, en primer lugar, para poder formalizar la empresa y habilitar todos los requerimientos necesarios para su funcionamiento.

Tabla 62 Inversión en Activos Intangibles y Diferidos

\begin{tabular}{lr}
\hline \multicolumn{1}{c}{ Descripción } & Valor Total \\
& \\
\hline Gastos Diversos & S/.6,405.00 \\
Estudios & S/.2,700.00 \\
Imprevistos (5\%) & S/. 455.25 \\
\hline \multicolumn{1}{c}{ Total } & S/.9,560.25 \\
\hline
\end{tabular}

\subsubsection{Inversión en capital de trabajo}

La inversión en capital de trabajo es aquella requerida para poder llevar a cabo las operaciones de empresa con normalidad en el corto plazo y evitar la interrupción del ciclo operativo de la misma. La manera más sencilla de definir el 
capital de trabajo es mencionar que corresponde al efectivo que una empresa o proyecto necesita para seguir produciendo mientras cobra lo vendido.

Partiendo de las premisas anteriores, a continuación se presenta el procedimiento seguido para la estimación del capital de trabajo. La inversión inicial en capital de trabajo se calcula mediante la siguiente formula:

$\mathrm{CT}=$ Costo Operacional $(\mathrm{CO}) *$ Costo Operacional Promedio Diario (COPD) Donde:

$\mathrm{CO}=30$ días

COPD $=$ Costo Operacional Anual/360 días

A continuación se presenta el cuadro resumen de los costos operacionales a medida de apoyo para la determinación del Costo Operacional Anual, tal y como sigue: 
Tabla 63. Determinación de Costos Operacionales

\begin{tabular}{|c|c|c|c|c|c|c|c|}
\hline Costos & Costos Fijos & $\%$ & Costos Variables & $\%$ & Costos Totales & $\% \mathrm{CF}$ & $\% \mathrm{CV}$ \\
\hline \multicolumn{8}{|l|}{ Costos de Producción } \\
\hline Mano de Obra Directa & S/. $100,800.00$ & 0.27 & & & & & \\
\hline Mano de Obra Indirecta & S/. $10,400.00$ & 0.03 & & & & & \\
\hline Depreciación & S/. $119,288.00$ & 0.32 & & & & & \\
\hline Mantenimiento & S/. $\quad 7,600.00$ & 0.02 & & & & & \\
\hline Subtotal & S/.238,088.00 & & & & S/.238,088.00 & 0.48 & \\
\hline Materiales Directos & & & S/. $1,703.65$ & 0.01 & & & \\
\hline Materiales Indirectos & & & S/. $89,307.65$ & 0.78 & & & \\
\hline Subtotal & & & S/. $91,011.30$ & & S/. $91,011.30$ & & 0.18 \\
\hline \multicolumn{8}{|l|}{ Gastos Administrativos } \\
\hline Remuneración del Personal & S/. $7,300.00$ & 0.02 & & & & & \\
\hline Amortización & S/. 1,912.05 & 0.01 & & & & & \\
\hline Gastos Diversos & S/. $8,740.00$ & 0.02 & & & & & \\
\hline Gastos de Alquiler & S/. $122,400.00$ & 0.32 & & & & & \\
\hline Subtotal & S/. $140,352.05$ & & & & S/. 140,352.05 & 0.28 & \\
\hline \multicolumn{8}{|l|}{ Gastos de Ventas } \\
\hline Transporte & & & S/. $22,200.00$ & 0.19 & & & \\
\hline Publicidad y Promoción & & & S/. $1,400.00$ & 0.01 & & & \\
\hline Subtotal & & & SI. $23,600.00$ & & S/. $23,600.00$ & & 0.05 \\
\hline Total & S/. $378,440.05$ & 1.00 & S/. $114,611.30$ & 1.00 & S/.493,051.35 & 0.77 & 0.23 \\
\hline
\end{tabular}

Es asi, que a partir de los valores referenciales de la tabla anterior, se obtiene lo siguiente:

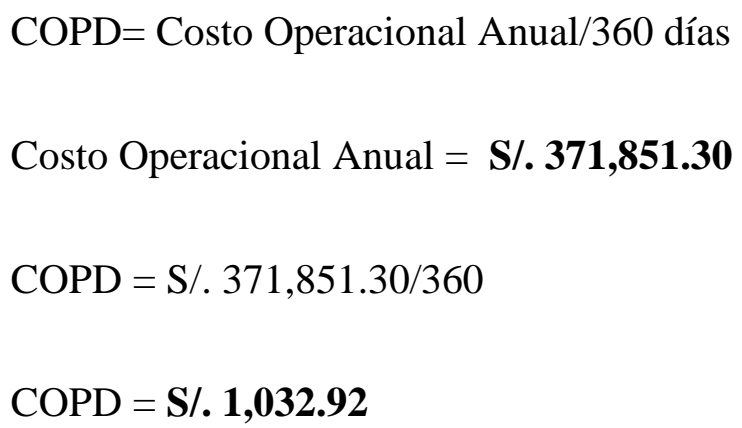

Y aplicándolo en la formula propuesta del Capital de Trabajo, se logra la siguiente estimación:

$\mathrm{CT}=$ Costo Operacional $(\mathrm{CO}) *$ Costo Operacional Promedio Diario (COPD) 
Capital de Trabajo $=30$ X S/. 1,032.92

Capital de Trabajo $=$ S/. 30,987.61

Entonces, corresponde tomar en consideración el efecto inflación para el cálculo del capital de trabajo, tal y como sigue:

Tabla 64 Capital de Trabajo Real

\begin{tabular}{lcccr}
\hline Periodo & Capital de Trabajo & Tasa de Inflación & Incremento por Inflación & Capital de Trabajo Real \\
\hline Primer Año & S/.30,987.61 & - & $S / .0 .00$ & $S / .30,987.61$ \\
Segundo Año & S/.30,987.61 & $2.50 \%$ & $S / .774 .69$ & $S / .31,762.30$ \\
Tercer Año & S/.31,762.30 & $2.50 \%$ & $S / .794 .06$ & $S / .32,556.36$ \\
Cuarto Año & S/.32,556.36 & $2.50 \%$ & $S / .813 .91$ & $S / .33,370.26$ \\
Quinto Año & S/.33,370.26 & $2.50 \%$ & $S / .834 .26$ & $S / .34,204.52$ \\
\hline
\end{tabular}

Nota: Para efectos de la tasa de inflación se ha tomado el reporte de inflación, así como las expectativas inflacionarias reportas por el BCPR.

Ahora bien, se tiene la siguiente tabla que resume el programa de necesidades de capital de trabajo para el periodo de evaluación económica, considerando así también los incrementos del capital de trabajo propios al programa de producción.

Tabla 65 Programa de Capital de Trabajo

\begin{tabular}{ccccccc}
\hline Detalle & Año 0 & Año 1 & Año 2 & Año 3 & Año 4 & Año 5 \\
\hline Capital de Trabajo & S/. 30,987.61 & S/. 3,128.65 & S/. 2,979.74 & S/. 2,855.59 & S/. 2,749.73 & 0 \\
\hline
\end{tabular}




\subsubsection{Costo del proyecto}

Para la determinación del Costo del Proyecto, se adopta la postura de la inversión total agregada por la Inversión Fija y el requerimiento de Capital de Trabajo, tal y como sigue:

Tabla 66 Costo de Inversión del Proyecto

\begin{tabular}{|c|c|c|c|c|c|c|}
\hline Detalle & Año 0 & Año 1 & Año 2 & Año 3 & Año 4 & Año 5 \\
\hline Inversión Fija & -S/.599,820.25 & & & & & \\
\hline Capital de Trabajo & -S/. 30,987.61 & -S/. 3,128.65 & -S/. 2,979.74 & -S/. 2,855.59 & -S/. 2,749.73 & S/.0.00 \\
\hline Inversión Total & $-S / .630,807.86$ & $-S / .3,128.65$ & -S/. 2,979.74 & $-S / .2,855.59$ & $-S / .2,749.73$ & S/.0.00 \\
\hline
\end{tabular}

\subsubsection{Inversiones Futuras}

No se consideran Inversiones futuras más que el incremento natural del capital de trabajo, dada la naturaleza de la vida de útil de la inversión fija, como corresponde; Maquinaria y Herramientas, Equipo, Muebles y Enseres, Vehículos, y demás; todo lo que cumple con la capacidad suficiente para cubrir los incrementos en la producción en correspondencia con el programa de ventas estipulado.

Tabla 67 Inversiones Futuras

\begin{tabular}{cccccc}
\hline Detalle & Año 1 & Año 2 & Año 3 & Año 4 & Año 5 \\
\hline Incrementos Capital de Trabajo & S/. 3,128.65 & S/. $2,979.74$ & S/. 2,855.59 & S/. 2,749.73 & S/. 0.00 \\
\hline
\end{tabular}

\subsection{Financiamiento}

Se recurrirá a una estructura de capital de 60/40 sobre la inversión total, por lo que, se adquirirá un monto de préstamo de S/. 378,484.72; separándonse un total de S/. 30,987.61 para cubrir las necesidades de corto plazo como lo es el capital de trabajo, y el restante del préstamo para inversión en activos fijos. 
Tabla 68 Financiamiento de la Inversión

\begin{tabular}{|c|c|c|c|}
\hline Detalle & Inversión & Capital propio & Deuda \\
\hline Activo Fijo Tangible & $\mathrm{S} / 590,260.00$ & $\mathrm{~S} / 242,762.89$ & $\mathrm{~S} / 347,497.11$ \\
\hline Capital de Trabajo & S/ $30,987.61$ & & S/ $30,987.61$ \\
\hline Gastos Preoperativos & S/ $\quad 9,560.25$ & $9,560.25$ & \\
\hline Total & $\mathrm{S} / 630,807.86$ & $\mathrm{~S} / 252,323.14$ & $\mathrm{~S} / 378,484.72$ \\
\hline
\end{tabular}

\subsubsection{Endeudamiento y condiciones}

Se recurrirá a una estructura de capital de 60/40, con una tasa de $25 \%$ como TEA proporcionado por el BCP para este tipo de préstamo con un monto de S/. 378484.72

Tabla 69 Estructura de endeudamiento

\begin{tabular}{lcc}
\hline \multicolumn{1}{c}{ Detalle } & Referencia & Valor \\
\hline Monto Total de Inversión & & $\mathrm{S} / 630,807.86$ \\
Estructura de deuda & $60 \%$ & $\mathrm{~S} / 378,484.72$ \\
Inversión Propia & $40 \%$ & $\mathrm{~S} / 252,323.14$ \\
Tasa de Interés Anual & $25 \%$ & \\
$\mathrm{~N}^{\circ}$ de Pagos (5 años) & 60 & \\
Pago & & $\mathrm{S} / 10,566.22$ \\
\hline
\end{tabular}

\subsubsection{Capital y Costo de Oportunidad}

(Pérez, 2009) El capital no solo puede ser la inversión de los accionistas puede ser prestamos de identidades bancarias las cuales se volverán activo para sacar una ganancia.

Para el cálculo del Costo de Oportunidad, se adopta primero la postura del cálculo del costo por el método del CAPM, para después desarrollar el Costo de Capital Promedio Ponderado.

CAPM (Capital Asset Pricing Model), modelo que vincula linealmente la rentabilidad de cualquier activo financiero con el riesgo de mercado de ese activo. 
Este análisis se realizó en base al modelo de Valorización del Activo del Capital, conocido por sus siglas como CAPM, también demostraremos el cálculo para el costo de capital $=\mathrm{Ke}$, y el Costo de la Deuda $=\mathrm{Kd}$, que serán indispensables para hallar el cálculo del WACC. Entonces se procede a la realizar los siguientes cálculos, tal y como sigue:

Para el Ke:

$$
K e=R f+R p
$$

Se considera lo siguiente:

Una Tasa Libre de Riesgo: $\mathrm{Rf}=3.31 \%$ anual, en concordancia con los certificados bancarios del BCRP. Para calcular el riesgo del proyecto se considera la siguiente foormula:

$$
R p=(R m-R f) * B
$$

Donde a partir del Valor Índice General de Precios de Acciones de BVL, se logra una rentabilidad nominal del $19 \%$ de manera correspondiente.

Ahora debe de considerarse el efecto real e involucrar a la inflación en las estimaciones, por lo que; en concordancia con la inflación anual de los últimos periodos de $2.5 \%$, se obtiene un rendimiento de mercado real, tal como sigue;

$$
\begin{aligned}
& \text { Rendimiento Nominal }=19 \% \\
& \text { Inflación }=2.5 \% \\
& \text { Rendimiento Real }=16.5 \%
\end{aligned}
$$


Ahora para el cálculo de la beta, se considera una beta de la empresa Buenaventura, porque está en el sector minero.

Beta apalancada: B S/d

Patrimonio: $\mathrm{P}$

Pasivo: D

Impuesto a la Renta: TC
1.09

3,106 Millones \$

308 Millones \$

$29.5 \%$

Por lo tanto es necesario calcular una beta despalancado, ya que se tiene que quitar la deuda de la empresa y solo trabajar con la parte operativa.

$$
B \frac{S}{D}=\frac{B \frac{c}{D}}{\left(1+(1-t c) * \frac{D}{P}\right.}
$$

Así se obtiene un beta despalancado de: $\mathrm{Bs} / \mathrm{d}=1.02$

Este indicador nos muestra que el riesgo del proyecto es mayor al riesgo de mercado, porque es mayor a 1 .

Por tanto se tienen un riesgo de proyecto de:

$$
\begin{aligned}
& \mathrm{Rp}=(\mathrm{Rm}-\mathrm{Rf}) * \mathrm{~B}=(16.5 \%-3.31 \%) * 1.02 \\
& \mathbf{R p}=\mathbf{1 3 . 4 5 \%} \text { Anual }
\end{aligned}
$$

Finalmente se calcula el costo del Capital:

$$
\begin{aligned}
& \mathrm{Ke}=\mathrm{Rf}+\mathrm{Rp} \\
& \mathrm{Ke}=3.31 \%+13.45 \%
\end{aligned}
$$




$$
\mathrm{Ke}=16.76 \%
$$

\subsubsection{Costo de capital promedio Ponderado}

Para el cálculo del WACC, se toma en consideración las estimaciones sobre el Ke realizadas, y se procede también a completar los siguientes cálculos:

Se tiene un Costo de Deuda del: 25\% Anual

Con esta debemos hallar el costo de la deuda después de impuestos, y para ello se deberá descontar el impuesto a la renta, tal y lo propone la formula:

$$
\begin{aligned}
& \mathrm{Td}=25 \% *(1-29.5 \%) \\
& \mathbf{T d}=\mathbf{1 7 . 5 \%}
\end{aligned}
$$

Ahora, necesitamos los siguientes datos para finalmente llevar el cálculo del WACC:

$\begin{array}{ll}\text { Inversión del Proyecto } & \text { S/. 630,807.86 } \\ \text { Inversión Propia } & \text { S/. 252,323.14 } \\ \text { Inversión Financiera } & \text { S/. 378,484.72 } \\ \text { Costo de Capital Ke } & 16.76 \% \\ \text { Costo de Deuda Kd } & 17.5 \%\end{array}$

Por lo que finalmente, se estima un WACC:

$$
W A C C=16.76 \% * \frac{252323.1}{630807.8}+17.5 \% * \frac{378484.7}{630807.8}
$$

$\mathrm{WACC}=\mathbf{2 4 . 2 \%}$ 


\subsection{Presupuesto Base}

El presupuesto Base en coherencia con algunos autores puede ser definido como; las necesidades de capital suficientes para permitir el inicio y la continuidad de la operación sobre el proceso productivo de la empresa.

Se presenta a continuación desde la perspectiva de Costos, el requerimiento de capital expresado en costos necesarios y suficientes para permitir el funcionamiento de la producción.

Tabla 70 Requerimiento de Capital

\begin{tabular}{|c|c|c|c|c|c|c|}
\hline Costos & Costos Fijos & $\%$ & Costos Variables & $\%$ & Costos Totales \%CF & $\% \mathrm{CV}$ \\
\hline \multicolumn{7}{|l|}{ Costos de Producción } \\
\hline Mano de Obra Directa & S/. $100,800.00$ & 0.27 & & & & \\
\hline Mano de Obra Indirecta & S/. $10,400.00$ & 0.03 & & & & \\
\hline Depreciación & S/. $119,288.00$ & 0.32 & & & & \\
\hline Mantenimiento & S/. $\quad 7,600.00$ & 0.02 & & & & \\
\hline Subtotal & S/. $238,088.00$ & & & & S/.238,088.00 0.48 & \\
\hline Materiales Directos & & & S/. $1,703.65$ & 0.01 & & \\
\hline Materiales Indirectos & & & S/. $89,307.65$ & 0.78 & & \\
\hline Subtotal & & & S/.91,011.30 & & S/.91,011.30 & 0.18 \\
\hline \multicolumn{7}{|l|}{ Gastos Administrativos } \\
\hline Remuneración del Personal & $S / .7,300.00$ & 0.02 & & & & \\
\hline Amortización & S/. $1,912.05$ & 0.01 & & & & \\
\hline Gastos Diversos & S/. $8,740.00$ & 0.02 & & & & \\
\hline Gastos de Alquiler & S/. $122,400.00$ & 0.32 & & & & \\
\hline Subtotal & S/. $140,352.05$ & & & & S/. $140,352.050 .28$ & \\
\hline \multicolumn{7}{|l|}{ Gastos de Ventas } \\
\hline Transporte & & & S/. $22,200.00$ & 0.19 & & \\
\hline Publicidad y Promoción & & & S/. $1,400.00$ & 0.01 & & \\
\hline Subtotal & & & S/. $23,600.00$ & & S/. $23,600.00$ & 0.05 \\
\hline Total & S/. $378,440.05$ & 1.00 & S/. $114,611.30$ & 1.00 & S/.493,051.35 0.77 & 0.23 \\
\hline
\end{tabular}

\subsubsection{Presupuesto de Ventas}

El presupuesto de Ventas en coherencia con algunos autores se define como; la programación de las unidades de venta y su valoración, de forma tal que se involucre también las estrategias sobre las ventas, es decir, las ventas a crédito y al contado como parte de la planificación. 
Para el caso en particular se presenta el presupuesto de ventas de manera agregada, tal y como sigue:

Tabla 71 Ingresos por ventas

\begin{tabular}{lccccc}
\hline \multicolumn{1}{c}{ Detalle } & Año 1 & Año 2 & Año 3 & Año 4 & Año 5 \\
\hline Pronostico de Ventas $(\mathrm{m} 3)$ & 56788.4 & 61102.3 & 65412.1 & 69721.9 & 74031.7 \\
Precio Estimado & S/.11.00 & S/.12.00 & S/.13.00 & S/.14.00 & S/. 15.00 \\
\hline Total & S/.624,672.40 & S/.733,227.60 & S/.850,357.30 & S/.976,106.60 & S/.1,110,475.50 \\
\hline
\end{tabular}

\subsubsection{Presupuesto de Costo de Producción}

Para el embotellamiento del oxigeno y la prestación del servicio necesitamos mano de obra, insumos y uso de los equipos de producción. La estructura seria la siguiente:

Tabla 72 Presupuesto de Costos Operacionales

\begin{tabular}{|c|c|c|c|c|c|c|}
\hline Detalle & Año 1 & Año 2 & Año 3 & Año 4 & Año 5 & Total \\
\hline \multicolumn{7}{|l|}{ Costos Directos } \\
\hline MOD & S/. $100,800.00$ & S/. $103,320.00$ & S/. $105,903.00$ & S/. $108,550.58$ & S/. 111,264.34 & S/. 529,837.91 \\
\hline Materiales Directos & S/. $1,703.65$ & S/. $1,746.24$ & S/. $1,789.90$ & S/. $1,834.65$ & S/. $1,880.51$ & S/. 8,954.95 \\
\hline Depreciación & S/. $119,288.00$ & S/. $119,288.00$ & S/. $119,288.00$ & S/. $119,288.00$ & S/. $119,288.00$ & S/. $596,440.00$ \\
\hline Subtotal & S/. 221,791.65 & S/. $224,354.24$ & S/. 226,980.90 & S/.229,673.22 & S/. $232,432.85$ & S/. 1,135,232.87 \\
\hline \multicolumn{7}{|c|}{ Costos Generales de Producción } \\
\hline MOI & S/. $10,400.00$ & S/. $10,660.00$ & S/. $10,926.50$ & S/. $11,199.66$ & S/. $11,479.65$ & S/. $54,665.82$ \\
\hline Materiales Indirectos & S/. $89,307.65$ & S/. $91,540.34$ & $\mathrm{~S} / .93,828.85$ & S/. $96,174.57$ & S/. $98,578.93$ & S/. $469,430.34$ \\
\hline Subtotal & S/.99,707.65 & S/. $102,200.34$ & S/. 104,755.35 & S/. $107,374.23$ & S/. $110,058.59$ & S/. 524,096.15 \\
\hline Total presupuesto de & S/. $321,499.30$ & S/. $326,554.58$ & S/. $331,736.25$ & S/. $337,047.45$ & S/. $342,491.44$ & S/. $1,659,329.02$ \\
\hline
\end{tabular}

\subsubsection{Presupuesto de compras}

El presupuesto de compras hace referencia a la inversión en la adquisición de la materia prima (que es el oxigeno del aire, el cual realmente no tiene un costo impuesto por el estado peruano) e insumos necesarios para permitir el proceso de producción y cumplir con el programa de ventas (solamente la soda cáustica). 
Tabla 73 Presupuesto de adquisición de materia prima directa

\begin{tabular}{lccrr}
\hline \multicolumn{1}{c}{ Concepto } & $\begin{array}{c}\text { Cantidad } \\
\text { Anual }\end{array}$ & Unidad & Valor Unitario & \multicolumn{2}{c}{ Valor Anual } \\
\hline Oxigeno & 56788.4 & $\mathrm{~m} 3$ & $\mathrm{~S} / .0 .00$ & $\mathrm{~S} / .0 .00$ \\
Soda caustica & - & Unidad & $\mathrm{S} / .0 .03$ & $\mathrm{~S} / .1,703.65$ \\
\hline Total & & & & $\mathrm{S} / .1,703.65$ \\
\hline
\end{tabular}

Se presenta a continuación un cuadro de resumen de los principales insumos directos a adquirir para producir el bien final.

Tabla 74 Presupuesto de adquisición de Insumos directos

\begin{tabular}{|c|c|c|}
\hline Concepto & Unidad & Valor Anual \\
\hline Agua & m3 & S/. 420.00 \\
\hline Luz & $\mathrm{Kw}$ & S/. 40,887.65 \\
\hline Cilindros & Global & S/. $48,000.00$ \\
\hline Total & & S/. 89,307.65 \\
\hline
\end{tabular}

\subsubsection{Presupuesto de gastos de ventas}

A continuación se presenta la tabla de resumen de los costos involucrados en el proceso de la venta de los bienes.

Tabla 75 Presupuesto de Gastos por Ventas

\begin{tabular}{lrrrrr}
\hline \multicolumn{1}{c}{ Detalle } & \multicolumn{1}{c}{ Año 1 } & \multicolumn{1}{c}{ Año 2 } & \multicolumn{1}{c}{ Año 3 } & \multicolumn{1}{c}{ Año 4 } & \multicolumn{1}{c}{ Año 5 } \\
\hline Transporte & S/.22,200.00 & S/.22,755.00 & S/.23,323.88 & S/.23,906.97 & S/.24,504.65 \\
Publicidad y Promoción & S/.1,400.00 & S/.1,912.05 & S/.1,912.05 & S/.1,912.05 & S/.1,912.05 \\
\hline Total & S/.23,600.00 & S/.24,667.05 & S/.25,235.93 & S/.25,819.02 & S/.26,416.70 \\
\hline
\end{tabular}

\subsubsection{Presupuesto de gastos de administración}

A continuación se presenta la tabla de resumen de los costos administrativos involucrados en el proceso de la producción y venta de los bienes. 
Tabla 76 Presupuesto de Gastos Administrativos

\begin{tabular}{|c|c|c|c|c|c|c|c|c|}
\hline Detalle & & Año 1 & Año 2 & & Año 3 & Año 4 & Año 5 & Total \\
\hline Remuneración del personal & S/ & $7,300.00$ & $7,482.50$ & S/ & $7,669.56$ & $7,861.30$ & $8,057.83$ & $\mathrm{~S} / 38,371.19$ \\
\hline Amortización & S/ & $1,912.50$ & $1,912.50$ & S/ & $1,912.50$ & $1,912.50$ & $1,912.50$ & S/ $9,562.50$ \\
\hline Gastos Diversos & S/ & $8,740.00$ & $8,958.50$ & S/ & $9,182.46$ & $9,412.02$ & $9,647.32$ & S/ $45,940.30$ \\
\hline Gastos de Alquiler & $\mathrm{S} /$ & $122,400.00$ & $\mathrm{~S} / 119,288.00$ & S/ & $119,288.00$ & $S / 119,288.00$ & $S / 119,288.00$ & $\mathrm{~S} / 599,552.00$ \\
\hline Total & S/ & $140,352.50$ & $\mathrm{~S} / 137,641.50$ & $\mathrm{~S} /$ & $138,052.52$ & $S / 138,473.82$ & $\mathrm{~S} / 138,905.65$ & $\mathrm{~S} / 693,425.99$ \\
\hline
\end{tabular}

\subsubsection{Presupuesto de marketing y ventas}

A continuación se presenta la tabla de resumen de los costos involucrados en el proceso de la venta de los bienes.

Tabla 77 Presupuesto de Gastos por Ventas

\begin{tabular}{lrrrrr}
\hline \multicolumn{1}{c}{ Detalle } & \multicolumn{1}{c}{ Año 1 } & \multicolumn{1}{c}{ Año 2 } & \multicolumn{1}{c}{ Año 3 } & \multicolumn{1}{c}{ Año 4 } & \multicolumn{1}{c}{ Año 5 } \\
\hline Transporte & S/.22,200.00 & S/.22,755.00 & S/.23,323.88 & S/.23,906.97 & S/.24,504.65 \\
Publicidad yPromoción & S/.1,400.00 & S/.1,912.05 & S/.1,912.05 & S/.1,912.05 & S/.1,912.05 \\
\hline Total & S/.23,600.00 & S/.24,667.05 & S/.25,235.93 & S/.25,819.02 & S/.26,416.70 \\
\hline
\end{tabular}

\subsubsection{Presupuesto de Gastos Financieros}

Se considera los intereses del préstamo tomado por una TEA del $25 \%$ y un capital de S/. 378,484.72. 
Tabla 78 Cuadro de amortización

\begin{tabular}{|c|c|c|c|c|c|}
\hline Periodo & Saldo Inicial & Cuota & Interés & Abono al Capital & Saldo Final \\
\hline 1 & $S / 378,484.72$ & $S / 10,566.22$ & $S / 7,103.88$ & $S / 3,462.34$ & $S / 375,022.38$ \\
\hline 2 & $S / 375,022.38$ & $S / 10,566.22$ & $S / 7,038.89$ & $S / 3,527.32$ & $S / 371,495.06$ \\
\hline 3 & $S / 371,495.06$ & $S / 10,566.22$ & $S / 6,972.69$ & $S / 3,593.53$ & $S / 367,901.53$ \\
\hline 4 & $S / 367,901.53$ & $S / 10,566.22$ & $S / 6,905.24$ & $S / 3,660.98$ & $S / 364,240.55$ \\
\hline 5 & $S / 364,240.55$ & $S / 10,566.22$ & $S / 6,836.53$ & $S / 3,729.69$ & $S / 360,510.86$ \\
\hline 6 & $S / 360,510.86$ & $S / 10,566.22$ & $S / 6,766.52$ & S/3,799.69 & $S / 356,711.17$ \\
\hline 7 & $S / 356,711.17$ & $S / 10,566.22$ & $S / 6,695.21$ & $S / 3,871.01$ & $S / 352,840.15$ \\
\hline 8 & $S / 352,840.15$ & $S / 10,566.22$ & $S / 6,622.55$ & $S / 3,943.67$ & $S / 348,896.49$ \\
\hline 9 & $S / 348,896.49$ & $S / 10,566.22$ & $S / 6,548.53$ & $S / 4,017.69$ & $S / 344,878.80$ \\
\hline 10 & $S / 344,878.80$ & $S / 10,566.22$ & $S / 6,473.12$ & $S / 4,093.10$ & $S / 340,785.70$ \\
\hline - & - & - & - & - & - \\
\hline - & - & - & - & - & - \\
\hline - & - & - & - & - & - \\
\hline 52 & $S / 86,752.79$ & $S / 10,566.22$ & $S / 1,628.29$ & S/8,937.93 & $S / 77,814.85$ \\
\hline 53 & $S / 77,814.85$ & $S / 10,566.22$ & $S / 1,460.53$ & $S / 9,105.69$ & S/68,709.16 \\
\hline 54 & S/68,709.16 & $S / 10,566.22$ & $S / 1,289.62$ & $S / 9,276.60$ & $S / 59,432.56$ \\
\hline 55 & $S / 59,432.56$ & $S / 10,566.22$ & $S / 1,115.51$ & $S / 9,450.71$ & $\mathrm{~S} / 49,981.85$ \\
\hline 56 & $S / 49,981.85$ & $S / 10,566.22$ & S/938.12 & $S / 9,628.10$ & $S / 40,353.76$ \\
\hline 57 & $S / 40,353.76$ & $S / 10,566.22$ & S/757.41 & $S / 9,808.81$ & $S / 30,544.95$ \\
\hline 58 & $S / 30,544.95$ & $S / 10,566.22$ & $S / 573.31$ & S/9,992.91 & $S / 20,552.04$ \\
\hline 59 & $S / 20,552.04$ & $S / 10,566.22$ & S/385.75 & $S / 10,180.47$ & $S / 10,371.56$ \\
\hline 60 & $S / 10,371.56$ & $S / 10,566.22$ & S/194.67 & $S / 10,371.55$ & $\mathrm{~S} / 0.0$ \\
\hline
\end{tabular}

\subsection{Presupuesto de Resultados}

Tabla 79 Presupuesto de resultados

\begin{tabular}{lrrrrr}
\hline \multicolumn{1}{c}{ Detalle } & \multicolumn{1}{c}{ Año 1 } & Año 2 & \multicolumn{1}{c}{ Año 3 } & \multicolumn{1}{c}{ Año 4 } & \multicolumn{1}{c}{ Año 5 } \\
\hline Ingresos Operacionales & S/.624,672.40 & S/.733,227.60 & S/.850,357.30 & S/.976,106.60 & S/.1,110,475.50 \\
Costo de Producción & S/.321,499.30 & S/.326,554.58 & S/.331,736.25 & S/.337,047.45 & S/.342,491.44 \\
Utilidad Bruta & S/.303,173.10 & S/.406,673.02 & S/.518,621.05 & S/.639,059.15 & S/.767,984.06 \\
Gastos de venta & S/.23,600.00 & S/.24,667.05 & S/.25,235.93 & S/.25,819.02 & S/.26,416.70 \\
Gastos de Adminsitración & S/.133,052.05 & S/.130,158.55 & S/.130,382.51 & S/.130,612.07 & S/.130,847.37 \\
Utilidad de Ope. Antes Imp. & S/.146,521.05 & S/.251,847.42 & S/.363,002.62 & S/.482,628.05 & S/.610,719.99 \\
Provisión de Impuestos & S/.43,956.32 & S/.75,554.23 & S/.108,900.78 & S/.144,788.42 & S/.183,216.00 \\
\hline Utilidad Neta & S/.102,564.74 & S/.176,293.19 & S/.254,101.83 & S/.337,839.64 & S/.427,503.99 \\
\hline
\end{tabular}

\subsubsection{Estado de Resultados Integrales proyectado}

El estado de Resultado de la empresa Oxigeno Industrial para los proximos cinco años, es: 
Tabla 80 Estado de Resultado presupuestado

\begin{tabular}{|c|c|c|c|c|c|c|}
\hline Rubros & 1 & 2 & 3 & 4 & & 5 \\
\hline Envase de $3 m^{3}(7 \%)$ & $3,975.19$ & $4,277.16$ & $4,578.85$ & $4,880.53$ & S/ & $5,182.22$ \\
\hline Envase de $6 \mathrm{~m}^{3}(6 \%)$ & $3,407.30$ & $3,666.14$ & $3,924.73$ & $4,183.31$ & S/ & $4,441.90$ \\
\hline Envase de $8 m^{3}(7 \%)$ & $3,975.19$ & $4,277.16$ & $4,578.85$ & $4,880.53$ & S/ & $5,182.22$ \\
\hline Envase de $10 \mathrm{~m}^{3}(80 \%)$ & S/ $45,430.72$ & S/ $48,881.84$ & S/ $52,329.68$ & S/ $55,777.52$ & S/ & $59,225.36$ \\
\hline Total Ingresos & $S / 624,672.40$ & $S / 672,125.30$ & S/ 784,945.20 & $S / 906,384.70$ & $S / 1$ & $110,475.50$ \\
\hline \multicolumn{7}{|l|}{ Costos directos } \\
\hline Materia prima y materiales & $2,200.00$ & $2,475.00$ & $2,750.00$ & $2,750.00$ & S/ & $2,750.00$ \\
\hline Mano de obra directa & S/ 153,664.95 & S/ 165,189.82 & S/ 176,714.69 & $S / 176,714.69$ & S/ & $176,714.69$ \\
\hline \multicolumn{7}{|l|}{ Gastos de fabricacion } \\
\hline Materiales indirectos & 700.00 & 787.50 & 875.00 & 875.00 & S/ & 875.00 \\
\hline Mano de obra indirecta & S/ 197,936.53 & S/ 197,936.53 & S/ 197,936.53 & S/ 197,936.53 & S/ & $197,936.53$ \\
\hline Gastos indirectos & $6,000.00$ & $6,225.00$ & $6,450.00$ & $6,450.00$ & S/ & $6,450.00$ \\
\hline Depreciacion amortizacion & S/ $155,280.20$ & $S / 155,280.20$ & S/ $155,280.20$ & $S / 155,280.20$ & S/ & $155,280.20$ \\
\hline \multicolumn{7}{|l|}{ Gastos de operación } \\
\hline Gasto de ventas & $1,400.00$ & $1,575.00$ & $1,750.00$ & $1,750.00$ & S/ & $1,750.00$ \\
\hline Gasto de administracion & $9,000.00$ & $9,000.00$ & $9,000.00$ & $9,000.00$ & S/ & $9,000.00$ \\
\hline Total de costos & $S / 526,181.68$ & S/538,469.05 & $S / 550,756.42$ & $S / 550,756.42$ & S/ & $550,756.42$ \\
\hline UAll & S/ $98,490.72$ & $S / 133,656.25$ & S/234,188.78 & $S / 355,628.28$ & S/ & $559,719.08$ \\
\hline Gastos Financieros & S/ $80,677.49$ & S/ $69,148.21$ & S/ $54,736.61$ & S/ $36,722.11$ & S/ & $14,203.96$ \\
\hline UAl & S/ $17,813.23$ & S/ $64,508.04$ & $S / 179,452.17$ & $S / 318,906.17$ & S/ & $545,515.12$ \\
\hline Impuesto a la Renta & $5,343.97$ & S/ $19,352.41$ & S/ $53,835.65$ & S/ $95,671.85$ & S/ & $163,654.54$ \\
\hline Utilidad Neta & S/ $12,469.26$ & S/ $45,155.63$ & $S / 125,616.52$ & $S / 223,234.32$ & S/ & $381,860.58$ \\
\hline Dividendos (60\%) & S/ $\quad 4,987.70$ & S/ $18,062.25$ & S/ $50,246.61$ & S/ $89,293.73$ & S/ & $152,744.23$ \\
\hline Utilidad Retenida & $7,481.56$ & S/ $27,093.38$ & S/ $75,369.91$ & S/ 133,940.59 & S/ & $229,116.35$ \\
\hline Utilidad Retenida Acumulada & $7,481.56$ & S/ $34,574.93$ & S/ 109,944.84 & $S / 243,885.44$ & S/ & $473,001.79$ \\
\hline
\end{tabular}




\subsubsection{Estado de situación financiera}

Se consideraron los siguientes puntos:

Tabla 81 Estado de Situación Financiera

Estado de Situación Financiera

\begin{tabular}{|c|c|c|c|c|c|c|}
\hline Rubros/Años & Año 0 & Año 1 & Año 2 & Año 3 & Año 4 & Año 5 \\
\hline \multicolumn{7}{|l|}{ ACTIVOS } \\
\hline Efectivo & & $S / 80,652.43$ & $S / 166,258.75$ & $S / 285,878.90$ & S/446,179.39 & $S / 679,243.37$ \\
\hline Capital de Trabajo & $S / 30,987.61$ & $S / 30,987.61$ & $\mathrm{~S} / 34,116.26$ & $\mathrm{~S} / 37,096.00$ & $\mathrm{~S} / 39,951.59$ & $S / 42,701.32$ \\
\hline Activo fijo fruto & $S / 599,820.25$ & $S / 599,820.25$ & $S / 599,820.25$ & $S / 599,820.25$ & $S / 599,820.25$ & $S / 599,820.25$ \\
\hline Depreciación y Amortización Acumulada (-) & & $S / 119,288.00$ & $S / 238,576.00$ & $\mathrm{~S} / 357,864.00$ & $S / 477,152.00$ & $S / 596,440.00$ \\
\hline ACTIVO TOTAL & $S / 630,807.86$ & $S / 592,172.29$ & $S / 561,619.26$ & $S / 564,931.15$ & $S / 608,799.23$ & $S / 725,324.94$ \\
\hline \multicolumn{7}{|l|}{ PASIVO Y PATRIMONIO } \\
\hline Cuentas por pagar & $S / 378,484.72$ & $S / 332,367.59$ & $S / 274,721.18$ & $S / 202,663.17$ & $S / 112,590.66$ & S/0.0 \\
\hline Capital & $S / 252,323.14$ & $S / 252,323.14$ & $S / 252,323.14$ & $S / 252,323.14$ & $S / 252,323.14$ & $S / 252,323.14$ \\
\hline Utilidad Retenida & & $\mathrm{S} / 7,481.56$ & $\mathrm{~S} / 34,574.93$ & $S / 109,944.84$ & $S / 243,885.44$ & $S / 473,001.79$ \\
\hline PASIVO Y PATRIMONIO TOTAL & $S / 630,807.86$ & $S / 592,172.29$ & $S / 561,619.26$ & $S / 564,931.15$ & $S / 608,799.23$ & $S / 725,324.9$ \\
\hline
\end{tabular}




\subsubsection{Flujo de caja Proyectado}

Los flujos de caja libre necesarios para valorar la factibilidad económica del proyecto son los siguientes:

Tabla 82 Flujo de Caja Económico y Financiero

\begin{tabular}{|c|c|c|c|c|c|c|c|c|c|c|c|c|}
\hline & & Año 0 & & Año 1 & & Año 2 & & Año 3 & & Año 4 & & Año 5 \\
\hline Inversión Inicial & $-S /$ & $630,807.86$ & & - & & - & & - & & - & & - \\
\hline Ingresos & & - & $\mathrm{S} /$ & $624,672.40$ & $\mathrm{~S} /$ & $733,227.60$ & $\mathrm{~S} /$ & $850,357.30$ & $\mathrm{~S} /$ & $976,106.60$ & $\mathrm{~S} /$ & $1,110,475.50$ \\
\hline Valor Residual & & - & & - & & - & & - & & - & $\mathrm{S} /$ & $55,199.80$ \\
\hline Costos y Gastos & & - & $-\mathrm{S} /$ & $366,163.80$ & $-\mathrm{S} /$ & $369,575.13$ & $-\mathrm{S} /$ & $375,736.70$ & $-\mathrm{S} /$ & $382,052.29$ & $-S /$ & $388,525.79$ \\
\hline Utilidad Bruta & & - & $\mathrm{S} /$ & $258,508.60$ & $\mathrm{~S} /$ & $363,652.47$ & $\mathrm{~S} /$ & $474,620.60$ & $\mathrm{~S} /$ & $594,054.31$ & $\mathrm{~S} /$ & $777,149.51$ \\
\hline Depreciación & & - & $-S /$ & $119,288.00$ & $-S /$ & $119,288.00$ & $-S /$ & $119,288.00$ & $-S /$ & $119,288.00$ & $-S /$ & $119,288.00$ \\
\hline Utilidad Operativa & & - & $\mathbf{S} /$ & $139,220.60$ & $\mathbf{S} /$ & $244,364.47$ & $\mathbf{S} /$ & $355,332.60$ & $\mathbf{S} /$ & $474,766.31$ & $\mathbf{S} /$ & $657,861.51$ \\
\hline Utilidad Después de Impuesto & & - & $\mathbf{S} /$ & $97,454.42$ & $\mathbf{S} /$ & $171,055.13$ & $\mathbf{S} /$ & $248,732.82$ & $\mathbf{S} /$ & $332,336.42$ & $\mathbf{S} /$ & $460,503.06$ \\
\hline Financiamiento & & $378,484.72$ & & & & & & & & & & \\
\hline Interés & & - & $-\mathrm{S} /$ & $80,677.49$ & $-\mathrm{S} /$ & $69,148.21$ & $-\mathrm{S} /$ & $54,736.61$ & $-\mathrm{S} /$ & $36,722.11$ & $-\mathrm{S} /$ & $14,203.98$ \\
\hline Amortización & & - & $-S /$ & $46,117.13$ & $-S /$ & $57,646.41$ & $-\mathrm{S} /$ & $72,058.01$ & $-S /$ & $90,072.52$ & $-S /$ & $112,590.64$ \\
\hline Escudo Tributario & & - & $\mathrm{S} /$ & $24,203.25$ & $\mathrm{~S} /$ & $20,744.46$ & $\mathrm{~S} /$ & $16,420.98$ & $\mathrm{~S} /$ & $11,016.63$ & $\mathrm{~S} /$ & $4,261.19$ \\
\hline Depreciación & & - & $\mathrm{S} /$ & $119,288.00$ & $\mathrm{~S} /$ & $119,288.00$ & $\mathrm{~S} /$ & $119,288.00$ & $\mathrm{~S} /$ & $119,288.00$ & $\mathrm{~S} /$ & $119,288.00$ \\
\hline Inversión Adicional de Capital de Trabajo & & - & $\mathrm{S} /$ & $3,128.65$ & $\mathrm{~S} /$ & $2,979.74$ & $\mathrm{~S} /$ & $2,855.59$ & $\mathrm{~S} /$ & $2,749.73$ & & - \\
\hline
\end{tabular}

Flujo de Fondos para el Inversionista

$\begin{array}{llllllllllll}-S / & 252,323.14 & \text { S/ } & 117,279.70 & \text { S/ } & 187,272.71 & \text { S/ } & 260,502.77 & \text { S/ } & 338,596.16 & \text { S/ } & 499,958.94\end{array}$




\section{Capitulo IX Evaluación Económica}

\section{Financiera}

\subsection{Evaluación Financiera}

\subsubsection{TIR (Tasa Interna de Retorno)}

"La tasa interna de retorno o TIR, es aquella tasa que hace el VAN igual a cero. La TIR mide la rentabilidad como un porcentaje, que se calcula sobre los saldos no recuperados en cada período" (Court, C. Aching \& J. Aching, 2009, p. 314)

A mayor tasa interna de retorno, más rentabilidad, se procede a compararla con el Costo de Capital Promedio Ponderado (WACC) y según el resultado obtenido, se determinara que la TIR Económica es mayor que el $\mathrm{WACC}=24.2 \%$, por lo tanto el presente estudio es viable.

\section{Tabla 83 Tasa Interna de Retorno}

\begin{tabular}{lr}
\hline \multicolumn{2}{c}{ Tasa Interna de Retorno } \\
\hline TIR & $72.58 \%$ \\
\hline
\end{tabular}

Entonces, se concluye que; El proyecto arroja rentabilidad positiva al tener una tasa de retorno de su capital por encima de la tasa del costo de capital, así que, se concluye que el proyecto tiene rentabilidad en su ejecución.

\subsubsection{VAN (Valor Actual Neto)}

"El valor actual neto o VAN actualiza a valor presente los flujos de caja futuros de un proyecto, descontados a un cierto tipo de interés y/o tasa de descuento, para compararlos con el valor inicial de la inversión" (Court, C. Aching \& J. Aching, 2009, P. 312). 
Para el cálculo del valor actual neto, se presenta nuevamente el Flujo Neto de Caja para los inversionistas y descontamos estos valores con la tasa del WACC: $24.20 \%$.

Tabla 84 Valor Actual Neto

\begin{tabular}{lr}
\hline \multicolumn{2}{c}{ Valor Actual Neto } \\
\hline VAN & S/ $410,948.02$
\end{tabular}

\subsubsection{PRI (Periodo de Recuperación de la Inversión)}

El Periodo de Recupero de Inversión (PRI) es el indicador que mide el tiempo en el que se recuperará el total de la inversión con la actualización de los flujos a valor presente utilizando la tasa de descuento.

Tabla 85 Flujos netos actualizados

\begin{tabular}{crrrrr}
\hline Año & \multicolumn{2}{c}{ Flujo Neto } & \multicolumn{1}{c}{ Flujo VP } & \multicolumn{2}{c}{ Flujo VP Acumulado } \\
\hline 0 & $-\mathrm{S} /$ & $252,323.14$ & $-\mathrm{S} / 252,323.14$ & $-\mathrm{S} /$ & $252,323.14$ \\
1 & $\mathrm{~S} /$ & $117,279.70$ & $\mathrm{~S} / 94,428.10$ & $-\mathrm{S} /$ & $157,895.04$ \\
2 & $\mathrm{~S} /$ & $187,272.71$ & $\mathrm{~S} / 121,403.53$ & $-\mathrm{S} /$ & $36,491.52$ \\
3 & $\mathrm{~S} /$ & $260,502.77$ & $\mathrm{~S} / 135,971.40$ & $\mathrm{~S} /$ & $99,479.88$ \\
4 & $\mathrm{~S} /$ & $338,596.16$ & $\mathrm{~S} / 142,296.97$ & $\mathrm{~S} /$ & $241,776.85$ \\
5 & $\mathrm{~S} /$ & $499,958.94$ & $\mathrm{~S} / 169,171.17$ & $\mathrm{~S} /$ & $410,948.02$
\end{tabular}

A partir de los flujos descontados, se estima el siguiente valor del PRI, utilizando el WACC calculado y la siguiente fórmula:

$$
\text { PRI }=(n-1)+\frac{\text { Io }- \text { Flujo Acumulado }_{(n-1)}}{\text { Flujo } \text { Actual }_{n}}
$$

Donde:

$\mathrm{n}=$ el periodo en el que el Flujo Acumulado es igual a la inversión.

Io = Inversión Inicial 
Tabla 86 Estimación del Período de Recuperación de la Inversión

$\frac{\overline{\text { Periodo Recupero de Inversión }}}{\text { PRI }}$

Dado el valor positivo del VAN, un PRI a mediano plazo (menor al periodo de evaluación) y una TIR mayor a la tasa de costo capital; se concluye que el proyecto tiene rentabilidad en su ejecución.

\subsubsection{ROE}

Ratio Económico que se encarga de mostrar la Rentabilidad Financiera de la empresa, relacionando el beneficio económico con los recursos necesarios para obtenerlo.

Para la determinación del Rendimiento sobre el Capital, que es una medida de cómo le fue a los inversionistas durante el año, se ha aplicado la formula sencilla en base a la utilidad neta y el capital contable; ya que, no se debe olvidar que la meta consiste en beneficiar a los accionistas, el ROE, debe ser expresado en un sentido contable.

$$
R O E=\frac{\text { Utiliad Neta }}{\text { Capital Contable }}
$$

Tabla 87 Rendimiento sobre el capital por año

\begin{tabular}{llllll} 
& Año 1 & Año 2 & Año 3 & Año 4 & Año 5 \\
\hline ROE & $26.56 \%$ & $29.70 \%$ & $33.21 \%$ & $36.79 \%$ & $40.31 \%$ \\
\hline
\end{tabular}




\subsubsection{Ratios}

Para reforzar el análisis de rentabilidad, se presenta los principales ratios para medir el desempeño de la operatividad del proyecto.

Tabla 88 Ratios

\begin{tabular}{llllll} 
& Año 1 & Año 2 & Año 3 & Año 4 & Año 5 \\
\hline ROS & $11.51 \%$ & $12.93 \%$ & $14.49 \%$ & $15.86 \%$ & $16.88 \%$ \\
\hline EBITDA & $19.68 \%$ & $20.47 \%$ & $21.42 \%$ & $22.65 \%$ & $24.11 \%$
\end{tabular}

Se aprecia que para el proyecto en particular, durante el primer año el proyecto genera 11 centavos de utilidad por cada sol de ventas, al mismo tiempo que 39 centavos por cada sol invertido. Puede notarse los valores relativamente bajos para el primer año de operación, sin embargo, estos ratios mejoran su performance para los subsiguientes años de operación.

\subsection{Análisis de Riesgo}

Empezaremos desarrollando la matriz de riesgos, que es una herramienta que aporta de manera rápida y sencilla una visión de los riesgos que afectan a la empresa. En este instrumento se detallan la posibilidad de que estos eventos terminen sucediendo.

Estas tablas están compuestas de los riesgos, la probabilidad de que terminen sucediendo, su gravedad, así como posibles soluciones. Esta herramienta 
de control y gestión permite diferenciar y clasificar los riesgos, según su tipología, nivel y factores.

Es necesario seguir los siguientes pasos para elaborar una matriz de riesgo:

1. Identificar los riesgos. Identificación de los riesgos inherentes a las actividades que desempeña la empresa. Como resultado se obtienen aquellos riesgos que ponen en peligro el cumplimiento de los objetivos que se plantea la organización.

2. Evaluar la probabilidad. Determinar la probabilidad de que los riesgos sucedan, así como las consecuencias en los resultados de la compañía. Para evaluar la probabilidad se utiliza un análisis cuantitativo y cualitativo.

Representación de la matriz de riesgos.

Se presenta la matriz aportando información rápida y sencilla sobre aquellos riesgos que afectan a la empresa y su probabilidad de ocurrencia.

Tabla 89 Factores de Riesgo 


\begin{tabular}{|c|c|c|c|}
\hline $\begin{array}{l}\text { Factores de riesgo donde se } \\
\text { ejecuta el plan de Negocio. }\end{array}$ & Factores de emplazamiento. & Factores meteorológicos. & Factores monetarios. \\
\hline $\begin{array}{l}\text { 1. Cultura, hábitos, costumbres, } \\
\text { creencias, intereses de la } \\
\text { población local. }\end{array}$ & $\begin{array}{l}\text { 1. Tráfico en la zona (personas, } \\
\text { vehículos, animales, otros) }\end{array}$ & $\begin{array}{l}\text { 1. Condiciones anormales (nieve, } \\
\text { lluvia, vientos, temperaturas, } \\
\text { radiación global, penetraciones } \\
\text { del mar, sismos, etc.) }\end{array}$ & $\begin{array}{l}\text { 1. Costos asociados a la } \\
\text { preparación de la negociación. }\end{array}$ \\
\hline $\begin{array}{l}\text { 2. Condiciones económicas de la } \\
\text { zona. }\end{array}$ & 2. Agresión al medio ambiente. & $\begin{array}{l}\text { 2. Riesgo de condiciones } \\
\text { extremas. }\end{array}$ & $\begin{array}{l}\text { 2. Costos asociados a la } \\
\text { elaboración de la documentación, } \\
\text { apertura y operación del negocio }\end{array}$ \\
\hline $\begin{array}{l}\text { 3. Estabilidad del Gobierno. } \\
\text { Riesgo político. }\end{array}$ & $\begin{array}{l}\text { 3. Operaciones / obras } \\
\text { adyacentes. }\end{array}$ & & $\begin{array}{l}\text { 3. Costos de la elaboración de la } \\
\text { oferta con relación al beneficio } \\
\text { esperado si se obtiene el } \\
\text { Contrato. }\end{array}$ \\
\hline $\begin{array}{l}\text { 4. Servicios médicos, de policía, } \\
\text { de atención contra incendios. }\end{array}$ & $\begin{array}{l}\text { 4. Peligros: a la salud, a la } \\
\text { seguridad, a la integridad } \\
\text { personal. }\end{array}$ & & 4. Incremento de precios. \\
\hline $\begin{array}{l}\text { 6. Acceso a la zona (transporte y } \\
\text { comunicaciones) }\end{array}$ & $\begin{array}{l}\text { 6. Garantía de servicios } \\
\text { necesarios (agua, energía, } \\
\text { teléfono, correo electrónico, } \\
\text { Internet, fax, telex, correo, } \\
\text { medios de comunicación masiva, } \\
\text { etc.) }\end{array}$ & & $\begin{array}{l}\text { 6. Tasas de cambio (importante } \\
\text { cuando se contrata todo o parte } \\
\text { en moneda extranjera o si existen } \\
\text { suministros procedentes del } \\
\text { exterior). }\end{array}$ \\
\hline
\end{tabular}




\begin{tabular}{|l|l|l|l|}
$\begin{array}{l}\text { 7. Condiciones de alojamiento } \\
\text { (facilidades temporales, } \\
\text { viviendas, distracción, } \\
\text { comedores, confort, etc.) }\end{array}$ & 7. Seguridad ciudadana. & 7. Índices de costos en la zona. \\
\hline $\begin{array}{l}\text { 8. Condiciones para la ejecución } \\
\text { de los negocios o la } \\
\text { comercialización (oficinas, } \\
\text { equipamiento, confort) }\end{array}$ & $\begin{array}{l}\text { 8. Desplazamiento involuntario } \\
\text { de personas desde y hacia la } \\
\text { zona. }\end{array}$ & & 8. Retrasos en pagos. \\
\hline 9. Otras infraestructuras. & & 9. Retenciones. \\
\hline & & 10. Premios por adelanto. \\
\hline & & 11. Multas por retrasos. \\
\hline & & $\begin{array}{l}12 . \text { Costos de los gastos } \\
\text { generales del Proyecto. }\end{array}$ \\
\hline & & $\begin{array}{l}13 . \text { Indefiniciones de anticipos } \\
\text { por la Propiedad para el inicio de } \\
\text { la ejecución. }\end{array}$ \\
\hline
\end{tabular}


Tabla 90 Plan de Contingencia por Suceso

\begin{tabular}{|l|l|}
\hline \multicolumn{1}{|c|}{ Suceso } & \multicolumn{1}{c|}{ Plan de Contingencia } \\
\hline Enfermedad del personal. & $\begin{array}{l}\text { Reorganizar el equipo de tal forma que haya traslape en } \\
\text { el trabajo y las personas comprendan el de los demás. }\end{array}$ \\
\hline Componentes defectuosos. & $\begin{array}{l}\text { Reemplazar los componentes defectuosos con los } \\
\text { comprados de fiabilidad conocida. }\end{array}$ \\
\hline Cambios en los requerimientos. & $\begin{array}{l}\text { Rastrear la información para valorar el impacto de los } \\
\text { requerimientos, maximizar la información oculta en } \\
\text { ellos. }\end{array}$ \\
\hline $\begin{array}{l}\text { El personal desconoce la tecnología requerida } \\
\text { para el plan de negocios. }\end{array}$ & $\begin{array}{l}\text { Se subcontrata a una compañía con experiencia en la } \\
\text { tecnología requerida que capacite al personal. }\end{array}$ \\
\hline En el caso de huelgas o manifestaciones & $\begin{array}{l}\text { Alquilar locales para la distribución de los balones de } \\
\text { Oxígeno. }\end{array}$ \\
\hline Cortes de fluido de energía & Adquirir un grupo de generación continua de energía. \\
\hline
\end{tabular}

\begin{tabular}{|l|l|}
\hline \multicolumn{1}{|c|}{ TIPO DE RIESGO } & PROBABILIDAD \\
\hline Cambio De Política & MUY PROBABLE \\
\hline Nuevos Competidores & MUY PROBABLE \\
\hline Dejamos De Ser Competitivos En Precio & $\begin{array}{l}\text { ES RARO QUE } \\
\text { SUCEDA }\end{array}$ \\
\hline Dependencia Excesiva De Un Cliente & $\begin{array}{l}\text { SERIA } \\
\text { EXCEPCIONAL }\end{array}$ \\
\hline Clientes Dejen De Pagar & ES POSIBLE \\
\hline Dependencia Excesiva Proveedores & ES POSIBLE \\
\hline Riesgo Desabastecerse De Insumos & ES POSIBLE \\
\hline Suben Tasas De Interés & ES POSIBLE \\
\hline Competencia Producto Del Extranjero & MUY PROBABLE \\
\hline Fuga De Cerebros Y Personal & $\begin{array}{l}\text { ES RARO QUE } \\
\text { SUCEDA }\end{array}$ \\
\hline Modernización De Presentación Del Producto & CASI SEGURO \\
\hline Cambios En La Legislación & MUY PROBABLE \\
\hline Grupos De Presión Pongan Dificultades & $\begin{array}{l}\text { SERIA } \\
\text { EXCEPCIONAL }\end{array}$ \\
\hline
\end{tabular}

\begin{tabular}{|l|l|}
\hline \multicolumn{1}{|c|}{ IMPACTO } \\
\cline { 2 - 2 } & \\
\hline INSIGNIFICANTE \\
\hline GRANDE \\
\hline GRANDE \\
\hline PEQUEÑO \\
\hline MODERADO \\
\hline GRANDE \\
\hline CATASTROFE \\
\hline PEQUEÑO \\
\hline PEQUEÑO \\
\hline MODERADO \\
\hline CATASTROFE \\
\hline MODERADO \\
\hline INSIGNIFICANTE \\
\hline
\end{tabular}




\section{Planes de mitigación de riesgos}

- Las acciones se definen antes de que ocurra o no ocurra el riesgo.

- Se asignan recursos por adelantado debido a la situación de riesgo identificada.

- Se mitigan los riesgos que están por encima del umbral establecido, aplicando planes de respuesta para reducir probabilidad e impacto

- Trabaja como un plan proactivo

\section{Planes de contingencia de riesgos}

- Se planifican ciertas acciones que se ponen en marcha sólo si las señales de advertencia se disparan.

- No se gastan recursos por adelantado

- No tratamos de cambiar la probabilidad e impacto de un riesgo, pero planificamos como controlarlo en caso de que ocurra.

- Trabaja como un plan reactivo. 


\subsubsection{Análisis de Punto de Equilibrio}

Dado que el punto de equilibrio es aquel en el que los ingresos son iguales a los costos, se puede determinar fácilmente el número de unidades a producir para alcanzar dicho punto.

El margen de utilidad es del $26.7 \%$, de esta forma el precio de venta unitario será de S/. 11.00/m3 de oxígeno, representado así:

$$
\begin{array}{ll}
\text { Costo Unitario } & =\mathrm{S} / .8 .68 \\
\text { Margen de Utilidad Bruta } & =26.7 \% \\
\text { Margen de Utilidad Bruta } & =\text { S } / .2 .32
\end{array}
$$

Ahora entonces, se tiene un precio de venta de:
$\begin{array}{ll}\text { Precio de Venta } & =\mathrm{CU}+\mathrm{MCU} \\ \text { PV } & =\mathrm{S} / .8 .68+\mathrm{S} / .2 .32 \\ \text { PV } & =\mathrm{S} / .11 .00\end{array}$

A partir del precio de venta determinado, se tiene un nivel de ingresos para el primer año de operación que equivale a;

$\begin{array}{ll}\text { Ingresos } & =\mathrm{PV}^{*} \mathrm{~m} 3 \text { a vender } \\ \text { Ingresos } & =\mathrm{S} / .11 .00 * 56788.4 \mathrm{~m} 3 \text { oxigeno } \\ \text { Ingresos } & =\mathrm{S} / .624,672.40\end{array}$

Ahora pasamos a calcular directamente el punto de equilibrio, tal y como sigue:

Punto de Equilibrio en $\mathrm{m} 3$ de oxigeno $=\mathrm{CFT} / \mathrm{MCU}$ 
En dónde:

CFT

MCU
$=$ Costos Fijos Tomados

$=$ Margen de Contribución Unitaria

Margen de Contribución Unitaria $=\mathrm{PV}-\mathrm{CVU}$

CVU

$=\mathrm{CVT} / \mathrm{Q}^{*}$

CVU

$=\mathrm{S} / .23,600.00 / 56788.4$

CVU

$=\mathrm{S} / .0 .42$

Entonces:

$\mathrm{MCU}$

$=\mathrm{S} / .11 .00-\mathrm{S} / .0 .42$

$\mathrm{MCU}$

$=\mathrm{S} / .10 .58$

Punto de Equilibrio en m3 oxigeno

PE

PE
$=\mathrm{CFT} / \mathrm{MCU}$

$=\mathrm{S} / .378,440.05 / \mathrm{S} / .10 .58$

$=35,754.4 \mathrm{~m} 3$ oxígeno

Así, la empresa debe de producir y vender un nivel de 35,754.4 m3 oxígeno el primer año para poder cubrir todos los gastos necesarios para el mantenimiento de la operatividad de la empresa, aunque no logre ni ganancias ni perdidas.

Ahora podemos calcular el punto de equilibrio en términos monetarios, tal y como sigue:

Punto de Equilibrio Monetario $=$ Costos Fijos Totales $(\mathrm{CFT}) /$ Índice de Contribución Unitaria (IC)

Donde: 
IC

IC

PE Monetario
$=\mathrm{MCU} / \mathrm{PVU}$

$=\mathrm{S} / .10 .58 / \mathrm{S} / .11 .00$

$=\mathrm{S} / . \mathbf{3 9 3}, 298.80$

Así, la empresa debe de producir y vender por un valor de S/. 393,298.80 el primer año para poder cubrir todos los gastos necesarios para el mantenimiento de la operatividad de la empresa, aunque no logre ni ganancias ni pérdidas.

\subsubsection{Análisis de sensibilidad}

El análisis de sensibilidad permite evaluar el proyecto bajo variaciones de ciertas variables al esperado, siendo estas positivas o negativas.

En este caso evaluaremos el desempeño del proyecto bajo variaciones de las dos variables principales Precio y Costo.

- El Precio se evaluará dentro de un rango de variación de entre $-40 \%$ y $+40 \%$ al precio definido en el proyecto, atribuyéndose esta posible variación a distintos factores tanto del mercado (entrada y salida de competidores) como al aumento de los costos necesarios.

- El Costo, de igual manera se evaluará dentro de un rango de variación de entre $-40 \%$ y $+40 \%$ a los costos variables definidos en el proyecto, atribuyendo esta posible variación principalmente al comportamiento de los insumos y servicios utilizados para conseguir el producto final.

\section{Análisis de Sensibilidad - Precio}


Tabla 91 Análisis de Sensibilidad - Precio

\begin{tabular}{cccc}
\hline Precio & \multicolumn{2}{c}{ VAN } & TIR \\
\hline $40 \%$ & \multicolumn{2}{c}{ S/1,029,217.09 } & $141.12 \%$ \\
$30 \%$ & S/ & $874,649.82$ & $124.12 \%$ \\
$20 \%$ & S/ & $720,082.56$ & $107.06 \%$ \\
$10 \%$ & S/ & $565,515.29$ & $89.91 \%$ \\
$0 \%$ & S/ & $410,948.02$ & $72.58 \%$ \\
$-10 \%$ & S/ & $256,380.75$ & $54.94 \%$ \\
$-20 \%$ & S/ & $101,813.49$ & $36.72 \%$ \\
$-26.6 \%$ & S/ & - & $24.20 \%$ \\
$-30 \%$ & $-S /$ & $52,753.78$ & $17.46 \%$ \\
$-40 \%$ & $-S /$ & $207,321.05$ & $-3.86 \%$
\end{tabular}

El análisis de sensibilidad al precio nos permite ver que, frente a un aumento de precio que puede provenir de distintas fuentes, aumentaría la utilidad generada por el proyecto evidenciándose con el aumento del VAN y TIR.

A su vez, indica que frente a la disminución de hasta $-26.6 \%$ del precio, el proyecto cumple con la generación de beneficio para los inversionistas.

\section{Análisis de Sensibilidad - Costos}

Tabla 92 Análisis de Sensibilidad - Costo

\begin{tabular}{cccc}
\hline Costo & \multicolumn{2}{c}{ VAN } & TIR \\
\hline $57 \%$ & S/ & - & $24.20 \%$ \\
$40 \%$ & S/ & $124,634.97$ & $38.53 \%$ \\
$30 \%$ & S/ & $196,213.23$ & $46.88 \%$ \\
$20 \%$ & S/ & $267,791.49$ & $55.35 \%$ \\
$10 \%$ & S/ & $339,369.76$ & $63.91 \%$ \\
$0 \%$ & S/ & $410,948.02$ & $72.58 \%$ \\
$-10 \%$ & S/ & $482,526.29$ & $81.36 \%$ \\
$-20 \%$ & S/ & $554,104.55$ & $90.23 \%$ \\
$-30 \%$ & S/ & $625,682.81$ & $99.20 \%$ \\
$-40 \%$ & S/ & $697,261.08$ & $108.25 \%$
\end{tabular}

El análisis de sensibilidad al costo nos permite evaluar el efecto de aumentar el costo de producción del producto y afectar la generación de beneficio para los 
clientes, por lo que la utilidad aumentaría en caso de encontrar maneras más eficientes de producir y mejorando la productividad del proceso.

En el caso de que los costos aumentaran sin aumentar los precios del producto, el proyecto estaría en posibilidad de generar beneficio para los inversionistas con un aumento en los costos de hasta $57 \%$.

\subsubsection{Análisis de escenarios}

Es necesario poder realizar análisis de escenarios, tomando en consideración el comportamiento de cambio posible de las dos variables más importantes en el éxito del proyecto, el Precio y el Costo.

Se definirán cinco escenarios para realizar el análisis, siendo los siguientes:

- Muy Optimista: Incremento de Precios en 10\% y una reducción de Costos en $10 \%$.

- Optimista: Incremento de Precios en 5\%. Reducción de Costos en 5\%.

- Conservador: Sin Incremento de Precios. Aumento de Costos en 5\%.

- Pesimista: Reducción de Precios en 5\%. Aumento de Costos en 5\%.

- Muy Pesimista: Reducción de Precios en 10\%. Aumento en Costos en 10\%. Los resultados de este análisis se evidencian con el comportamiento del VAN y TIR, como se muestran en la siguiente tabla: 
Tabla 93 Análisis de Escenarios

\begin{tabular}{lccccc}
\hline & Escenario & Precio & Costo & VAN & TIR \\
\hline 1 & Muy Optimista & $+10 \%$ & $-10 \%$ & $\mathrm{~S} / 637,093.55$ & $98.731 \%$ \\
2 & Optimista & $+5 \%$ & $-5 \%$ & $\mathrm{~S} / 524,020.79$ & $85.661 \%$ \\
3 & Conservador & - & $+5 \%$ & $\mathrm{~S} / 375,158.89$ & $68.236 \%$ \\
4 & Pesimista & $-5 \%$ & $+5 \%$ & $\mathrm{~S} / 297,875.26$ & $59.467 \%$ \\
5 & Muy Pesimista & $-10 \%$ & $+10 \%$ & $\mathrm{~S} / 184,802.49$ & $46.253 \%$
\end{tabular}

Al pasar el proyecto por un test de este tipo podemos visualizar cuál sería el desempeño del proyecto en distintos escenarios. Siendo importante visualizar el comportamiento en los escenarios Pesimista y Muy Pesimista, en los que se puede visualizar que se genera beneficio aún en un improbable caso de disminución de Precio de $10 \%$ y aumento de Costo en $10 \%$. 


\section{Conclusiones}

PRIMERA.- Se determinó que una de las principales características del sector analizado es que la demanda existente debe conformarse, para satisfacer sus requerimientos de Oxigeno industrial, con una única planta productora de Oxigeno industrial y dos empresas encargadas de la distribución de Oxigeno industrial, las cuales son insuficientes para cubrir la demanda actual y la demanda potencial del departamento de Puno.

SEGUNDA.- Después de realizar el análisis del entorno competitivo se determinó que la confianza de cliente es uno de los factores más importantes y más difíciles de conseguir, por lo tanto el presente plan de negocios propone estrategias basadas en la calidad y seguridad para poder obtener esta confianza y lograr fidelizar a nuestros clientes.

TERCERA.- De acuerdo a las características y necesidades del mercado, las empresas consumidoras de Oxigeno industrial exigen y necesitan un producto y servicio con calidad y seguridad, por lo cual nuestra propuesta de negocio está orientada exclusivamente a cubrir estas necesidades, a través de la elaboración de un producto de alta pureza y la prestación de un servicio basado en un estricto protocolo de seguridad.

CUARTA.- Los factores locacionales y las características de nuestro competidor directo nos permitieron establecer a la ciudad de Juliaca, capital de la provincia de San Román dentro del departamento de Puno, como el lugar adecuado para la ubicación de nuestra empresa, esta ciudad es considerada como la zona comercial del departamento de Puno, además es esta ciudad que se encuentran las oficinas principales de nuestros potenciales clientes. 


\section{Recomendaciones}

1. En la medida de las posibilidades, volver a realizar el estudio de mercado tomando una muestra totalmente aleatoria, y con un cuestionario más amplio en sus preguntas para poder proyectar de mejor forma el mercado potencial, efectivo, disponible y objetivo.

2. Desarrollar una evaluación de factibilidad a un proyecto que además de apuntar al mercado industrial del oxígeno, también pueda atender a la demanda en hospitales y clínicas, para el oxígeno medicinal.

3. Evaluar económica y financieramente al plan de negocios considerando una capacidad de planta mayor, para que los costos fijos se puedan diluir por unidad de metro cubico y obtener economías de escala que repercutan en mejores indicadores de rentabilidad.

4. Extender las zonas donde se ofrecerá el producto y servicio, planteándose a largo plazo cubrir todo el departamento de Puno y como siguiente paso los departamento vecinos. 


\section{Referencias}

Atkins, G. (2012 Definición E Implementación Del Plan De Acción Para El Cambio De Imagen De Una Empresa Productora Y Comercializadora De Gases Industriales. (Tesis pre grado) Pontificia Universidad Católica Del Perú. Lima, Peru.

Basu, C. (2005). ¿Qué es una política de recursos humanos? México.

Borello, A. (1994) El Plan de Negocios. Madrid. Dias de Santos.

Cabana, F. (2007). Abello Linde 100 años. Barcelona: RAF Impresores.

Calderon, J. (28 de setiembre del 2016) Sepa que proyectos Mineros estan listos para iniciar en la region Puno. La Republica, p.13.

Corbetta, P. (2003). Metodologia y Tecnicas de Investigacion Social. Madrid: McGrawHill.

Court, E., Aching, C \& Aching, J. (2009). Matemáticas Financieras. Argentina. CENGAGE Learning.

Cryogas (2016) Historia de la empresa. Recuperado de http: // www. cryogas. com.co / Web /CO/ Compania/Historia

Cuadrado, C. (2007). Protocolo y Comunicación en la Empresa. Madrid. Fundacion CONFEMETAL.

Deutsche Bank:. (13 de Junio de 2017). Peru es la economia emergente menos vulnerable. Gestion, p. 11.

Dirección de Promoción Minera (2016). Perú 2016: Anuario Minero Reporte Estadístico. Lima: Ministerio de Energía y Minas. 
Direccion General de Mineria. (23 de Julio de 2016). Crecimiento del sector Minero en el Peru. Gestion, pág. 17.

Francfort, R. (20 de Diciembre de 2016). Linde y Praxair llegan a auerdo para fusionarse. Gestion, pág. 13.

Healey M. (2009). ¿Qué es el branding? Barcelona. Gustavo Gili.

Instituto Nacional de Estadistica e Informatica. (2017). Producto Bruto Interno Trimestral. Lima.

McCarthy J. \& Perreault W. (1996). Marketing: planeación estratégica de la teoría a la práctica. Bogotá. McGrawHill

Maximixe. (19 de Agosto de 2016). Industria metalmecanica caeria 5.6\%. Gestion, pág. 14.

Municipalidad Provincial de San Roman (2015) Plan Director de Juliaca.

Nosnik. A. (2005). Culturas Organizacionales: origen, consolidación y desarrollo. España. Gesbiblo.

Malhotra, N. (2008). Investigación de Mercados.Mexico.Pearson Educación.

Porter, M. (2009). Ser Competitivo. Madrid: Deusto.

Rios, M. (21 de Febrero de 2017). Sector Construccion: ¿Que impulasara su crecimiento? Gestion, pág. 18.

Rodríguez. A. (2013). Fundamentos de Mercadotecnia. Andalucía. Universidad Andaluza Inca Garcilaso.

Schein. E. (1988). Cultura Empresarial y Liderazgo. Barcelona. Plaza \& Janes Editores 
Tamborero, J. (n.d) NTP 495: Soldadura oxiacetilénica y oxicorte: normas de seguridad. Lima.

Wall, R. (21 de diciembre del 2016) Linde y Praxair crean un gigante del gas industrial de US\$66.600 millones. Diario La nación. Argentina. Recuperado de http://www.lanacion.com.ar/1969109-linde-y-praxair-crean-un-gigante-del-gasindustrial-de-us66600-millones. 


\section{Apéndices}

\section{Apéndice A: Cuestionario}

\section{Empresa de producción y distribución de oxigeno industrial}

Le pedimos responder con sinceridad a la presente encuesta que permitirá establecer el comportamiento de la empresa consumidora de oxigeno industrial, las principales características que se busca en el producto y más importante en el tipo de servicio y su aceptación y/o rechazo para un nuevo proveedor que mejore el servicio sobre la oferta existente.

Datos solicitados

Razón Social:

Referencia Laboral:

Nombre del Propietario:

RUC:

Dirección:

Celular:

¿Es usted quien toma las decisiones con respecto a la compra del oxígeno industrial en su empresa?

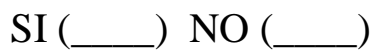

Si marcó NO, le agradecemos no continuar las siguientes preguntas.

1. ¿En qué ciudad está ubicada su empresa
a) Juliaca. ( )
b) Puno.
c) Azángaro. ( )
d) Otros ( ) Especifique:

2. Qué tipo de actividad económica realiza su empresa
a) Explotación Minera ( )
b) Fabricación de productos metálicos ( )

3. Actualmente, ¿Cuál es la empresa proveedora a la cual accede?
a) CIGA S.A.
( )
b) OXYTEX
( )
c) OXYTEX GASES ANDINOS
d) OTROS

4. Actualmente, ¿La empresa que le abastece del oxígeno industrial logra cubrir el volumen total de su requerimiento?
a) $\mathrm{Si}$
( )
b) A veces ( )
c) $\mathrm{No}$
( ) 
Mencione un breve comentario:

5. Actualmente, ¿Se encuentra Usted satisfecho con su(s) proveedor(es)?
a) $\mathrm{Si}$
( )
b) No
( )

Mencione un breve comentario:

6. Al ser un nuevo proveedor que le ofrece un servicio mejorado sobre el actual, es decir; con el nivel requerido de $99.5 \%$ de pureza sobre el oxígeno industrial, con una flexibilidad y rapidez en la entrega, y una capacidad de generación que le garantice cubrir el total de sus requerimientos, ¿Le gustaría a Usted contar en la región de Puno con este nuevo y mejorado servicio sobre el oxígeno industrial?
a) $\mathrm{Si}$
( )
b) No
$($ )

Mencione un breve comentario:

7. De acuerdo al enunciado de la pregunta anterior, al ser un nuevo proveedor con una oferta en base a un servicio mejorado sobre el oxígeno industrial, ¿Está Usted dispuesto a adquirir el oxígeno industrial bajo este servicio mejorado y diferenciado?
a) $\mathrm{Si}$
$($ )
b) No
( )

Mencione un breve comentario:

8. Actualmente, ¿Cuál es el nivel de pureza requerido sobre el oxígeno industrial para su adquisición?
a) Del $70 \%$ al $80 \%$ de nivel de pureza. ( )
b) Del $90 \%$ al $99.5 \%$ de nivel de pureza. ( )
c) Otro
( ) Especifique:

9. Actualmente, ¿Cuál es el nivel de precios al cuál adquiere el oxígeno industrial por cada $\mathrm{m} 3$ ?
a) Menos de S/. 6.00
b) De S/. 6.90 hasta $S / .10 .00$
( )
c) De S/. 11.00 hasta S/. 15.00
d) Más de S/. 15.00

Mencione un breve comentario: 
10. Actualmente ¿Cuántos $\mathrm{m} 3$ de oxigeno industrial consume al mes?
a) $15 \mathrm{~m} 3$
( )
b) $30 \mathrm{~m} 3$
( )
c) $40 \mathrm{~m} 3$
( )
d) $50 \mathrm{~m} 3$
( )
e) $65 \mathrm{~m} 3$
f) $70 \mathrm{~m} 3$
$($ )
d) Otro:
( )
( ) Especifique:

Mencione un breve comentario:

11. ¿En qué meses baja, sube, o se mantiene su consumo de oxigeno industrial?
a) Enero
b) Febrero
c) Marzo
d) Abril
e) Mayo
f) Junio
g) Julio
h) Agosto
i) Septiembre
j) Noviembre
k) Diciembre

Mencione un breve comentario:

12. A continuación se presentan algunos de los factores incidentes sobre las decisiones de compra de un producto, señale aquellos que tienen mayor influencia sobre su propia decisión de comprar el oxígeno industrial a su(s) proveedor(es). Otorgue una escala de valoración, y de ser el caso añada algún otro factor que considere también relevante en su decisión de compra.

\begin{tabular}{|l|l|l|l|l|l|}
\hline $\begin{array}{l}\text { Factor de } \\
\text { Compra }\end{array}$ & $\begin{array}{l}\text { Muy } \\
\text { Importante }\end{array}$ & Importante & Indiferente & $\begin{array}{l}\text { Poco } \\
\text { Importante }\end{array}$ & $\begin{array}{l}\text { Nada } \\
\text { Importante }\end{array}$ \\
\hline Precio & & & & \\
\hline Calidad & & & & \\
\hline $\begin{array}{l}\text { Tiempo de } \\
\text { Entrega }\end{array}$ & & & & \\
\hline $\begin{array}{l}\text { Flexibilidad } \\
\text { sobre la } \\
\text { entrega }\end{array}$ & & & & \\
\hline $\begin{array}{l}\text { Capacidad } \\
\text { de } \\
\text { respuesta }\end{array}$ & & & & \\
\hline Confianza & & & & \\
\hline Otros & & & & & \\
\hline & & & & & \\
\hline & & & & \\
\hline
\end{tabular}


Mencione un breve comentario:

13. Actualmente, ¿Con qué frecuencia Usted adquiere oxigeno industrial para sus operaciones en la empresa?
a) Semanal
b) Quincenal
( )
c) Mensual
( )
e) Otros
( ) Especifique:

Mencione un breve comentario:

14. Actualmente y de acuerdo a la pregunta anterior, ¿la cantidad de oxigeno industrial en $\mathrm{m} 3$ que Usted adquiere para sus operaciones en la empresa, es siempre el mismo volumen de requerimiento?
a) $\mathrm{Si}$
( )
b) No

Mencione un breve comentario:

15. De acuerdo a las tendencias de crecimiento del sector al que la empresa pertenece, y analizando su planificación de mercado y financiera, ¿Tiene usted para su empresa planes de expansión "crecimiento" que conlleven a un requerimiento adicional del oxígeno industrial para el siguiente año?
a) $\mathrm{Si}$
( )
b) No
( )

Mencione un breve comentario:

MUCHAS GRACIAS POR SU COLABORACIÓN 


\section{Apéndice B: Cuestionario (entrevista a tomadores de decisiones)}

1. ¿A su criterio cuál es la característica entre los usuarios de oxígeno industrial en el departamento de Puno?

2. ¿Usted cree que se cubre toda la demanda de oxígeno industrial en el departamento de Puno?

3. ¿Podría usted precisar cuáles serían las fortalezas y debilidades entre los principales distribuidores de oxígeno industrial en el departamento de Puno?

4. ¿Cuál es la nueva tendencia entre los usuarios de oxígeno industrial en el departamento de Puno?

5. ¿Qué cualidades y características debe contar una empresa productora de oxígeno industrial para posicionarse en un mercado como el departamento de Puno? 


\section{Apéndice C: Ficha técnica del oxígeno industrial}

\section{Características:}

$\checkmark$ El oxígeno, gas que hace posible la vida y es indispensable para la combustión, constituye más de un quinto de la atmósfera ( $21 \%$ en volumen, $23 \%$ en peso).

$\checkmark$ Este gas es inodoro, incoloro y no tiene sabor. A presión atmosférica y temperaturas inferiores a $-183^{\circ} \mathrm{C}$, es un líquido ligeramente azulado, un poco más pesado que el agua.

$\checkmark$ Todos los elementos (salvo gases inertes) se combinan directamente con él, usualmente para formar óxidos, reacción que varía en intensidad con la temperatura.

Usos

$\checkmark$ Por su propiedad comburente, en combustión.

$\checkmark$ En mezclas con acetileno y otro gases combustibles para soldadura y corte.

\section{Uso Industrial}

$\checkmark$ El Oxígeno gaseoso, por sus propiedades comburentes, es corrientemente usado en procesos de combustión para obtener mayores temperaturas.

$\checkmark$ En mezclas con Acetileno u otros gases combustibles, es utilizado en soldadura y corte oxigas.

$\checkmark$ Por sus propiedades oxidantes, es utilizado en diversas aplicaciones en siderurgia, industria papelera, electrónica y química.

$\checkmark$ El Oxígeno Líquido, LOX, es utilizado principalmente para explosivos y como comburente en propulsión espacial. 


\section{Seguridad}

$\checkmark$ Nunca utilizar oxígeno a presión sin saber manipular correctamente cilindros, reguladores, etc.

$\checkmark$ Evitar toda combustión cercana a depósitos o vías de flujo de oxígeno.

$\checkmark$ Evitar la presencia de combustibles, especialmente aceites o grasas, en las cercanías de oxígeno (incluso en el suelo o en ropas).

$\checkmark$ El contacto de la piel con oxígeno líquido (o depósitos no aislados) puede causar graves heridas por quemadura, debido a su baja temperatura.

$\checkmark$ Debe usarse protección adecuada para manejo de líquidos criogénicos.

$\checkmark$ A temperatura y presión normal el oxígeno no es corrosivo y puede ser usado satisfactoriamente con todos los metales comunes, sin embargo debe evitarse el uso de aluminio y sus aleaciones, o de aceros al carbono y de baja aleación, por la combustión exotérmica que puede producirse en presencia de oxígeno puro.

$\checkmark$ Los aceros al carbono no aleados se convierten en un material frágil a las temperaturas criogénicas del oxígeno líquido.

$\checkmark$ La humedad hidrata los óxidos metálicos, con lo cual se expanden y pierden su rol protector, por lo que deben eliminarse de cualquiera instalación que va a usarse con oxígeno. 